UNIVERSIDADE DE BRASÍLIA

Faculdade de Tecnologia

DISSERTAÇÃO DE MESTRADO

\title{
Controle de Sistema não Linear de Separação Gás/Líquido sob ação de Efeitos Transientes Fluídicos por Sliding Control
}

\author{
Luiz Henrique Moreira de Paula
}

Dissertação submetida ao Departamento de Engenharia Mecânica da Faculdade de Tecnologia da Universidade de Brasília como requisito parcial para obtenção do grau de Mestre Engenheiro em Sistemas Mecatrônicos.

Banca Examinadora

Prof. Dr. Eugênio L. F. Fortaleza, ENM/UnB

Orientador

Prof. Dr. André Murilo de Almeida Pinto, FGA/UnB

Examinador interno

Prof. Dr. Mario Cesar Mello Massa de Campos, PETROBRAS/CENPES/PDEP/TOOL

Examinador externo 


\section{FICHA CATALOGRÁFICA}

DE PAULA, LUIZ HENRIQUE MOREIRA

Controle de Sistema não Linear de Separação Gás/Líquidosob ação de Efeitos Transientes Fluídicos por Sliding Control

[Distrito Federal] 2015.

xii, NP., 210 x 297 mm (ENM/FT/UnB, Mestre, Sistemas Mecatrônicos, 2015).

Dissertação de Mestrado - Universidade de Brasília. Faculdade de Tecnologia.

Departamento de Engenharia Mecânica.
1. $\mathrm{PC} 01$
2. $\mathrm{PC} 02$
3. $\mathrm{PC} 03$
4. $\mathrm{PC} 04$
I. ENM/FT/UnB
II. Título (série)

\section{REFERÊNCIA BIBLIOGRÁFICA}

DE PAULA, L. H. M. (2015). Controle de Sistema não Linear de Separação Gás/Líquidosob ação de Efeitos Transientes Fluídicos por Sliding Control, Dissertação de Mestrado em Sistemas Mecatrônicos, Publicação ENM.DM-91A/15, Departamento de Engenharia Mecânica, Faculdade de Tecnologia, Universidade de Brasília, Brasília, DF, NP.

\section{CESSÃO DE DIREITOS}

AUTOR: Luiz Henrique Moreira de Paula

TÍTULO: Controle de Sistema não Linear de Separação Gás/Líquidosob ação de Efeitos Transientes Fluídicos por Sliding Control.

GRAU: Mestre ANO: 2015

É concedida à Universidade de Brasília permissão para reproduzir cópias desta dissertação e para emprestar ou vender tais cópias somente para propósitos acadêmicos e científicos. O autor reserva outros direitos de publicação e nenhuma parte desse trabalho de conclusão de curso pode ser reproduzida sem autorização por escrito do autor.

Luiz Henrique Moreira de Paula

Endereço

Bairro

CEP XXXX-XXX - Brasília - DF - Brasil 


\section{Dedicatória}

Àquelas que, num instante, trouxeram vida resignificando cada momento. Cada instante, agora, um momento vivido não mais pela necessidade da razão, matemática, mas em comtemplação à necessidade, bela, poética. Feliz aquele que em algum momento, ainda que por um instante, teve motivo suficiente para viver e produzir. E viveu e produziu. Às três, parte indissociável da minha vida: Simone, Sofia e Luiza

Luiz Henrique Moreira de Paula 


\section{Agradecimentos}

Agredeço a todos que contribuiram diretamente com minha formação moral, intelectual e profissional. À minha família pela sustentação, aos professores pela dedicação, aos amigos pela força e ao orientador pela oportunidade

Luiz Henrique Moreira de Paula 


\section{RESUMO}

O controle do nível do líquido no interior de um separador gás/líquido do tipo VASPS pode ser uma tarefa complicada, não linearidades associadas ao sistema dinâmico que descreve seu comportamento, combinadas a perturbações ao escoamento podem resultar em um comportamento de difícil previsão. A abordagem de controle adotada no presente trabalho foi baseada num tipo de controle robusto aplicado a sistemas em que parte de suas dinâmicas são precisamente conhecidas. O controle deslizante (Sliding Control), apesar de sua confiabilidade induz descontinuidades no sistema que podem ser prejudiciais ao atuador, no caso do VASPS, uma bomba tipo ESP. Algumas adaptações foram adotadas no sentido de se amenizar esse problema. Assim, um modelo baseado na teoria de Transientes em Fluidos foi assumido e numericamente resolvido utilizando-se o método das equações características. Neste trabalho propõe-se um controlador robusto o suficiente para manter o nível o líquido no interior do separador dentro um intervalo com limites preestabelecidos e que consiga seguir uma trajetória desejada ao longo do tempo de forma a evitar o esforço demasiado do atuador.

Palavras Chaves: Sliding Control, Separação Submarina, Transiente em Fluidos, Método das Equações Características, VASPS. 


\begin{abstract}
Liquid level control inside a subsea gas-liquid separator like VASPS, can be a difficult task. Nonlinearities of the dynamical system combined with disturbances on pipelines flow can result on randomness on liquid level behavior. The control approach chosen for the present study was a robust control generally applied to systems where parts of the dynamics are not well known. The Sliding Control despite of its reliability, induces discontinuities in the system that could be harmful to actuator, an ESP pump for VASPS case. Some adaptations were introduced in order to circumvent this problem. An imprecise system model using fluid transient theory was considered and numerically evaluated by method of characteristics. The present paper purposes a controller robust enough to keep the liquid level between specified limits, track a trajectory to be followed by level values along time and, additionally, able to avoid actuator overwork.
\end{abstract}

Keywords: Sliding Control, Subsea Separation, Fluid Transient, Method of Characteristics, VASPS. 


\section{SUMÁRIO}

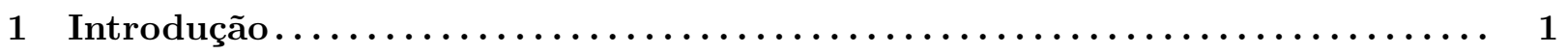

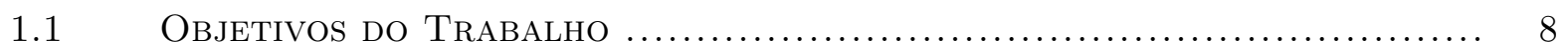

1.2 Organização do Trabalho Escrito ..................................... 9

2 Revisão Bibliográfica...................................... 10

2.1 A Produģão em Águas Profundas no Contexto Nacional ............. 10

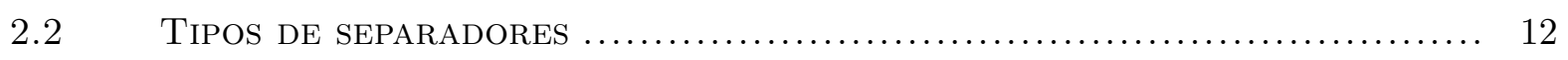

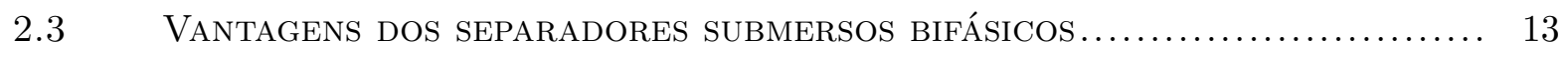

2.4 FUNCIONAMENTO DO SEPARADOR CICLÔNICO TIPO VASPS .................. 15

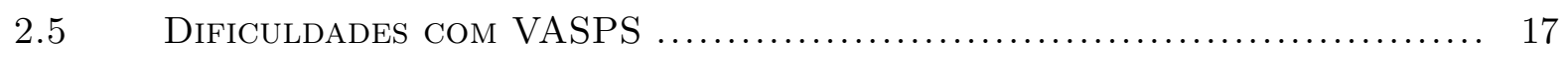

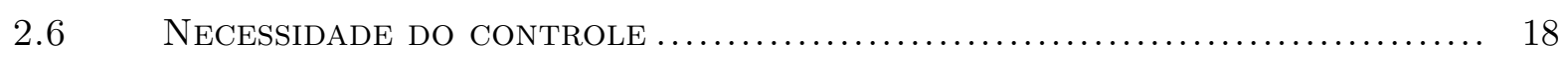

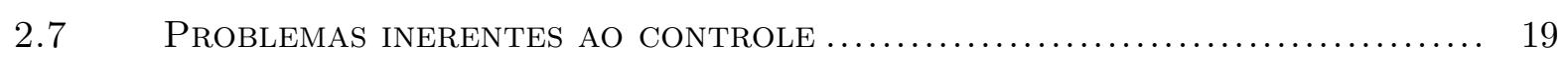

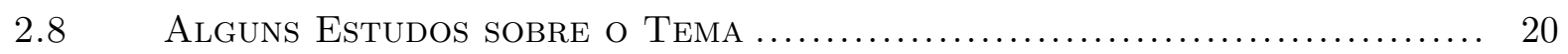

2.8.1 Modelo mecanístico Para o Separador Ciclônico ….................. 21

2.8.2 Controle com minimização de esforços no Separador Submarino .... 23

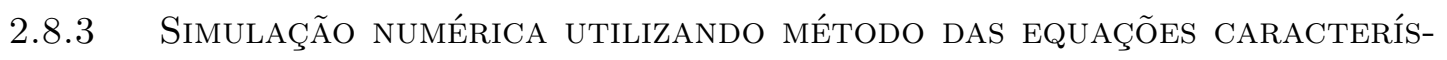

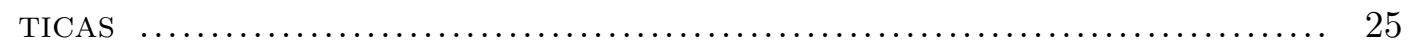

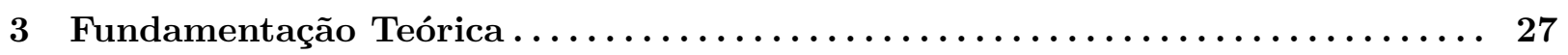

3.1 Equações de Transientes para o Escoamento na Tubulação de Saída

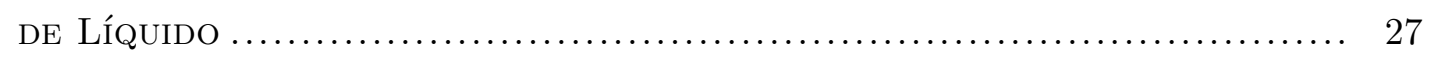

3.1.1 CASO A - TUBULAÇÃo anCorada SOMENTE EM SUa EXTREMidade INICIAL.. 31

3.1.2 CASO B - TUBULAÇÃO ANCORADA LONGITUdiNALMENTE ................... 33

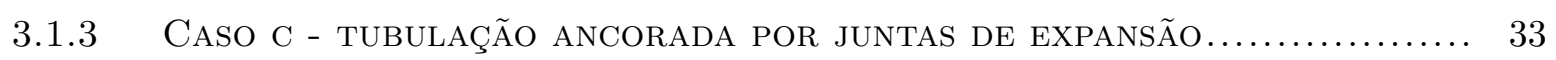

3.2 EquaÇÕES DIFERENCIAIS BÁSICAS PARA TRANSIENTES EM FLUIDOS ........... 34

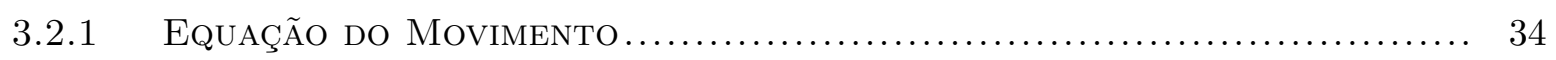

3.2 .2 EquaÇÃo da ContinUidade............................................ 37

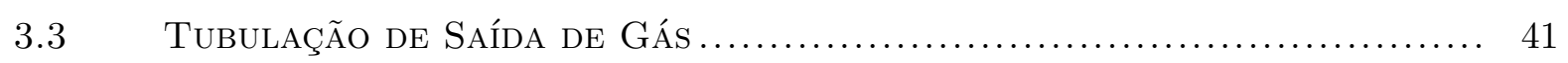

3.3.1 EquaÇÕes Básicas de Escoamento Transiente para Gás Natural .... 41

3.3.2 Escoamento em Regime Permanente..................................... 45

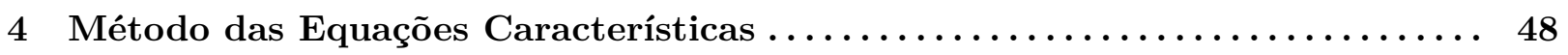

4.1 MÉtodo das EquaÇões Características para Escoamento do Líquido 48 


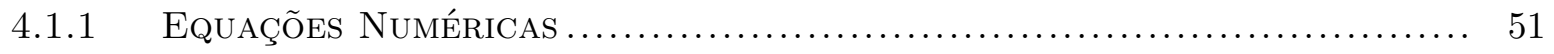

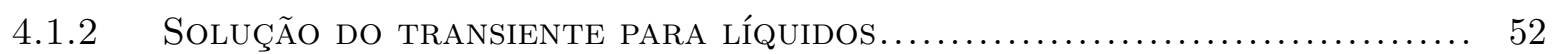

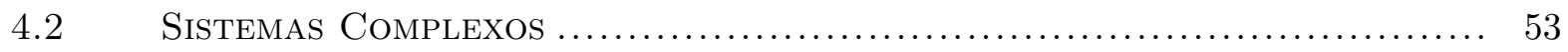

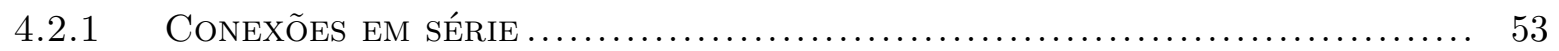

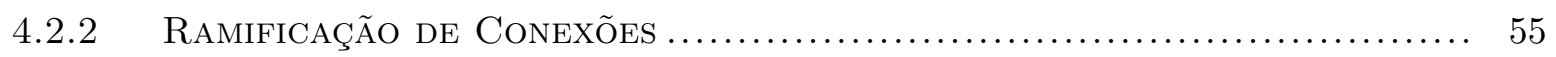

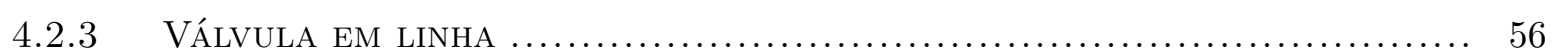

4.3 Acionamento de uma Bomba Centrífuga............................ 57

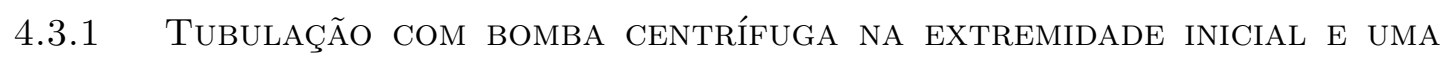
VÁLVULA NA EXTREMIDADE FINAL .................................. 57

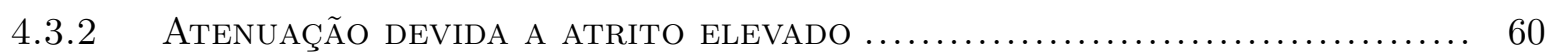

4.4 Método das EquaÇÕes Características com InterpolaÇÕes ............ 61

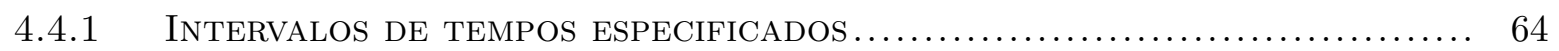

4.4.2 Redes Características ......................................... 67

4.5 Método das EquaÇões Característica para Escoamento de Gás...... 69

$4.5 .1 \quad$ MUltiplicador InERCIAL .......................................... 72

5 Modelo do Separador Centrífugo Submerso $\ldots \ldots \ldots \ldots \ldots \ldots \ldots \ldots \ldots \ldots \ldots \quad \mathbf{7 4}$

5.1 Interior do Separador Centrífugo................................... 74

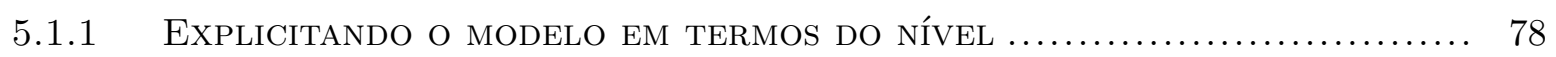

5.2 COMPORTAMENTO DO SISTEMA DO NÍVEL NO INTERIOR DO SEPARADOR CEN-

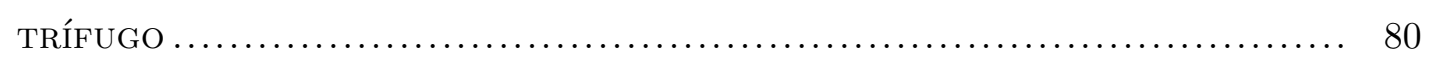

5.2.1 Comportamento em Termos dos Parâmetros $\Gamma$ e $\beta \ldots \ldots \ldots \ldots \ldots \ldots \ldots . . . \ldots 3$

5.3 Reposta do Sistema a Sinais de Entrada Clássicos ..................... 87

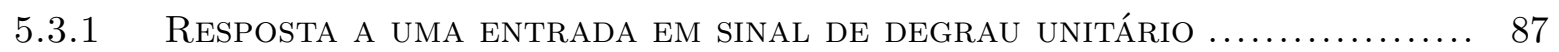

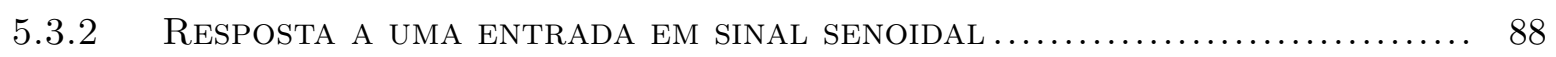

5.3 .3 RESPOSTA A UMA ENTRAdA EM SINAL DE ONDA QUADRADA $\ldots \ldots \ldots \ldots \ldots \ldots . \ldots . \ldots$

5.3.4 EFeito da VARiaÇão de Velocidade de RotaÇ̃̃o da BOMBA.............. 90

5.4 Resposta a Variação da Frequência de Sinal de Entrada Oscilatório 92

$5.5 \quad$ ESTUdO DO SISTEMA NÃO-LINEAR ................................. 93

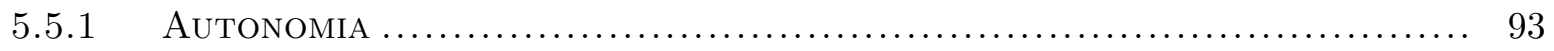

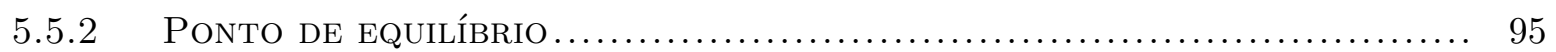

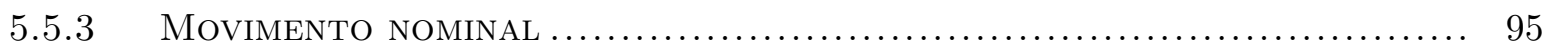

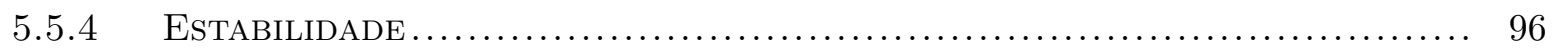

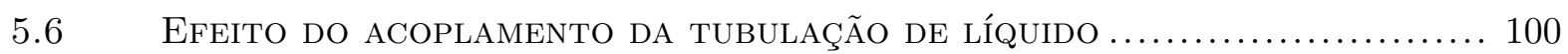

$5.6 .1 \quad$ ESTUdO DE CASO .................................................. 100

6 Controle Deslizante ........................................ 116

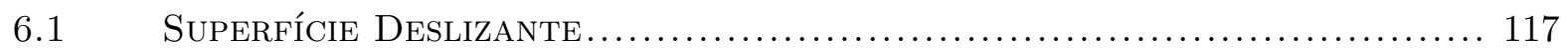

6.1.1 Relação entre os Limites dos Valores do Erro de Posição e os Limites impostos À Superfície ................................... 118

6.1.2 Limites Impostos aos Elementos do Vetor Erro........................... 121

6.2 Lei de Convergência Aplicada e Controle do Separador Submerso.. 124 
6.2.1 Determinação da Lei da Controle a partir da Lei de Convergência 124

6.2.2 Controle do Separador Ciclônico ..................................... 127

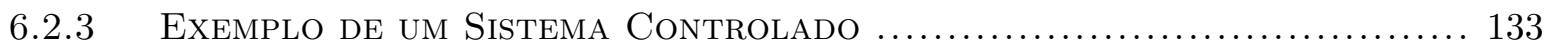

6.3 Filtragem do Sinal de Controle ................................... 135

6.3.1 Filtro de Primeira Ordem ........................................ 138

6.3.2 Sinal de Controle Filtrado frente a Lei de Convergência .......... 140

6.3.3 Regiões de Convergência do Sistema Filtrado ........................ 142

6.4 Convergência sob AtenuaÇÃo do Sinal de Controle..................... 148

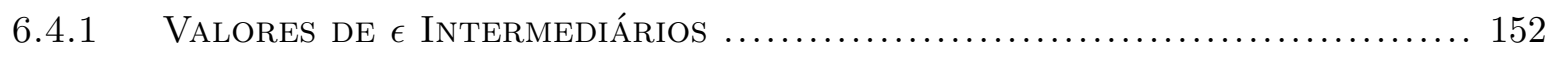

6.4.2 Efeitos da AtenuaÇão do Sinal de Controle devido variaÇão de $\epsilon_{f}$

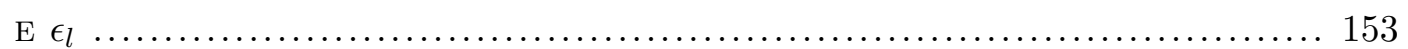

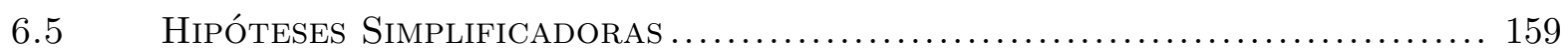

6.6 Formato Final do Controlador Proposto ............................ 161

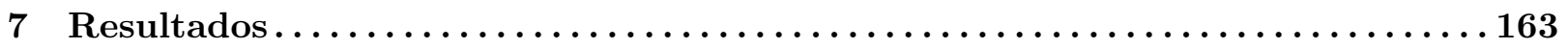

7.1 Algorítimos de Solução do Sistema do Separador Ciclônico Submerso 163

7.2 Aplicação Teórica do Controlador a um Protótipo de Separador DO TIPO VASPS ................................................. 166

7.2.1 Arranjo do Separador com Pressão do Gás Constante............... 171

7.2.2 Arranjo com Pressão Variável no Interior do Separador ............. 180

7.2 .3 Entrada em Sinal Senoidal ......................................... 189

7.2.4 Entrada em Sinal de Onda Quadrada ................................ 194

7.2.5 Sistema Controlado sob AÇão de Perturbação Transiente .......... 199

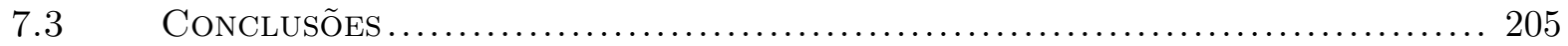

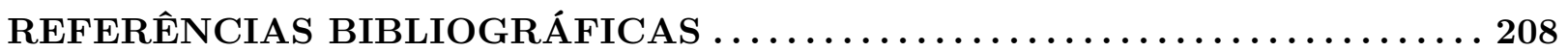

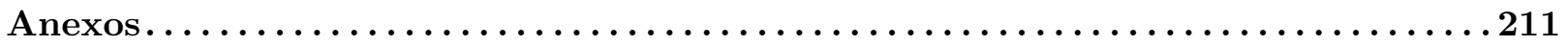

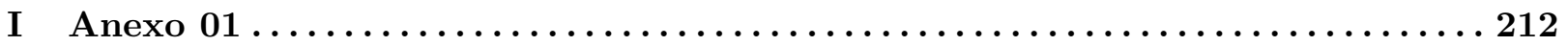

I.1 InstruÇão Para UtilizaÇÃo da Interface Gráfica....................... 212

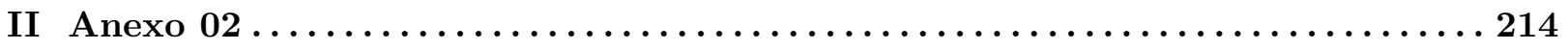

II.1 Exemplo de UtilizaÇÃo do algorítimo de ResoluÇÃo Numérica ........ 214

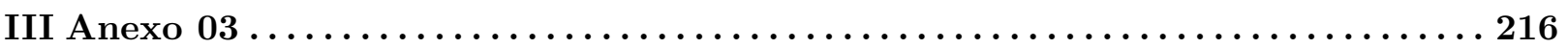

III.1 CóDIGO DA FUNÇÃO LevelControl ...................................... 216

III.2 CóDIGO DA FUNÇÃO classGasPipe ................................... 217

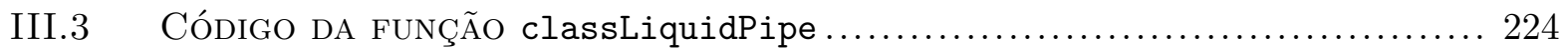

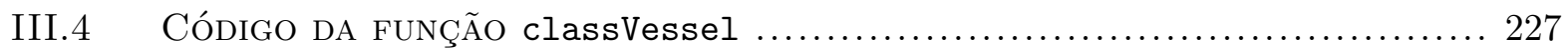




\section{LISTA DE FIGURAS}

1.1 Esquema do separador, três partes serão analisadas separadamente para a modelagem do sistema. Parte 1 - tubulação de saída líquido. Parte 2 - tubulação saída de gás. Parte 3 - Interior do separador

2.1 Produção brasileira em barris de petróleo dia. Fonte: [Estrela 2003] .................... 11

2.2 Separador Centrífugo Submerso. Fonte: [Rosa, Franca e Ribeiro 2001] ............... 16

2.3 Espessura do filme e velocidade tangencial em relação à distância axial abaixo do bocal de entrada. Fonte: [Rosa, Franca e Ribeiro 2001]

2.4 Diagrama de blocos do sistema do separador submerso controlado. Fonte: [Melo, Serapiao e Mendes 2009]

2.5 Diagrama de blocos do controlador de Melo. Fonte: [Melo, Serapiao e Mendes 2009] 25

3.1 Volume de controle da tubulação

3.2 Com perturbação do escoamento, a tubulação com paredes finas se deforma e há uma variação de sua área de seção transversal $\Delta$ A. A tubulação com raio inicial $R$ após a deformação terá raio $R+\delta$.

3.3 Semicilindro da tubulação sujeito a forças resultantes de ação da propagação de uma onda sônica. $T$ é a força exercida pelo semicilindro. $\gamma H D$ a força aplicada, devido a variação de pressão na tubulação. e é a espessura da tubulação. D o diâmetro...

3.4 diagrama de corpo livre para seção transversal de um elemento de fluido no interior de uma tubulação .............................................................. 35

3.5 Volume de controle para equação da continuidade .................................. 38

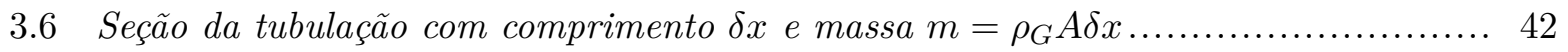

3.7 diagrama de corpo livre de segmento de fluido no interior de uma tubulação........... 43

4.1 Linhas característica, determinam a região de validades do conjunto de equações utilizado para resolver as equações de transientes ...................................... 51

4.2 Linhas característica. Plano discretizado.............................................. 51

4.3 Tubulação em série.............................................................. 54

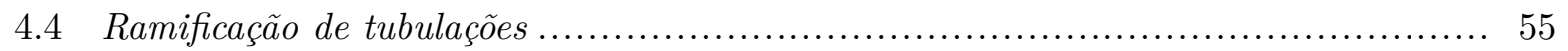

4.5 Tubulação com um orifício em linha. Sentido positivo do fluxo indicado pela seta.... 56

4.6 sistema formado de bomba e válvula ........................................... 58

4.7 Curvas características usadas para solucionar as equações completas................... 62

4.8 Curvas características. Intervalo de tempos especificados ............................ 64 
4.9 reta de interpolação utilizada para se encontrar o valor de $H_{R}$......

4.10 rede característica. As distancias ao longo da tubulação e os tempos de computação não são mais fixos por isso os pontos em cada camada do eixo t, nãa estão necessariamente na mesma altura...

4.11 Linhas características dão a curva de validade do conjunto de equações características 70

4.12 Fluxo aproximado pela média entre os pontos $A$ e $P$. ...

5.1 Separador centrífugo. $M_{G}$ é a taxa de massa de gás, $P_{G}$ é a pressão do gás no interior do recipiente. $M$ é a taxa de massa de líquido, $P$ é a pressão do líquido no interior do recipiente. Os sobrescritos in e out referem-se a entrada e saida, respectivamente.

5.2 Condições de contorno no interior do separador centrífugo e na tubulação de líquido 76

5.3 O ponto 1, na base da tubulação de gás coincide com o interior do separador, logo os valores de pressão e vazão do gás são os mesmos neste ponto..................... 78

5.4 Curva característica típica (Hversus Q) de uma bomba centrífuga. Fonte: [Volk 2013$] 82$

5.5 A parte real do retrato de fases do sistema intercepta a circunferência (em azul) em, pelo menos, dois pontos. A linha clara (em verde) mostra a curva de validade

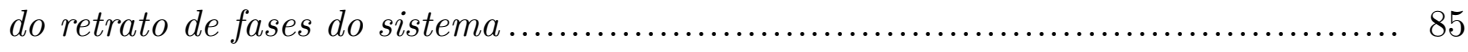

5.6 Retrato de fases para entrada em sinal unitário................................... 88

5.7 Curva do nível com o tempo (em azul) e da velocidade do nível (em verde) para uma condição inicial de nível acima da posição de equilíbrio. ......................... 88

5.8 Retrato de fases para entrada em sinal senoidal. ............................... 89

5.9 Gráfico do nível em relação ao tempo (em azul) e da velocidade do nível (em verde) para uma entrada sinusoidal ................................................ 89

5.10 Gráfico do nível em relação ao tempo (em azul) e da velocidade do nível (em verde) para uma entrada um sinal de onda quadrada.

5.11 Histórico temporal do nível para diferentes velocidades de rotação da bomba. Quando $\gamma=1$ a bomba trabalha em sua capacidade de rotação máxima.

5.12 Diagrama de bode do sistema estudado (linha contínua). Diagrama de bode para uma sistema linear equivalente (linha tracejada).

5.13 Trajetória 1: instável. Trajetória 2: marginalmente estável. Trajetória 3: assintoticamente estável.

5.14 Com $\beta$ variável com o tempo há uma mudança no retrato de fases do sistema. Pode ser observado pela circunferência de referência (em azul) há um descolamento dos pontos do retrato de fases à medida que $\beta$ avança em sua trajetória. Como consequência, um ponto (como o ponto mínimo) inicialmente na posição p passará para posição $p_{2}$ ao final da trajetória.

5.15 Separador Centrífugo com nível inicial igual a zero e com vazão de entrada constante igual à vazão inicial de saída. No tempo $t=t_{c}$ a válvula é subitamente fechada pela metade. (a) Nível do líquido no interior do separador. (b) vazão para vários pontos ao longo do comprimento da tubo. (c) pressão em termos da altura piezométrica ao longo do comprimento da tubulação. 
5.16 Numeração dos pontos ao longo da tubulação.

5.17 Parâmetro $C_{M 2}$ tende a ficar constante o que assegura a convergência do sistema.... 106

5.18 Gráficos mostrados na Figura 5.15 para um tempo de simulação maior. Percebese a convergência do sistema para o ponto de equilíbrio com o estabelecimento do regime permanente.

5.19 Sistema descrito pelo exemplo do estudo de caso, sob entrada em degrau unitário e com a válvula na extremidade oposta da tubulação aberta todo tempo. (a) Nível no interior do separador centrífugo. (b) vazões em cada ponto considerado. (c) pressão em termos da altura piezométrica ao longo do comprimento da tubulação.

5.20 Sistema descrito pelo exemplo do estudo de caso, sob entrada sinusoidal e com a válvula na extremidade oposta da tubulação aberta todo tempo. (a) Nível no interior do separador centrífugo. (b) vazões em cada ponto considerado. (c) pressão em termos da altura piezométrica ao longo do comprimento da tubulação.

5.21 Sistema descrito pelo exemplo 1, sob entrada em sinal de onda quadrada e com a válvula na extremidade oposta da tubulação aberta to o tempo. (a) Nível no interior do separador centrífugo. (b) vazões em cada ponto considerado. (c) pressões em cada ponto.

5.22 Superfície gerada para pressão ao longo do comprimento da tubulação e ao longo do tempo. A superfície é referente a resposta do sistema a uma vazão de entrada sinusoidal. Esse resultado foi mostrado na Figura 5.20 em representação bidimensional

5.23 Pressões médias (em termos de altura piezométrica $(m)$ ) em cada ponto da tubulação para o intervalo de tempo em que os efeitos transientes são significativos variando com o aumento da velocidade do pulso de pressão a $(\mathrm{m} / \mathrm{s})$....

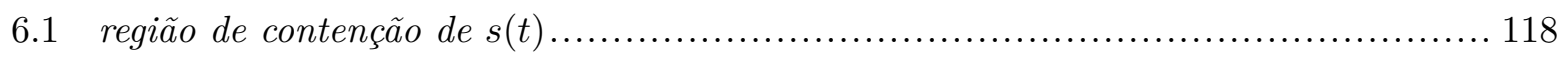

6.2 Diagrama de blocos de filtro de primeira ordem onde p é o operador laplaciano ....... 119

6.3 Diagrama de blocos com sucessivos filtros passa-baixa aplicados a s. O erro de trajetória é a saída do sistema descrito pelo diagrama. p é o operador laplaciano .... 120

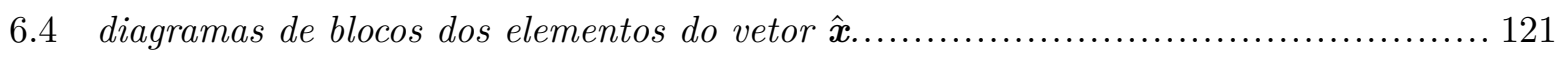

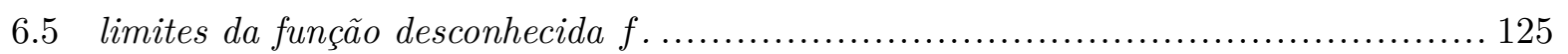

6.6 Pressões da coluna de líquido $p_{L}$ e do gás acima da coluna $p_{G}$ no interior do separador ciclônico. l é o nível do líquido no interior do separador e o ponto de

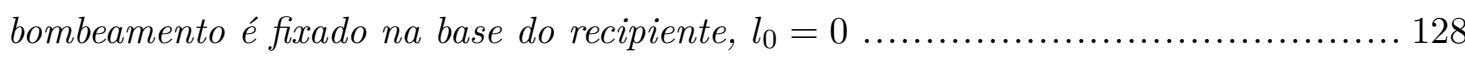

6.7 Sistema do exemplo, controlado. A trajetória do sinal de l acompanha a trajetória $l_{d} 134$

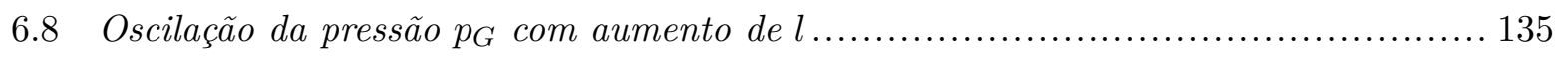

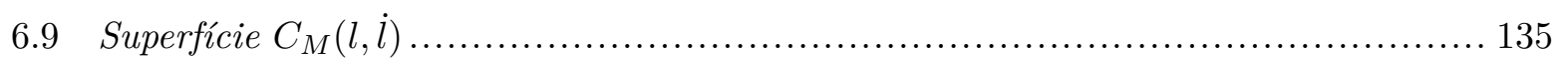

6.10 sinal de controle descontínuo u após filtragem torna-se um sinal contínuo $\gamma$......... 137

$6.11 C(p)$ é a função que descreve o filtro aplicado no domínio de laplace, e p é o operador

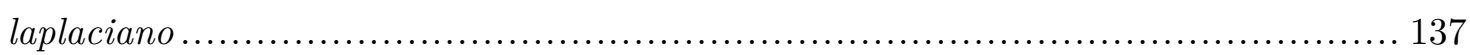

6.12 Sinal de controle passa por um filtro de primeira ordem. $k, T$ e a são constantes e $p$ é o operador laplaciano.... 
6.13 Quando o erro de trajetória s é negativo, a sua taxa de variação temporal será positiva, forçando, s para zero. Quando o erro de trajetória s é positivo, a sua taxa temporal será positiva, forçando, s também para zero. Nos dois casos, ṡs é menor que zero

6.14 Sucessivas passagens através da superfície s darão à curva que descreve a trajetória do sistema um formato que se assemelha a a uma vibração em torno da trajetória desejada.

6.15 Condições de convergência para $s \geq 0$

6.16 Condições de convergência para $s<0$.

6.17 Plano śs versus s. Várias curvas para diferentes valores de delta são mostradas, em três regiões de comportamento distintos. Curvas em verde: região sob a lei de convergência. Curvas em amarelo: região em que há convergência, mas fora de lei de convergência. Curvas em vermelho: região de divergência

$6.18 \epsilon=0$. Condições de convergência para $s \geq 0$ parte superior da Figura e $s<0$ parte inferior. Região verde:sistema sob a lei convergência. Região amarela: convergência fraca. Região vermelha: trajetórias divergem

6.19 Intervalo de valores para os quais o sistema terá trajetórias convergentes independentemente do sinal de $s$

$6.20 \epsilon=1$. Condições de convergência para $s \geq 0$ parte superior da Figura e $s<0$ parte inferior. Região verde:sistema sob a lei convergência. Região amarela: convergência fraca. Região vermelha: trajetórias divergem

6.21 Se $\epsilon=0$, não intervalo de valores para os quais o sistema terá trajetórias convergentes independentemente do sinal de $s$

6.22 Intervalo produtivo de $\delta$ para quatro valores diferentes $(\epsilon=1, \epsilon=0.9, \epsilon=0.5$ e $\epsilon=0)$

6.23 Sinal de controle u descrito por uma função sinusoidal sin $(\omega t)$ com frequência angular $\omega$

6.24 Intervalo produtivo de $F$ para quatro valores diferentes $\epsilon$

6.25 Regiões de comportamento do sistema em relação a F. Região 1: valor proposto para $F$ estará dentro de um intervalo acertadamente assumido. Região 2: valor proposto para $F$ estará dentro de um intervalo erroneamente assumido.Região 3: $F$ dentro dos limites do intervalo 6.120, mas fora do intervalo $A \leq F \leq B$.

6.26 Sinal de controle assumindo as hipóteses simplificadoras.

7.1 Organograma do algorítimo de cálculo do nível no interior do separador.

7.2 Ilustração do protótipo de separador ciclônico desenvolvido por Storti 2013, (esquerda) e vista do corte longitudinal vertical do protótipo (direita). Fonte: [Storti $2013]$

7.3 Esquema geral do aparato experimental utilizado. Fonte: [Storti 2013] 168

7.4 Esquema simplificado do separador com tubulações de escoamento das fases gasosa e líquida.... 
7.5 Sinal de controle passa por um filtro de primeira ordem. $k, T$ e $a$ são constantes e $p$ é o operador laplaciano

7.6 (a) Trajetória do nível do líquido no interior do separador. A linha pontilha escura indica a trajetória desejada. As linhas pontilhadas indicam indicam a tolerância permitida ao nível e a linha sólida indica a trajetória efetivamente seguida pelo nível. (b) $\gamma$, fração da frequência de rotação da bomba.

7.7 (a) Vazão na tubulação de escoamento do líquido $\mathrm{em} \mathrm{m}^{3} / \mathrm{s}$ para cada ponto em que a tubulação foi divida. (b) Altura Piezométrica (m) ao longo da tubulação de escoamento do líquido em para cada ponto em que a tubulação foi divida. Os valores de contorno do problema são mostrados pela retas amarelas em (a) e em (b).

7.8 Pontos referentes aos segmentos da tubulação de escoamento do líquido. O sentido do escoamento a partir da base conectada ao recipiente de separação é identificado pelas setas

7.9 Variação quadrática de u no intervalo dado na inequação 7.21

7.10 (a) Trajetória do nível do líquido no interior do separador. A linha pontilha escura indica a trajetória desejada. As linhas pontilhadas indicam indicam a tolerância permitida ao nível e a linha sólida indica a trajetória efetivamente seguida pelo nível. (b) $\gamma$, fração da frequência de rotação da bomba.

7.11 (a) Vazão na tubulação de escoamento do líquido em $\mathrm{m}^{3} / \mathrm{s}$ para cada ponto em que a tubulação foi divida.(b) Altura Piezométrica $(m)$ ao longo da tubulação de escoamento do líquido em para cada ponto em que a tubulação foi divida. Os valores de contorno do problema são mostrados pela retas amarelas em (a) e em (b) .......... 180

7.12 Valores de contorno para os problemas de escoamento nas tubulações de saída de gás e de líquido....

7.13 Padrões de Escoamento bifásico gás/líquido em tubos horizontais. Fonte: [Bratland, Gregory e Aziz 2010]

7.14 Mapa do padrão de escoamento em tubo horizontal. Fonte: [Mandhane, Gregory e Aziz 1973]

7.15 (a) Trajetória do nível do líquido no interior do separador. A linha pontilha escura indica a trajetória desejada. As linhas pontilhadas indicam a tolerância permitida ao nível e a linha sólida indica a trajetória efetivamente seguida pelo nível. (b) $\gamma$, fração da frequência de rotação da bomba.

7.16 (a) Altura Piezométrica (m) ao longo da tubulação de escoamento do líquido em para cada ponto em que a tubulação foi divida. (b) Vazão na tubulação de escoamento do líquido em $\mathrm{m}^{3} / \mathrm{s}$ para cada ponto em que a tubulação foi divida. Os valores de contorno do problema são mostrados pela retas amarelas em (a) e em (b)....

7.17 (a) Pressão do gás (x1,01325 $10^{5} \mathrm{~Pa}$ ) ao longo da tubulação de escoamento do líquido em para cada ponto em que a tubulação foi divida, a abcissa é dada em segundos. (b) Vazão na tubulação de escoamento do líquido em $\mathrm{kg} / \mathrm{s}$ para cada ponto em que a tubulação foi divida, a abcissa é dada em segundos. Os valores de contorno do problema são mostrados pela retas amarelas em (a) e em (b).... 
7.18 (a) Pressão do gás (x1,01325 $10^{5} \mathrm{~Pa}$ ) ao longo da tubulação de escoamento do líquido em para cada ponto em que a tubulação foi divida, a abcissa é dada em segundos. (b) Vazão na tubulação de escoamento do líquido em $\mathrm{kg} / \mathrm{s}$ para cada ponto em que a tubulação foi divida, a abcissa é dada em segundos. Os valores de contorno do problema são mostrados pela retas amarelas em (a) e em (b)

7.19 (a) Trajetória do nível do líquido no interior do separador em metros (m). A linha pontilhada escura indica a trajetória desejada. As linhas pontilhadas indicam indicam a tolerância permitida ao nível e a linha sólida indica a trajetória efetivamente seguida pelo nível. (b) $\gamma$, fração da frequência de rotação da bomba.

7.20 (a) Altura Piezométrica $(m)$ ao longo da tubulação de escoamento do líquido em para cada ponto em que a tubulação foi divida. (b) Vazão na tubulação de escoamento do líquido em $\mathrm{m}^{3} / \mathrm{s}$ para cada ponto em que a tubulação foi divida. A linha pontilhada preta que aparece no detalhe superior de (b) é a curva da vazão mássica do líquido na entrada do separador. Os valores de contorno do problema são mostrados pela retas amarelas em (a) e em (b)

7.21 (a) Pressão do gás ( $x 1,0132510^{5} \mathrm{~Pa}$ ) ao longo da tubulação de escoamento do líquido em para cada ponto em que a tubulação foi divida, a abcissa é dada em segundos. (b) Vazão na tubulação de escoamento do líquido em $\mathrm{kg} / \mathrm{s}$ para cada ponto em que a tubulação foi divida, a abcissa é dada em segundos. A linha pontilhada preta é a curva da vazão mássica de gás na entrada do separador. Os valores de contorno do problema são mostrados pela retas amarelas em (a) e em (b)

7.22 (a) Trajetória do nível do líquido no interior do separador em metros ( $m$ ). A linha pontilhada escura indica a trajetória desejada. As linhas pontilhadas indicam indicam a tolerância permitida ao nível e a linha sólida indica a trajetória efetivamente seguida pelo nível. (b) $\gamma$, fração da frequência de rotação da bomba.

7.23 (a) Altura Piezométrica $(m)$ ao longo da tubulação de escoamento do líquido em para cada ponto em que a tubulação foi divida. (b) Vazão na tubulação de escoamento do líquido em $\mathrm{m}^{3}$ /s para cada ponto em que a tubulação foi divida. A linha pontilhada preta que aparece no detalhe superior de (b) é a curva da vazão mássica do líquido na entrada do separador.. Os valores de contorno do problema são mostrados pela retas amarelas em (a) e em (b)

7.24 (a) Pressão do gás ( $x 1,0132510^{5} \mathrm{~Pa}$ ) ao longo da tubulação de escoamento do líquido em para cada ponto em que a tubulação foi divida, a abcissa é dada em segundos. (b) Vazão na tubulação de escoamento do líquido em $\mathrm{kg} / \mathrm{s}$ para cada ponto em que a tubulação foi divida, a abcissa é dada em segundos. A linha pontilhada preta é a curva da vazão mássica de gás na entrada do separador. Os valores de contorno do problema são mostrados pela retas amarelas em (a) e em (b)

7.25 (a) Trajetória do nivel do líquido no interior do separador em metros ( $m)$. A linha pontilha escura indica a trajetória desejada. As linhas pontilhadas indicam indicam a tolerância permitida ao nível e a linha sólida indica a trajetória efetivamente seguida pelo nível. (b) $\gamma$, fração da frequência de rotação da bomba. 
7.26 O pulso de pressão ao longo da tubulação de escoamento de líquido causado pelo fechamento parcial da válvula, tem duração menor à medida que se aproxima da base da tubulação. As cores das setas indicam o padrão de cores adotado para cada ponto ao longo da tubulação, utilizado nas simulações.

7.27 (a) Altura Piezométrica (m) ao longo da tubulação de escoamento do líquido em para cada ponto em que a tubulação foi divida. (b) Vazão na tubulação de escoamento do líquido em $\mathrm{m}^{3} / \mathrm{s}$ para cada ponto em que a tubulação foi divida. A linha pontilhada preta que aparece no detalhe superior de (b) é a curva da vazão mássica do líquido na entrada do separador.

7.28 (a) Pressão do gás $\left(x 1,0132510^{5} \mathrm{~Pa}\right)$ ao longo da tubulação de escoamento do líquido em para cada ponto em que a tubulação foi divida, a abcissa é dada em segundos. (b) Vazão na tubulação de escoamento do líquido em $\mathrm{kg} / \mathrm{s}$ para cada ponto em que a tubulação foi divida, a abcissa é dada em segundos. A linha pontilhada preta é a curva da vazão mássica de gás na entrada do separador. 


\section{LISTA DE TABELAS}

2.1 Benefícios e algumas relutâncias para o uso de sistemas de separação submarina.

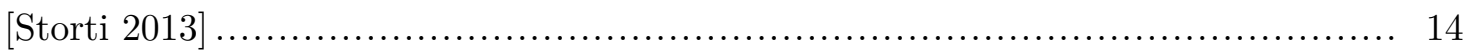

6.1 rótulos das regiões de validade e convergência do sistema controlado .................. 145

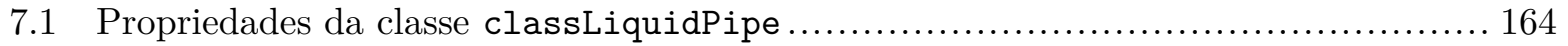

7.2 Propriedades da classe classGasPipe .............................................. 165

7.3 Cores para identificação dos pontos ao longo das tubulações de saída ................. 176 


\section{LISTA DE SÍMBOLOS}

\section{Símbolos Utilizados no Capítulo 3}

\section{Escoamento do Líquido}

$\begin{array}{lll}\gamma & \text { peso específico do fluido } & {\left[\mathrm{kg} / \mathrm{m}^{2} \mathrm{~s}^{2}\right]} \\ \rho & \text { densidade do líquido }(\gamma / g) & {\left[\mathrm{kg} / \mathrm{m}^{3}\right]} \\ g & \text { aceleração da gravidade } & {\left[\mathrm{m} / \mathrm{s}^{2}\right]} \\ A & \text { área da seção transversal da tubulação } & {\left[\mathrm{m}^{2}\right]} \\ \Delta V & \text { incremento da velocidade de escoamento } & {[\mathrm{m} / \mathrm{s}]} \\ a & \text { velocidade de propagação da onda gerada pela perturbação } & {[\mathrm{m} / \mathrm{s}]} \\ \Delta H & \text { incremento da pressão manométrica medido em termos de altura piezométrica } & {[\mathrm{m}]} \\ L & \text { comprimento da tubulação } & {[\mathrm{m}]} \\ \Delta A & \text { variação da área transversal da tubulação de escoamento do líquido } & {\left[\mathrm{m}^{2}\right]} \\ K & \text { modulo de elasticidade do fluido } & \\ \Delta \mathcal{V} / \mathcal{V} & \text { fração de variação de volume do líquido } & \\ \xi & \text { deformação lateral da tubulação de líquido } & \\ \xi_{1} & \text { deformação axial da tubulação de líquido } & \\ \xi_{2} & \text { deformação transversal da tubulação de líquido } & {[P a]} \\ \mu & \text { coeficiente de Poisson }\left(\xi / \xi_{1}\right) & {[P a]} \\ \sigma_{1} & \text { tensão axial na tubulação de líquido } & {[\mathrm{rad}]} \\ \sigma_{2} & \text { tensão lateral na tubulação de líquido } & \\ \alpha & \text { inclinação da tubulação de líquido em relação à horizontal } & \end{array}$




\section{Escoamento do Gás}

$\begin{array}{lll}p & \text { pressão absoluta } & {[\mathrm{Pa}]} \\ \rho_{G} & \text { densidade do gás } & {\left[\mathrm{kg} / \mathrm{m}^{3}\right]} \\ z & \text { compressibilidade do gás } & \\ R & \text { constante dos gases ideais } & {[\check{\mathrm{r} C}]} \\ T & \text { temperatura } & {\left[\mathrm{m}^{2}\right]} \\ A & \text { área transversal da tubulação de escoamento do gás } & {[\mathrm{kg}]} \\ m=\rho_{G} A \delta x & \text { massa do gás contida em uma seção da tubulação de comprimento } \delta x & \\ \tau_{0} & \text { tensão de cisalhamento devido ao atrito do fluido com as paredes da tu- } & {[\mathrm{Pa}]} \\ & \text { bulação } & {[\mathrm{rad}]} \\ \theta & \text { ângulo que a tubulação faz com a horizontal } & {\left[\mathrm{m} / \mathrm{s}^{2}\right]} \\ g & \text { aceleração da gravidade } & {[\mathrm{m}]} \\ D & \text { diâmetro da tubulação } & \end{array}$

\section{Símbolos Utilizados no Capítulo 5}

$l \quad$ nível do líquido no interior do separador centrífugo submerso $\quad[m]$

A área da seção transversal do recipiente de separação

$q_{\text {in }} \quad$ vazão de líquido que entra no recipiente de separação

$\left[\mathrm{m}^{3} / \mathrm{s}\right]$

quat vazão de líquido que sai do recipiente de separação

$\left[\mathrm{m}^{3} / \mathrm{s}\right]$

$\rho \quad$ densidade do líquido

$\left[\mathrm{kg} / \mathrm{m}^{3}\right]$

$\gamma \quad$ parâmetro com valor entre zero e um, que descreve a velocidade de rotação da bomba submersa (a rotação é máxima para $\gamma=1$ )

$p_{G} \quad$ pressão gás no interior do separador

$p \quad$ pressão do líquido no ponto em que é bombeado

$V_{G} \quad$ volume do gás no interior do recipiente de separação

$V \quad$ volume do recipiente de separação

$\left[m^{3}\right]$

$V_{L} \quad$ volume do líquido no recipiente de separação

$\left[m^{3}\right]$

\section{Símbolos Utilizados no Capítulo 7}

H Altura piezométrica ao longo da tubulação de saída de líquido

$Q \quad$ Vazão ao longo da tubulação de saída do líquido

$P \quad$ Pressão ao longo da tubulação de saída do gás

$[P a]$

$M \quad$ Vazão mássica ao longo da tubulação de saída de gás 


\section{Capítulo 1}

\section{Introdução}

A tendência mundial de produção e exploração petróleo em águas profundas aponta na direção da pesquisa e desenvolvimento de tecnologias específicas adaptadas às demandas que emergem desse novo ambiente de produção. Vários estudos vêm sendo desenvolvidos, dentre estes destaca-se os separadores submarinos os quais são assentados próximos ao poço de petróleo e são responsáveis por separar o fluido multifásico coletado e escoá-lo em duas fases distintas por tubulações próprias com o auxílio de uma bomba elétrica. O processamento do petróleo retirado de poços localizados em águas profundas depende, atualmente, de etapas de produção desenvolvidas na superfície da lâmina d'água. É o caso, por exemplo, da produção nas plataformas petrolíferas que recebem um fluído multifásico e o submetem a uma série de processos como separação gás/óleo e separação líquido/líquido com consequente tratamento da água separada a qual poderá ter diversos destinos como descarte ou reinjeção no reservatório. Um dos panoramas para esse novo ambiente de produção é o desenvolvimento de tecnologias capazes de transferir etapas do processamento para o leito do oceano com a vantagem de se obter instalações em superfície mais compactas e de menor custo.

Atualmente, o desenvolvimento de tecnologias que permitam a exploração submarina tem como vertente o deslocamento de etapas da produção de petróleo para o leito submarino. Dentre as etapas a serem deslocadas, vários avanços vêm sendo alcançados no que diz respeito ao processo de separação de fases com várias vantagens sobre os processos de separação atuais, feitos na plataforma, como possibilidade de aumento da vida produtiva de um poço e a redução do peso total sobre a plataforma.

A ideia associada à separação submarina é aumentar a eficiência das plataformas de produção. De acordo com Pinheiro, Val e Mendes 2009, o sistema atual utilizado na separação de fases gas/óleo/água executado na superfície da plataforma é bastante dispendioso já que os fluidos multifásicos a serem bombeados estão sujeitos a um tipo de escoamento bastante irregular. Esse comportamento de escoamento ainda é agravado pelo fato de a elevação ser feita a partir do nível do leito do oceano. Sifões acoplados à estrutura vertical dos risers de elevação que canalizam a produção até a plataforma, facilitam a formação de bolhas de gás largas, essas bolhas podem gerar um padrão de escoamento em golfadas bastante severo. 
O que leva autores como Rassenfoss 2011, a admitir argumentos para o deslocamento de etapas, como processamento da água e separação de fases, das plataformas para o leito do oceano. Um desses argumentos é o fato de que campos offshore obsoletos produzem mais água do que óleo. Quando as instalações de tratamento d'água na plataforma atingem sua capacidade, um tampão é colocado na saída de óleo. A interrupção no fluxo de água que sobe na direção da plataforma, aumenta a força necessária para se obter um fluxo de produção de óleo, de forma que há cada vez menos óleo sendo elevado à plataforma à medida que a pressão do reservatório declina. Em última instância, a pressão natural do reservatório não será mais suficiente para elevar água ou óleo até a superfície e, se nada for feito, será o fim da produção. Nesse ponto faz-se necessário uma intervenção para que se consiga manter a produção, uma das formas é o bombeamento do fluido a ser elevado. Outra maneira, é a redução da carga a ser elevada procedendo a separação da água e do óleo no fundo do oceano, assim apenas o óleo deverá ser enviado à plataforma descartando-se a água já no local da separação. Depois de algumas décadas de desenvolvimento e testes essa última opção começa a emergir como uma alternativa.

Para intervenção por bombeamento algumas tecnologias já vêm, há algum tempo, sendo testadas não só na intenção de prolongamento da vida útil dos reservatórios, como para otimizar o processo de produção com deslocamento de etapas para o leito do oceano. Assim, surgem conceitos como o de separação gás/líquido, nesse caso, uma vez retirado o gás, a fase líquida será elevada até a plataforma por um sistema de bombeamento. Rosa, Franca e Ribeiro 2001, afirmam que a tecnologia de separação gás/líquido empregada na indústria por várias décadas tem sido baseada em processos de separação por ação gravitacional, nesse tipo de processo, geralmente são empregados recipientes grandes e pesados. Esse tipo de tecnologia é visto como um "fardo" para exploração offshore já que os custos associados a estruturas navais são especialmente sensíveis a variáveis como peso e tamanho. A necessidade de se explorar reservas em campos submarinos, bem como de se diminuir custos com equipamentos e tem motivado pesquisas de desenvolvimento de novas técnicas de separação mais compactas e de menor custo.

O otimismo surgido em relação ao desenvolvimento de tecnologias e ao crescimento da produção em águas profundas já contava com entusiastas como Chiesa e Eriksen 2000, desde o início da década de 2000. Esse otimismo no entanto, encontrava barreiras à época, que mais de uma década depois são, ainda, pontos chave para o desenvolvimento da exploração offshore. Para esses autores o transporte dos fluidos produzidos em águas profundas apresenta desafios de uma série de fatores que podem tornar a exploração economicamente dispendiosa. Medidas como a redução da pressão do poço, necessária para elevação do petróleo à plataforma, e uma abordagem adequada e confiável ao escoamento multifásico, típico desse tipo de exploração, são avanços que podem contribuir para a atratividade econômica da produção em águas profundas.

No desenvolvimento do processamento submarino dos últimos anos destacam-se tecnologias que incluem separação de duas ou três fases e pressurização de líquido e fluidos multifásico. A separação bifásica traz a vantagem de reduzir a pressão necessária à elevação do líquido uma vez que permite o escoamento do gás enquanto o líquido é bombeado por outra tubulação. Dentre as tecnologias de separação bifásica pode-se, ainda, destacar o VASPS (Vertical Annular Separation Pump System). Esse tipo de equipamento é instalado em um poço falso no leito submarino 
próximo aos poços de produção. A produção desses poços é escoada para um mainfold que a envia para o VASPS. No VASPS o gás, ou pelo menos a maior parte dele, é separado da fase líquida e o escoamento dos fluidos é realizado em linhas diferentes, uma para o fluido gasoso e outra para o liquido. O gás é impulsionado por sua pressão natural enquanto líquido é enviado para a plataforma de produção com a utilização de um sistema adequado de bombeamento. [Melo, Serapiao e Mendes 2009]

Shiguemoto et al. 2011 atribui às atuais descobertas de campos de reservatórios de petróleo no Brasil, como o campo de Tupi na Bacia Santos, grande incentivo à procura de novas tecnologias que possibilitem a exploração e produção de petróleo em águas profundas. Segundo o autor, um dos desenvolvimentos mais promissores é a utilização do conceito de ciclones, utilizada nos VASPS. Neste tipo de equipamento não há partes móveis o que o torna mais simples, além de ter a característica de ser compacto e leve. Isso pode significar redução de custos de instalação e manutenção.

Uma visão geral do conceito de processamento submarino, é apresentada no trabalho de Chiesa e Eriksen 2000, de onde infere-se que esse tipo de processamento tipicamente incorpora etapas que constituem um sistema global, essas etapas ou "blocos" são listadas da seguinte forma:

1. Sistema de separação das fases, em duas ou três fases;

2. Modulo de impulsão do líquido, que pode ser constituído por bombas centrífugas;

3. Sistema de retirada de óleo da água através de hidrociclones de modo que a água atinja requisitos de qualidades necessários para sua re-injeção ou descarte;

4. Sistema de monitoramento da qualidade da água; e

5. Sistema de manejo de fase sólida com a utilização de hidrociclones para separação desta fase.

No que diz respeito a sistemas de separação submarina, há alguns modelos disponíveis na indústria tanto de separadores bifásicos, como a tecnologia VASPS, quanto de separadores trifásicos. Há bombas derivadas de adaptações das já existentes para uso onshore, capazes de oferecer uma variada gama de vazões e altura piezométrica. ${ }^{1}$ Um modelo de bomba centrífuga seguindo o conceito CoSSP${ }^{2}$ (Sistema de Separação e Bombeamento Submarino Configurável) foi idealizado a partir da configuração de bombeamento multifásico desenvolvido pela Nuovo Pignonne já implementada no campo de submarino de Agip Prezioso, Itália. Outra alternativa é a utilização de bombas elétricas submersíveis (Electrical Submersible Pump - ESP), essa com um grande histórico de aplicação em diferentes tipos de condições e ambientes. [Chiesa e Eriksen 2000]

O separador centrifugo basicamente separa dois fluidos de características distintas e os envia para um destino previamente especificado. O separador foco do presente trabalho separa gás e

\footnotetext{
${ }^{1}$ Altura piezométrica representa a energia em unidade de peso de líquido submetido a uma dada pressão

${ }^{2}$ Configurable Subsea Separation and Pumping System -CoSSP. Arquitetura de exploração submarina desenvolvida pela Sonsub, um grupo da empresa italiana Saipem especializado em veículos operados remotamente -ROV.

${ }^{3}$ Nuovo Pignone é uma ramificação da empresa General Eletrics -GE especializada em turbo-máquinas, bombas, compressores e sistemas de medição.
} 
líquido advindos de um poço de petróleo e que entram no recipiente de separação por uma boca de admissão. Esse aparato pode ser entendido como um sistema constituído de três partes distintas:

- a entrada do sistema que irá receber gás e líquido misturados

- uma parte destinada à separação, onde o gás é separado do líquido por processos que envolvem aplicação de forças centrifugas e ação gravitacional sobre o fluido

- uma parte constituída por um sistema de tubulações e bombeamento para o líquido que irão elevar os fluidos já separados ao seu destino.

Dada as vantagens esperadas pelo deslocamento de etapas de produção de petróleo para o fundo do mar, especialmente no caso da separação bifásica, algumas tecnologias vêm sendo testadas. No VASPS a separação da fase gás óleo é feita em uma estrutura cilíndrica fixada no fundo do oceano e que utiliza o conceito de separação ciclônica. [Pinheiro, Val e Mendes 2009]. Neste sistema, a fase gasosa é separada da fase líquida durante o escoamento por diferença de densidade, o que permite uma transmissão monofásica por duas linhas distintas, em direção à plataforma. Com esse sistema há um ganho de produção significativo, especialmente na produção de gás. [Melo, Mendes e Serapiao 2007]

No sistema VASPS a separação gás/líquido se inicia pela injeção da mistura multifásica em um hidrociclone de entrada. O fluido separado escoa abaixo por uma série de juntas de separação em espiral que realizam o segundo estágio de separação. O líquido separado é então descartado para um reservatório de líquido o qual é incorporado um ciclone de areia para remoção de sólidos. Esse tipo de sistema utiliza muitos componentes já existentes e utilizados em cabeças de poço comuns e pode ser instalado em utilizando tecnologias convencionais de perfuração. O custo de instalação, deve ser baixo o suficiente para que se possa instalar um VASPS por unidade de produção com benefícios em termos de flexibilidade operacional e disponibilidade do sistema. [Baker e LucasClementes 1990]

No que tange ao funcionamento do separador, Melo, Mendes e Serapiao 2007, chamam a atenção para algumas dificuldades encontradas com o uso da tecnologia de separação bifásica submersa. Segundo os autores, apesar da grande aceitação desde a implantação em campo no Brasil, distúrbios causados por escoamento em golfadas ${ }^{4}$ na entrada do sistema aliados a não-linearidades do sistema tornam a análise de tendência de comportamento difícil. Essa dificuldade de se antecipar a resposta do sistema leva à necessidade de acompanhamento constante do equipamento por um controlador. Além disso, o desempenho do sistema depende do acompanhamento de suas partidas e paradas, o que resulta em várias intervenções manuais.

Neste ponto, vale salientar que uma maneira eficiente para se trabalhar com esse tipo de equipamento é a adoção de um controlador capaz de manter o nível do líquido em seu interior entre limites que possibilitem uma separação eficaz sem gerar risco ao separador. A imposição de um limite superior para o nível do líquido justifica-se pela necessidade de haver espaço no interior

\footnotetext{
${ }^{4}$ Padrão de escoamento em golfadas é caracterizado pela formação de bolhas de gás alongadas no interior da tubulação precedidas por pistões de líquido que podem ou não conter gás disperso.
} 
do separador suficiente para que o estágio de separação secundária não seja comprometido. Se houver líquido ocupando um espaço significativo da hélice de separação nesse estágio a eficiência da separação poderá ser comprometida. O limite inferior do nível do líquido advém da imposição de não haver entrada de gás no sistema de bombeamento, o que poderia danificá-lo.

Várias características do funcionamento do separador ciclônico indicam a necessidade de aplicação de um controlador ao sistema. O nível do líquido no interior do separador deve ser controlado para que o líquido não ultrapasse um dado limite de altura, diminuindo a eficiência da separação. Por outro lado, se o nível do líquido no interior do separador estiver abaixo de um dado limite mínimo, a ponto de ficar abaixo do ponto de captação da bomba submersa, uma grande quantidade de gás entrará na bomba, afetando seu funcionamento e podendo causar sérios danos. Em contraposição à tentativa de controle do nível, aparecem dificuldades relacionadas a distúrbios causados pelo regime de escoamento na entrada, geralmente em golfadas. Esse tipo de distúrbio associado a não-linearidades inerentes ao sistema levam a um comportamento altamente randômico o que torna difícil seu controle, demandando constante supervisão de um operador. [Shiguemoto et al. 2011]

Um aparente problema para adoção de um controlador é a pressão no interior do recipiente de separação. O líquido contido na parte inferior do separador é bombeado para uma plataforma através da bomba (ESP), sendo esta o principal elemento a atuar no controle do nível. Além de invadir o espaço destinado à separação secundária, um nível de líquido acima do limite máximo pré-estabelecido pode provocar um aumento na pressão de separação, visto que o nível do líquido reduz o espaço que o gás pode ocupar no separador. No entanto, este aumento de pressão também depende do comprimento da linha de gás até a plataforma de produção. Comprimento, esse, que pode alcançar alguns quilômetros, fazendo com que a pressão não seja tão sensível ao nível de liquido na piscina. [Melo, Serapiao e Mendes 2009]

Pinheiro, Val e Mendes 2009, lembram que apesar do fato de os limites máximo e mínimo do nível no interior do separador deverem ser estritamente respeitados, o nível poderá se comportar livremente entre esses limites o que pode facilitar o trabalho de elaboração do controlador.

Na tentativa de se manter o nível do líquido no interior do separador entre os limites estipulados, alguns problemas podem aparecer. O principal elemento de controle, o atuador, é a bomba de escoamento do líquido, um equipamento caro e de difícil acesso. Assim, qualquer projeto de controle deverá considerar sua otimização de forma que a bomba não seja submetida a esforços desnecessários.

Quanto aos possíveis atuadores a operarem no controle do sistema, Melo, Serapiao e Mendes 2009 analisam a dificuldade de se utilizar atuadores diferentes da bomba submersa como válvulas de fluxo, segundo eles separadores como VASPS não são sistemas compactos, tendo em torno de 70 metros. Esses equipamentos não apresentam válvula de controle de fluxo na saída, mas uma válvula tipo $c h o k e^{5}$ instalada na linha de gás que pode estar alguns quilômetros de distância. Deste modo, é impraticável realizar o controle de nível de líquido na piscina através de uma contrapressão

\footnotetext{
${ }^{5}$ Válvula choque. Válvula utilizada para quebrar a pressão do escoamento produzido e permitir o controle da vazão do poço produtor, harmonizando-a à pressão de trabalho dos equipamentos a jusante.
} 
gerada pelo fechamento desta válvula na linha gás. Tampouco se pode realizar controle de pressão no vaso separador com a mesma velocidade (ou mesma 'constante de tempo') do controle de nível de líquido." [Melo, Serapiao e Mendes 2009]

No que diz respeito a vida útil da bomba, há uma estrita relação entre sua durabilidade e a quantidade de mudanças em sua velocidade de rotação sendo tão mais durável quanto menor for a quantidade de mudanças na velocidade [Pinheiro, Val e Mendes 2009]. Dessa forma, um controlador eficiente não pode configurar apenas um regulador padrão baseado nos requisitos do sistema, mas numa estratégia de controle capaz de responder ao comportamento do sistema e as suas não linearidades e de preservar o atuador o máximo possível.

Surge então, a necessidade do aprimoramento de mecanismos de controle que possam tornar o funcionamento do sistema eficiente de forma a compensar as dificuldades de operação impostas pelo sistema. Assim, do ponto de vista do controle, o interesse nesse tipo de sistema surge da necessidade de se controlar o nível do líquido separado no interior do equipamento de maneira a mantê-lo dentro de um intervalo de valores pré especificado. Faz-se necessário, para tanto, uma abordagem teórica capaz de lidar com a variável a ser controlada mesmo diante de possíveis fatores complicadores que possam ser impostos pela dinâmica do sistema. O escoamento dos fluidos no interior de suas respectivas tubulações de saída pode ser estudado a partir das equações do momento e da continuidade. Quando discutidas a partir da perspectiva da teoria de Transientes em Fluidos essas equações apresentam termos que relacionam a propagação de pulsos de ondas resultantes de distúrbios transientes, com a pressão e a vazão ao longo das tubulações de saída e ao longo do tempo. Esses distúrbios transientes podem ser causados por acontecimentos como acionamento de uma bomba ou fechamento e abertura de uma válvula, possivelmente, afetando substancialmente o nível do líquido no interior do separador [Wylie e Streeter 1978]. A modelagem por teoria de transientes em fluidos aplicada ao separador centrífugo se justifica na medida em que possibilita o equacionamento dos efeitos dinâmicos no interior das tubulações tanto para parte de escoamento do líquido quanto para o escoamento do gás. Dessa forma é possível prever-se não só o nível de líquido no interior do separador em função do comportamento dos fluidos separados nas respectivas tubulações de saída, como também, é possível acompanhar o comportamento no interior dessas tubulações.

Faz-se necessário salientar que outros fatores não abordados no presente estudo fazem parte da dinâmica do sistema e deverão ser considerador na busca de um modelo mais acurado que descreva seu comportamento. Fatores como o escoamento multifásico no interior do equipamento, a separação das fases bem como a geometria interna do separador ${ }^{6}$, por exemplo, são fatores que influenciarão a variável a ser controlada. Espera-se, no entanto, que um modelo obtido a partir da teoria de transientes em fluidos seja suficientemente robusto para descrever satisfatoriamente o sistema.

O separador centrífugo submerso, no presente trabalho, será dividido em três zonas de estudo: tubulação de líquido, tubulação de gás e interior do separador. A divisão, bem como um esquema do separador pode ser visto na Figura 1.1. A primeira parte refere-se à tubulação de líquido e a

\footnotetext{
${ }^{6} \mathrm{Na}$ seção 2.4 é apresentado uma geometria típica de separadores centrífugos submersos
} 
segunda à tubulação de gás, ambas mostradas na Figura.

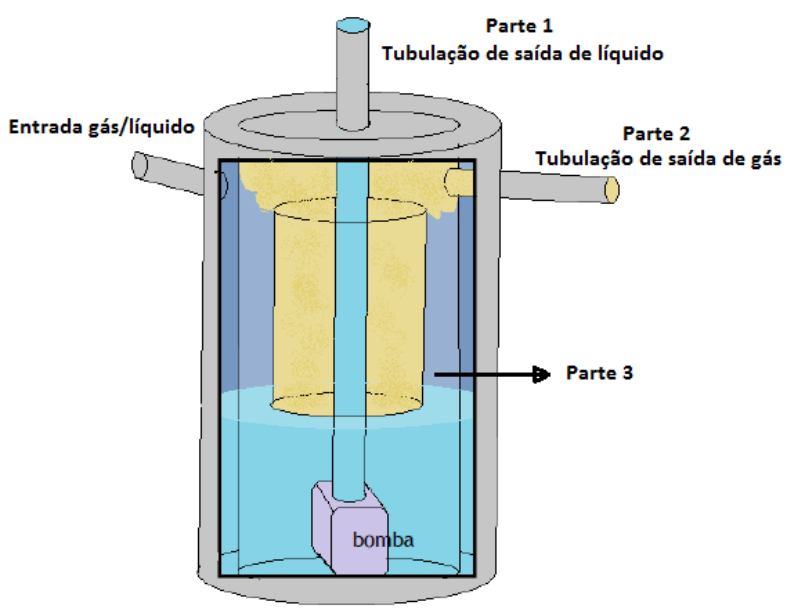

Figura 1.1: Esquema do separador, três partes serão analisadas separadamente para a modelagem do sistema. Parte 1 - tubulação de saída líquido. Parte 2 - tubulação saída de gás. Parte 3 Interior do separador

A terceira parte, referente ao interior do separador é ilustrada na Figura 1.1 pelo retângulo no meio da Figura. Nesta parte ocorre a interseção de dois problemas de valor inicial e de contorno distintos. Um referente ao escoamento do gás e outro referente ao escoamento do líquido, ambos em suas respectivas tubulações de saída. A pressão e vazão do líquido no início da tubulação de saída é função da altura da coluna de líquido no interior do separador, bem como uma função da pressão da camada de gás no interior do separador e acima da coluna de líquido. Adicionando-se ao sistema a entrada multifásica, tem-se um sistema fechado com comportamento difícil de prever e ainda efeito transientes.

A escolha de uma técnica de controle adequada necessita considerar as características do sistema estudado tais como não linearidades associadas ao escoamento no interior do separador bem como nas tubulações de saída, o regime de escoamento na entrada, muitas vezes em golfadas, e as possíveis perturbações suficientes para causar transientes no escoamento escoamento do líquido e do gás no interior de suas respectivas tubulações de saída.

Uma maneira de se abordar o problema é a utilização de uma técnica de controle que seja capaz de manter o comportamento do sistema sob limites predeterminados sem que seja necessário o conhecimento de toda a dinâmica do sistema. Assim, parte da complexidade associada ao comportamento do sistema poderá ser negligenciada pelo modelo matemático que descreve o controlador. No entanto, o controlador deverá ser robusto o suficiente para que possa controlar o sistema mesmo sob ação de efeitos adversos como transientes no escoamento dos fluidos.

O controle deslizante (Sliding Control) é um método de controle não linear que altera a dinâmica de um sistema não linear pela aplicação de um sinal de controle descontínuo que força o sistema a se manter sobre uma superfície (sliding surface), que dá as condições para que a variável controlada do sistema mantenha um erro próximo a zero em relação a uma variável predeterminada. Slotine e LI 1991, classificam o controle deslizante como robusto, apropriado para tratar 
sistemas não lineares que tenham incertezas em seu modelo. Na estrutura desse tipo de controlador há uma parte nominal, similar a realimentação linearizante e termos adicionais que lidarão com as incertezas do modelo dinâmico.

O modelo dinâmico adotado para determinação do nível do líquido no interior do separador apresenta incertezas associadas a partes que são tratadas como não modeladas. Essas incertezas advém de variáveis que obtidas pela solução dos dois conjuntos de equações que descrevem o comportamento do escoamento do gás e do líquido em suas respectivas tubulações a serem discutidos no Capítulo 3, levantados pela teoria de transientes em fluidos. A vantagem de se tratar essas variáveis como incertezas do sistema é que é possível representar sua dinâmica por uma equação de primeira ordem, apesar de se estar lidando com uma dinâmica de ordem superior fortemente não linear já que as equações que governam o escoamento do líquido dentro das tubulações de saída são equações diferenciais não lineares no tempo e no espaço. Assim, visualizando-se o separador centrífugo submerso como um sistema dinâmico com incertezas associadas, o controle deslizante torna-se um excelente candidato a ser adotado como técnica para a elaboração da lei de controle do problema.

\subsection{Objetivos do Trabalho}

Intenta-se propor um controlador para o sistema de separação ciclônica, capaz de manter o nível do líquido dentro de limites preestabelecidos de forma que não haja prejuízo do processo de separação das fases (com nível do líquido muito alto) e não se permita que a fase gasosa separada alcance o atuador (nível de líquido muito baixo). Pretende-se ainda, que a arquitetura do controlador permita sua adequação à necessidade de preservação do atuador evitando que trabalhe demasiadamente e tenha sua vida útil diminuída. Assim o controlador deverá ser capaz de forçar o nível do líquido a seguir uma dada trajetória, desta forma será possível, em trabalhos futuros, estabelecer-se trajetórias otimizadas que mantenham o nível dentro de um intervalo especificado e preserve o atuador. Nessa direção foram tomadas as seguintes ações:

- Levantar modelos numéricos do escoamento nas tubulações de saída a partir da consideração das características de escoamento próprias do fluido (compressibilidade, viscosidade, densidade) com o estabelecimento da relação entre o modelo de escoamento nas respectivas tubulações e as características de comportamento impostas ao sistema como condição de contorno variável advindo de entrada em golfada, geração de transientes por atrito ou distúrbios externos.

- Utilizar um método numérico apropriado para a solução das equações que governam o sistema.

- Propor de um controlador capaz de submeter o nível no interior do separador a intervalos de valores requeridos sob condições de operação desejáveis.

- Realizar adaptações que se fizerem necessárias no sentido de se obter um controlador que não 
submeta o atuador (sistema de bombeamento com bomba tipo ESP) à esforços desnecessários e consequente diminuições de sua vida útil.

- Simular o comportamento do sistema controlado tomando como base o protótipo de separador ciclônico submerso desenvolvido por Storti 2013.

\subsection{Organização do Trabalho Escrito}

Este trabalho foi organizado em sete Capítulos sendo o primeiro a introdução. No segundo Capítulo é realizada uma revisão bibliográfica onde são apresentados alguns estudos que abordam tanto os tipos de separadores e abordagens de controle. No terceiro Capítulo é apresentada a fundamentação teórica necessária à modelagem do sistema a partir da perspectiva da teoria de Transientes em Fluidos. O quarto Capítulo foi dedicado ao procedimento utilizado para solução numérica dos conjuntos de equações estabelecidas para o escoamento dos fluidos, gás e líquido, ao longo de suas respectivas tubulações de saída e ao longo do tempo. No quinto Capítulo é realizado um estudo do modelo geral simplificado que caracteriza o separador ciclônico, no intuito de identificar características gerais do sistema dinâmico não linear associado, abordando conceitos próprios ao estudo de sistemas não lineares como ponto de equilíbrio do sistema, autonomia e estabilidade. No sexto Capítulo foi discutido e proposto uma abordagem de controle baseada no método de Sliding Control, foi apresentado uma adaptação ao controlador onde o sinal de controle é filtrado como forma de se alcançar um controle que não demande do atuador do sistemas esforços demasiados. Nesse Capítulo ainda são discutidos as condições gerais de estabilidade do sistema controlado bem como as hipóteses assumidas como garantia de aplicabilidade do controlador proposto. O sétimo Capítulo foi destinado à apresentação dos resultados obtidos a partir da simulação do sistema controlado tomando como base o protótipo de separador ciclônico desenvolvido por Storti 2013. 


\section{Capítulo 2}

\section{Revisão Bibliográfica}

\subsection{A Produção em Águas Profundas no Contexto Nacional}

No contexto nacional, as tecnologias de exploração submarina vêm sendo impulsionadas pela ativa participação da empresa brasileira Petrobras no desenvolvimento de conhecimento e equipamentos necessários para que se possa atingir poços profundos, típicos dos mananciais de petróleo brasileiros. Dentre essas tecnologias pode-se citar a separação gás/líquido no leito oceânico com desenvolvimento de conceitos como VASPS. No ano de 2002, já se era sabido que as reservas provadas de gás e petróleo no Brasil chegavam a 11,01 bilhões de barris de óleo equivalente (BOE) ${ }^{1}$, sendo que até o ano de 2010 essas reservas já atingiam mais de 15 bilhões de barris, segundo os critérios da $\mathrm{SPE}^{2}$. Grande parte dessas reservas estão localizadas em águas profundas ${ }^{3}$ ou ultra profundas ${ }^{4}$, o que levou a uma redistribuição das quantidades relativas produzidas no que diz respeito às produções onshore e offshore ao longo do tempo. Em 1987, apenas 1,7\% da produção média anual advinha de reservatórios submarinos, já no ano de 2002 a quantidade havia saltado para $66 \%$. No ano de 2014 a Petrobras aferia uma produção diária de mais de 2 milhões de barris -BOE [Petrobras 2014], sendo que até 2002, 64\% do petróleo produzido advinha de águas profundas e ultra profundas tornando-a a maior produtora em águas profundas no mundo [Procad 2004] [Estrela 2003]. A evolução da produção brasileira pode ser observada na Figura 2.1, onde observa-se um salto de produção para 1,6 milhões de barris em apenas uma década.

\footnotetext{
${ }^{1}$ BOE. Unidade utilizada para permitir a conversão de um volume de gás natural em volume de líquido equivalente. Em geral, utiliza-se a relação aproximada de $1.000 \mathrm{~m} 3$ de gás para $1 \mathrm{~m} 3$ de petróleo.

${ }^{2}$ Society of Petroleum Engineers.

${ }^{3}$ Águas profundas - profundidade de 401 a 1500 metros

${ }^{4}$ Águas ultra profundas - profundidade de mais de 1500 metros
} 


\section{Produção de Petróleo da Petrobras}

(1.000 barris por dia)

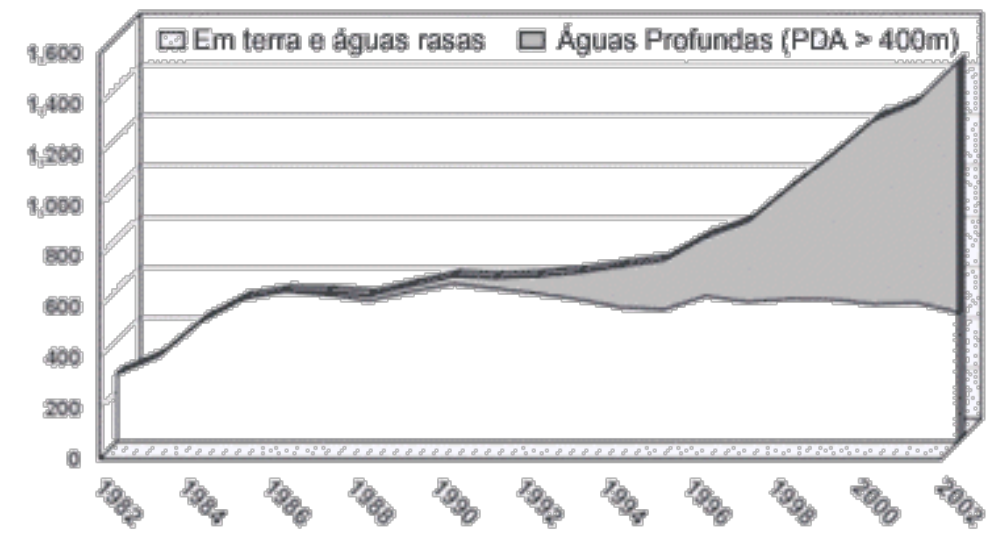

Figura 2.1: Produção brasileira em barris de petróleo dia. Fonte: [Estrela 2003]

O Estabelecimento do Brasil, via Petrobras, como grande explorador submarino, dada sua vocação intrínseca fundamentada na disponibilidade de recursos naturais e experiência na área, só pôde ser confirmado após uma série de avanços organizacionais, técnicos e científicos frutos de diversos empreendimentos feitos pela empresa. Dentre esses empreendimentos, alguns programas se destacaram na concretização da "marcha para o fundo do mar". Com o objetivo de capacitar tecnologicamente a Petrobras, bem como todo o complexo de instituições e empresas envolvidas com a exploração de petróleo no Brasil, no sentido de desenvolver equipamentos e tecnologias que viabilizassem a produção de petróleo em águas profundas, a Petrobras executou, a partir de 1986 uma série de programas de capacitação. Foram os denominados Programas de Capacitação Tecnológica em Águas Profundas - PROCAP. Morais 2013, descreve esses programas como uma inovação organizacional que introduziu novas práticas e procedimentos "para estabelecer novas modalidades de colaboração com instituições de pesquisa e empresas fornecedoras de bens e serviços, entre outros aprimoramentos na gestão". [Morais 2013]

Entre os anos de 1986 e 2000 foram lançados três PROCAP's. O primeiro, PROCAP 1.000 executado entre os anos de 1986 e 1991 integrou cerca de 109 projetos interdisciplinares e teve um custo de US\$ 68 milhões, o programa procurava, entre outros, adaptar e desenvolver equipamentos submarinos como árvores de natal e risers ${ }^{5}$, alcançar novas concepções de desenvolvimento como sistemas de bombeamento multifásico de petróleo. Um dos resultados desse programa foi a elaboração, pela primeira vez no mundo, de um processo de instalação de uma bomba tipo BCS ${ }^{6}$ dando origem ao conceito BCSS ${ }^{7}$ [Morais 2013]. O segundo programa denominado PROCAD 2.000, objetivou o desenvolvimento de tecnologias para produção de petróleo em águas com até 2000 metros de profundidade, o programa foi executado entre os anos de 1992 e 1999 e dentre seus principais desenvolvimentos tecnológicos pode-se destacar o desenvolvimento de árvore de natal submarina para 2500 metros conjunta com BCSS e o desenvolvimento de sistema de bombeamento

\footnotetext{
${ }^{5}$ Risers - linhas que interligam os equipamentos submersos aos de superfície, o trecho do duto que fica suspenso é denominado de riser.

${ }^{6}$ BCS - Bombeamento Centrífugo Submerso

${ }^{7}$ BCSS - Bombeamento Centrífugo Submerso Submarino
} 
centrífugo submerso submarino, VASPS, para separação bifásica gás/líquido no leito submarino. [Morais 2013].

\subsection{Tipos de separadores}

Dentro desse panorama de deslocamento de algumas etapas de produção e em resposta às dificuldades geradas pelo escoamento multifásico, foram desenvolvidas tecnologias como:

1. GLCC (Gas-Liquid Cylindrical Ciclone), resultado do esforço conjunto de desenvolvimento da Chevron ${ }^{8}$ e da Universidade de Tulsa ${ }^{9}$, este tipo de equipamento é especialmente adaptado para aplicações que requerem separação parcial com no caso de composições com medidores multifásicos ou sendo usados como pré-separadores isolados. [Rosa, Franca e Ribeiro 2001]

2. Separador Ciclônico - CS (Cyclone Separator) é o resultado do esforço conjunto de desenvolvimento da Petrobras e da Universidade de Campinas-SP e foi inicialmente concebido como parte de uma tecnologia de bombeamento do petróleo produzido em campos submarinos. Assim como na tecnologia VASPS, o fluido multifásico é separado no interior do CS, este instalado no leito do oceano, e então, escoado até a plataforma por duas linhas independentes, uma para gás e outra para líquido. O líquido, uma mistura de óleo e água, é bombeado por uma bomba ESP convencional enquanto o gás escoa para a plataforma pela diferença de pressão existente entre o recipiente de separação do CS e o recipiente coletor instalado na superfície. [Rosa, Franca e Ribeiro 2001]

3. VASPS (Vertical Annular Separation Pumping System), já mencionado neste trabalho, é uma tecnologia de separação bifásica gás/líquido patenteada pela empresa inglesa British Petroleum ${ }^{10}$ que também utilizada bomba tipo ESP para escoamento do líquido e pressão natural para elevação do gás até a plataforma. Este sistema é utilizado em campos explorados pela Petrobras desde 2001. Outras empresas buscam desenvolver esse tipo de tecnologia como é o caso da Shell ${ }^{11}$ que considera a utilização de um separador que utilize bomba tipo ESP para o projeto BC-10 na bacia de Campos ${ }^{12}$. [McClimans e Fantoft 2006]

4. Separador Inline, resultado de um programa de desenvolvimento conjunto entre CDS e Statoil esse tipo de separador é baseado na tecnologia ciclônica podendo ser considerado um mono-ciclone. O princípio básico de funcionamento consiste na utilização de elementos de

\footnotetext{
${ }^{8}$ Chevron, com sede nos Estados Unidos, é uma das grandes empresas mundiais do ramo energético, especialmente petrolífero suas incluem extração e transporte de petróleo e gás natural; refino de petróleo; produção e venda de produtos químicos e geração de energia.

${ }^{9}$ Universidade de Tulsa - Universidade privada localizada na cidade de Tulsa, Oklahoma, Estados Unidos.

${ }^{10}$ British Petroleum- originalmente Anglo-Persian Oil Company e depois British Petroleum, multinacional sediada no Reino Unido que opera no setor de energia, sobretudo de petróleo e gás.

${ }^{11}$ Shell Oil Company- subsidiária nos Estados Unidos da Royal Dutch Shell, uma multinacional petrolífera de origem anglo-holandesa, que está entre as maiores empresas petrolíferas do mundo.

${ }^{12}$ Parque da Conchas BC-10. Projeto da Petrobras para bacia de Campos. O parque das conchas entrou em operação em 2009 e produz, atualmente, cerca de 50 mil barris (BOE) por dia.
} 
redemoinho estático que induzem fluxos ciclônicos para pressionar em direção às parede dos tubos enquanto há a condução do gás para o interior do tubo. [Kremleva et al. 2010]

5. Separadores tipo Caisson foram desenvolvidos pela Shell sendo separadores de duas fases a serem posicionados no leito submarino. A separação das fases líquida e gasosa ocorre no interior do equipamento bem como na sua entrada inclinada e tangencial. O líquido, mais pesado, é dirigido para as paredes do separador e escoa para baixo em direção ao sistema de bombeamento. O gás, mais leve, migra para parte superior do equipamento escoando através de uma saída própria. [Deuel et al. 2011]

6. Separação Submarina Água/Óleo (SSAO), este tipo de separação tem como principal objetivo o processamento primário dos fluidos no leito marinho dando um destino deferente à água produzida para que ela não seja conduzida à plataforma de produção. Entre os benefícios pode-se citar o alívio da planta de produção que permanecerá apenas com uma quantidade residual de água. [Albuquerque et al. 2013]

\subsection{Vantagens dos separadores submersos bifásicos}

A separação gás/líquido ao nível do leito do oceano apresenta vantagens como o aumento da taxa de recuperação do reservatório na medida em que se reduz a pressão a esse nível. A utilização de bombeamento monofásico e o escoamento dos fluidos separados em tubulações distintas, reduz, ou até mesmo evita, problemas típicos relacionados ao escoamento multifásico como a deposição de hidratos ${ }^{13}$, escoamento intermitente e golfadas. A diminuição das incertezas relacionadas às fortes não-linearidades típicas do escoamento multifásico, torno o sistema mais fácil de se gerenciar o que pode resultar em menos intervenções. [Rosa, Franca e Ribeiro 2001]

Outro ponto, destacado por Melo, é que, dependendo do cenário, existe a possibilidade de instalar o sistema de separação bifásica em substituição a plataformas que possuem alto custo de manutenção, sendo a produção direcionada para outras plataformas próximas. [Melo, Serapiao e Mendes 2009]. Investigações indicam que um sistema com um separador VASPS pode funcionar, seguramente, em reservatórios a uma distância de 50 a 100km da unidade de produção. A essa distância é possível evitar problemas operacionais associados à formação de hidratos, teste do sistema e monitoração de instabilidade de fluxo e escoamento em golfadas. [Baker e Lucas-Clementes 1990].

Storti 2013, lista os benefícios da utilização de sistemas de separação submarina bem como algumas relutâncias associadas como apresentado na tabela 2.1

\footnotetext{
${ }^{13}$ Hidratos - moléculas de água, ao mudar para a fase sólida, "aprisionam"moléculas de gás natural Esses compostos se formam em condições comuns nas linhas submarinas de transmissão de petróleo: sob baixa temperatura (cerca de $4{ }^{\circ} \mathrm{C}$ ) e pressão elevada e na presença de água e gás natural.
} 
Tabela 2.1: Benefícios e algumas relutâncias para o uso de sistemas de separação submarina. [Storti 2013

\begin{tabular}{ll}
\hline Benefícios & Relutância \\
\hline Redução da contrapressão imposta na região de & A complexidade da arquitetura submarina \\
areia do reservatório permitindo uma maior taxa & aumenta com a utilização de separadores. \\
de produção melhorando a recuperação final. & $\begin{array}{l}\text { Manifolds, válvulas, sistemas de controle, } \\
\text { instrumentação, todos aumentam os custos e a }\end{array}$ \\
& $\begin{array}{l}\text { complexidade do sistema. Portanto o uso de } \\
\text { sistema de separação submarina depende da }\end{array}$ \\
& relação custo/benefício. \\
\hline A possibilidade de o gás ser re-comprimido e re-- & A estação de bombeamento de líquido requer \\
injetado para fornecer a pressão de suporte para & enormes quantidades de energia, para o qual \\
o reservatório. & uma fonte de energia pode ou não existir em \\
& uma plataforma. \\
\hline
\end{tabular}

A possibilidade de utilizar bombas centrifuga para elevar o líquido.

A linha de gás sofre uma queda de pressão mais baixa, reduzindo a necessidade de recompressão do gás.

Ajuda nos problemas de garantia de escoamento, pois como uma grande porcentagem do hidrocarboneto mais leve é desviada através da linha de gás, ajudando a evitar problemas de formação de hidratos ou reduzir a quantidade de metano a ser injetado.

Despressurização do separador e da linha de escoamento de líquido através da linha de gás podendo eliminar a formação de hidratos durante as paradas de produção.

A pressão do separador pode ser abaixada para permitir mais facilmente a re-partida dos poços.

O esquema de separação submarina gáslíquido permite também a redução do diâmetro dos risers e linhas de escoamento (flowlines).

O correto processamento de fluidos no leito marinho também permite estações menores de processo hospedadas nas plataformas.

A utilização de separadores bifásicos submarinos como VASPS, ainda apresenta vantagem de reduzir os custos da exploração offshore quando comparado aos sistemas de separação convencionais que utilizam recipientes de separação maiores e mais pesados [Bensoussan e Lions 1984]. 
Outras vantagens do VASPS sobre sistemas convencionais são elencadas por Devegowda e Scott 2003:

1. Fácil acesso aos equipamentos de separação e bombeamento em caso de falhas;

2. Reduz a quantidade de capital envolvido já que a única linha de escoamento multifásico é a que leva do poço até a entrada do VASPS;

3. Custos de operação reduzidos em relação ao fornecimento de energia já que as linhas de alimentação elétrica não precisam se estender até o campo de produção.

\subsection{Funcionamento do separador ciclônico tipo VASPS}

Pode-se compreender o equipamento, VASPS, como sendo composto por três estágios: uma câmara de expansão onde a maior parte do gás se expande enquanto o líquido separado escoa para baixo, um caminho helicoidal onde a maior parte do gás que ainda estiver retido será separado por força centrífuga, um reservatório na parte de baixo onde a pequena quantidade de gás remanescente é separada por ação gravitacional e onde é instalado o equipamento de bombeamento do líquido (geralmente uma bomba ESP). [Bensoussan e Lions 1984]

Alguns pesquisadores classificam os estágios de separação como primário, secundário e terciário. Esse tipo de nomenclatura é benéfico no sentido de padronizar a terminologia associada ao VASPS e tecnologias afins, e possibilitar uma referência direta às etapas de separação no interior do equipamento de acordo com diferentes processos conceituais aos quais a mistura gás/óleo são submetidas durante o processo de separação bifásica. Dessa forma, Melo, Mendes e Serapiao 2007 explicitam três estágios:

1. Separação primária: a que ocorre na câmara de expansão;

2. Separação secundária: é composta por uma estrutura helicoidal e utiliza o princípio de separação centrífuga;

3. Separação terciária: composta por uma piscina na qual o líquido se acumula e parte do gás é separada de forma gravitacional.

Com base nos estágios de separação Melo, Serapiao e Mendes 2009, descrevem o funcionamento do separador centrífugo, VASPS no caso de seu estudo, da seguinte forma: "O bocal de entrada dá acesso a uma câmara de expansão que permite que a mistura de líquido e gás descarregue na direção tangencial do separador". Desta forma, o campo centrífugo gerado na saída do bocal permitirá que parte do gás seja liberada. Após essa separação sobrará o líquido e um gás disperso, ambos serão empurrados contra as paredes, e fluirão como um filme na direção da seção da hélice. O filme sofrerá uma aceleração na direção vertical e fluirá para a parte de baixo do separador. "A separação gás-líquido ocorre em bolhas dispersas que se movem radialmente para o interior do hélice e alcançam a interface líquido/gás. Sobre o filme flui parte do gás previamente segregado, 
que alcança o anular de gás através dos furos existentes na parte cilíndrica central da hélice. A piscina na parte inferior do vaso coleta o líquido e algum gás eventualmente disperso". [Melo, Serapiao e Mendes 2009]

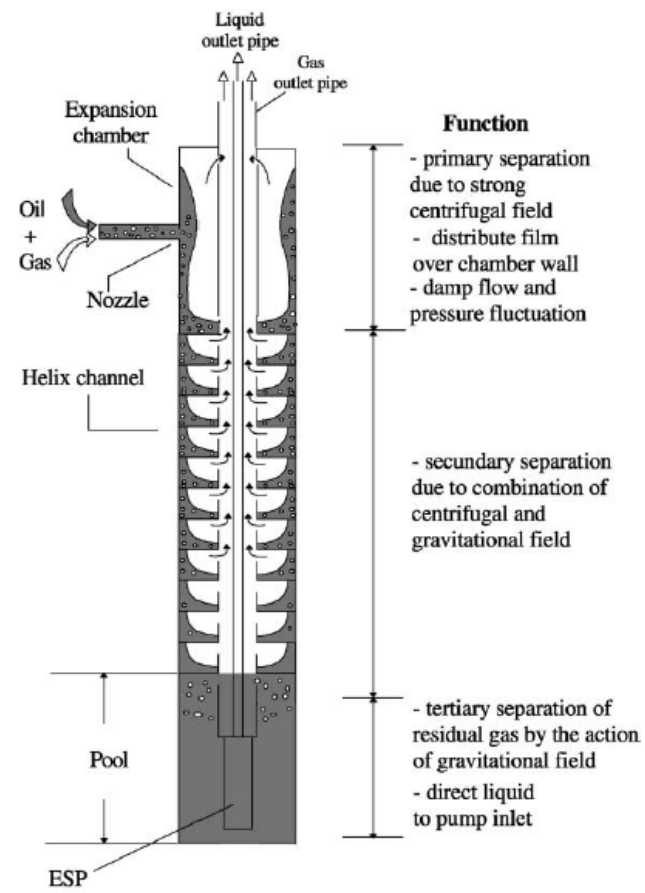

Figura 2.2: Separador Centrífugo Submerso. Fonte: [Rosa, Franca e Ribeiro 2001]

A Figura 2.2 mostra a representação de um separador centrífugo com seus três estágios. A mistura gás óleo entra por um bocal na parte superior do separador, escoa por uma hélice fixa posicionada ao longo do equipamento e é depositado numa piscina situada na parte inferior onde é colocado uma bomba submersa, geralmente do tipo ESP. A separação se dá num processo global que pode ser entendido pelas três etapas de separação. Em linhas gerais, o processo de separação pode ser descrito da seguinte forma:

- Separação Primária. A mistura bifásica entra pelo bocal com velocidade suficiente para que seja impelida a um movimento tangencial seguindo a forma geométrica cilíndrica do separador. Como apontado por Melo, uma parte do gás é separado nesse estágio mas a mistura persiste. Ainda impelida pela velocidade inicial de entrada e pela geometria do equipamento a mistura começa a girar formando um filme de líquido com bolhas dispersas, nesse ponto aumenta a importância da referida força centrífuga que empurra o líquido contra as paredes do separador e força o movimento do gás na direção radial até a interface gás/líquido onde se desprende, e há separação de fases. A medida que a mistura gira nas paredes do separador, mais gás é separado. [Rosa, Franca e Ribeiro 2001]

- Separação Secundária. Na descida ao longo da hélice, a gravidade é a principal força motora do movimento do líquido, adicionalmente há presença de forças centrífuga, devido ao movimento rotacional da mistura, e de cisalhamento a medida que a mistura é compelida 
contra as paredes do recipiente. O desenvolvimento hidrodinâmico do escoamento se dá por volta do quarto ao sexto passo da hélice. Como há, nesse estágio, bolhas de gás dispersas no filme de líquido, o escoamento pode ser classificado como o de um filme de líquido estratificado com bolhas de gás dispersas, esse filme escoa num plano inclinado em relação ao eixo principal de simetria do separador, de acordo a disposição espacial da hélice. $\mathrm{O}$ gás liberado nesse estágio, se movimenta na parte superior interna do espaço formado entre as pás da hélice antes de entrar nos orifícios de acesso à tubulação de escoamento de gás. Esses orifícios situam-se na parte superior do descrito espaço entra as pás. O passo da hélice determina a vazão da mistura bem como a quantidade de líquido que poderá ser admitida no interior do segundo estágio de separação. [Rosa, Franca e Ribeiro 2001]

- Separação Terciária. O terceiro estágio se inicia quando a mistura atinge a piscina na parte inferior do separador e é governada principalmente por forças gravitacionais. A intenção é separar as bolhas de gás que permaneceram dispersas no filme do líquido ou que foram reinjetadas na mistura no momento em que o líquido cai na piscina. O terceiro estágio é a última barreira para se evitar que seja injetado gás na bomba, portanto, espera-se que até esse ponto a quantidade de gás dispersa na fase líquida seja desprezível. [Rosa, Franca e Ribeiro 2001]

\subsection{Dificuldades com VASPS}

Além das dificuldades brevemente discutidas na introdução como distúrbios causados por escoamento em golfadas e não linearidades associadas ao sistema, outra dificuldade associada à separação bifásica, que de acordo com McClimans e Fantoft 2006, configura um de seus grandes desafios, é a separação do gás a partir de óleos muito viscosos. As fases levadas ao interior do separador, inicialmente separadas quando encontravam-se no fundo do poço, ao escoar através das tubulações de produção, são submetidas a agitação e a esforços de cisalhamento o que gera a dispersão de uma fase na outra. Essa dispersão é potencializada pela presença de emulsificantes naturais de caráter lipofílico dominante (asfaltenos, resinas, ácidos naftênicos, o outros) presentes no petróleo, que dão origem a formação de emulsões ${ }^{14}$ do tipo água-óleo (A/O). Os agentes emulsificantes migram para interface entre as duas fases formando uma barreira que impede o contato entre as gotas de água e óleo, o que estabiliza a emulsão. Adicionalmente, sabe-se que emulsões podem ser estabilizadas pela presença, na interface, de materiais insolúveis finamente divididos como partículas sólidas que podem estar presentes no óleo levado ao separador. Durante a agitação das fases no interior da tubulação, várias porções de gás podem ser aprisionadas em pequenos clusters no interior das emulsões formando uma multifase difícil de se separar dada a alta viscosidade associada ao óleo que forma a fase líquida.

Há ainda, no que diz respeito aos sistemas de separação bifásica, um problema relacionado ao reinício de sua operação. Uma vez parado o sistema por algum motivo operacional, será necessário reiniciá-lo fazendo com que a mistura bifásica volte a escoar pelo separador. No entanto, emulsões

\footnotetext{
${ }^{14}$ Emulsão é a mistura entre dois líquidos imiscíveis em que um deles (a fase dispersa) encontra-se na forma de finos glóbulos no seio do outro líquido (a fase contínua), formando uma mistura estável.
} 
podem ter sido formadas, fazendo-se necessário a utilização de bombas multifásicas ao invés de monofásicas com objetivo de tornar o sistema mais robusto, já que haverá gás disperso em meio a fase líquida. O custo dessa robustez com a utilização equipamento extra para bombeamento multifásico é a diminuição da altura piezométrica alcançada pelo sistema. Bombas multifásicas, geralmente apresentam menor eficiência que as monofásicas. [McClimans e Fantoft 2006].

Mesmo com todos os benefícios apontados em relação à separação bifásica submersa, existia, segundo Devegowda e Scott 2003, pelo menos até meados do ano de 2003, uma certa relutância na adoção desse tipo de técnica. Essa relutância (ver tabela 2.1) justifica-se por motivos como a complexidade da arquitetura da planta submersa e a confiabilidade da tecnologia.

Pode-se citar ainda algumas soluções para os desafios relacionados a implantação de sistemas de separação submarina :

1. Utilização de mini $T L P \mathrm{~s}^{15}$ ou mini $F P S O$ s para atuarem como estação de força de suprimento elétrico da planta submersa. [Devegowda e Scott 2003]

2. Desenvolvimento de métodos novos para diminuir a quantidade de sólidos que entram no sistema. [Devegowda e Scott 2003]

3. Parte do gás pode ser renjetado na base do riser para diminuir efeitos danosos com escoamento em golfada e como forma de aumentar a eficiência na elevação do gás. [Devegowda e Scott 2003]

\subsection{Necessidade do controle}

Várias características do funcionamento do separador ciclônico indicam a necessidade de aplicação de um controlador ao sistema. O nível do líquido no interior do separador deve ser controlado para que o líquido não ultrapasse um dado limite de altura, caso isso ocorra a eficiência da separação será comprometida uma vez que se o estágio de separação secundária for inundado com líquido o espaço reservado para separação ciclônica feita a altura das hélices será comprometido. Por outro lado, se o nível do líquido no interior do separador estiver abaixo de um dado limite mínimo, a ponto de ficar abaixo do ponto de captação da bomba submersa, uma grande quantidade de gás entrará na bomba, afetando seu funcionamento e podendo causar sérios danos. Em contraposição à tentativa de controle do nível aparecem dificuldades relacionadas a distúrbios causados pelo regime de escoamento na entrada, geralmente em golfadas. Esse tipo de distúrbio associado a não-linearidades inerentes ao sistema levam a um comportamento altamente randômico sendo difícil ações necessárias para seu controle, isso demanda constante supervisão de um operador. [Shiguemoto et al. 2011]

O líquido contido na piscina é bombeado para uma plataforma através da BCS (ou ESP), sendo este o principal elemento a atuar no controle do nível da piscina. Além de invadir o espaço

\footnotetext{
${ }^{15}$ Plataforma de pernas atirantadas (Tension-leg platform- TLP) é uma estrutura flutuante ancorada verticalmente por meio da qual se produz petróleo e gás natural. É especialmente utilizada em casos de reservatórios de mais de 300 metros de profundidade.
} 
ocupado pela hélice e prejudicar o processo de separação, um nível acima do limite máximo préestabelecido pode provocar um aumento na pressão de separação, visto que o nível do líquido reduz o espaço que o gás pode ocupar no separador. No entanto, este aumento de pressão também depende do comprimento da linha de gás até a plataforma de produção. Comprimento, esse, que pode alcançar alguns quilômetros, fazendo com que a pressão não seja tão sensível ao nível de liquido na piscina. Desta forma, cada caso deve ser analisado com cuidado. [Melo, Serapiao e Mendes 2009]

Pinheiro, Val e Mendes 2009, lembram que apesar do fato de os limites máximo e mínimo do nível no interior do separador deverem ser estritamente respeitados, o nível poderá se comportar livremente entre esses limites o que pode facilitar o trabalho de elaboração do controlador.

\title{
2.7 Problemas inerentes ao controle
}

Na tentativa de se manter o nível do líquido no interior do separado entre os limites estipulados, alguns problemas podem aparecer. O principal elemento de controle, principal atuador, é a bomba de escoamento do líquido, um equipamento caro e de difícil acesso. Assim, qualquer projeto de controle deverá considerar a otimização do atuador de forma que a bomba não seja submetida a esforços desnecessários.

Quanto aos possíveis atuadores a operarem no controle do sistema, Melo, Serapiao e Mendes 2009, analisam a dificuldade de se utilizar atuadores diferentes da bomba submersa como válvulas de fluxo, in verbis:

\begin{abstract}
"Uma das características próprias de separadores como o VASPS é que, estes não configuram um sistema compacto, tendo em torno de 70 metros de altura. Esses equipamentos também não apresentam uma válvula de controle de fluxo de saída, mas uma válvula choke ${ }^{16}$ instalada na linha de gás que pode estar alguns quilômetros de distância. Deste modo, é impraticável realizar o controle de nível de líquido na piscina através de uma contrapressão gerada pelo fechamento desta válvula na linha gás. Tampouco se pode realizar controle de pressão no vaso separador com a mesma velocidade (ou mesma 'constante de tempo') do controle de nível de líquido."
\end{abstract}

Devido ao seu elevado custo, o ponto crítico do controle do separador é a bomba centrífuga. Esse custo pode ser contabilizado pelo tempo médio entre falhas (TMF) que é uma média entre os intervalos de tempo que a bomba apresentou algum de feito ou mal funcionamento. Para que se preserve o atuador de forma a se obter a maior vida útil possível deve-se controlar o sistema no sentido de se obter um alto TMF com mínimo de variação nas condições de trabalho da bomba, permanecendo no ponto ótimo de operação o maior tempo possível a fim de se alcançar o ponto de controle ou a condição de controle desejada. A maioria dos separadores VASPS têm seu atuador acionado por um inversor de frequência que permite uma maior flexibilidade na operação e controle

\footnotetext{
${ }^{16}$ Válvula choque. Válvula utilizada para quebrar a pressão do escoamento produzido e permitir o controle da vazão do poço produtor, harmonizando-a à pressão de trabalho dos equipamentos a jusante.
} 
do sistema com o uso de uma variada gama de frequências sob pena de dificultar a estabilização do atuador no ponto ótimo. [Melo, Serapiao e Mendes 2009]

No que diz respeito a vida útil da bomba, há uma estrita relação entre sua durabilidade e a quantidade de mudanças em sua velocidade de rotação sendo tão mais durável quanto menor for a quantidade de mudanças na velocidade [Pinheiro, Val e Mendes 2009]. Dessa forma, um controlador eficiente não pode configurar apenas um regulador padrão baseado nos requisitos do sistema, mas numa estratégia de controle capaz de responder ao comportamento do sistema e as suas não linearidades e de preservar o atuador o máximo possível.

\subsection{Alguns Estudos sobre o Tema}

Atualmente, há vários sistemas de bombeamento submerso multifásico em operação. O sistema de separação bifásico VASPS está em operação no Brasil desde o ano de 2001. Fjosne 2002, percebe a separação submarina assim como o bombeamento multifásico como uma realidade, para ele esse tipo de tecnologia vem se tornando madura e testada, pronta para ser submetida a uma análise completa de identificação de seu potencial econômico.

Alguns modelos vêm sendo utilizado na descrição do comportamento do separador ciclônico. A despeito da complexidade inerente ao escoamento multifásico e a complexidade adicionada pelos distúrbios acrescentados ao sistema por fatores como entrada multifásica com padrão de escoamento em golfadas, os modelos utilizados na descrição do separador para fins de controle são bastante simplificados.

Vale, Garcia e Villa 2002, descrevem a instalação e operação do separador ciclônico na bacia de Campos, Brasil. Segundo o autor o desenvolvimento da tecnologia de separação bifásica seguiu algumas fases que se diferenciam pelas características dos desafios encontrados em cada uma. Na primeira do desenvolvimento do VASPS, de 1990 a 1991, foram realizados testes de laboratório, na segunda fase, de 1993 a 1995, foram realizados testes em superfície no campo de AGIP em Trecate, Itália. Na fase pré-submersa, de 1995 a 1997, foram realizados teste no polo de Atalaia, Brasil e já na fase de demonstração submarina, de 1998 a 2002, foram realizados testes na Bacia de Campos, Brasil.

Do ponto de vista mecânico o separador VASPS descrito por Vale é baseado numa árvore submersa sendo que o equipamento desenhado para Marimbá tem componentes como: fundação, conectores simples e compostos, separador composto de câmara de pressão e hélice, conjunto superior com plug de fechamento, bomba submersa com tubo de descarga do líquido. A câmara de pressão é composta por seis juntas, cada uma com 6 metros de comprimento e 26 polegadas de diâmetro. O sistema de controle é composto de uma unidade de força hidráulica, um módulo de controle submerso, uma estação de controle principal, válvula choke submersa e sensores de nível. [Vale, Garcia e Villa 2002]

Dos trabalhos publicados relacionados ao controle do separador submerso, destaca-se as abordagens de Melo, Mendes e Serapiao 2007, com a aplicação de Lógica Fuzzy para o acionamento e 
determinação da velocidade de rotação da bomba submersa; o trabalho de Pinheiro, Val e Mendes 2009, com uma estratégia de intervenção estocástica. Uma abordagem interessante do comportamento não linear do sistema é feita por Shiguemoto et al. 2011, onde o método de equações características é utilizado para se obter um modelo simplificado do sistema de separação em função do comportamento do escoamento das fases separadas pelas tubulações de escoamento de gás e líquido. No que diz respeito ao modelo mecanístico do separador bifásico, Rosa, Franca e Ribeiro 2001, desenvolveram estudo caracterizando cada estágio de separação de acordo com testes realizados.

A abordagem de Pinheiro, Val e Mendes 2009, baseada em controle de impulsos estocásticos, trabalha com esses impulsos como sendo transformados em uma sequência de iterados problemas de paradas ideais, os quais podem ser expressos como uma sequência de desigualdades variacionais.

A partir do modelo simplificado de Teixeira et al. 2004, e do levantamento realizado em Teixeira et al. 2006, Foram conduzidos dois estudos com abordagens diferentes para o sistema de controle. Numa primeira abordagem Melo, Mendes e Serapiao 2007, procuram melhorar o desempenho do sistema, realizando um controle Fuzzy-PID para a variação do nível da "piscina", minimizando o erro deste contra um sinal de referência. Numa segunda abordagem Melo, Serapiao e Mendes 2009, voltam-se para a estabilização do sinal de controle de forma minimizar a quantidade de rampas de aceleração da bomba que realiza o BCS (bombeio centrífugo submerso), aumentando sua vida útil e reduzindo custos operacionais, em detrimento do controle de nível, que deve oscilar dentro da faixa de estabilidade.

\subsubsection{Modelo mecanístico para o Separador Ciclônico}

Rosa, Franca e Ribeiro 2001, desenvolveram trabalho com modelos em escala reduzida para testes em laboratório. O conjunto de testes consistia em um circuito fechado para escoamento do líquido e um circuito aberto para o ar. A tubulação foi confeccionada em material transparente o que permitiu um acompanhamento visual do comportamento dos fluidos. Nesse conjunto foram testados líquidos de diferentes viscosidades sob diferentes vazões, tanto para líquido quanto para o gás. Além disso, os testes foram realizados para três protótipos com configurações diferentes, sendo a câmara de expansão, onde se dá o primeiro estágio de separação, diferente para cada um deles. Para dois desses protótipos a câmara de expansão foi confeccionada com formato cônico, enquanto o último a câmara teve um formato cilíndrico.

O autor levanta a seguinte relação adimensional entre a altura $(h)$ do filme do fluido que escoa no equipamento e a velocidade de escoamento da mistura:

$$
\frac{h}{\sqrt{A_{n}}}=C R e^{n} \sqrt{F r_{n}}(1+f)^{0.25}
$$

Na equação $A n$ é a área transversal do bocal por onde entra a mistura; Re é o número de Reynolds referente ao diâmetro do bocal; $f$ é a razão volumétrica gás/óleo, ou a vazão do gás dividida pela vazão de óleo; As constantes $C$ e $n$ são empíricas e; o número de Froude, referente 
ao diâmetro $(D)$ do bocal, é dado por:

$$
F r_{n}=\frac{V_{m i x}^{2}}{g D}
$$

O início da distância axial do caminho percorrido pela mistura é tomado como sendo a seção de saída do bocal e as medições realizadas mostraram que o filme desce vai se torna mais espesso, perde a velocidade axial e o campo centrífugo se torna mais fraco. A partir do quinto ao oitavo diâmetro equivalente abaixo do bocal a velocidade tangencial se torna muito pequena e o filme praticamente cai em queda livre, segundo o autor a análise dos dados obtidos pode servir de critério para o estabelecimento do comprimento da câmara de expansão.

A Figura 2.3 mostra dados experimentais que comprovam o aumento da espessura do filme à medida que a distância axial aumenta em contraposição à diminuição da velocidade axial com o deslocamento axial da mistura.

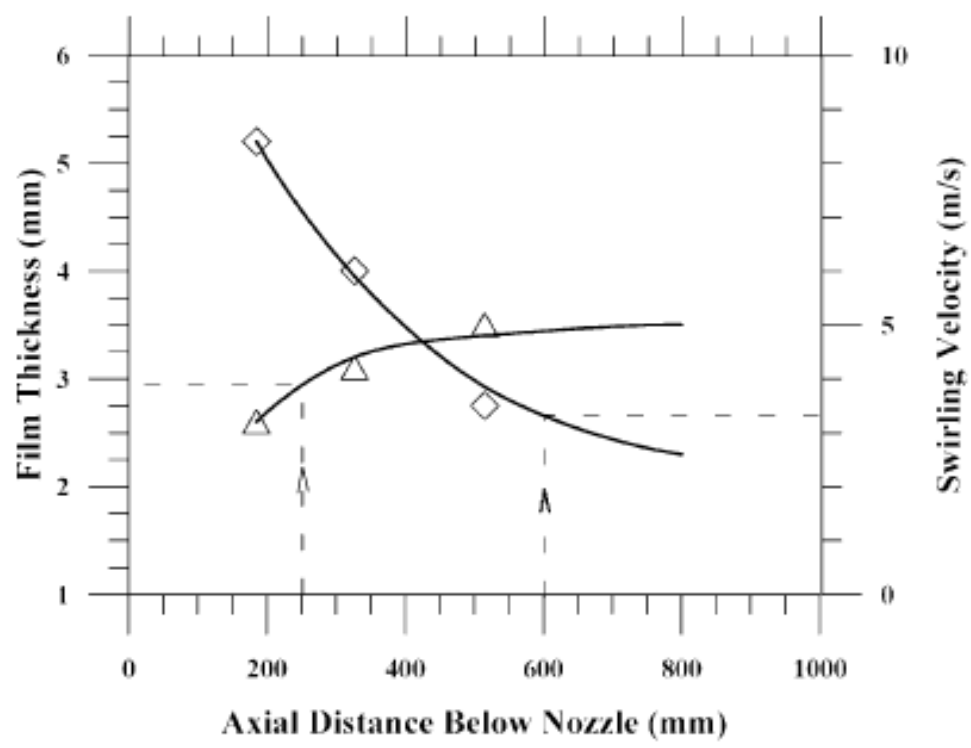

Figura 2.3: Espessura do filme e velocidade tangencial em relação à distância axial abaixo do bocal de entrada. Fonte: [Rosa, Franca e Ribeiro 2001]

Calculada a hidrodinâmica do filme de líquido descendo pela hélice, pode-se calcular o tempo ou o comprimento da hélice para o qual uma bolha de gás alcança a interface gás/óleo da mistura e se separa do líquido. O autor utiliza a definição de bolha crítica como sendo aquela que viaja próxima a parte mais externa e mais baixa do canal por onde escoa a mistura quando esta entra no segundo estágio de separação. A bolha crítica viajará o caminho mais longo através do filme seguindo uma trajetória determinada por uma combinação dos campos gravitacional e centrífugo. Dessa forma, existirão bolhas dispersas no líquido ao final do caminho do segundo estágio se o tempo que a bolha crítica leva para chegar a interface for maior que o tempo que a mistura permanece no canal de separação. O tempo $\left(t_{H}\right)$ que a bolha crítica permanece dentro do filme 
de líquido no segundo estágio é dado por:

$$
t_{H}=\frac{L}{V_{L}}
$$

Na equação, $L$ é o comprimento da hélice e $V_{L}$ a velocidade média do líquido. O tempo crítico que a bolha leva para chegar até a interface da mistura depende da velocidade total da bolha que é uma soma vetorial de suas velocidades radial e vertical. O deslocamento vertical é devido ao campo gravitacional e leva a $t_{Y}$ calculado por:

$$
t_{Y}=\frac{L_{y}}{V_{Y}}
$$

onde $L_{Y}$ é o comprimento da projeção vertical do caminho percorrido pela bolha e $V_{Y}$ é o componente vertical da velocidade da bolha dado por:

$$
V_{Y}=\sqrt{\frac{8}{3}(1-a) \frac{\left(\rho_{L}-\rho_{G}\right)}{\rho_{L}} \frac{g r_{b}}{C_{D}}}
$$

Para equação, $\alpha$ é a fração de vazio da mistura; $r_{b}$ é o raio da bolha; $C_{D}$ o coeficiente de arrasto; $g$ a aceleração da gravidade. O descolamento da bolha crítica na direção radial é dominado pela força centrífuga e leva o tempo $t_{R}$ dado por:

$$
t_{R}=\frac{L_{R}}{V_{R}}
$$

onde $L_{R}$ é o comprimento radial da projeção do caminho da bolha crítica e $V_{R}$ a componente radial de sua velocidade. Semelhantemente $V_{Y}$, considerando o raio médio da hélice $\left(R_{M}\right)$ tem-se $V_{R}$ como:

$$
V_{R}=\sqrt{\frac{8}{3}(1-a) \frac{\left(\rho_{L}-\rho_{G}\right)}{\rho_{L}} \frac{V_{L}^{2} r_{b}}{R_{M} C_{D}}}
$$

Infere-se, então, que quando o tempo que o filme de líquido permanece dentro do segundo estágio de separação for, concomitantemente, menor que o tempo de deslocamento vertical $\left(t_{H} / t_{Y}\right.$ $<1$ ) e menor que o tempo de deslocamento radial $\left(t_{H} / t_{R}<1\right)$, não haverá bolhas dispersas no filme do líquido quando este alcançar a saída da hélice. [Rosa, Franca e Ribeiro 2001]

\subsubsection{Controle com minimização de esforços no Separador Submarino}

Melo, Serapiao e Mendes 2009, propõem um controlador voltado ao tratamento do sinal de controle de forma a mantê-lo sob poucas alterações e a manter o sinal de saída (nível de líquido no interior do separador) dentro da faixa de estabilidade prevista para o sistema. O autor modela o sistema segundo uma dinâmica simplificada com a taxa de variação do volume de líquido sendo dada pela seguinte equação: 


$$
\frac{d V_{l}}{d t}=q_{l \_i n}-q_{l \_o u t}
$$

$V_{l}$, é o volume de líquido; $q_{l \_i n}$ é vazão de líquido que entra; $q_{l \_o u t ~}$ é a vazão de líquido que sai do separador.

A altura $(h)$ do nível está relacionada ao volume por um fator geométrico em função do diâmetro $(d)$, da seguinte maneira:

$$
\frac{d h}{d t}=\frac{1}{p d^{2} / 4} \frac{d V_{l}}{d t}
$$

A vazão de saída do separador é tomada como a vazão da bomba, essa uma função da frequência $(f)$ de rotação da bomba é descrita da seguinte maneira:

$$
\frac{d q_{l \_o u t}}{d t}=-0.0577 f^{3}+8.0786 f^{2}-249.18 f-263.36
$$

O diagrama de blocos do sistema controlado considerado no trabalho é apresentado na Figura 2.4 .

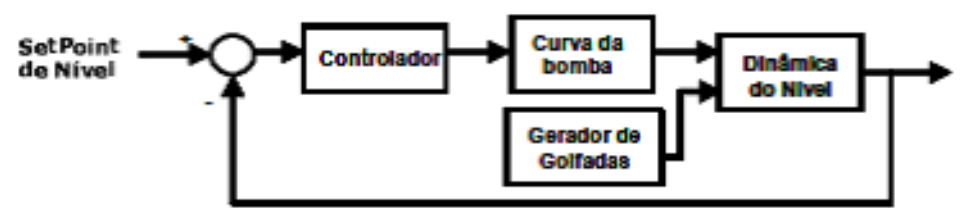

Figura 2.4: Diagrama de blocos do sistema do separador submerso controlado. Fonte: [Melo, Serapiao e Mendes 2009]

Foi proposto um controlador que utiliza um conceito denominado classificador de média, o qual reduz o efeito de grandes distúrbios através da realização de uma média móvel sobre a pertinência classificada, limitando a faixa de estabilidade a regiões de trabalho que permitam acompanhar a ordem de grandeza do sinal de referência e ainda permitindo sua oscilação. Passado pelas etapas de classificação de pertinência e média móvel, como trata-se de um controlador sensível a mudanças bruscas do sinal de controle foi adicionado um filtro de sinal entre o controlador e o atuador para simular os efeitos de saturação do sinal. Como mesmo com a adição do filtro o sinal de controle continuou oscilatório, aplicou-se o conceito de histerese para fixar a variação de saída até que o sistema retorne à região de trabalho original por efeito do próprio comportamento do processo e não apenas por ação corretiva do controlador. A Figura 2.5 mostra o diagrama de blocos do controlador. 


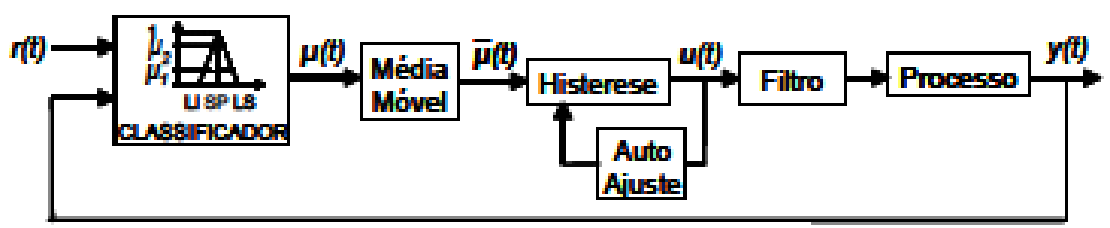

Figura 2.5: Diagrama de blocos do controlador de Melo. Fonte: [Melo, Serapiao e Mendes 2009]

A cerca do controlador proposto e seus resultados Melo, Serapiao e Mendes 2009, concluem que essa abordagem permitiu reduzir de 40 acionamentos da bomba, por controladores anteriormente estudados por ele, para 10 acionamentos em um dia de trabalho. Esse resultado condiz com informações de campo de que cada alteração na rotação da bomba é seguida de um intervalo de duas a três horas quando se procede manualmente com acompanhamento de um operador. Além disso a duração dos acionamentos também foi reduzida.

\subsubsection{Simulação numérica utilizando método das equações características}

Shiguemoto et al. 2011, considera um modelo numérico para o cálculo da variação do nível do líquido no interior do separador, esse modelo não leva em conta variações das propriedades de pressão, volume ou temperatura do óleo, portanto, não considera a possível dissociação de gás que pode ocorrer tanto no riser quanto no separador devido a variações de temperatura e pressão.

Equações de massa e momento são assumidas para solução do escoamento unidimensional na tubulação que transmite gás para a plataforma, uma vez separado no interior do separador ciclônico (VASPS nesse estudo especificamente). Essas equações são apresentadas a seguir:

$$
\begin{gathered}
\frac{\partial p}{\partial t}+\frac{B^{2}}{A} \frac{\partial M}{\partial x} d x=0 \\
\frac{\partial p}{\partial x}+\frac{f B^{2} M^{2}}{2 D A^{2} p}+\frac{\rho_{G} g}{B^{2}} \operatorname{sen} \theta+\frac{a^{2}}{A} \frac{\partial M}{\partial t}=0
\end{gathered}
$$

Nas equações acima $p$ é a pressão do gás; $\rho_{G}$ sua densidade; $A$, a área de seção transversal da tubulação de gás; $\alpha$ é um multiplicador inercial introduzido por Yow 1972; $M$ é a taxa de massa do gás; $t$ e $x$ são, respectivamente, variáveis temporal e de distância ao longo do comprimento da tubulação; $f$ é o fator de atrito de Darcy-Weisbach; A velocidade do som $B$ é dada por:

$$
B=\sqrt{\gamma Z R T}=\sqrt{\gamma \frac{p}{\rho_{G}}}
$$

Onde $\gamma$ é o coeficiente de calor específico; Z o fator de compressibilidade; R, a constante dos gases; $\mathrm{T}$, a temperatura absoluta.

O escoamento pela tubulação de líquido é descrito com as equações de massa e momento con- 
sideradas para um fluido imcompressível, de forma que tem-se as seguintes equações diferenciais:

$$
\begin{gathered}
\frac{\partial H}{\partial t}+\frac{a^{2}}{g A} \frac{\partial Q}{\partial x} d x=0 \\
\frac{\partial Q}{\partial t}+\frac{f_{L} Q|Q|}{2 D A}+g A \frac{\partial H}{\partial x}=0
\end{gathered}
$$

Onde $H$ e $Q$, são respectivamente a altura piezométrica e a vazão volumétrica do líquido e a, é $a$ velocidade do líquido em sua respectiva tubulação de escoamento que depende de parâmetros como o módulo de elasticidade do fluido, o módulo de Young referente à tubulação a espessura das paredes da tubulação e a densidade do líquido.

As equações do escoamento do fluido tanto para a tubulação de líquido quanto para tubulação de gás são resolvidas numericamente pelo método das equações características. A partir da vazão calculada para o líquido, pelo segundo conjunto de equações diferenciais, no ponto em que a tubulação de líquido interfaceia o recipiente do separador pode-se calcular o nível interno de líquido no interior do equipamento. O nível será uma função da quantidade de líquido que sai em detrimento da quantidade de líquido que entra pelo bocal, no início do processo de separação. Esse nível, no entanto será perturbado por fatores como a pressão do gás dentro do recipiente que atua no sentido de empurrar a coluna de líquido para baixo. A pressão do líquido no separador é obtida pela solução numérica do primeiro conjunto de equações diferencias.

No momento da solução do conjunto de equações diferenciais para determinar a quantidade de líquido que sai do separador por unidade de tempo, leva-se levado em conta o trabalho realizado pela bomba subersa. Essa é modelada segundo uma equação de segundo grau em relação à sua frequência de rotação.

O controle estocástico apresentado por Pinheiro, Val e Mendes 2009, é adotado no trabalho de Shiguemoto et al. 2011, onde é feita uma abordagem baseada em controle de impulsos estocásticos, esses impulsos são transformados em uma sequência de iterados problemas de paradas ideais, os quais podem ser expressos como uma sequência de desigualdades variacionais. 


\section{Capítulo 3}

\section{Fundamentação Teórica}

Neste Capítulo serão apresentadas as equações necessárias para o estudo do escoamento do líquido e do gás no interior das tubulações de saída dos fluídos separados sob a perspectiva da teoria de Transiente em Fluidos. São apresentadas as equações necessárias à descrição do comportamento do líquido em termos de sua pressão e vazão ao longo do comprimento da tubulação e ao longo do tempo (seção 3.1 e 3.2), da mesma forma que para o caso do escoamento do gás em sua respectiva tubulação (seção $3 \cdot 3$ ).

\subsection{Equações de Transientes para o Escoamento na Tubulação de Saída de Líquido}

Considere uma tubulação com uma válvula em sua extremidade final, no instante em que a válvula é fechada o fluido nas proximidades da extremidade é levado de uma velocidade inicial $V_{0}$ para o repouso pelo desenvolvimento de uma alta pressão na parede da válvula. Esse efeito é propagado ao longo da tubulação através de camadas subsequentes do fluido que são levadas ao repouso, uma após a outra. Pode-se visualizar, então, um pulso de pressão viajando à velocidade sônica $a$ na direção contrária e com pressão suficiente para aplicar um impulso ao fluido de maneira a trazê-lo ao repouso.

No volume de controle mostrado na Figura 3.1 onde observa-se uma frente de onda movendo-se para esquerda com velocidade $a-V_{0}$. Esse movimento causa uma variação da altura manométrica $\Delta H$ através da válvula que é acompanhada por uma variação de velocidade $\Delta V$. Aplicando a equação do momento na direção do eixo da tubulação é possível igualar a componente da força resultante nessa direção à taxa temporal de variação do momento dentro do volume de controle mais o efluxo de momento do volume de controle. O eixo que atravessa o centro da tubulação longitudinalmente será assinalado por $x$. 


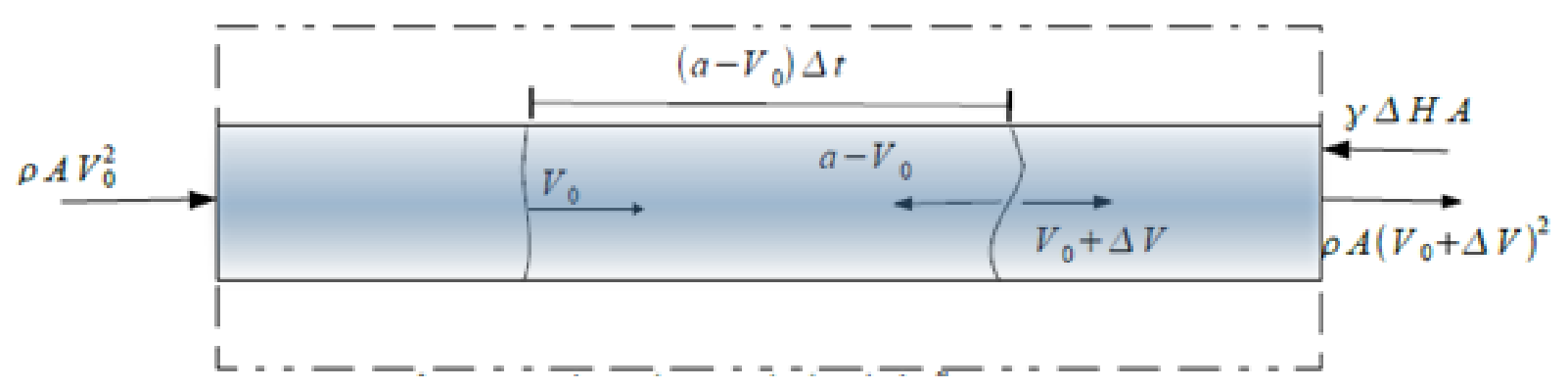

Figura 3.1: Volume de controle da tubulação

A variação do momento no interior do volume de controle descrita por:

$$
\rho A\left(a-V_{0}\right) \Delta t \frac{\left(V_{0}+\Delta V-V_{0}\right)}{\Delta t}=\rho A\left(a-V_{0}\right) \Delta V
$$

O efluxo de momento que passa pelo volume de controle, observado na Figura 3.1, é dado por:

$$
\text { efluxo }=\rho A\left(V_{0}-\Delta V\right)^{2}-\rho A V_{0}^{2}
$$

Logo, a equação de momento pode ser escrita da seguinte forma:

$$
-\gamma \Delta H A=\rho A\left(a-V_{0}\right) \Delta V+\rho A\left(V_{0}+\Delta V\right)^{2}-\rho A V_{0}^{2}
$$

Para equação acima tem-se $\gamma=$ peso específico do fluido, $\rho=$ densidade do líquido $(\gamma / g)$, $g=$ aceleração da gravidade, $A=$ área da seção transversal da tubulação, $\Delta V=$ incremento da velocidade de escoamento, $a=$ velocidade de propagação da onda gerada pela perturbação e $\Delta H$ = incremento da pressão manométrica.

A equação 3.3 é expandida de forma que desconsiderando-se os termos quadráticos $\Delta V^{2}$, encontra-se a variação de altura manométrica:

$$
\Delta H=-a \frac{\Delta V}{g}\left(1-\frac{V_{0}}{a}\right) \approx-a \frac{\Delta V}{g}
$$

onde $V_{0} / a<<1$

Considere agora, um fechamento repentino da extremidade final da tubulação. Nesse caso poderá ocorrer deformação da tubulação por uma distância $\Delta s$. Assumindo que essa deformação percorra $\Delta s$ em $\frac{L}{a}$ segundos, onde $L$ é o comprimento da tubulação, tem-se uma velocidade de deformação igual a $\Delta s \frac{L}{a}$. A variação da velocidade de escoamento do fluido poderá ser descrita por $\Delta s \frac{L}{a}-V_{0}=\Delta V$. Tem-se, então, a massa de fluido que entra na tubulação após um período de tempo $\frac{L}{a}$, igual a $\rho A V_{0} \frac{L}{a}$, sendo acomodada na tubulação por três fatores principais:

- variação da área transversal da tubulação de escoamento do líquido $(\Delta A)$; 
- aumento de volume causado pela expansão $(\Delta s)$ da tubulação;

- deformação do líquido $(\Delta \rho)$ devido ao aumento de pressão.

A massa de fluido será dada pela somatória desses fatores:

$$
\rho A V_{0} \frac{L}{a}=\rho L \Delta A+\rho A \Delta s+L A \Delta \rho
$$

Aplicando-se a relação $\Delta V=\Delta s \frac{L}{a}-V_{0}$ à equação acima, obtém-se a seguinte expressão:

$$
-\frac{\Delta V}{a}=\frac{\Delta A}{A}+\frac{\Delta \rho}{\rho}
$$

Observe que se a tubulação estiver apoiada de forma que não haja deformação longitudinal $(\Delta s=0)$ ainda haverá incremento na velocidade de escoamento. A variação da velocidade $V$, como descrita pela equação 3.6, mostra que tanto a deformação da área transversal da tubulação quanto a deformação do líquido influenciam na variação da velocidade. Da simplificação obtida para o incremento de pressão $\Delta H$ mostrado pela equação 3.4 e pela equação da variação da velocidade de escoamento do líquido 3.6, chega-se ao valor da velocidade $(a)$ de propagação da onda que percorre a tubulação no sentido oposto ao escoamento:

$$
a^{2}=\frac{g \Delta H}{\Delta A / A+\Delta \rho / \rho}
$$

o módulo de elasticidade $(\mathrm{K})$ do fluido é definido da seguinte forma

$$
K=\frac{\Delta p}{\Delta \rho / \rho}=\frac{-\Delta p}{\Delta \mathcal{V} / \mathcal{V}}
$$

$\Delta \mathcal{V} / \mathcal{V}$ é a fração de variação de volume. De posse do módulo de elasticidade, a velocidade de propagação da onda assume a forma:

$$
a^{2}=\frac{K / \rho}{1+(K / A)(\Delta A / \Delta p)}
$$

Alguns casos representativos podem ser retirados da equação 3.9, por exemplo caso as paredes da tubulação de escoamento do líquido sejam muito espessas, as deformações transversais da tubulações serão mínimas sendo que qualquer incremento da área de seção transversal poderá ser considerada muito menor que a variação de pressão na tubulação $(\Delta A \ll \Delta p)$. A velocidade $a$ poderá ser aproximada por:

$$
a^{2}=\frac{K}{\rho}
$$

Por outro lado, no caso de tubulações muito flexíveis espera-se grandes variações da área de seção transversal da tubulação para pequenas variações de pressão, assim, pode-se considerar $\frac{K}{A} \frac{\Delta A}{\Delta p} \gg 1$ e a velocidade de propagação da onda gerada pela perturbação será dada por: 


$$
a=\sqrt{\frac{K / \rho}{(K / A)(\Delta A / \Delta p)}}=\sqrt{\frac{A}{\rho} \frac{\Delta p}{\Delta A}}
$$

Já para o caso de tubulações com paredes finas, três situações representativas devem ser abordadas:

(a) tubulação ancorada somente em sua extremidade inicial

(b) tubulação ancorada longitudinalmente

(c) tubulação ancorada por juntas de expansão

A determinação da velocidade $a$ para esses casos, demanda uma análise um pouco mais minuciosa das deformações sofridas pela tubulação e das tensões percebidas quando essas deformações ocorrem. No que diz respeito às deformações sofridas, seja o coeficiente de Poisson definido por:

$$
\mu=-\frac{\xi}{\xi_{1}}
$$

onde $\xi$ é a deformação lateral da tubulação enquanto $\xi_{1}$ é a deformação axial.

Pode-se determinar a relação existente entre a variação da área de seção transversal com auxílio do coeficiente de Poisson, já que essa variação é resultado da deformação lateral total, ou deformação circunferencial a ser denominada por $\xi_{T}$. Dessa forma, será possível determinar o valor da velocidade de propagação $a$, a partir de $\mu$ estabelecendo-se valores que podem ser obtidos a partir de características físicas da tubulação. Se a área de seção transversal da tubulação variar de uma quantidade $\delta$, essa variação poderá ser descrita pela seguinte equação:

$$
\Delta A=\pi(R+d)^{2}-\pi R^{2}
$$

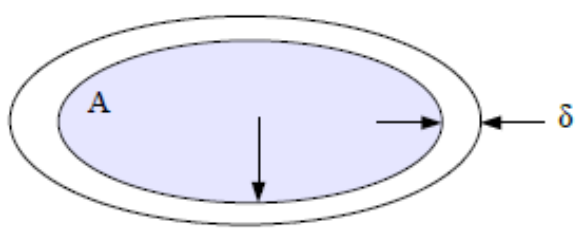

$\mathrm{R}$

Figura 3.2: Com perturbação do escoamento, a tubulação com paredes finas se deforma e há uma variação de sua área de seção transversal $\Delta A$. A tubulação com raio inicial $R$ após a deformação terá raio $R+\delta$

$R$ é o raio da circunferência inicial da tubulação.

Uma ilustração da seção transversal da tubulação de escoamento de líquido, bem como da variação $\delta$, são mostrados na Figura 3.2. Pequenas deformações possibilitam desconsiderar-se os 
fatores quadráticos da equação 3.13 já que eles se tornam muito pequenos em relação às outras grandezas da equação, assim a deformação poderá ser simplificada:

$$
\Delta A=2 \pi R \delta
$$

A deformação $\delta$ em termos da deformação total do tubo $\xi_{T}$, será dada por $\delta=\xi_{T} R$, de forma que a variação da área transversal poderá se escrita na seguinte forma:

$$
\Delta A=2 \pi R \Delta \xi_{T} R
$$

e, em termos da área da circunferência mostrada na Figura 3.2:

$$
\frac{\Delta A}{A}=2 \Delta \xi_{T}
$$

A deformação total $\xi_{T}$, de que trata a equação acima, é a soma das duas parcelas que medem a deformação lateral sofrida pela tubulação $\left(\xi_{2}\right)$ e a deformação lateral resultante da deformação axial percebida pela tubulação $(\xi)$ a qual está relacionado com a deformação axial pelo coeficiente de Poisson. Assim, tem-se para deformação total:

$$
\xi_{T}=\xi_{2}+\xi
$$

e, a partir do coeficiente de Poisson dado pela equação 3.12, pode-se escrever:

$$
\xi_{T}=\xi_{2}-\mu \xi_{1}
$$

As deformações axial e lateral, respectivamente $\xi_{1}$ e $\xi_{2}$, estão relacionadas ao módulo de elasticidade de Young $(E)$ através das tensões axial, $\sigma_{1}$, e lateral, $\sigma_{2}$ da seguinte forma:

$$
\sigma_{1}=\frac{\xi_{1}}{E}, \quad \sigma_{2}=\frac{\xi_{2}}{E}
$$

Com as relações entre deformações e tensões obtidas para a tubulação, será possível prever a velocidade $a$ para os três casos evocados.

\subsubsection{Caso a - tubulação ancorada somente em sua extremidade inicial}

No caso em que a tubulação ancorada somente em sua extremidade inicial, a tensão axial é dada pela força exercida sobre a válvula fechada $(\gamma H A)$ dividida pela área sujeita a essa força $(\pi D e)$ :

$$
\sigma_{1}=\frac{\gamma H A}{\pi D e}
$$


onde $e$ é a espessura da tubulação e $D$, o seu diâmetro. Com a variação de pressão dada por $\Delta p=\gamma \Delta H$ e a área de seção transversal da tubulação dada por $A=\pi D^{2} / 4$, chega-se a variação da tensão axial em função da variação de pressão:

$$
\Delta \sigma_{1}=\frac{D \Delta p}{4 e}
$$

A intenção é chegar-se a uma equação que relacione a variação da área transversal em relação a variação da pressão na tubulação, em uma função que seja escrita em termos das propriedades físicas da tubulação como o coeficiente de Elasticidade e a espessura da parede da tubulação. Logo, obtida a relação em termos do variação de tensão axial, o próxima passo será obter-se uma relação semelhante para a variação de tensão transversal $\left(\Delta \sigma_{2}\right)$. Uma equação que relaciona a tensão transversal $\left(\sigma_{2}\right)$ à variação de pressão $\Delta p$ pode ser obtida considerando-se as forças que agem sobre o semicilindro da tubulação, essas forças aparecem devido à ação da propagação da onda, causada pela perturbação do fluxo. A Figura 3.3 ilustra esse semicilindro, onde são mostradas as tensões às quais a tubulação está submetida em razão da aplicação da força $\gamma H D$.

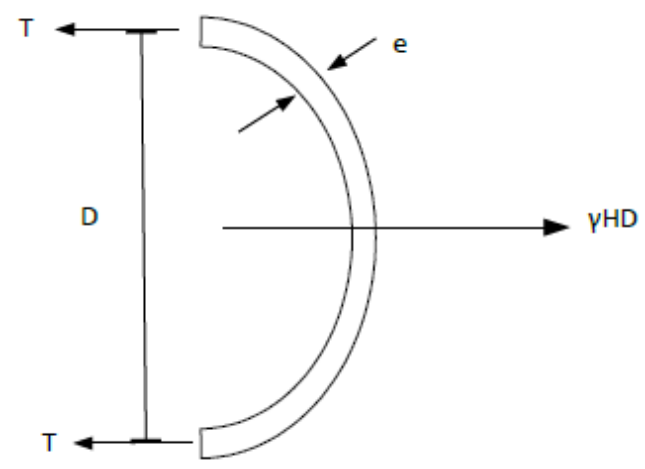

Figura 3.3: Semicilindro da tubulação sujeito a forças resultantes de ação da propagação de uma onda sônica. T é a força exercida pelo semicilindro. $\gamma H D$ a força aplicada, devido a variação de pressão na tubulação. e é a espessura da tubulação. D o diâmetro.

A partir da Figura 3.3, é possível observar que a força de restauração exercida pelo semicilindro será o dobro da força aplicada pela variação da pressão, em virtude da geometria do tubo. Assim, a tensão transversal será descrita da seguinte forma:

$$
\sigma_{2}=\frac{T}{e}=\frac{\gamma H D}{2 e}
$$

e, expressando a equação 3.22 em termos de variação da tensão:

$$
\Delta \sigma_{2}=\frac{\gamma \Delta H D}{2 e}=\frac{D \Delta p}{2 e}
$$

A relação entre a variação da área transversal e a variação de pressão, será obtida substituindose as equações 3.16 e 3.18 na equação que dá velocidade de propagação da onda gerada pela 
perturbação do fluido, equação 3.9, logo:

$$
\frac{\Delta A}{A \Delta p}=\frac{2}{\Delta p}\left(\Delta \xi_{2}-\mu \Delta \xi_{1}\right)
$$

das relações obtidas para deformação total e módulo de elasticidade:

$$
\frac{\Delta A}{A \Delta p}=\frac{2}{\Delta p}\left(\Delta \sigma_{2}-\mu \Delta \sigma_{1}\right)
$$

Por fim, com auxílio das equações que descrevem a variação da tensão axial 3.21 e a variação de tensão transversal 3.23, chega-se a:

$$
\frac{\Delta A}{A \Delta p}=\frac{D}{2 E e}\left(1-\frac{\mu}{2}\right)
$$

\subsubsection{Caso b - tubulação ancorada longitudinalmente}

No caso da tubulação estar ancorada longitudinalmente espera-se que não haja deformação axial, ou seja $\xi_{1}=0$. Os efeitos da pressão no interior da tubulação que tendam à deformá-la axialmente serão observados em forma de tensões transversais, de forma que a tensão axial torna-se $\sigma_{1}=\mu \sigma_{2}$ e o termo $\frac{\Delta A}{A \Delta p}$, dado pela equação 3.25 :

$$
\frac{\Delta A}{A \Delta p}=\frac{2}{\Delta p E}\left(\Delta \sigma_{2}-\mu^{2} \sigma^{2}\right)=\frac{D}{E e}\left(1-\mu^{2}\right)
$$

\subsubsection{Caso c - tubulação ancorada por juntas de expansão}

No caso da tubulação ancorada por juntas de expansão, as tensões axiais produzidas pela propagação da onda sônica serão absorvidas pelas juntas, de maneira que $\sigma_{1}=0$, portanto:

$$
\frac{\Delta A}{A \Delta p}=\frac{2}{\Delta p E} \sigma_{2}=\frac{D}{E e}
$$

Determinada a fração $\frac{\Delta A}{A \Delta p}$ para os três casos distintos, chega-se à seguinte equação geral para a velocidade $a$ :

$$
a=\sqrt{\frac{K / \rho}{1+\left(\frac{K D}{E e}\right) c_{1}}}
$$

onde $c_{1}$ é dado por:

$$
\begin{cases}\text { caso a: } & c_{1}=1-\mu / 2 \\ \text { caso b: } & c_{1}=1-\mu^{2} \\ \text { caso c: } & c_{1}=1\end{cases}
$$




\subsection{Equações diferenciais básicas para transientes em fluidos}

O estabelecimento da velocidade de propagação da onda gerada pela perturbação do fluido permite levantar as equações que ditarão o comportamento do fluido em termos de variáveis como a pressão e vazão do fluido ao longo da tubulação. O comportamento do fluido será descrito por um conjunto de equações advindas da consideração da equação do movimento e da equação da continuidade aplicada ao escoamento do fluido no interior da tubulação que o direciona a partir do separador submarino em direção à plataforma. Da equação do movimento chega-se a uma equação diferencial em termos da pressão do fluido e de sua velocidade, sendo essa equação escrita em termos de derivadas parciais em relação ao tempo e à distância longitudinal ao longo da tubulação. Já a equação da continuidade leva a uma equação diferencial equivalente em termos das mesmas variáveis, pressão (descrita em altura piezométrica) e velocidade do fluido. Nesta última, haverá um termo dependente da velocidade $(a)$ da frente de onda transiente que possibilita estabelecer o comportamento do líquido no interior da tubulação levando em conta perturbações sobre seu escoamento. Uma vantagem desse tipo de abordagem é a possibilidade de prever-se, por exemplo, como a pressão ao longo da tubulação reagirá ao fechamento repentino de uma válvula em sua extremidade ou, ainda, no momento do acionamento do sistema de bombeamento, parte importante do funcionamento do separador estudado no presente trabalho.

O principal interesse de se prever o comportamento do fluido frente a essas perturbações, ou seja, o comportamento sob ação de transientes, é relacionar esse comportamento ao nível do líquido no interior do separador ciclônico, como será feito no Capítulo 5, assim, será possível propor um controlador que não só mantenha o nível do líquido sob valores especificados, mas que o faça considerando os efeitos transientes aos quais o sistema está exposto.

\subsubsection{Equação do Movimento}

A equação do movimento é obtida em termos da pressão na linha central da tubulação e da velocidade média do escoamento. Tanto a pressão do fluido quanto sua velocidade são funções do tempo $t$ e da posição $x$ ao longo do eixo longitudinal da tubulação $(p=p(x, t)$ e $V=V(x, t))$. Durante desenvolvimento da equação, a pressão é convertida em altura piezométrica $(H=H(x, t))$. Considere, então o diagrama de corpo livre para a seção transversal de um elemento de fluido conforme mostrado na Figura 3.4, a variável $x$ é a coordenada que mede a distância ao longo do eixo da tubulação a partir de uma origem arbitrária. O tubo tem uma inclinação $\alpha$ em relação à horizontal e a área $A$ é uma função de $x$. O subscrito x, refere-se à derivada em relação a essa coordenada. 


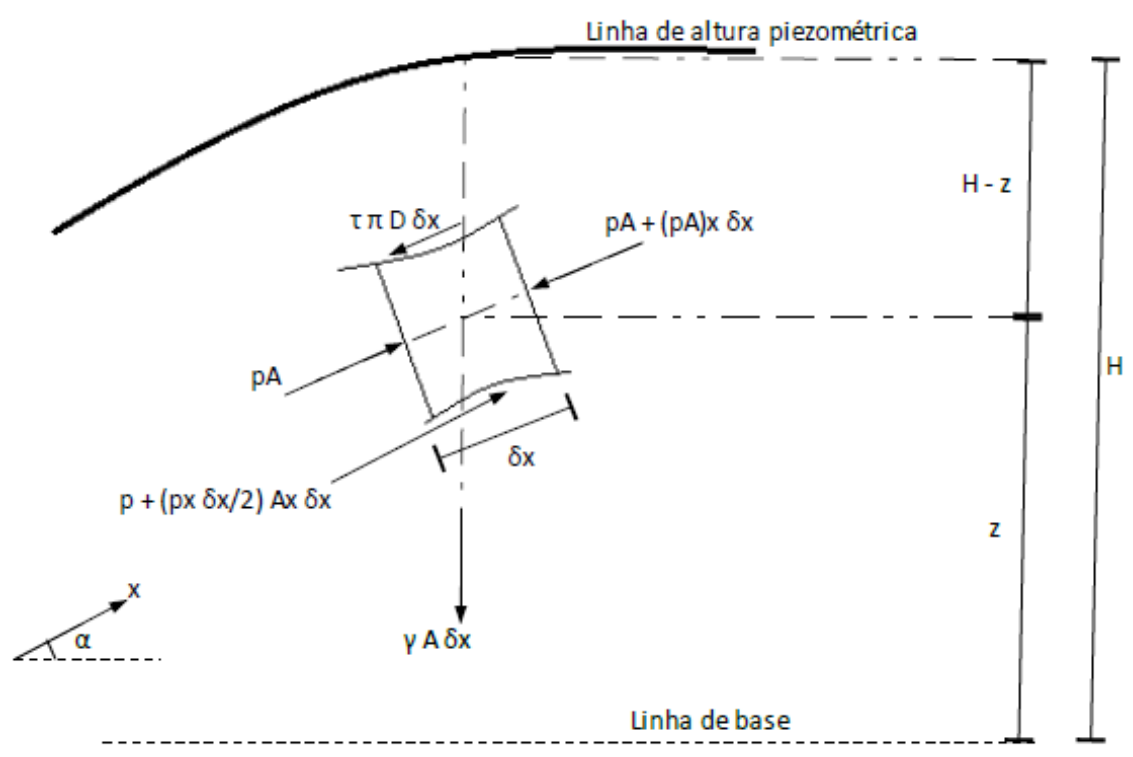

Figura 3.4: diagrama de corpo livre para seção transversal de um elemento de fluido no interior de uma tubulação

As forças que atuam sobre o elemento de fluido do diagrama de corpo livre são devido a pressões normais de contato de superfície nas faces transversais e à tensões agindo na periferia do elemento. A massa do elemento de fluido é $\rho A \delta x$, enquanto sua velocidade é dada por $V$. Dessa forma, o somatório das forças sobre a seção transversal do elemento de fluido pode ser igualada à sua massa vezes aceleração $(\rho A \delta x d V / d t)$ [Wylie e Streeter 1978]. Logo, a partir do diagrama pode-se escrever:

$$
p A-\left(p A+\frac{\partial}{\partial x}(p A) \delta x\right)+\left(p+\frac{\partial p}{\partial x} \frac{\delta x}{2}\right) \frac{\partial A}{\partial x} \delta x-\tau_{0} \pi D \delta x-\gamma A \delta x \operatorname{sen} \alpha=\rho A \delta x \dot{V}
$$

nessa equação as parcelas que contêm termos quadráticos $\delta x^{2}$ são desprezadas, de forma que eliminando-as e simplificando a equação, chega-se ao seguinte somatório de forças:

$$
\frac{\partial p}{\partial x} A+\pi \tau_{0} D-\rho g A \operatorname{sen} \alpha+\rho A \dot{V}=0
$$

A tensão de cisalhamento sobre o elemento de fluido $\tau$ é tida como a mesma que ocorreria se o fluido estivesse estático $\left(\tau=\tau_{0}\right)$. Então, a partir da relação do fator de fricção de DarcyWeisbach é possível relacionar a tensão de cisalhamento com a velocidade [Wylie e Streeter 1978] pela equação:

$$
\tau_{0}=\frac{\rho f V|V|}{8}
$$

onde $f$ é o fator de fricção. Combinando essa equação com a equação de Darcy-Weisbach 


$$
\Delta p=\frac{\pi f L}{D} \frac{V^{2}}{2}
$$

chega-se a seguinte relação entre a variação de pressão e a tensão de cisalhamento:

$$
\Delta p \frac{\pi D^{2}}{4}=\pi \tau_{0} D L
$$

Essa equação será utilizada para formulação final da equação diferencial para o escoamento do líquido advinda da equação do movimento. Outra equação a ser considerada nessa formulação é a derivada total da velocidade, como já mencionado, a velocidade do fluido é função tanto do tempo quanto da posição, de forma que para se obter a aceleração do fluido deve-se considerar derivada total da velocidade:

$$
\frac{d V}{d t}=V \frac{\partial V}{\partial x}+\frac{\partial V}{\partial t}
$$

Então, substituindo a equação da variação de pressão com a força de cisalhamento 3.35 e a equação da derivada total 3.36 no somatório das forças que agem sobre o elemento de fluido, equação 3.32 , chega-se à equação diferencial procurada:

$$
\frac{1}{\rho} \frac{\partial p}{\partial x}+V \frac{\partial V}{\partial x}+\frac{\partial V}{\partial t}+g \operatorname{sen} \alpha+\frac{f}{2 D} V|V|=0
$$

Até o momento, nenhuma simplificação a cerca do forma da tubulação foi requerida, o que torna a equação acima aplicável tanto para dutos divergentes quanto para dutos convergentes. No intuito de simplificar a equação, propõe-se a seguinte mudança de variável que relaciona pressão e altura piezométrica:

$$
p=\rho g(H-z)
$$

onde $z$ é a altura do elemento de fluido mostrado na Figura 3.4 que coincide com a elevação da linha central da tubulação no ponto $x$. A variação da pressão em relação a posição $x$ ao longo da tubulação será descrita da seguinte forma:

$$
\frac{\partial p}{\partial x}=\rho g\left(\frac{\partial H}{\partial x}-\frac{\partial z}{\partial x}\right)=\rho g\left(\frac{\partial H}{\partial x}-\operatorname{sen} \alpha\right)
$$

A substituição do valor de $\frac{\partial p}{\partial x}$ na equação 3.37 leva à primeira equação do conjunto das duas que serão utilizadas para prever o comportamento do fluido no interior da tubulação:

$$
g \frac{\partial H}{\partial x}+V \frac{\partial V}{\partial x}+\frac{\partial V}{\partial t}+\frac{f}{2 D} V|V|=0
$$

Apesar de ter sido utilizada uma relação de atrito com termo quadrático da velocidade, $V^{2}$, uma formulação com uma lei exponencial poderia ser utilizada para descrição comportamento do 
fluido [Wylie e Streeter 1978]. No caso da lei exponencial o termo $\frac{f}{2 D} V|V|$ é substituído por:

$$
\frac{\lambda V\left|V^{n-1}\right|}{D^{m}}
$$

$\lambda, n$ e $m$ são parâmetros da equação a serem determinados experimentalmente.

Uma importante observação a cerca da equação 3.40, é que essa é uma formulação geral para a qual um fluido escoando em regime permanente, seria um caso particular. Assim, essa equação deve permanecer válida mesmo quando o fluido escoar em regime permanente. A validade da equação pode ser facilmente provada aplicando-se as condições de regime permanente $\frac{\partial V}{\partial x}=0 \mathrm{e}$ $\frac{\partial V}{\partial t}=0$ à equação 3.40 a qual se reduz a:

$$
\Delta H=\frac{-f \Delta x}{2 g D} V|V|
$$

que é a própria equação de Darcy-Weisbach. Como esperado para o regime permanente, a varição de pressão ao longo do comprimento da tubulação será devida somente ao atrito do fluido descrito essa equação.

\subsubsection{Equação da Continuidade}

A equação da continuidade será utilizada para estabelecer-se a segunda equação diferencial que completa o conjunto de equações necessárias para que se possa descrever o escoamento do líquido na tubulação. A partir da equação da continuidade é possível se realizar duas diferenciações diretamente, uma em relação ao movimento axial da tubulação e outra em relação à massa da partícula fluídica, dessa forma obtém-se duas derivadas totais. Uma terceira derivada total é obtida através da diferenciação em relação ao movimento da onda que se propaga no interior da tubulação.

A tubulação é considerada como relativamente fixa a ponto de se mover ou deformar apenas quando a superfície interna se move ou deforma. A esse ponto, uma observação a cerca da aplicação da teoria precisa ser realizada. No caso de uma tubulação submersa haverão forças externas que podem movimentar e deformar a tubulação. E, especificamente, no caso do separador ciclônico submerso, foco deste trabalho, essas forças são as típicas de ambientes offshore e aparecem principalmente devido ao comportamento natural de ambientes subaquáticos. Espera-se, no entanto, que essas forças não invalidem a aplicação do presente desenvolvimento teórico de forma que o movimento da água não gere tensões sobre a tubulação, suficientes para deformá-la significativamente a ponto de invalidar a aplicação da equação da continuidade obtida para o escoamento do líquido no interior da tubulação. A formulação de um equação que considere as forças subaquáticas está fora do escopo do presente trabalho e deverá ser tema de trabalhos de estudos futuros. 


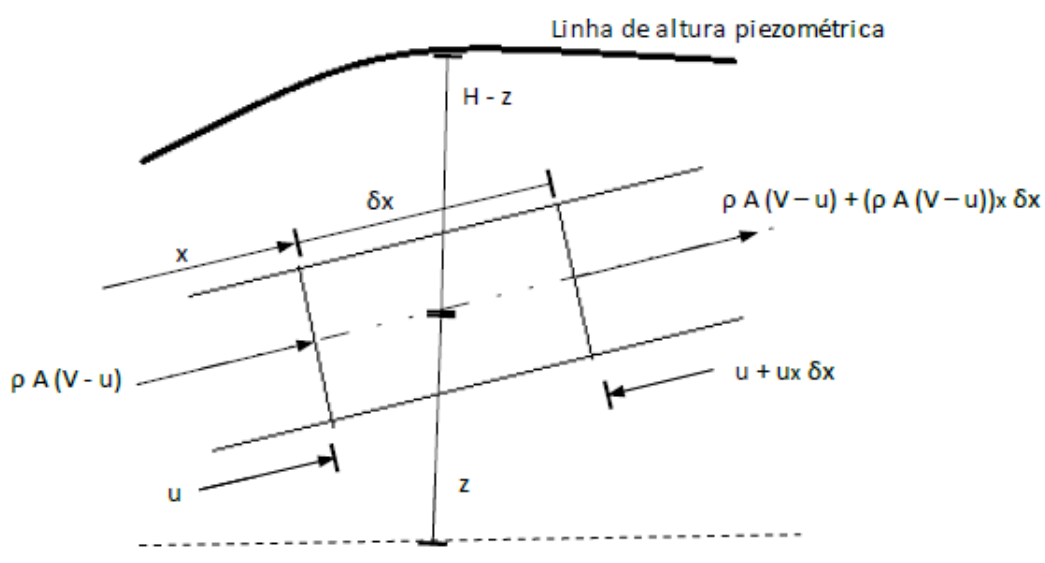

Figura 3.5: Volume de controle para equação da continuidade

O diagrama da Figura 3.5 mostra um volume de controle com comprimento $x$ num dado instante $t$ em que a parede da tubulação se move, ou deforma a uma velocidade $u$. Os subscritos $x$, indicam derivada em relação à distância $x$ ao longo da tubulação. A lei da conservação da massa diz que a taxa temporal de massa que entra no volume de controle é igual a taxa temporal de aumento do volume de controle, o que pode ser traduzido em termos das variáveis apresentadas, da seguinte forma:

$$
-\frac{\partial}{\partial x}(\rho A(V-u)) \delta x=\frac{D}{D t}(\rho A d x)
$$

A derivada total em relação ao movimento axial da tubulação é dada pela seguinte transformada:

$$
\frac{D}{D t}=u \frac{\partial}{\partial x}+\frac{\partial}{\partial t}
$$

e a taxa temporal de variação do comprimento $\delta x$ do volume de controle é dada por:

$$
\frac{D}{D t} \delta x=\frac{\partial u}{\partial x} \delta x
$$

Expandindo a equação 3.43 chega-se a seguinte relação:

$$
\frac{\partial}{\partial x}(\rho A V) \delta x-\frac{\partial}{\partial x}(\rho A u) \delta x+\frac{D}{D t}(\rho A) d x+\rho A \frac{D}{D t} \delta x=0
$$

A ultima parcela da equação acima é dada pela equação 3.45, logo, substituindo-se essa parcela pode se eliminar convenientemente o comprimento do volume de controle $\delta x$, logo:

$$
\frac{\partial}{\partial x}(\rho A V)-\frac{\partial}{\partial x}(\rho A u)+\frac{D}{D t}(\rho A)+\rho A \frac{\partial u}{\partial x}=0
$$

a partir da definição da derivada total temporal apresentada na equação 3.44, é possível se expandir a equação acima, assim chega-se a: 


$$
\frac{\partial}{\partial x}(\rho A V)-\frac{\partial(\rho A)}{\partial x} u-\frac{\partial u}{\partial x} \rho A+u \frac{\partial}{\partial x}(\rho A)+\frac{\partial}{\partial t}(\rho A)+\rho A \frac{\partial u}{\partial x}=0
$$

ou, simplificando:

$$
\frac{\partial}{\partial x}(\rho A V)+\frac{\partial}{\partial t}(\rho A)=0
$$

Esse resultado exprime as taxas de variação da área de seção transversal atribuída ao volume de controle, da velocidade e da densidade do fluido em relação a $x$ e ao tempo $t$. A equação fornece uma relação geral para escoamento do líquido, no entanto uma forma mais simplificada ainda pode ser obtida. O objetivo é sumarizar numa mesma equação as varáveis referentes à altura piezométrica $(H)$ e velocidade do líquido $(V)$, assim como foi feita para equação do movimento na seção 3.2.1, de maneira que se tenha duas equações que permitam calcular os valores dessas variáveis posteriormente. Nessa direção, a equação 3.49 será reescrita expandindo-se as taxas de variação em relação a $x$, logo:

$$
\rho A \frac{\partial V}{\partial x}+V \frac{\partial}{\partial x}(\rho A)+\frac{\partial}{\partial t}(\rho A)=0
$$

A partir da definição da derivada temporal para um volume de controle com velocidade $V$ $\left(\frac{D}{D t}=V \frac{\partial}{\partial x}+\frac{\partial}{\partial t}\right)$, é possível simplificar a equação 3.50

$$
\frac{\partial V}{\partial x}+\frac{1}{\rho A} \frac{D}{D t}(\rho A)=\frac{\partial V}{\partial x}+\frac{1}{\rho A}(\dot{\rho} A+\rho \dot{A})=0
$$

A forma final da equação será, então, dada por:

$$
\frac{\partial V}{\partial x}+\frac{\dot{\rho}}{\rho}+\frac{\dot{A}}{A}=0
$$

Vale salientar que até o momento não foram assumidas simplificações para se chegar esta ultima equação (equação 3.52), desta forma a equação continua válida tanto para líquidos quanto para sólidos podendo ser aplicada para inclusive para tubulações muito flexíveis e para os casos de tubos convergentes ou divergentes.

Para se obter a equação em termos de $H$ e $V$, introduz-se o efeito da razão de Poisson:

$$
\frac{\dot{\rho}}{\rho}=\frac{\dot{p}}{K}
$$

Adicionalmente, considerando a expansão da parede da tubulação por unidade de área, por unidade de tempo

$$
\frac{\dot{A}}{A}=\frac{\dot{p} D}{2 e E} \frac{D}{2} \frac{\pi D}{A}=\frac{\dot{p} D}{e E}=2 \dot{\xi}_{T}
$$


A partir das relações entre deformação total $\xi_{T}$ e as tensões axiais e laterais, $\sigma_{1}$ e $\sigma_{2}$ (ver equação 3.18), pode-se reescrever a equação 3.52 da seguinte forma:

$$
\frac{\partial V}{\partial x}+\frac{\dot{p}}{K}+\frac{2}{E}\left(\dot{\sigma}_{2}-\mu \dot{\sigma}_{1}\right)=0
$$

A tensão transversal ou circunferencial é proporcional à pressão em termos dos parâmetros que descrevem a tubulação como seu diâmetro $D$ e espessura de parede $e\left(\sigma_{2}=\frac{p D}{2 e}\right)$, assim como sua taxa de variação temporal $\left(\dot{\sigma}_{2}=\frac{\dot{p} D}{2 e}\right)$, para fins de simplificação assume-se que a taxa temporal de variação do diâmetro da tubulação é pequeno, portanto $D$ considerado constante em relação ao tempo. Já a taxa de variação da tensão axial deverá ser considerada para os três casos discutidos na seção 3.1 de forma que para:

caso a - tubulação ancorada na base: $\dot{\sigma}_{1}=\frac{\dot{p} D}{4 e}$

caso $b$ - tubulação ancorada longitudinalmente: $\dot{\sigma}_{1}=\mu \dot{\sigma}_{2}$

caso $c$ - tubulação com juntas de expansão: $\dot{\sigma}_{2}=0$

A substituição dos valores de $\sigma_{1}$ e $\sigma_{2}$, na equação 3.55 leva ao seguinte resultado:

$$
a^{2} \frac{\partial V}{\partial x}+\frac{\dot{p}}{\rho}=0
$$

onde $a$ teve seu valor enunciado pela equação 3.29.

Por fim, para se obter a equação da conservação em termos de $H$ e $V$ basta se obter o valor de $\dot{p}$ e aplicá-lo à equação 3.56. Esse valor será obtido a partir da relação entre a pressão e altura piezométrica correspondente:

$$
p=\rho g(H-z)
$$

A derivada temporal total da pressão será:

$$
\begin{gathered}
\dot{p}=\rho g(\dot{H}-\dot{z}) \\
\dot{p}=\rho g\left(V \frac{\partial H}{\partial x}+\frac{\partial H}{\partial t}-V \frac{\partial z}{\partial x}-\frac{\partial z}{\partial t}\right)
\end{gathered}
$$

Considerando que não haja movimento transversal da tubulação, não haverá variação da posição $z$ do volume de controle em relação ao tempo, $\operatorname{logo} \frac{\partial z}{\partial t}=0$, e a variação de $z$ em relação a $x$ será a própria inclinação da tubulação, ou seja, $\frac{\partial z}{\partial x}=\operatorname{sen} \alpha$. Encontrado, então, o valor da taxa da pressão pode-se reescrever equação 3.56

$$
V \frac{\partial H}{\partial x}+\frac{\partial H}{\partial t}-V \operatorname{sen} \alpha+\frac{a^{2}}{g} \frac{\partial V}{\partial x}=0
$$




\subsection{Tubulação de Saída de Gás}

\subsubsection{Equações Básicas de Escoamento Transiente para Gás Natural}

A modelagem do separador ciclônico foi dividia em três partes, tubulação de líquido, tubulação de gás e interior do separador. Esta seção serão discutidas as equações básicas utilizadas para modelagem da tubulação de gás, assim como no caso da seção 2. Esta teoria é aplicável para escoamento de gás natural, portanto, assim como no caso do líquido, um excelente ponto de partida para modelagem do escoamento da gás no sistema do separador.

Para o desenvolvimento de uma teoria para escoamento de gases em tubulação algumas simplificações serão assumidas [Wylie e Streeter 1978]:

1. o escoamento é isotérmico;

2. expansões das paredes da tubulação são pequenas de modo que seus efeitos podem ser desprezados;

3. A tubulação tem inclinação constantes para uma determinada seção de equacionamento;

4. A equação de estado dos gases é dada por $p=z \rho R T$, onde $z$ é a compressibilidade do gás e é considerada constante no âmbito de uma dada seção de equacionamento;

5. Relações de escoamento unidimensional são utilizadas;

6. O fator de atrito é uma função da rugosidade das paredes da tubulação e do número de Reynolds;

7. Mudanças na energia cinética do gás ao longo da tubulação são consideradas de pouca importância, portanto, desprezadas.

\subsubsection{Equação de Estado}

A equação de estado utilizada para descrever o comportamento do gás natural é

$$
p=z \rho_{G} R T
$$

onde $p$ é a pressão absoluta (geralmente varia entre 100 e 200 psi); $z$ a compressibilidade do gás (geralmente varia entre 1,00 e 1,08); $R$ a constante dos gases ideais; $T$ a temperatura (varia entre 15 e $\left.40{ }^{\circ} \mathrm{C}\right)$; e $\rho_{G}$ a densidade do gás.

Assumindo um escoamento isotérmico, a velocidade de propagação da onda acústica no interior da tubulação é dada por:

$$
B=\sqrt{\frac{p}{\rho_{G}}}=\sqrt{z R T}
$$




\subsubsection{Equação da Continuidade}

A equação da continuidade será expressa da seguinte forma [Wylie e Streeter 1978]:

$$
\vec{\nabla} \cdot \rho_{G} \vec{V}+\frac{\partial \rho_{G}}{\partial t}=0
$$

No caso de deslocamento unidimensional na direção $(x)$ longitudinal da tubulação e com velocidade $u$ :

$$
\frac{\partial}{\partial x} \hat{i} \cdot\left(\rho_{G} u\right) \hat{i}+\frac{\partial \rho_{G}}{\partial t}=0
$$

onde $\hat{i}$ é o vetor unitário da direção $x$. Expandindo a equação acima:

$$
\frac{\partial \rho_{G}}{\partial x} u+\rho_{G} \frac{\partial u}{\partial x}+\frac{\partial \rho_{G}}{\partial t}=0
$$

Se a velocidade do fluido for uniforme ao longo da tubulação, então:

$$
\frac{\partial \rho_{G}}{\partial x} u+\frac{\partial \rho_{G}}{\partial t}=0
$$

Considerando as dimensões do tubo constantes, pode-se escrever:

$$
\frac{\partial m}{\partial x} u+\frac{\partial m}{\partial t}=0
$$

A massa do gás contida em uma seção da tubulação de comprimento $\delta x$ será $m=\rho_{G} A \delta x$, onde $A$ é a área transversal da tubulação de escoamento do gás. Assumindo a condição de velocidade uniforme:

$$
\frac{\partial d x}{\partial t} \frac{\partial m}{\partial x}+\frac{\partial}{\partial t}\left(\rho_{G} A d x\right)=0
$$

$\mathrm{ou}$

$$
\frac{\partial \dot{m}}{\partial x} \delta x=-\frac{\partial}{\partial t}\left(\rho_{G} A \delta x\right)
$$

A Figura 3.6 mostra um segmento da tubulação de escoamento do gás com comprimento $\delta x$ contendo sua quantidade de massa correspondente.

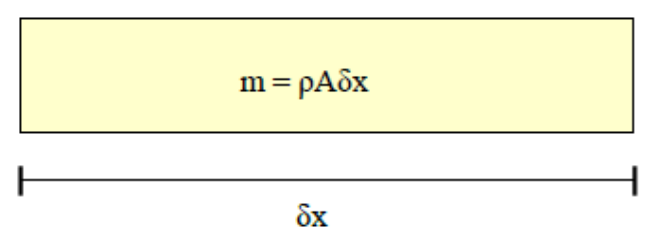

Figura 3.6: Seção da tubulação com comprimento $\delta x$ e massa $m=\rho_{G} A \delta x$ 
A equação da continuidade para o escoamento do gás será dada em termos da vazão mássica do fluido e de sua pressão ao longo da tubulação, de forma que para se chegar a uma formulação com essas variáveis considere a derivada temporal da equação da velocidade de propagação da onda acústica na tubulação (equação 3.62)

$$
\frac{\partial \rho_{G}}{\partial t}=\frac{1}{B^{2}} \frac{\partial p}{\partial t}
$$

Substituindo-se $\frac{\partial \rho_{G}}{\partial t}$ na equação na equação 3.69, a equação da continuidade poderá ser escrita da seguinte forma:

$$
\frac{B^{2}}{A} \frac{\partial \dot{m}}{\partial x}+\frac{\partial p}{\partial t}=0
$$

Em notação simplificada, sendo $M_{x}$ a taxa temporal de variação da massa, e equação 3.71 será dada por:

$$
\frac{B^{2}}{A} M_{x}+p_{t}=0
$$

\subsubsection{Equação do Movimento}

Considere o diagrama de corpo livre referente a um segmento de fluido que escoa no interior da tubulação. O somatório das forças que atuam sobre esse segmento é:

$$
p A-p A-p_{x} \delta x A-\tau_{0} \pi D \delta x-\rho_{G} g A \delta x \operatorname{sen} \theta=m \dot{V}
$$

onde $\tau_{0}$ é a tensão de cisalhamento devido ao atrito do fluido com as paredes da tubulação e $\theta$ é o ângulo que a tubulação faz com a horizontal, $g$ é a aceleração da gravidade e $D$ o diâmetro da tubulação. É introduzido um fator adimensional artificial o qual, se estritamente interpretado deve ser igual a 1, $\alpha_{M}$ é chamado multiplicador artificial e pode ser assumir valores diferentes da unidade sem causar erros significativos na equação do movimento.

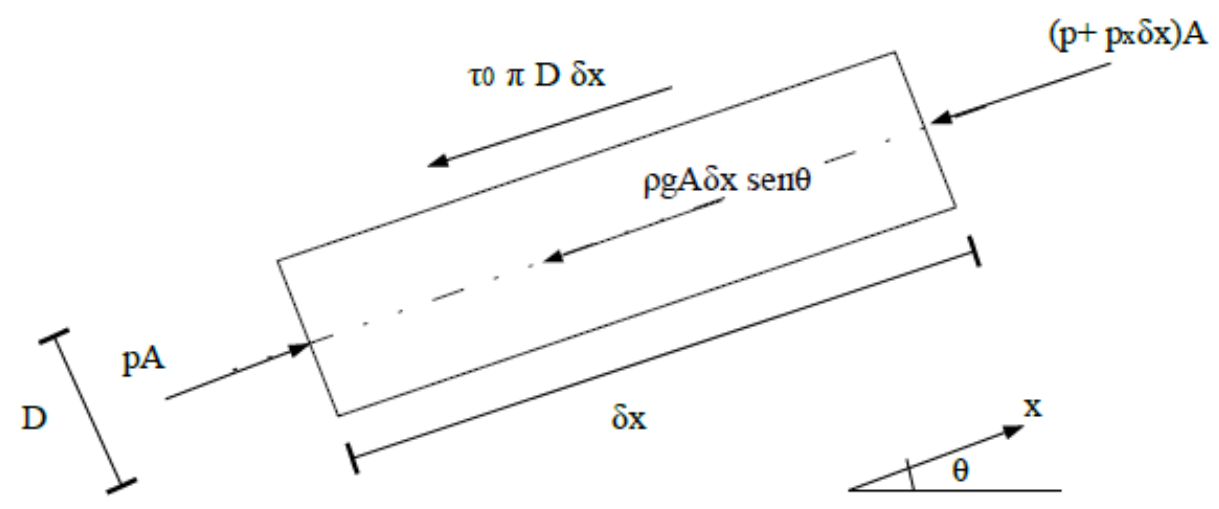

Figura 3.7: diagrama de corpo livre de segmento de fluido no interior de uma tubulação 
Com a introdução de um multiplicador artificial, o somatório das forças sobre o elemento de fluido, será reescrito:

$$
-p_{x} \delta x A-t_{0} \pi D d \delta x-\rho_{G} g A \delta x \operatorname{sen} \theta=\alpha_{M}^{2} \rho_{G} A d x \dot{V}
$$

$\mathrm{ou}$

$$
-p_{x}-\frac{\tau_{0} \pi D}{A}-\rho_{G} g \operatorname{sen} \theta=a_{M}^{2} \rho_{G} \dot{V}
$$

Com auxílio da equação de Darcy-Weisbach é possível encontrar-se a seguinte relação para tensão de cisalhamento:

$$
\tau_{0}=\frac{\rho_{G} f V^{2}}{8}=\frac{\rho_{G} f}{8} \frac{M^{2}}{p^{2}} \frac{B^{4}}{A^{2}}=\frac{\rho_{G} f}{8}\left(\frac{\partial m}{\partial t}\right)^{2} \frac{B^{4}}{p^{2} A^{2}}=\frac{f B^{2} M^{2}}{8 p A^{2}}
$$

Assim como no caso da equação da continuidade, o objetivo aqui é obter a equação diferencial do movimento do fluido em termos da vazão másica e da pressão ao longo da tubulação de escoamento do gás. Considere então, a derivada total da velocidades dada por:

$$
\frac{D V}{D t}=\frac{\partial V}{\partial x}+\frac{\partial V}{\partial t}
$$

Se não houver variação da velocidade ao longo do comprimento do tubo a derivada total se reduzirá à derivada parcial da velocidade em relação ao tempo. Escrevendo a velocidade como $V=M /\left(\rho_{G} A\right)$ e a partir da relação entre a densidade do gás e a velocidade de onda acústica dada pela equação 3.62 , obtém-se para a aceleração do fluido no interior da tubulação:

$$
\frac{D V}{D t}=\frac{\partial V}{\partial t}=\frac{\partial}{\partial t}\left(\frac{M}{\rho_{G} A}\right)=\frac{B^{2}}{A} \frac{\partial}{\partial t}\left(\frac{M}{p}\right)=\frac{B^{2}}{A p}\left(\frac{\partial M}{\partial t}-\frac{M}{p} \frac{\partial p}{\partial t}\right)
$$

Substituindo-se o valor encontrado para tensão de cisalhamento $\tau_{0}$ e a aceleração do fluido no interior da tubulação (equações 3.76 e 3.78 ) na equação 3.75 , tem-se:

$$
-p_{x}-\frac{f B^{2} M^{2}}{8 p A^{2}} \frac{p D}{A}-\frac{p g}{B^{2}} \operatorname{sen} \theta=\alpha_{M}^{2} \rho_{G} \frac{B^{2}}{A p}\left(M_{t}-\frac{M}{p} p_{t}\right)
$$

A partir do valor da área de seção transversal da tubulação $A=\pi D^{2} / 4$, e do valor da densidade do gás $\rho_{G}$, pode-se escrever:

$$
p_{x}+\frac{f B^{2} M^{2}}{2 D p A^{2}}+\frac{p g}{B^{2}} \operatorname{sen} \theta+\frac{\alpha_{M}^{2}}{A}\left(M_{t}-\frac{M}{p} p_{t}\right)=0
$$

Como previsto pela equação da continuidade, a derivada parcial da pressão do gás em relação ao tempo é proporcional à derivada parcial da vazão mássica em relação ao deslocamento ao longo do comprimento da tubulação, $p_{t}=\frac{-B^{2}}{A} M_{x}$. Observe que na última parcela da equação 3.80 há um termo multiplicado à taxa de pressão $p_{t}$. Esse termo será bastante simplificado quando 
for considerado o valor de $p_{t}$ previsto pela equação da continuidade. Além disso, a equação da derivada total da velocidade 3.77 permite escrever $V=\frac{B^{2} M}{p A}$, assim, será possível chegar-se à seguinte relação:

$$
\frac{-M}{p} p_{t}=\frac{-B^{2}}{A} \frac{M}{p} M_{x}=-V M_{x}
$$

Considerando que a distância infinitesimal $d x$ percorrida pelo fluido é aproximadamente $B d t$, a equação 3.81 poderá ser aproximada:

$$
V M_{x}=V \frac{\partial M}{\partial x} \approx \frac{V}{B} \frac{\partial M}{\partial t}=\frac{V}{B} M_{t}
$$

De forma que a equação do movimento torna-se:

$$
p_{x}+\frac{f B^{2} M^{2}}{2 D p A^{2}}+\frac{p g}{B^{2}} \operatorname{sen} \theta+\frac{\alpha_{M}^{2}}{A} M_{t}\left(1-\frac{V}{B}\right)=0
$$

Por fim, como a velocidade de escoamento de gases é geralmente muito menor que a velocidade de propagação da onda acústica, a razão $V / B$ será muito menor que a unidade e a equação do movimento poderá ser aproximada para:

$$
p_{x}+\frac{f B^{2} M^{2}}{2 D p A^{2}}+\frac{p g}{B^{2}} \operatorname{sen} \theta+\frac{\alpha_{M}^{2}}{A} M_{t}=0
$$

\subsubsection{Escoamento em Regime Permanente}

O escoamento em regime permanente é um caso particular do escoamento transiente previsto pelas equações da continuidade e do movimento, portanto, essas equações devem ser capazes de prevê-lo. De fato com algumas considerações pertinentes pode-se chegar ao valor da variação da pressão do gás ao longo da tubulação como uma razão dos parâmetros do sistema utilizados, até agora, para descrever o escoamento. Para tanto deve-se lembrar que no escoamento em regime permanente não há variação de massa com o passar do tempo de forma que se $M=\frac{\partial m}{\partial t}=$ constante, então $M_{t}=\frac{\partial^{2} m}{\partial t^{2}}=0$. Assim para o regime permanente a equação do movimento 3.84 assume a seguinte forma:

$$
\frac{\partial p}{\partial x}+\frac{f B^{2} M^{2}}{2 D p A^{2}}+\frac{p g}{B^{2}} \operatorname{sen} \theta=0
$$

Como $f$ é constante já que para regime permanente no número de Reynolds é constante, a única variável independente da equação acima é $x$, logo:

$$
d p+\left(\frac{f B^{2} M^{2}}{2 D p A^{2}}+\frac{p g}{B^{2}} \operatorname{sen} \theta\right) d x=0
$$


Logo, a equação acima pode ser rearranjada da seguinte forma:

$$
\frac{B^{2}}{g \operatorname{sen} \theta} p d p+\left(p^{2}+\frac{f B^{4} M^{2}}{2 D A^{2} g \operatorname{sen} \theta}\right) d x=0
$$

Considere agora, a seguinte mudança de variáveis:

$$
\begin{aligned}
& r=p^{2}+{\frac{f B^{4} M^{2}}{2 g D A}}^{2} \operatorname{sen} \theta \\
& d r=2 p d p
\end{aligned}
$$

Com as novas variáveis a equação 3.87 torna-se:

$$
\frac{B^{2}}{2 g} \operatorname{sen} \theta d r+r d x=0
$$

Essa última equação a qual é integrada entre os limites $p_{1}$ e $p_{2}$ para pressão e entre zero e $\Delta x$ para distância, logo:

$$
\int \frac{d r}{r}+\frac{2 g \operatorname{sen} \theta}{B^{2}} \int d x=0=\ln r+\frac{2 g \operatorname{sen} \theta}{B^{2}} x
$$

A partir do valor de $r$ e aplicando os limites de integração:

$$
\left.\ln \left(p^{2}+f B^{4} M^{2}\right)\right|_{p 1} ^{p 2}+\left.\frac{2 g \operatorname{sen} \theta}{B^{2}}\right|_{0} ^{\Delta x}=0
$$

de onde chega-se à seguinte forma:

$$
\ln \left(\frac{p_{1}^{2}+f B^{4} M^{2} /\left(2 g D A^{2} \operatorname{sen} \theta\right)}{p_{2}^{2}+f B^{4} M^{2} /\left(2 g D A^{2} \operatorname{sen} \theta\right)}\right)=\frac{2 g \operatorname{sen} \theta}{B^{2}} \Delta x
$$

Define-se então uma segunda transformação de variáveis tal que:

$$
s=\frac{2 g \operatorname{sen} \theta}{B^{2}} \Delta x
$$

permitindo que a exponencial da equação 3.92 seja escrita de forma simplificada

$$
\frac{p_{1}^{2}+f B^{4} M^{2} /\left(2 g D A^{2} \operatorname{sen} \theta\right)}{p_{2}^{2}+f B^{4} M^{2} /\left(2 g D A^{2} \operatorname{sen} \theta\right)}=e^{s}
$$

Resolvendo esta última equação para $p_{2}^{2}$ :

$$
p_{2}^{2}=\frac{1}{e^{s}}\left(p_{1}^{2}+\frac{f B^{4} M^{2}}{2 g D A} \operatorname{sen} \theta\left(1-e^{s}\right)\right)
$$

Explicitando o termo $\frac{\Delta x}{s}$ que é obtido pela definição de $s$ (equação 3.93): 


$$
p_{2}^{2}=\frac{1}{e^{s}}\left(p_{1}^{2}+\frac{f B^{2} M^{2} \Delta x}{D A^{2}} \frac{\left(1-e^{s}\right)}{s}\right)
$$

A equação que fornece a pressão do fluido será rearranjada da seguinte forma:

$$
\left(p_{1}-p_{2}\right)\left(p_{1}+p_{2}\right)=\frac{f B^{2} M^{2} \Delta x}{D A^{2}} \frac{\left(e^{s}-1\right)}{s}+p_{2}^{2}\left(e^{s}-1\right)
$$

$\mathrm{Ou}$

$$
\left(p_{1}-p_{2}\right)=\frac{f B^{2} M^{2} \Delta x}{D A^{2}\left(p_{1}+p_{2}\right)} \frac{\left(e^{s}-1\right)}{s}+\frac{p_{2}^{2}}{\left(p_{1}+p_{2}\right)}\left(e^{s}-1\right)
$$

Essa, é a expressão que exprime a variação de pressão ao longo da tubulação de escoamento do gás. No caso particular em que a tubulação seja horizontal, tem-se $s=0$, logo:

$$
\lim _{s \rightarrow 0} \frac{\left(e^{s}-1\right)}{s}=\lim _{s \rightarrow 0} \frac{e^{s}}{1}=1
$$

De maneira que a pressão do gás ao longo da tubulação em regime permanente se reduz a:

$$
p_{2}^{2}=p_{1}^{2}-\frac{f B^{2} M^{2}}{D A^{2}} \Delta x
$$

As equações empíricas são amplamente utilizadas na indústria de gás natural e geralmente têm a forma $p_{2}^{2}=p_{1}^{2}-$ constante $\frac{M^{m}}{D^{n}} \Delta x$, onde $m, n$ são assumem valores diferentes dependendo da rugosidade da tubulação e do número de Reynolds do escoamento [Wylie e Streeter 1978]. 


\section{Capítulo 4}

\section{Método das Equações Características}

O método das equações características é uma técnica utilizada para solução de equações diferenciais parciais sendo tipicamente aplicado a equações diferenciais de primeira ordem. Em geral, o método das equações características pode ser adotado para solução de qualquer equação diferencial hiperbólica. Nesse método, as equações parciais diferenciais a serem resolvidas são reduzidas a uma família de equações ordinárias e suas soluções integradas a partir de valores iniciais conhecidos. Na seção 4.1 é apresentado o método das equações características para um caso simplificado das equações que descrevem o escoamento ao longo de uma tubulação de líquido. Nas seções 4.2 e 4.3 são mostradas adaptações na técnica necessárias para resolver sistemas que apresentam variações como junção de tubulações, adição de válvulas ou bombas de elevação do líquido às tubulações. Na seção 4.4 é apresentada uma variação da técnica necessária a solução do conjunto de equações completas que descrevem o escoamento do líquido, enquanto na seção 4.5 é discutida a utilização do método das equações características para solução das equações que descrevem o escoamento do gás em sua respectiva tubulação de saída.

\subsection{Método das Equações Características para Escoamento do Líquido}

Na Capítulo 3 duas equações diferenciais foram obtidas para o escoamento do líquido em uma tubulação cilíndrica, essas equações descrevem a pressão, em termos de altura piezométrica $(H)$ e a velocidade $(V)$ de um fluido no interior de uma tubulação tomando em conta os efeito de transientes sobre o fluido. Os termos não lineares das equações dificultam a obtenção de uma solução analítica fazendo-se necessário a adoção de método numérico que leve em conta a evolução temporal e espacial do sistema como requerem as equações encontradas. Um método que pode ser utilizado para obtenção da solução dessas equações é o método das equações características que será brevemente discutido a seguir. As equações diferencias a serem resolvidas são a equação do momento escrita como:

$$
L_{1}: g \frac{\partial H}{\partial x}+V \frac{\partial V}{\partial x}+\frac{\partial V}{\partial t}+\frac{f}{2 D} V|V|=0
$$


e a equação da continuidade, escrita da seguinte forma:

$$
L_{2}: V \frac{\partial H}{\partial x}+\frac{\partial H}{\partial t}-V \operatorname{sen} a+\frac{a^{2}}{g} \frac{\partial V}{\partial x}=0
$$

Os rótulos $L_{1}$ e $L_{2}$ são adotados apenas para facilitar a identificação das respectivas equações. Em notação simplificada, com subscrito $x$ denotando taxa de variação em relação a $x$ e o subscrito $t$ denotando taxa de variação em relação ao tempo, as equações acima tornam-se:

$$
L_{1}: g H_{x}+V V_{x}+V_{t}+\frac{f}{2 D} V|V|=0
$$

e

$$
L_{2}: V H_{x}+H_{t}-V \operatorname{sen} \alpha+\frac{a^{2}}{g} V_{x}=0
$$

As equações do momento e da continuidade formam um par de equações diferenciais parciais hiperbólicas não lineares em termos de duas variáveis dependentes, velocidade e altura piezométrica e duas variáveis independentes, o tempo e a distância ao longo da tubulação. Pelo método das equações características, essas equações são transformadas em quatro equações ordinárias que permitirão o desenvolvimento de uma solução numérica para o problema. Para mostrar o procedimento utilizado na determinação das equações ordinárias e subsequentemente a solução das equações diferenciais, considere o seguinte conjunto de equações simplificadas:

$$
\begin{gathered}
L_{1}: g H_{x}+V_{t}+\frac{f}{2 D} V|V|=0 \\
L_{2}: H_{t}+\frac{a^{2}}{g} V_{x}=0
\end{gathered}
$$

Seguindo na direção da solução das equações diferenciais, propõe-se a seguinte combinação das duas através da introdução de um parâmetro desconhecido $\lambda$ :

$$
L_{1}+\lambda L_{2}=0
$$

Essa combinação resultará na seguinte equação:

$$
g H_{x}+V_{t}+\frac{f}{2 D} V|V|+\lambda H_{t}+\lambda \frac{a^{2}}{g} V_{x}=0
$$

A equação ser rearranjada da seguinte forma:

$$
\lambda\left(\frac{g}{\lambda} H_{x}+H_{t}\right)+\lambda\left(\frac{V_{t}}{\lambda}+\frac{a^{2}}{g} V_{x}\right)+\frac{f}{2 D} V|V|=0
$$

Tanto $H$ quanto $V$ são dependentes de $x$ e $t$, portanto sendo a posição $x$ dependente do tempo, 
pela regra da cadeia, pode-se escrever:

$$
\frac{d H}{d t}=H_{x} \frac{d x}{d t}+H_{t} \quad, \quad \frac{d V}{d t}=V_{x} \frac{d x}{d t}+V_{t}
$$

se a $\frac{d x}{d t}$ for atribuído um valor tal que $\frac{d x}{d t}=\frac{g}{\lambda}=\frac{\lambda a^{2}}{g}$, então a equação 4.9 se torna:

$$
\frac{d H}{d t}+\frac{d V}{d t}+\frac{f}{2 D} V|V|=0
$$

Pode-se, então, determinar um valor para $\lambda$ :

$$
\frac{g}{\lambda}=\frac{\lambda a^{2}}{g} \longrightarrow \lambda= \pm \frac{g}{a}
$$

o que leva a

$$
\frac{d x}{d t}= \pm a
$$

A variação na posição da onda está relacionada à variação do tempo pela velocidade de propagação da onda $a$ gerada por efeitos transientes sobre escoamento. A substituição do valor de $\lambda$ na equação 4.11 leva a dois conjuntos de equações que são agrupados em pares e identificados como $C^{+}$e $C^{-}$. Os valores positivos de $\lambda$ foram utilizados para transformar as equações diferenciais parciais originais em duas equações diferenciais totais cada uma válida apenas no âmbito de uma restrição específica. Essa restrição é dada pela inclinação da curva de $x$ em relação a $t$, conforme a equação 4.13. Para o primeiro par de equações:

$$
\left.\begin{array}{c}
\frac{g}{a} \frac{d H}{d t}+\frac{d V}{d t}+\frac{f}{2 D} V|V|=0 \\
\frac{d x}{d t}=a
\end{array}\right\} C^{+}
$$

A equação das derivadas totais de $H$ e $V$ só são válidas quando $\frac{d x}{d t}=a$. Do mesmo modo, para o segundo par:

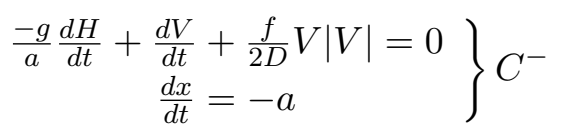

A equação diferencial que relaciona $H$ e $V$ só será válida quando $\frac{d x}{d t}=-a$.

Graficamente, é possível visualizar as curvas de validade do conjunto de equações 4.14 e 4.15 através das chamadas linhas características que aparecem no plano xt mostrado na Figura 4.1. Como a velocidade $a$ pode ser considerada constante para grande parte das aplicações que envolvem transientes [Wylie e Streeter 1978], a curva de validade das equações será uma reta, justificando a nomenclatura adotada. 


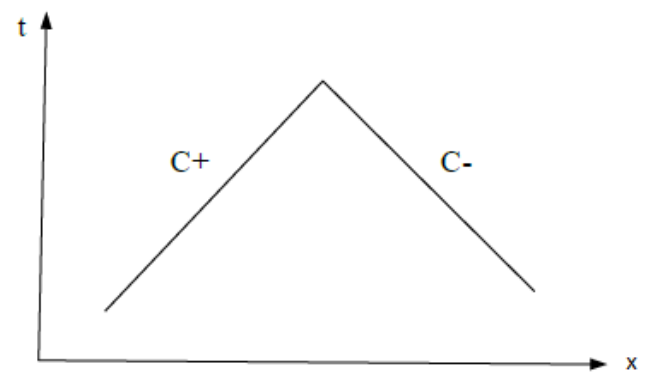

Figura 4.1: Linhas característica, determinam a região de validades do conjunto de equações utilizado para resolver as equações de transientes

\subsubsection{Equações Numéricas}

Para solução numérica do conjunto 4.14 e 4.15, a tubulação de escoamento de líquido será dividida em $N$ partes iguais de comprimento $\Delta x$. Com isso, tem-se uma variação temporal $\Delta t$ correspondente à altura do retângulo mostrado na Figura 4.2 dado por $\Delta t=\Delta x / a$. Considere, então, o plano discreto $x t$ mostrado na Figura 4.2. Se $H$ e $V$ são quantidades conhecidas do ponto $A$ mostrado na Figura, a equação 4.14 poderá ser integrada entre os limites $A$ e $P$. Semelhantemente, conhecendo-se os valores de $H$ e $V$ no ponto $B$, uma segunda integração poderá ser realiza para equação 4.15, tomando-se como limites de integração os pontos $B$ e $P$. Essas integrações são realizadas através do raciocínio apresentado a seguir.

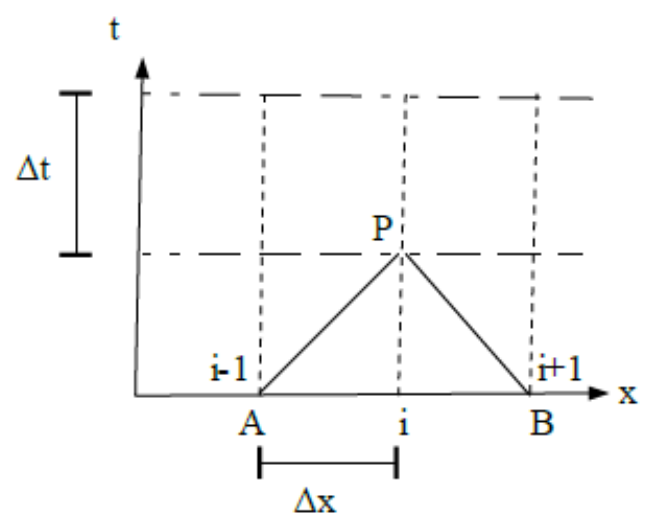

Figura 4.2: Linhas característica. Plano discretizado

Seja a equação diferencial do par de equações 4.14 multiplicada por $\frac{a}{g} d t=\frac{d x}{g}$

$$
d H+\frac{a}{g} d V+\frac{f}{2 g D} V|V| d x=0
$$

Escrevendo essa última em termos da vazão $Q=A V$

$$
d H+\frac{a}{g} \frac{d Q}{A}+\frac{f}{2 g D A^{2}} Q|Q| d x=0
$$


Integrando a equação acima entre os limites $A$ e $P$

$$
\int_{H_{A}}^{H_{P}} d H+\frac{a}{g A} \int_{Q_{A}}^{Q_{P}} d Q+\frac{f}{2 g D A^{2}} \int_{x_{A}}^{x_{P}} Q|Q| d x=0
$$

Os dois primeiros termos da equação acima são integrais puras, portanto, de fácil integração. A variação de $Q$ com a distância $x$, no entanto, não é conhecida. Utiliza-se então, uma aproximação de primeira ordem para a solução da integral de $|Q|$. Segundo Wylie e Streeter 1978, este tipo de aproximação é suficiente para a maioria dos casos, exceto naqueles em que o termo de friç̧ão é muito significativo. A integração desta última leva, finalmente, ao seguinte resultado:

$$
H_{P}-H_{A}+\frac{a}{g A}\left(Q_{P}-Q_{A}\right)+\frac{f}{2 g D A}{ }^{2} Q_{A}\left|Q_{A}\right| \Delta x=0
$$

Aplicando-se o mesmo raciocínio ao par de equações $C^{-}$, mostrado em 4.15, tem-se:

$$
H_{P}-H_{B}-\frac{a}{g A}\left(Q_{P}-Q_{B}\right)+\frac{f}{2 g D A^{2}} Q_{B}\left|Q_{B}\right| \Delta x=0
$$

De posse dessas equações será possível, após uma pequena manipulação algébrica, se obter o valor das variáveis dependentes $H$ e $Q$ para um determinado ponto $P$ no interior da tubulação. Esse ponto, será uma função dos valores das variáveis dependentes em pontos adjacentes $(A$ e $B)$ num instante de tempo imediatamente anterior. A computação dos valores de $H$ e $Q$ será um malha no plano cartesiano $t x$ sendo o valor dessas variáveis obtidos para um determinado ponto nesse plano, o resultado do histórico do escoamento do fluido do interior da tubulação. Como a computação dos valores das variáveis no ponto $P$ é realizado a partir de valores num instante $(t-\Delta t)$ imediatamente anterior, faz-se necessário o conhecimento de $H$ e $Q$ para o instante inicial, ou do início do histórico, esses valores serão obtidos considerando-se que nesse instante o fluido escoa em regime permanente. A condição de regime permanente é obtida quando $Q_{A}=Q_{B}=Q_{P}$.

\subsubsection{Solução do transiente para líquidos}

A solução do regime transiente em fluidos para líquidos, começa estabelecendo-se as condições de regime permanente do sistema para um instante $t=0$. As variáveis dependentes $H$ e $Q$ são quantidades conhecidas inicialmente e são utilizadas para calcular os próximos valores a cada etapa de computação, ou seja, a cada instante, ou a cada passo temporal $\Delta t$. Os valores de $Q$ e $H$ nos pontos $A$ e $B$ serão utilizados para calcular os próximos valores no ponto $P$.

A solução consistirá, então, em encontrar os valores das variáveis dependentes para cada ponto ao longo da tubulação a uma distância $\Delta x$ preestabelecida, para um instante igual $t=\Delta t$. $\mathrm{O}$ mesmo procedimento será repetido para $t=2 \Delta t$, e repetido o número de vezes necessário para se alcançar o tempo de equacionamento desejado.

As equações 4.19 e 4.20 podem ser rearranjadas e reescritas, respectivamente, da seguinte forma: 


$$
\begin{aligned}
& H_{P i}=H_{i-1}+B Q_{i-1}-R Q_{i-1}\left|Q_{i-1}\right|-B Q_{P i} \\
& H_{P i}=H_{i+1}-B Q_{i+1}+R Q_{i+1}\left|Q_{i+1}\right|+B Q_{P i}
\end{aligned}
$$

onde $R=\frac{f \Delta x}{2 g D A^{2}}$ será o fator de atrito do sistema e $B$ será dado por $B=\frac{a}{g A}$. Os subscritos referemse à mesma situação mostrada pela Figura 4.2, onde $i-1$ e $i+1$ coincidem com o pontos $A$ e $B$, respectivamente, para uma determinada distância ao longo do eixo da tubulação. Aplicando-se uma segunda simplificação notacional as equações 4.21 e 4.22 tornam-se:

$$
\begin{aligned}
& H_{P i}=C_{P}-B Q_{P i} \\
& H_{P i}=C_{M}+B Q_{P i}
\end{aligned}
$$

onde

$$
C_{P}=H_{i-1}+B Q_{i-1}-R Q_{i-1}\left|Q_{i-1}\right| \quad \text { e } \quad C_{M}=H_{i+1}-B Q_{i+1}+R Q_{i+1}\left|Q_{i+1}\right|
$$

Para uma dada etapa de computação dos valores de $H_{P}$ e $Q_{P}$, os valores de $C_{P}$ e $C_{M}$ são previamente conhecidos, portanto constantes, já que foram obtidos na etapa anterior. O valor de $H_{P}$ poderá, então, ser isolado a partir das equações 4.23 e 4.24 na forma:

$$
H_{P i}=\frac{C_{P}+C_{M}}{2}
$$

O valor de $Q_{P}$ será obtido pela substituição desse resultado contendo o valor de $H_{P}$ em uma das duas equações 4.23 ou 4.24 .

\subsection{Sistemas Complexos}

Num separador ciclônico a descrição do escoamento do óleo pode necessitar da utilização de sistemas complexos como bifurcações ou junções de tubulações ou mesmo, um caminho de escoamento com tubulações de diferentes diâmetros. Esses fatores têm consequência direta sobre o regime transiente, logo, sobre o comportamento do fluido. Esta seção visa estabelecer um tratamento para esse tipo de situação. As equações desenvolvidas até o momento são base da resolução de sistemas complexos, bastando, em muitos casos, uma adequada interpretação dos valores iniciais de computação para $H$ e $Q$ em cada interface.

\subsubsection{Conexões em série}

Conexões de tubulação em série podem ser aplicadas às junções de vários tubos com diâmetros diferentes ou mesmo a um tubo único com diferentes valores de rugosidade ou espessura. Considere a junção esquematizada na Figura 4.3. 


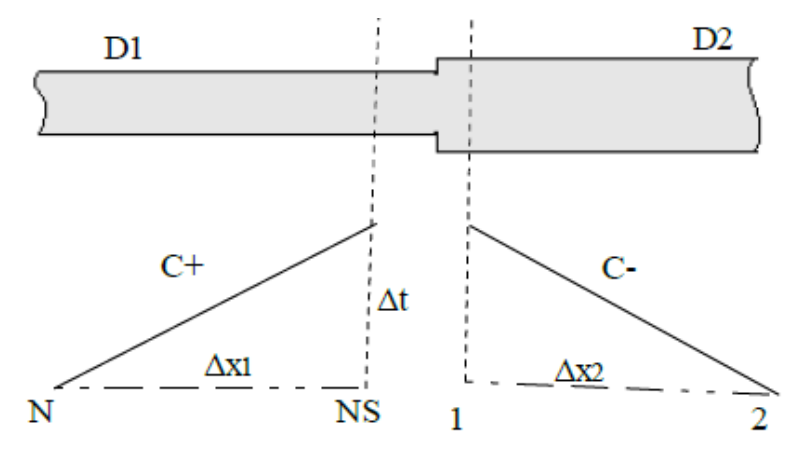

Figura 4.3: Tubulação em série

A equação 4.26 é aplicada à tubulação $D_{1}$, enquanto a equação 4.27 é aplicada à tubulação $D_{2}$.

$$
\begin{aligned}
& C^{+}: H_{P 1}(i)=C_{P 1}-B_{1} Q_{P 1}(i) \\
& C^{-}: H_{P 2}(i)=C_{M 2}+B_{2} Q_{P 2}(i)
\end{aligned}
$$

$C_{P 1}$ e $B_{1}$ são quantidades que relacionam a pressão e a vazão no interior da tubulação $D_{1}$, conforme descrito pela equação 4.23 enquanto as variáveis $C_{m 2}$ e $B_{2}$ são quantidades relacionadas de acordo com a equação 4.24 , mas que se referem à tubulação $D_{2}$. Para efeito de clareza das explanações subsequentes, assume-se uma modificação na notação da seguinte maneira: os subscritos 1 e 2 fazem referência às tubulações $D 1$ e $D 2$ respectivamente, enquanto o índice entre parênteses indica a posição discreta ao longo do comprimento da tubulação.

A equação da continuidade conjugada com a condição de que a altura piezométrica $(H)$ na junção deverá ser a mesma para os dois tubos, impõe-se as seguintes relações:

$$
H_{P 1}(N S)=H_{P 2} \quad, \quad Q_{P 1}(N S)=Q_{P 2}
$$

A partir dessas relações e resolvendo 4.26 e 4.27 simultaneamente, chega-se a:

$$
Q_{P 2}(1)=\frac{C_{P 1}-C_{M 2}}{B_{1}+B_{2}}
$$

Uma vez encontrado $Q_{P 2}$, o valor de $H_{P 2}$ poderá ser obtido por aplicação direta do resultado de uma das equações 4.26 ou 4.27. A determinação de $H$ e $Q$ no interior de cada tubulação e ao longo do tempo será obtida pelos métodos descritos nas seções anteriores (ver seção 4.1.2). 


\subsubsection{Ramificação de Conexões}

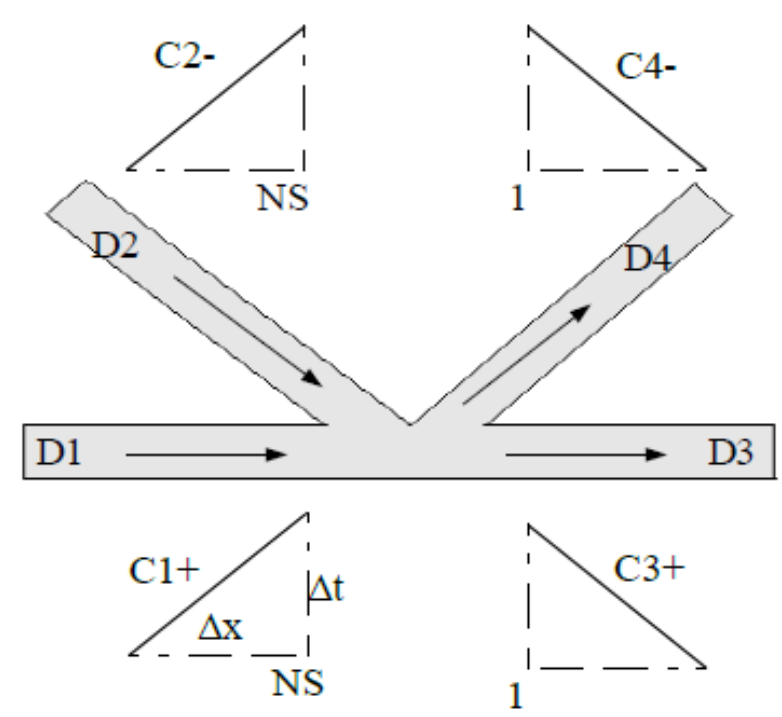

Figura 4.4: Ramificação de tubulações

Para junções entre duas ou mais tubulações em paralelo, assume-se uma altura piezométrica comum quando efeitos secundários puderem ser desprezados. Considere o esquema de tubulações ramificadas da Figura 4.4, nesse caso, a equação 4.26 será escrita para os tubos $D_{1}$ e $D_{2}$ e a equação 4.27 será escrita para os tubos $D_{4}$ e $D_{5}$. Admitindo uma altura piezométrica comum na interface dos quatro tubos, ou seja, $H_{P}=H_{P 1}(N S)=H_{P 2}(N S)=H_{P 3}(1)=H_{P 4}(1)$ é possível obter-se os valores das vazões $Q_{P 1}$ e $Q_{P 2}$, a partir da equação 4.26 , logo:

$$
Q_{P 1}(N S)=\frac{-H_{P}+C_{P 1}}{B_{1}} \quad, \quad Q_{P 2}(N S)=\frac{-H_{P}+C_{P 2}}{B_{2}}
$$

A partir da equação 4.27 , obtém-se os valores de $Q_{P 3}$ e $Q_{P 4}$

$$
-Q_{P 3}=\frac{-H_{P}+C_{M 3}}{B_{3}} \quad, \quad-Q_{P 4}=\frac{-H_{P}+C_{M 4}}{B_{4}}
$$

No tratamento de sistemas complexos, o incremento do tempo da computação realizada para determinação de $H$ e $Q$ deverá ser o mesmo para todos os tubos. É preciso tomar um certo cuidado com a escolha $\Delta t$ e com o número segmentos $N$ que as tubulações foram divididas para aplicação do método das equações características. Assim, para cada tubo $j$, assume-se a seguinte relação entre $\Delta t$ e $N$ :

$$
\Delta t=\frac{L_{j}}{a_{j} N_{j}}
$$

Diferentes segmentos de tubulação apresentam características distintas, como área de seção 
transversal diferentes, a velocidade $a^{1}$ do pulso gerado pela pertubação do escoamento do fluido. Esse fato somado ao de que as diferentes tubulações do sistema ramificado, podem ter comprimentos diferentes, resulta em valores próprios de $\Delta t$ para cada tubo. Assim, o resultado da equação 4.32 pode não ser o mesmo para todas as tubulações do sistema. No entanto, como as velocidades do pulso no interior de cada tubo não são conhecidas com grande acurácia, pode-se preceder pequenos ajustes $a_{1}, a_{2}, \ldots, a_{n}$ de forma que possam ser encontrado valores de $N_{1}, N_{2}, \ldots, N_{n}$ mais adequados.

\subsubsection{Válvula em linha}

Se uma válvula ou um orifício estiver localizado entre dois tubos diferentes, a equação da válvula, ou orifício, deverá ser admitida como condição a ser aplicada à extremidade de cada tubo. Na Figura 4.5, o sentido do fluxo do fluido será admitido como positivo quando coincidir com o sentido da seta.

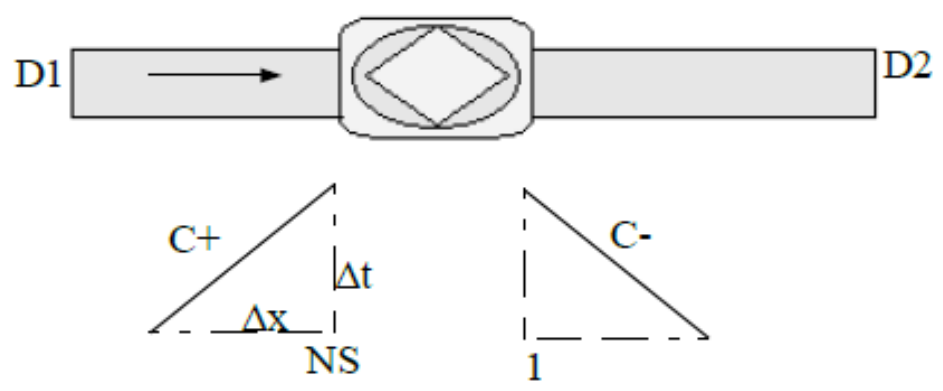

Figura 4.5: Tubulação com um orifício em linha. Sentido positivo do fluxo indicado pela seta

A equação do orifício é descrita da seguinte forma:

$$
Q_{P 2}(1)=Q_{P 1}(N S)=\frac{Q_{0} \tau}{\sqrt{H_{0}}} \sqrt{H_{P 1}(N S)-H_{P 2}(1)}
$$

onde $H_{0}$ é a queda de altura piezométrica através do orifício no caso de regime permanente, com um fluxo $Q_{0}$ e com $\tau=1$. E $\tau$ é um número adimensional que vai de zero a um, sendo $\tau=1$ quando a válvula estiver totalmente aberta.

Combinando as equações 4.26 , para o tubo $D 1$, e 4.27 , para o tubo $D_{2}$ chega-se ao seguinte valor da vazão da tubulação 1 no ponto $N S$ :

$$
Q_{P 1}(N S)=-C_{v}\left(B_{1}+B_{2}\right)+\sqrt{C_{v}^{2}\left(B_{1}+B_{2}\right)^{2}+2 C_{V}\left(C_{P 1}-C_{M 2}\right)}
$$

onde $C_{v}=\frac{Q_{0}^{2} \tau}{2 H_{0}}$. De modo semelhante, se o fluxo se desenvolver na direção negativa

$$
Q_{P 2}(1)=Q_{P 1}(N S)=\frac{-Q_{0} t}{\sqrt{H_{0}}} \sqrt{H_{2}(1)-H_{P 1}(N S)}
$$

\footnotetext{
${ }^{1} \mathrm{~A}$ velocidade $a$ foi discutida na seção 3.1 .
} 


$$
Q_{P 1}(N S)=C_{v}\left(B_{1}+B_{2}\right)-\sqrt{C_{v}^{2}\left(B_{1}+B_{2}\right)^{2}-2 C_{V}\left(C_{P 1}-C_{M 2}\right)}
$$

\subsection{Acionamento de uma Bomba Centrífuga}

O acionamento de uma bomba levará a mudança de regime de um líquido escoando na tubulação para o regime transiente. No caso de separador ciclônico há necessidade de acionar uma bomba periodicamente para que seja mantido um nível adequado em seu interior. As condições para uma máquina de fluxo são:

$$
\frac{H}{a^{2}}=\text { constante } \quad \frac{Q}{a}=\text { constante }
$$

onde $H$ é o aumento de altura piezométrica realizado pela bomba e $\alpha$ é frequência de trabalho da bomba normalizada por sua frequência nominal. A curva da bomba será modelada pela seguinte equação:

$$
H_{P 2}(1)-H_{P 1}(N S)=\alpha^{2} H_{S}+a_{1} \alpha Q_{P 1}(N S)+a_{2} Q_{P 1}^{2}(N S)
$$

Combinando a equação 4.38 com as equações 4.26 e 4.27, chega-se a:

$$
Q_{P 1}(N S)=\frac{B_{1}+B_{2}-a_{1} \alpha}{2 a_{2}}\left(1-\sqrt{1-\frac{4 a_{2}\left(\alpha^{2} H_{S}+C_{P 1}-C_{M 2}\right)}{\left(B_{1}+B_{2}-a_{1} \alpha\right)^{2}}}\right)
$$

No caso em que a bomba está operando diretamente no reservatório de líquido, a equação acima pode ser simplificada pela eliminação da equação de compatibilidade $C^{+}$.

\subsubsection{Tubulação com bomba centrífuga na extremidade inicial e uma válvula na extremidade final}

Considere, agora, que o líquido será bombeado por uma tubulação e que em sua extremidade final há uma válvula. Tanto o acionamento da bomba quanto a abertura ou fechamento da válvula irão causar transientes no escoamento do líquido. As condições de contorno do problema devem levar em conta esses dois equipamentos de forma que as equações apresentadas até aqui, possam ser usadas para determinar o comportamento do líquido em termos de altura piezométrica $H$ e da vazão $Q$ do líquido no interior da tubulação. Esse tipo de arranjo é o que é esperado para separadores ciclônicos submersos. Nesse tipo de separador há uma bomba submersa utilizada para bombear a fase líquida já separada através de sua tubulação. No caso de não ser utilizado uma válvula na tubulação, a análise apresentada a seguir continua sendo válida já que essa caso é equivalente ao de uma tubulação com a válvula sempre aberta.

Seja, então, o sistema descrito composto por uma bomba e que gere uma elevação máxima de altura piezométrica igual a $H_{s}$. Suponha, ainda que essa bomba que esteja trabalhando para 
gerar uma altura $H_{R}$ a uma vazão $Q_{0}$. A bomba está acoplada a uma tubulação de diâmetro $D$ e comprimento $L$ e tem em sua extremidade uma válvula conforme mostrado na Figura 4.6.

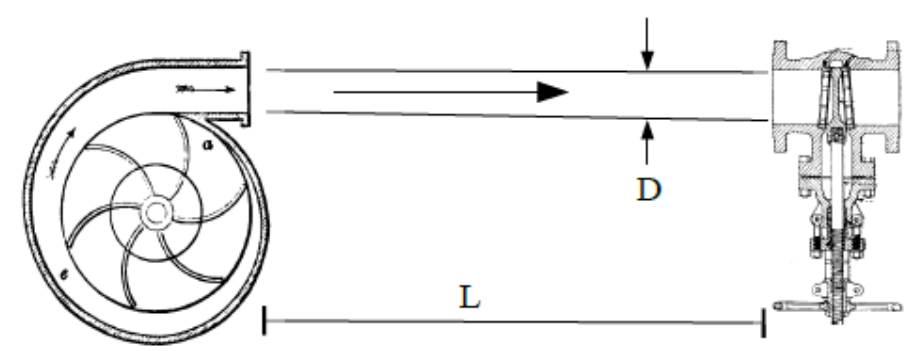

$\mathrm{HR}, \mathrm{Q} 0$

Figura 4.6: sistema formado de bomba e válvula

A tubulação é dividida em $N$ partes de comprimento $\Delta x$, de forma que o passo temporal a ser computado será $\Delta t=\Delta x / a$. Como condição de contorno na extremidade inicial, onde é acoplada a bomba, utiliza-se a equação 4.38. Observe que neste caso a bomba não está na junção de dois tubos, mas diretamente no reservatório, de forma que a equação poderá ser simplificada, logo:

$$
H_{p}(1)=\alpha^{2} H_{S}+a_{1} \alpha Q_{P}(1)+a_{2} Q_{P}^{2}(1)
$$

onde $a_{1}$ e $a_{2}$ são parâmetros a serem determinados experimentalmente ou obtidos a partir da curva característica da altura manométrica da bomba a ser adotada num caso prático. Em alguns casos, por exemplo quando a vazão for bastante significativa, a constante $a_{1}$ poderá ser desprezada. Uma forma de se encontrar o valor para $a_{2}$, neste caso, prevista pela literatura [Wylie e Streeter 1978] é:

$$
a_{2}=\frac{H_{R}-H_{S}}{Q_{0}^{2}}
$$

Como o bombeamento do líquido é realizado diretamente a partir do reservatório a equação 4.39 poderá ser reescrita da seguinte forma:

$$
Q_{P}(1)=\frac{B}{2 a_{2}}\left(1-\sqrt{1-\frac{4 a_{2}\left(\alpha^{2} H_{S}-C_{M}\right)}{B^{2}}}\right)
$$

onde $C_{M}=H(2)-B Q(2)+R Q(2)|Q(2)|$

Para as condições de contorno na extremidade final da tubulação considere a linha de base da elevação da altura piezométrico sobre a válvula. A equação da vazão em função da abertura da válvula para um escoamento em regime permanente é dada por:

$$
Q_{0}=\left(C_{d} A_{G}\right)_{0} \sqrt{2 g H_{0}}
$$

onde $Q_{0}$ é a vazão do fluido em regime permanente; $H_{0}$ é a perda de carga através da válvula 
em regime permanente; e $\left(C_{d} A_{G}\right)_{0}$ é a área da abertura total da válvula multiplicada por um coeficiente de descarga $\left(C_{d}\right)$. De forma geral, tem-se que;

$$
Q_{P}=C_{d} A_{G} \sqrt{2 g \Delta H}
$$

onde $\Delta H$ é a perda de carga instantânea sobre a válvula. Definindo-se uma quantidade adimensional de abertura da válvula tal que:

$$
\tau=\frac{C_{d} A_{G}}{\left(C_{d} A_{G}\right)_{0}}
$$

as equações 4.43 e 4.44 poderão ser combinadas da seguinte forma:

$$
Q_{P}=Q_{0} \tau \sqrt{\frac{\Delta H}{H_{0}}}
$$

Com essa equação pode-se inferir que a vazão será zero quando $\tau=0$ e máxima quando $\tau=1$. Considere agora um ponto ao longo da tubulação de escoamento do líquido correspondente a $n-1$, sendo $n$ o enésimo ponto obtido para um tubulação divida em $N$ segmentos. No ponto $n+1$ será observada um queda instantânea $\Delta H$ é dada por:

$$
\Delta H=H_{P}(n+1)
$$

Com base nesse valor da variação da altura piezométrica no ponto $n+1$ a equação da vazão na válvula pode ser reescrita, logo:

$$
Q_{P}(n+1)=Q_{0} \tau \sqrt{\frac{H_{P}(n+1)}{H_{0}}}
$$

$\mathrm{Ou}$

$$
Q_{P}^{2}(n+1)=\frac{\left(Q_{0} t\right)^{2}}{H_{0}} H_{P}(n+1)
$$

Sendo o valor $H_{P}(n+1)=C_{P}-B Q_{P}(n+1)$ dado pela equação 4.26 , chega-se à equação para determinação da vazão do líquido no ponto $n+1$ como sendo:

$$
Q_{P}^{2}(n+1)+\frac{\left(Q_{0} t\right)^{2}}{H_{0}} B Q_{P}(n+1)-\frac{\left(Q_{0} t\right)^{2}}{H_{0}} C_{P}=0
$$

A resolução desta última equação leva ao valor da vazão procurado

$$
Q_{P}(n+1)=-B C_{v}+\sqrt{\left(B C_{v}\right)^{2}+2 C_{v} C_{P}}
$$

onde defini-se $C_{v}=\frac{\left(Q_{0} \tau\right)^{2}}{H_{0}}$.

Para que o valor de $Q_{P}(n+1)$ seja determinado ainda falta obter o valor do denominador de 
$C_{v}$, ou seja, o valor de $H_{0}$. Esse valor corresponde à perda inicial de carga sobre a válvula quando o fluxo do líquido estiver em regime permanente, portanto:

$$
H_{0}=H_{R}-\frac{f L}{D} \frac{Q_{0}^{2}}{2 g A^{2}}
$$

Vale ressaltar que as condições iniciais de $H$ e $Q$, ou seja $H(1), H(2), \ldots, H(n+1)$ e $Q(1), Q(2), \ldots, Q(n+$ 1) poderão ser obtidas admitindo-se esses valores iguais ao do regime permanente no instante $t=0$.

\subsubsection{Atenuação devida a atrito elevado}

Para um escoamento não permanente em que a perda de energia devida a efeitos viscosos é significante, a aproximação de primeira ordem apresentada na seção 4.1 .1 e admitida até agora, não será suficiente para descrever o comportamento do fluido. Na discussão apresentada, considerou-se a equação integral do comportamento do líquido como sendo:

$$
\int_{H_{A}}^{H_{P}} d H+\frac{a}{g A} \int_{Q_{A}}^{Q_{P}} d Q+\frac{f}{2 g D A^{2}} \int_{x_{A}}^{x_{P}} Q|Q| d x=0
$$

e uma aproximação de primeira ordem na seguinte forma:

$$
\int_{x_{A}}^{x_{P}} Q|Q| d x=Q|Q| \Delta x
$$

Essa aproximação perderá sua validade [Wylie e Streeter 1978], por exemplo, para o escoamento de alguns óleos, para escoamento em tubulações curtas de diâmetro pequeno com fluidos de alta viscosidade ou em casos de velocidades de escoamento muito baixas. Um método sugerido pelo autor para se avaliar a acurácia da aproximação de primeira ordem, é a avaliação do passo temporal de discretização seguindo o seguinte critério guia:

$$
\frac{f \Delta t \bar{Q}}{4 D A} \leq 1
$$

onde $\bar{Q}$ é o escoamento médio.

$\mathrm{Na}$ maioria dos casos no entanto, o lado esquerdo da equação 4.55 é muito menor que a unidade. Mas nos casos em que os efeitos do atrito são significativos a acurácia da solução pode ser melhorada garantindo-se sua estabilidade pela utilização de uma aproximação de segunda ordem para integral da equação 4.53. Seja então, a seguinte aproximação:

$$
\int_{x_{A}}^{x_{P}} Q|Q| d x=\left(Q_{A}+Q_{P}\right)\left|Q_{A}+Q_{P}\right| \Delta x
$$

A utilização destas levará as equações características a assumirem a seguinte forma: 


$$
\left\{\begin{array}{l}
C^{+}: H_{P}-H_{A}-B\left(Q_{P}-Q_{A}\right)+R\left(Q_{A}+Q_{P}\right)\left|Q_{A}+Q_{P}\right|=0 \\
C^{-}: H_{P}-H_{B}-B\left(Q_{P}-Q_{B}\right)+R\left(Q_{B}+Q_{P}\right)\left|Q_{B}+Q_{P}\right|=0
\end{array}\right.
$$

Uma solução numérica poderá ser utilizada para se chegar ao valor da vazão $Q_{P}$. Para tanto, considere a função $F$ obtida a partir da subtração das equações características $C^{+}$e $C^{-}$:

$$
F=H_{B}-H_{A}-B\left(2 Q_{P}-Q_{A}-Q_{B}\right)+\frac{R}{4}\left(\left(Q_{A}+Q_{P}\right)\left|Q_{A}+Q_{P}\right|+\left(Q_{B}+Q_{P}\right)\left|Q_{B}+Q_{P}\right|\right)=0
$$

Para solução de $Q_{P}$ utiliza-se o método de Newton, começando por um valor estimado para cada passo temporal. Esse valor será sucessivamente corrigido aplicando-se uma correção iterativa até que o valor de $F$ esteja arbitrariamente próximo a zero. A correção será realizada pela seguinte relação:

$$
F+\frac{d F}{d Q_{p}} \Delta Q=0
$$

onde $\frac{d F}{d Q_{p}}=2 B+\frac{R}{2}\left(\left|Q_{A}+Q_{P}\right|+\left|Q_{B}+Q_{P}\right|\right)$

\subsection{Método das Equações Características com Interpolações}

As equações base, utilizadas para modelagem do escoamento transiente no interior de tubulações foram as equações simplificadas, mostradas abaixo, discutidas no início da seção 4.1

$$
\left\{\begin{array}{l}
L_{1}: g H_{x}+V_{t}+\frac{f}{2 D} V|V|=0 \\
L_{2}: H_{t}+\frac{a^{2}}{g} V_{x}=0
\end{array}\right.
$$

Essas formas são apropriadas para transientes em tubulações relativamente rígidas. No caso de materiais mais flexíveis faz-se necessário a utilização das equações básicas completas ou seja:

$$
\left\{\begin{array}{l}
L_{1}: g H_{x}+V V_{x}+V_{t}+\frac{f}{2 D} V|V|=0 \\
L_{2}: V H_{x}+H_{t}-V \operatorname{sen} \alpha+\frac{a^{2}}{g} V_{x}=0
\end{array}\right.
$$

O método das equações características precisa ser adequado de forma a se conseguir uma solução das equações que lide com as fortes não-linearidades associadas. De forma semelhante ao procedimento utilizado anteriormente, admita um multiplicador de valor desconhecido $\lambda$ que leve a seguinte combinação das equações $L_{1}$ e $L_{2}$

$$
L_{1}+\lambda L_{2}=0
$$

$\mathrm{Ou}$ 


$$
\lambda\left(H_{x}\left(V+\frac{g}{\lambda}\right)+H_{t}\right)+\left(V_{x}\left(V+\frac{a^{2}}{g} \lambda\right)+V_{t}\right)-\lambda V \operatorname{sen} \alpha+\frac{f}{2 D} V|V|=0
$$

Se $\frac{d x}{d t}$ puder ser escrito na forma:

$$
\frac{d x}{d t}=V+\frac{g}{\lambda}=V+\frac{a^{2}}{g} \lambda
$$

então a equação 4.63 , poderá ser escrita da seguinte maneira:

$$
\lambda \frac{d H}{d t}+\frac{d V}{d t}-\lambda V \operatorname{sen} \alpha+\frac{f}{2 D} V|V|=0
$$

Assim, o valor de $\lambda$ pode ser obtido a partir da equação 4.64, logo:

$$
\lambda= \pm \frac{g}{a} \frac{d x}{d t}=V \pm a
$$

As equações características assumirão a seguinte forma:

$$
\begin{aligned}
& \left.\begin{array}{l}
\frac{g}{a} \frac{d H}{d t}+\frac{d V}{d t}-\frac{g}{a} V \operatorname{sen} \alpha+\frac{f}{2 D} V|V|=0 \\
\frac{d x}{d t}=V+a
\end{array}\right\} C^{+} \\
& \left.\begin{array}{l}
\frac{-g}{a} \frac{d H}{d t}+\frac{d V}{d t}+\frac{g}{a} V \operatorname{sen} \alpha+\frac{f}{2 D} V|V|=0 \\
\frac{d x}{d t}=V-a
\end{array}\right\} C^{-}
\end{aligned}
$$

Como a velocidade é uma função da distância e do tempo $V=V(x, t)$, o plano $x t$ será descrito por curvas características ao invés das linhas apresentadas na seção 4.1 para $C^{+}$e $C^{-}$. Essas curvas são mostradas na Figura 4.7.

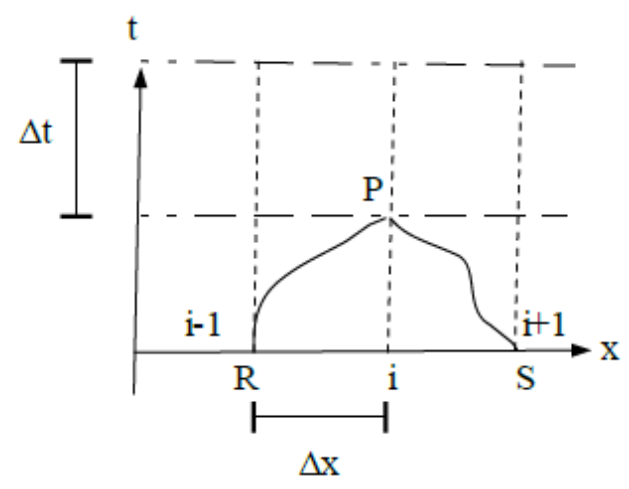

Figura 4.7: Curvas características usadas para solucionar as equações completas

Na Figura são mostrados os pontos ao longo do comprimento da tubulação separados pela distância $\Delta x$. Os pontos $R$ e $S$ estão na mesma linha horizontal o que indica que as variáveis dependentes do sistema $H$ e $Q$, serão obtidas para esses pontos no mesmo instante $t$. O ponto $P$ é um ponto intermediário entre $R$ e $S$ mas os valores das variáveis correspondentes a ele são tomadas 
para um tempo posterior $t+\Delta t$. A solução das equações características quando realizada ao longo do eixo $x$ para diferentes intervalos de tempo subsequentes, ou seja, para diferentes valores ao longo do eixo $y$, resultará no mapeamento das variáveis dependentes no plano $x t$ e o acúmulo dos dados obtidos será o próprio histórico de comportamento do escoamento do líquido no interior da tubulação.

Para determinação de $H$ e $Q$ considere, primeiramente, a multiplicação da equação da curvas característica $C^{+}$por $d t$, seguido da integração da equação entre os limites de $S$ e $R$

$$
\int_{H_{R}}^{H_{P}} \frac{g}{a} d H+\int_{Q_{R}}^{Q_{P}} \frac{d Q}{A}-\frac{g}{a} \operatorname{sen} \alpha \int_{t_{R}}^{t_{P}} Q_{R} d t+\frac{f}{2 D A^{2}} \int_{t_{R}}^{t_{P}} Q_{R}\left|Q_{R}\right| d t=0
$$

Assumindo uma aproximação de primeira ordem para os dois últimos termos integrais:

$$
H_{P}-H_{R}-\frac{a_{R}}{g A}\left(Q_{P}-Q_{R}\right)-\frac{Q_{R}}{A}\left(t_{P}-t_{R}\right) \operatorname{sen} \alpha+\frac{a_{R} f}{2 g D A^{2}} Q_{R}\left|Q_{R}\right|\left(t_{P}-t_{R}\right)=0
$$

onde $a_{R}$ na equação acima refere-se à velocidade do pulso de onda transiente causado pela perturbação do escoamento do fluido no ponto $R$. A partir do valor de $\frac{d x}{d t}$ para curva característica $C^{+}$pode-se escrever a seguinte relação entre a distância entre os pontos $P$ e $R$ :

$$
x_{P}-x_{R}=\left(V_{R}+a_{R}\right)\left(t_{P}-t_{R}\right)
$$

Aplicando os mesmos argumentos para o par da equação característica $C^{-}$:

$$
H_{P}-H_{S}-\frac{a_{S}}{g A}\left(Q_{P}-Q_{S}\right)-\frac{Q_{S}}{A}\left(t_{P}-t_{S}\right) \operatorname{sen} \alpha+\frac{a_{S} f}{2 g D A^{2}} Q_{S}\left|Q_{S}\right|\left(t_{P}-t_{S}\right)=0
$$

$$
x_{P}-x_{S}=\left(V_{S}+a_{S}\right)\left(t_{P}-t_{S}\right)
$$

onde $a_{S}$ é a velocidade do pulso de onda transiente no ponto $S$. O próximo passo será a solução numérica das equações características.

Para o presente caso, no entanto, a solução do conjunto de equações completas 4.61 não é facilmente obtido a partir da consideração dos valores de $H$ e $Q$ em dois pontos adjacentes como foi feito para o conjunto de equações simplificadas 4.60. Será necessário levar-se em conta valores intermediários de $H$ e $Q$ para a solução das equações completa, isso é feito pela interpolação do valores em dois pontos adjacentes da tubulação como será mostrado pelas abordagens propostas nas seções 4.4.1 e 4.4.2. A obtenção desses valores intermediários é obtida a partir as equações das distancias entre pontos adjacentes $R$ e $P$, e $P$ e $S$ conforme as equações 4.71 e 4.73 , respectivamente. Para solução numérica das curvas características duas abordagens serão apresentadas:

(a) utilização de intervalos de tempo especificados onde são atribuídos valores definidos a $x_{P}$ e $t_{P}$ 
em cada etapa de computação. Contudo, se a velocidade do pulso de onda for muito variável o método de rede característica deve ser utilizado. Velocidades muito variável ocorrerão quando a tubulação muito deformável ou para líquidos muito compressíveis.

(b) rede característica.

\subsubsection{Intervalos de tempos especificados}

Seja o plano $x t$ mostrado na Figura 4.8

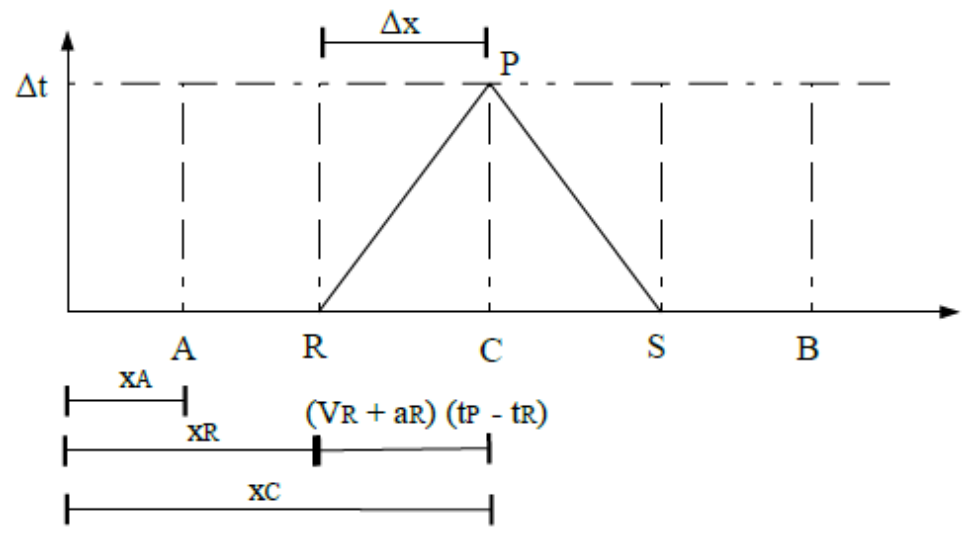

Figura 4.8: Curvas características. Intervalo de tempos especificados

Conhecendo-se as condições do escoamento nos pontos $A, B$ e $C$, uma interpolação linear pode ser usada para calcular $Q$ e $H$ nos pontos $R$ e $S$. A velocidade do fluido entre os pontos $R$ e $C$ será tomada como a velocidade do fluido adicionada da velocidade de propagação da onda transiente no ponto $R$, a qual é proporcional à diferença de vazão entre os dois pontos. A diferença entre os pontos $C$ e $R$ no interior da tubulação mostrados na Figura é, justamente, o tempo que o fluido leva para percorrer essa distância a uma velocidade $V_{R}+a_{R}$. Escrevendo essa diferença em termos da vazão, tem-se:

$$
x_{C}-x_{R}=\left(V_{R}+a_{R}\right)\left(t_{P}-t_{R}\right)=\frac{1}{A}\left(Q_{C}-Q_{R}\right)\left(t_{P}-t_{R}\right)
$$

Analogamente, em relação ao ponto $A$ tem-se para diferença $x_{C}-x_{A}$ o seguinte:

$$
x_{C}-x_{A}=\left(V_{A}+a_{A}\right)\left(t_{P}-t_{A}\right)=\frac{1}{A}\left(Q_{C}-Q_{A}\right)\left(t_{P}-t_{A}\right)
$$

Se o fluido levar o mesmo tempo para percorrer o espaço entre $A$ e $R$ que o levado para percorrer o espaço entre $R$ e $C$, então $\left(t_{P}-t_{R}\right)=\left(t_{P}-t_{A}\right)$. Logo, dividindo-se as equações 4.74 e 4.75 acima chega-se a:

$$
\frac{x_{C}-x_{R}}{x_{C}-x_{A}}=\frac{Q_{C}-Q_{R}}{Q_{C}-Q_{A}}
$$


A divisão da tubulação do líquido em segmentos conforme ilustrado pela Figura 4.8 impõe a coincidência dos pontos $C$ e $P$, e como a variação de comprimento $\Delta x$ equivale à diferença entre os pontos $x_{C}$ e $x_{A}$ pode-se reescrever a equação da seguinte forma:

$$
\frac{x_{C}-x_{R}}{\Delta x}=\frac{Q_{C}-Q_{R}}{Q_{C}-Q_{A}}
$$

A partir do valor de $x_{C}-x_{R}$, tem-se:

$$
\frac{\left(Q_{R}+A a_{R}\right)\left(t_{P}-t_{R}\right)}{A \Delta x}=\frac{Q_{C}-Q_{R}}{Q_{C}-Q_{A}}
$$

Será possível, então, obter-se o valor da vazão no ponto $R$ mostrado na Figura 4.8, observando que o incremento temporal pode ser expresso como $\Delta t=t_{P}-t_{R}$

$$
Q_{R}=\frac{Q_{C} A \Delta x-a_{R} A\left(Q_{C}-Q_{A}\right) \Delta t}{A \Delta x+\left(Q_{C}-Q_{A}\right) \Delta t}=\frac{Q_{C}-\zeta_{R}\left(Q_{C}-Q_{A}\right)}{1+\frac{\theta}{A}\left(Q_{C}-Q_{A}\right)}
$$

onde $\theta=\frac{\Delta t}{\Delta x}$ e $\zeta_{R}=\theta_{R}$.

Aplicando-se o mesmo raciocínio, chega-se a uma relação para $Q_{S}$ em termos de quantidades conhecidas, dado por:

$$
Q_{S}=\frac{Q_{C}-\zeta_{S}\left(Q_{C}-Q_{B}\right)}{1-\frac{\theta}{A}\left(Q_{C}-Q_{B}\right)}
$$

onde $\theta=\frac{\Delta t}{\Delta x}$ e $\zeta_{S}=\theta_{S}$

As alturas piezométricas nos pontos $R$ e $S$ podem ser encontradas de maneira semelhante, ou seja, admitindo-se uma interpolação. A equação da reta usada para se interpolar o valor no ponto $R$ é

$$
\frac{x_{C}-x_{R}}{x_{C}-x_{A}}=\frac{H_{C}-H_{R}}{H_{C}-H_{A}}
$$

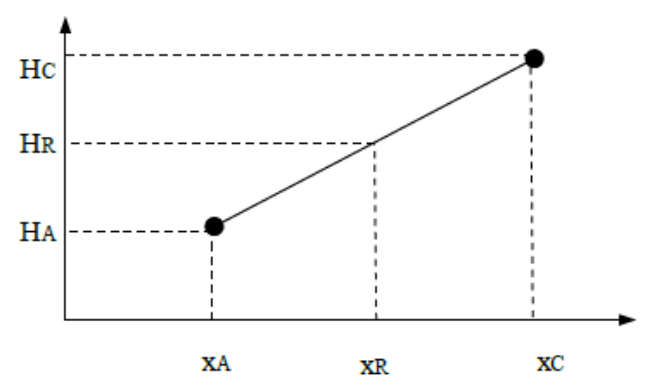

Figura 4.9: reta de interpolação utilizada para se encontrar o valor de $H_{R}$

A partir do valor da distância $x_{C}-x_{R}$ dado pela equação 4.74 , a equação de reta de interpolação 
para altura piezométrica pode ser reescrita da seguinte forma:

$$
\frac{\frac{1}{A}\left(Q_{R}+a_{R}\right) \Delta t}{\Delta x}=\frac{H_{C}-H_{R}}{H_{C}-H_{A}}
$$

de onde pode-se obter, então, o valor de $H_{R}$

$$
H_{R}=H_{C}-\left(\frac{Q_{R} \theta}{A}+\zeta_{R}\right)\left(H_{C}-H_{A}\right)
$$

Lembrando que a reta de interpolação de $H$ para o ponto $S$ tem inclinação negativa, raciocínio semelhante leva à solução de $H_{S}$

$$
H_{S}=H_{C}+\left(\frac{Q_{S} \theta}{A}-\zeta_{S}\right)\left(H_{C}-H_{B}\right)
$$

Por fim, para se encontrar os valores de $H$ e $Q$ no ponto $P$ o qual está a um passo temporal à frente, é preciso resolver seis equações, por passo temporal entende-se o intervalo de tempo $\Delta t$.

Em resumo a obtenção do valor da variável dependente $H_{P}$, será feita da seguinte maneira:

- Os valores de $H_{R}$ e $H_{S}$ são obtidos pela interpolação dos valores conhecidos $H_{A}, H_{B}, H_{C}$, e configuram funções na seguinte forma

$$
\begin{aligned}
& H_{R}=H_{R}\left(H_{C}, H_{A}\right) \\
& H_{S}=H_{S}\left(H_{C}, H_{B}\right)
\end{aligned}
$$

- Semelhantemente, os valores de $Q_{R}$ e $Q_{S}$ são obtidos pela interpolação dos valores conhecidos $Q_{A}, Q_{B}, Q_{C}$ são funções na seguinte forma:

$$
\begin{aligned}
& Q_{R}=Q_{R}\left(Q_{C}, Q_{A}\right) \\
& Q_{S}=Q_{S}\left(Q_{C}, Q_{B}\right)
\end{aligned}
$$

- Uma vez obtidos os valores de $H$ e $Q$ nos pontos $R$ e $S$, os valores de $H_{P}$ e $Q_{P}$ poderão ser calculados com auxílio das equações características $C^{+}(4.70)$ e $C^{-}(4.72)$

Seja então as equações características $C^{+}$e $C^{-}$escritas na seguinte forma:

$$
\left.\begin{array}{ll}
C+: & H_{P}(i)=C_{P}-B_{R} Q_{P}(i) \\
C-: & H_{P}(i)=C_{P}-B_{R} Q_{P}(i)
\end{array}\right\}
$$


onde

$$
\begin{aligned}
& C_{P}=H_{R}+Q_{R}\left(B_{R}+\frac{\Delta t}{A} \operatorname{sen} \alpha-\frac{f a_{R} \Delta t}{2 g D A^{2}}\left|Q_{R}\right|\right) \\
& C_{M}=H_{S}-Q_{S}\left(B_{S}-\frac{\Delta t}{A} \operatorname{sen} \alpha-\frac{f a_{S} \Delta t}{2 g D A^{2}}\left|Q_{S}\right|\right) \\
& B_{S}=\frac{a_{S}}{g A} \\
& B_{R}=\frac{a_{R}}{g A}
\end{aligned}
$$

O valor de $H_{P}$ será dado por

$$
H_{P}(i)=\frac{C_{P}+C_{M}}{2}
$$

onde $Q_{P}$ poderá ser obtido substituindo-se o valor de $H_{P}$ na equação característica $C^{+}$ou em $C^{-}$.

Uma importante limitação deve ser assegurada para utilização do método de interpolação: a condição $\Delta t(V+a) \leq \Delta x$, deve sempre ser respeitada sob o risco se de perder a estabilidade das soluções obtendo-se uma resposta erroneamente divergente.

\subsubsection{Redes Características}

Quando um fluido com uma velocidade de propagação de onda transiente variável está sendo analisado o método de interpolação pode levar a erro da solução. Esse tipo de velocidade variável ocorre em casos como quando há uma pequena quantidade de gás na tubulação ou no caso em que o líquido escoando é bastante deformável. Erros da solução também ocorrerão quando a velocidade de propagação da onda for muito baixa de forma que a velocidade da partícula fluídica seja da mesma ordem de magnitude da velocidade de propagação da onda. Nesses casos utiliza-se o método de redes características o qual apresenta os seguintes aspectos:

- evita interpolações utilizando soluções diretas para as equações $C^{+}$e $C^{-}$.

- as posições das interseções das linhas características não são fixas como nos métodos discutidos até este ponto.

- a solução numérica é feita de forma similar aos métodos anteriores.

A rede característica é esquematizada na Figura 4.10. As condições do sistema ao longo da tubulação são conhecidas para o tempo inicial e pela utilização das equações 4.70 e 4.72, assim, é possível obter-se as condições nos pontos $a, b$ e $c$. Após encontrado os valores de $H, Q, x$ e $t$ nesses pontos pode-se continuar a avançar na rede para se achar as condições do sistema nos pontos $d$ e $e$. 


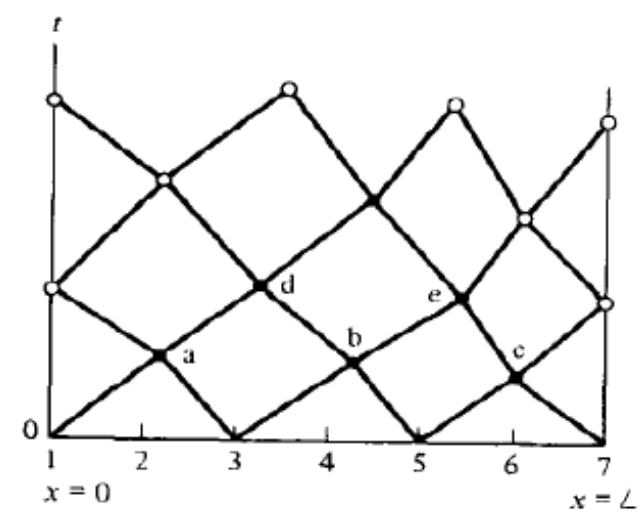

Figura 4.10: rede característica. As distancias ao longo da tubulação e os tempos de computação não são mais fixos por isso os pontos em cada camada do eixo $t$, não estão necessariamente na mesma altura

O procedimento será realizado como se segue. A solução simultânea das equações $x_{P}-x_{R}=$ $\left(V_{R}+a_{R}\right)\left(t_{P}-t_{R}\right) \quad$ e $\quad x_{P}-x_{S}=\left(V_{S}+a_{S}\right)\left(t_{P}-t_{S}\right)$ leva aos seguintes valores de $t$ e $x$ para um intervalo de tempo imediatamente posterior

$$
\begin{gathered}
t_{P}=\frac{x_{R}-x_{S}-\left(V_{R}+a_{R}\right) t_{R}+\left(V_{S}-a_{S}\right) t_{S}}{\left(V_{S}-a_{S}\right)-\left(V_{R}+a_{R}\right)} \\
x_{P}=x_{R}+\left(V_{R}+a_{R}\right)\left(t_{P}-t_{S}\right)
\end{gathered}
$$

Observe que os intervalos de tempo para cada computação dos valores ao longo do comprimento da tubulação não são necessariamente os mesmos. O intervalo de tempo $\left(t_{P}\right)$ considerado para se encontrar as variáveis dependentes $H$ e $Q$ no ponto $a$ podem não coincidir com o intervalo de tempo adotado para o ponto $c$. Da mesma forma, as distâncias entre os pontos não são necessariamente idênticas, assim a diferença entre a posição dos pontos $a$ e $b$ pode não coincidir com a diferença entre $b$ e $c$. Os pontos são mostrados na Figura 4.10.

Achados $x_{P}$ e $t_{P}$, e lembrando que os valores de $t_{R}$ e $x_{R}$ são valores conhecidos pois foram obtidos na etapa de computação anterior, pode-se determinar $H_{P}$ e $Q_{P}$ com a utilização das equações 4.70 e 4.72 escritas na seguintes formas:

$$
\begin{gathered}
Q p=\frac{1}{B_{R}+B_{S}}\left(H_{S}-H_{R}+Q_{R}\left(B_{R}-\frac{a_{R} f\left(t_{P}-t_{R}\right)}{2 g D A^{2}}\left|Q_{R}\right|\right)+Q_{S}\left(B_{S}-\frac{a_{S} f\left(t_{P}-t_{S}\right)}{2 g D A^{2}}\left|Q_{S}\right|\right)\right) \\
H_{P}=H_{S}+B_{S}\left(Q_{P}-Q_{S}+\frac{f}{2 D A} Q_{S}\left|Q_{S}\right|\left(t_{P}-t_{S}\right)\right)
\end{gathered}
$$




\subsection{Método das Equações Característica para Escoamento de Gás}

O método das equações característica é aplicado ao escoamento de gás natural utilizando-se um procedimento semelhante ao usado para o escoamento do líquido. As variáveis utilizadas nas equações que descrevem o escoamento do gás foram apresentadas e discutidas quando da elaboração dessas equações na seção 3.3. Adicionalmente, algumas considerações devem ser feitas. Como o regime permanente é um caso particular da teoria de transientes em fluidos as equações resultantes das discussões teóricas devem prever esse comportamento sendo reduzidas às equações de regime permanente quando as hipóteses para tal forem admitidas. Duas equações, obtidas na seção 3.3, devem ser resolvidas para determinar o comportamento do fluido, a equação da continuidade e a equação do movimento:

$$
L_{1}: \frac{B^{2}}{A} M_{x}+p_{t}=0
$$

$\mathrm{e}$

$$
L_{2}: p_{x}+\frac{f B^{2} M^{2}}{2 D p A^{2}}+\frac{p g}{B^{2}} \operatorname{sen} \theta+\frac{a^{2}}{A} M_{t}=0
$$

Essas equações são combinadas por um multiplicador desconhecido $\lambda$, da seguinte forma:

$$
\lambda L_{1}+L_{2}=0
$$

o que leva a:

$$
\frac{\alpha_{M}^{2}}{A}\left(\frac{\lambda B^{2}}{\alpha_{M}^{2}} M_{x}+M_{t}\right)+\lambda\left(\frac{1}{\lambda} p_{x}+p_{t}\right)+\frac{p g \operatorname{sen} \theta}{B^{2}}+\frac{f B^{2} M^{2}}{2 D A^{2} p}=0
$$

Da teoria de cálculo, se a posição $x$ for função do tempo, sabendo que $M$ é função da posição e do tempo $M=M(x, t)$, a derivada total de $M$ em relação ao tempo será:

$$
\frac{d M(x, t)}{d t}=\frac{d M}{d x} \frac{d x}{d t}+\frac{d M}{d t}=M_{x} \frac{d x}{d t}+M_{t}
$$

Comparando a equação 4.96 com o primeiro termo do lado direito da equação 4.95, obtém-se:

$$
\frac{\lambda B^{2}}{a^{2}} M_{x}+M_{t}=M_{x} \frac{d x}{d t}+M_{t}
$$

onde é possível encontrar um valor para $\frac{d x}{d t}$, dado por:

$$
\frac{\lambda B^{2}}{\alpha_{M}^{2}}=\frac{d x}{d t}
$$

Aplicando o mesmo raciocínio ao segundo termo da equação 4.95, ou seja, partindo da derivada total da pressão em relação ao tempo, com $x$ sendo também uma função do tempo, chega-se a um 
segundo valor para $\frac{d x}{d t}$

$$
\frac{d p(x, t)}{d t}=p_{x} \frac{d x}{d t}+p_{t}=\frac{1}{\lambda} p_{x}+p_{t}
$$

Dessa forma, chega-se um segundo valor da taxa de variação de $x$ com o tempo em termos de $\lambda$ :

$$
\frac{d x}{d t}=\frac{1}{\lambda}
$$

As duas equações obtidas para $\frac{d x}{d t}$ permitem chegar-se ao valor do multiplicador desconhecido

$$
\lambda= \pm \frac{\alpha_{M}}{B}
$$

desta maneira, a equação 4.95 poderá ser reescrita em termos do valor de $\lambda$ e das derivadas totais da vazão mássica $M$ e da pressão $p$ :

$$
\frac{a^{2}}{A} \frac{d M}{d t} \pm \frac{a}{B} \frac{d p}{d t}+\frac{p g \operatorname{sen} \theta}{B^{2}}+\frac{f B^{2} M^{2}}{2 D A} p=0
$$

Observe que esta equação só será válida sobre uma curva no plano $x t$ que tenha inclinação $\frac{1}{\lambda}$. Esse é o valor de $\frac{d x}{d t}$ que descreve a inclinação da linha característica ao longo da qual a equação 4.102 poderá ser aplicada. A partir do valor obtido para $\lambda$ pode-se obter as inclinações da linhas características que serão utilizadas para reolver o conjunto de equações diferenciais referentes ao gás, logo:

$$
\frac{d x}{d t}= \pm \frac{B}{\alpha_{M}}
$$

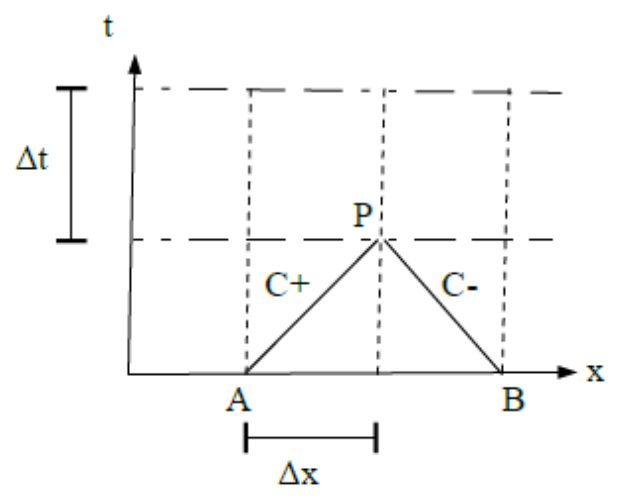

Figura 4.11: Linhas características dão a curva de validade do conjunto de equações características

Como na solução para escoamento de líquidos, há dois pares de equações para solução a serem resolvidos. As linhas característica são indicadas na Figura 4.11. $A$ e $B$ representam pontos ao 
longo do comprimento da tubulação do gás o qual é dividido em segmentos de comprimento $\delta t$. O ponto $P$ é um ponto intermediário mas a uma distância $\Delta t$ da linha que liga os ponto $A$ e $B$ no plano cartesiano $x t$ mostrado na Figura 4.11. $C^{+}$e $C^{-}$são as linhas características das equações diferenciais parciais para o escoamento do gás, e serão utilizadas na determinação da vazão mássica e da pressão do gás ao longo da tubulação e do tempo. Encontrada a equação deferencial que descreve o comportamento do gás no interior da tubulação parte-se para uma solução numérica do escoamento através da multiplicação da equação 4.102 por $d x=(B / \alpha) d t$ :

$$
\alpha_{M} \frac{B}{A} d M+d p+\left(\frac{p g \operatorname{sen} \theta}{B^{2}}+\frac{f B^{2} M^{2}}{2 D A} p\right) d x=0
$$

Integrando a equação acima entre os limites $A$ e $P$ :

$$
\frac{\alpha_{M} B}{A}\left(M_{P}-M_{A}\right)+\left(p_{P}-p_{A}\right)+\int_{A}^{P}\left(\frac{p g \operatorname{sen} \theta}{B^{2}}+\frac{f B^{2} M^{2}}{2 D A} p\right) d x=0
$$

Como o regime permanente é um caso particular do transiente descrito pela equação acima, esta deve concordar com os resultados quando foi discutido o regime permanente na seção 3.3.2. A equação encontrada para a variação de pressão em cada segmento da tubulação em regime permanente é mostrado pela equação 4.106. Os segmentos são admitidos como pontos ao longo da tubulação equidistantes por um comprimento $\delta x$, divisões que são ilustradas pela Figura 4.11

$$
\left(p_{1}-p_{2}\right)=\frac{f B^{2} M^{2} \Delta x}{D A^{2}\left(p_{1}+p_{2}\right)} \frac{\left(e^{s}-1\right)}{s}+\frac{p_{2}^{2}}{\left(p_{1}+p_{2}\right)}\left(e^{s}-1\right)
$$

Então, para que haja a requerida concordância entre a equação geral 4.105 e o regime permanente, será admitida uma solução de segunda ordem para o termo integral da equação, de forma que a vazão mássica será resolvida por um termo do tipo $M|M|$. Essa solução leva à equação característica $C^{+}$na seguinte forma:

$C+: \alpha_{M} \frac{B}{A}\left(M_{P}-M_{A}\right)+\left(p_{P}-p_{A}\right)+\frac{f B^{2} \Delta x^{2}}{2 D A}\left(p_{P}+p_{A}\right) \frac{e^{s}-1}{s} \frac{M_{P}+M_{A}}{2}\left(\frac{M_{P}+M_{A}}{2}\right)+\frac{p_{P}^{2}}{\left(p_{P}+p_{A}\right)}\left(e^{s}-1\right)=0$

Assim, a exigência de se conter o regime permanente como caso particular é respeitada, uma vez que, como pode ser facilmente observado, quando imposta a condição de escoamento permanente $M_{P}=M_{A}$, a equação 4.107 se reduz à equação 4.106. A solução de segunda ordem para o termo de atrito é obtida admitindo-se a média da taxa temporal de massa entre os pontos $A$ e $P$, conforme ilustrado pela Figura 4.12 .

$$
M^{2}=\frac{M_{P}+M_{A}}{2}\left(\frac{M_{P}+M_{A}}{2}\right)
$$




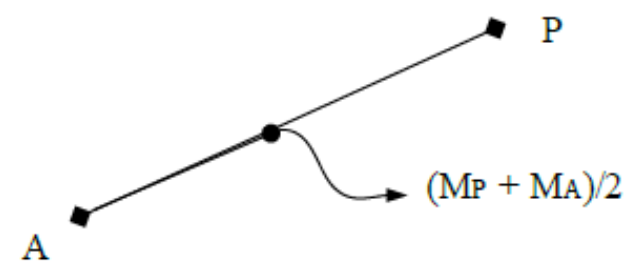

Figura 4.12: Fluxo aproximado pela média entre os pontos $A$ e $P$

Outra aproximação que pode ser usada para o atrito de escoamento, na medida que prevê o regime permanente como caso particular, é:

$$
M^{2}=\frac{M_{P}\left|M_{P}\right|+M_{A}\left|M_{A}\right|}{2}
$$

Aplicando o mesmo raciocínio, chega-se à equação característica $C^{-}$:

$C^{-}: \frac{\alpha B}{A}\left(M_{P}-M_{B}\right)-\left(p_{P}-p_{B}\right)+\frac{f B^{2} \Delta x^{2}}{2 D A}\left(p_{P}+p_{B}\right) \frac{e^{s}-1}{s} \frac{M_{P}+M_{B}}{2}\left|\frac{M_{P}+M_{B}}{2}\right|+\frac{p_{P}^{2}}{\left(p_{P}+p_{B}\right)}\left(e^{s}-1\right)=0$

\subsubsection{Multiplicador Inercial}

O multiplicador inercial $\alpha_{M}$ é calculado a partir da metodologia desenvolvida por [Yow 1972] o qual define um erro adimensional que utiliza as seguintes variáveis adimensionais:

$$
m=\frac{V_{0}}{B}, \quad \sigma=\frac{f L}{2 D}, \quad p_{d}=\sqrt{1-2 \sigma m^{2}}, \quad \omega_{0}=\frac{\omega L}{B}, \quad \Delta q=\frac{\Delta M}{M_{0}}, \quad h=\frac{\Delta x}{L}
$$

$V_{0}$ é a componente de velocidade estacionária na extremidade inicial, $\Delta M$ é a meia amplitude de flutuação, $L$ é o comprimento da tubulação, $D$ o diâmetro da tubulação, $\omega$ é a frequência circular da oscilação do escoamento. $\mathrm{O}$ valor de $\Delta x$ é obtido pela razão entre o comprimento $L$ e o número de elementos que a tubulação é dividida.

$$
\Delta x=\frac{L}{N}
$$

O multiplicador Inercial $\alpha_{M}$ é calculado, tomando-se as variáveis adimensionais, da seguinte maneira:

$$
a^{2}=1-\frac{(\sigma m h)^{2}}{3 p_{d}}+\psi \frac{\sqrt{p_{d}\left(1+\sigma m \omega_{0}\right)^{2}}}{m \omega_{0} \Delta q}
$$

$\psi$ na equação acima, é uma quantidade adimensional pequena, geralmente variando entre $0.01 \mathrm{e}$ 0.05, valores que serão utilizados na parte dos resultados apresentados no casos estudados nesse 
trabalho. Um estudo mais detalhado pode levar a valores mais acurados de $\psi$, uma forma de se realizar esse tipo de estudo é o estabelecimento da relação entra $\alpha$ e $\psi$, pela determinação das outras variáveis, assim, poder-se-á comparar o ajuste das curvas de pressão e vazão dadas pela solução do conjunto de equações dos gases, com resultados experimentais.

Para o escoamento em regime transiente a frequência de oscilação circular é aproximada pela seguinte expressão:

$$
\omega \approx \frac{\pi}{2} \frac{d p / d t}{\Delta p} \Delta q=\frac{A}{B} \frac{\Delta p}{M_{0}}
$$

onde $\Delta p$ é a variação de pressão no contorno. Assim, se a taxa de variação temporal da massa for uma função do tempo no contorno, tem-se:

$$
\omega \approx \frac{\pi}{2} \frac{d M / d t}{\Delta M} \Delta q=\frac{A}{B} \frac{\Delta M}{M_{0}}
$$

O multiplicador inercial irá mudar durante o escoamento transiente, dessa forma pode-se impor zonas temporais de maneira a ajustar o incremento do tempo antecipadamente. Se para cada comprimento o multiplicador inercial for dado por:

$$
\alpha_{M i}=\frac{B \Delta t}{\Delta x_{i}}
$$

onde não serão necessárias interpolações. 


\section{Capítulo 5}

\section{Modelo do Separador Centrífugo Submerso}

O modelo a ser utilizado para determinação da variável controlada (o nível no interior de recipiente de separação) é discutido na seção 5.1. Nas seções 5.2, 5.3 e 5.4 é realizado um discussão sobre o comportamento da forma geral da equação que descreve o sistema enquanto a seção 5.5 classifica o sistema não linear. Na seção 5.6.1 é apresentado um caso representativo em que os resultados são obtidos pela implementação dos métodos de solução apresentados.

\subsection{Interior do Separador Centrífugo}

Para se chegar a um modelo que descreve o nível do líquido no interior do separador algumas simplificações deverão ser admitidas. Não espera-se que a geometria interna do separador interfira no deslocamento do líquido separado a ponto de se fazer necessário admitir um modelo dinâmico que considere a posição do nível do líquido como função de possíveis barreiras internas impostas pela geometria. Assim, o segmento de interesse do separador, onde espera-se que haja variação do nível do líquido separado, será tratado um cilindro simples, sem obstáculos internos. Apesar da possibilidade da separação do fluido bifásico não estar totalmente completa ao final do terceiro estágio de separação ${ }^{1}$, as fases serão consideradas como totalmente separadas, logo, não haverá bolhas de gás na fase líquida. Com isso espera-se obter um modelo simplificado mas, robusto e completo o suficiente para se tenha uma boa perspectiva do comportamento do nível do líquido e se possa controlá-lo convenientemente.

Do comportamento do líquido no interior do recipiente de separação serão obtidos valores de contorno para o escoamento do líquido e do gás nas respectivas tubulações. Esses valores possibilitarão a solução do escoamento nas respectivas tubulações, o que se faz necessário já que eles influenciam a própria dinâmica da variação do nível do líquido no separador. Assim, deve-se chegar a um modelo único que descreva o nível a partir dos escoamentos do gás e do líquido. A principal vantagem esperada por esse tipo de abordagem é a previsão de efeitos transientes no

\footnotetext{
${ }^{1}$ Os estágios de separação do separador ciclônico (VASPS) foram discutidos no Capítulo 1 - Introdução.
} 
escoamento o que possibilitará o desenvolvimento de um controlador capaz de lidar com esses efeitos, mantendo o nível do líquido dentro dos limites de valores especificados para cada caso prático.

O principal interesse deste Capítulo é chegar-se a um modelo matemático capaz de descrever o comportamento do nível de líquido no interior do separador centrífugo submerso. Vários fatores têm efeito direto sobre essa variável, como a velocidade de bombeamento, o tempo de bombeamento, a pressão tanto do líquido quanto do gás no interior do recipiente. Desses fatores depende também o comportamento dos fluidos no interior da tubulação responsável por escoá-los até à plataforma. Num sistema interligado é de se esperar, como de fato acontece, que a ação inversa também aconteça, ou seja, que a pressão e vazão na tubulação interfira no fluido dentro do recipiente de forma a alterar o nível do líquido.

Considerando líquido como fluido incompressível, seu nível no interior do separador pode ser descrito por uma equação diferencial de primeira ordem da seguinte forma:

$$
\frac{d l}{d t}=\frac{1}{A}\left(q_{\text {in }}-q_{\text {out }}\right)
$$

ou em termos de vazão mássica:

$$
\frac{d l}{d t}=\frac{1}{A \rho}\left(M_{\text {in }}-M_{\text {out }}\right)
$$

onde $l$ é o nível de líquido no interior do separador; $A$ é área da seção transversal do separador; $\rho$ é a densidade do líquido; $M_{i n}$ é a vazão de massa $\left(\frac{d m}{d t}\right)$ de líquido que entra no separador; $M_{o} u t$ é a vazão de massa que sai do separador.

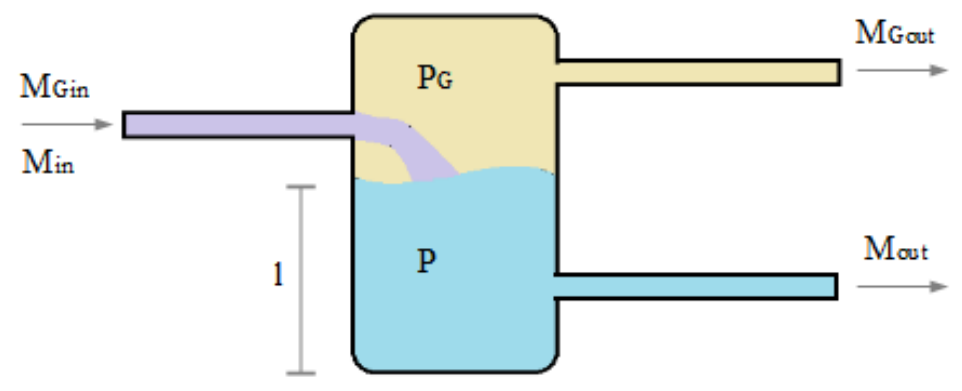

Figura 5.1: Separador centrífugo. $M_{G}$ é a taxa de massa de gás, $P_{G}$ é a pressão do gás no interior do recipiente. $M$ é a taxa de massa de líquido, $P$ é a pressão do líquido no interior do recipiente. Os sobrescritos in e out referem-se a entrada e saída, respectivamente

A solução proposta no Capítulo 4 para as equações que determinam o escoamento do líquido em sua tubulação pertinente admite a separação da tubulação em $N$ segmentos para os quais serão computados valores de pressão e velocidade do fluido (ou altura piezométrica e vazão). O conjunto de equações que modelam o escoamento na tubulação foi apresentada na seção 3.1 com a seguinte forma: 


$$
L_{1}: g H_{x}+V V_{x}+V_{t}+\frac{f}{2 D} V|V|=0
$$

e

$$
L_{2}: V H_{x}+H_{t}-V \operatorname{sen} \alpha+\frac{a^{2}}{g} V_{x}=0
$$

Conforme discutido na ocasião, para solução dessas equações é necessário estabelecer condições de contorno tanto na base, que no caso do separador centrífugo está ligada ao recipiente, quanto da extremidade oposta, a qual pode conter uma válvula, ou despejar o fluido diretamente para atmosfera. Para que o líquido consiga chegar à plataforma faz-se necessário, ainda, um sistema de bombeamento o qual deverá ser considerado no estabelecimento das condições de contorno da base da tubulação. No caso de uma bomba centrífuga, essas condições foram descritas na seção 4.3 da seguinte forma ${ }^{2}$ :

$$
H_{P 2}(1)-H_{P 1}(N S)=\gamma^{2} H_{S}+a_{1} \gamma Q_{P 1}(N S)+a_{2} Q_{P 1}^{2}(N S)
$$

com a vazão calculada por:

$$
Q_{P 1}(N S)=\frac{B_{1}+B_{2}-a_{1} \gamma}{2 a_{2}}\left(1-\sqrt{1-\frac{4 a_{2}\left(\gamma^{2} H_{S}+C_{P 1}-C_{M 2}\right)}{\left(B_{1}+B_{2}-a_{1} \gamma\right)^{2}}}\right)
$$

Conforme mostra a Figura 5.2, o ponto $N S$ refere-se ao interior do separador, portanto, as variáveis referenciadas nas equações acima para esse ponto dão os valores de pressão e vazão no interior do recipiente enquanto o ponto 1 , refere-se ao primeiro ponto a ser computado dentro da tubulação de escoamento do líquido.

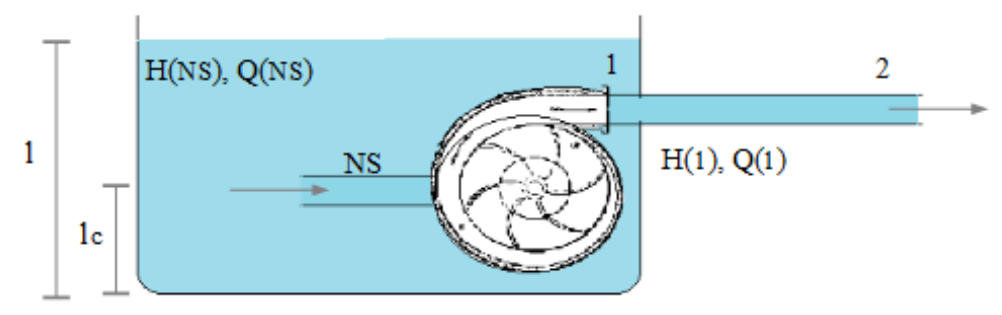

Figura 5.2: Condições de contorno no interior do separador centrífugo e na tubulação de líquido

A vazão de saída expressa na equação 5.1 entra no calculo da vazão de saída de líquido do separador dado pela equação 5.6 como sendo a vazão no ponto $N S$ de forma que a pressão do líquido no separador poderá ser computada como pressão (ou altura piezométrica $H(N S)$ ) no ponto $N S$. Um complicador do equacionamento do nível do líquido vêm do fato de a pressão

\footnotetext{
${ }^{2}$ Quando apresentado na seção 4.3, foi adotado, para efeito de clareza das explanações, uma notação da seguinte maneira: os subscritos 1 e 2 fazem referência às tubulações conectadas entre si. Neste caso, o subscrito 1 referencia o interior do separador enquanto o subscrito 2 faz referência à tubulação de saída do líquido. Os índices entre parênteses indicam a posição discreta ao longo co comprimento da tubulação.
} 
total do líquido a ser bombeado ser uma função da pressão do gás que disputa espaço com ele no interior do separador centrífugo. A pressão do líquido no ponto em que é captado pela bomba será o somatório da pressão exercida pela coluna de líquido nesse ponto com a pressão exercida pelo gás acima dela [Shiguemoto et al. 2011], logo:

$$
p=p_{G}+\rho g\left(l-l_{c}\right)
$$

onde a pressão $p_{G}$ é obtida pela seguinte relação

$$
p_{G}=\frac{z m_{G} R T}{M_{M} V_{G}}
$$

onde $z$ é a compressibilidade do gás; $m_{G}$ a massa; $R$ constante dos gases ideais; $T$ é a temperatura do gás; $M_{M}$ é a massa molar do gás; $V_{G}$ o volume ocupado pelo gás no interior do recipiente de separação. $\mathrm{O}$ volume do gás pode ser obtido subtraindo-se o volume ocupado pelo líquido do volume total do recipiente $V_{G}=V-V_{L}$.

Assim como no caso do líquido, a solução do escoamento na tubulação de gás deve levar em conta as condições de contorno do sistema. O valor da pressão e da vazão do gás na base da tubulação, ou na junção entre a tubulação e o separador centrífugo, darão os valores de contorno das equações que determinam o comportamento do gás ao longo de sua tubulação de escoamento. As equações que modelam o escoamento do gás, discutidas na seção 3.3, são as seguintes:

$$
L_{1}: \frac{B^{2}}{A} M_{x}+p_{t}=0
$$

$\mathrm{e}$

$$
L_{2}: p_{x}+\frac{f B^{2} M^{2}}{2 D p A^{2}}+\frac{p g}{B^{2}} \operatorname{sen} \alpha+\frac{\alpha_{M}^{2}}{A} M_{t}=0
$$

O multiplicador inercial $\alpha_{M}$ foi apresentado na seção 3.3.1.3. A solução para essas equações pelo método das equações características foi proposta na seção 4.5 e onde foi obtida uma equação válida para uma curva específica $\frac{d x}{d t}$, conforme as equações abaixo:

$$
\frac{\alpha_{M}^{2}}{A} \frac{d M}{d t} \pm \frac{a}{B} \frac{d p}{d t}+\frac{p g \operatorname{sen} \alpha}{B^{2}}+\frac{f B^{2} M^{2}}{2 D A^{2} p}=0
$$

onde, $\frac{d x}{d t}= \pm \frac{B}{a}$.

Como no caso dos líquidos, a solução pelo método das equações características fornece os valores da pressão do gás e de sua vazão ao longo do comprimento da tubulação a cada instante de tempo. Assim, sabendo os valores no tempo inicial, $t=t_{0}$, é possível calcular-se os demais. 


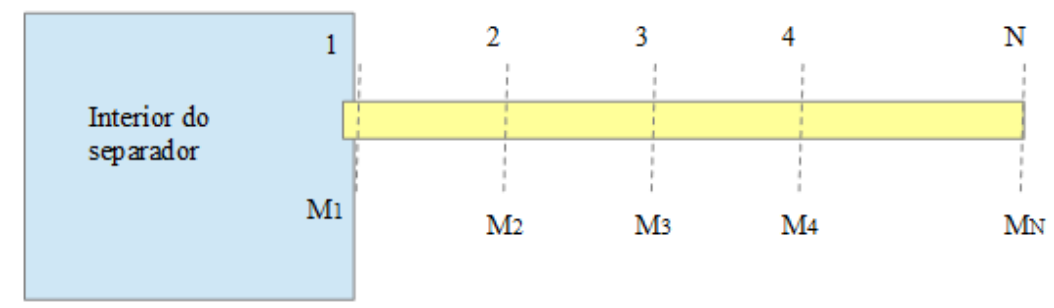

Figura 5.3: O ponto 1, na base da tubulação de gás coincide com o interior do separador, logo os valores de pressão e vazão do gás são os mesmos neste ponto.

Para solução da equação 5.8 ainda falta uma relação para a quantidade de gás no interior do separador. Essa relação é dada pela equação abaixo:

$$
\frac{d m_{G}}{d t}=M_{G i n}-M_{G o u t}
$$

Observe que todas as equações sugeridas até o momento são referentes a fatores que influenciam a quantidade de líquido que sai do separador $q_{o u t}$ na equação 5.1. Não foi discutido até aqui, a taxa de líquido que entra no separador. De fato muitas conclusões podem ser retiradas considerandose $q_{\text {in }}$ como um sinal de entrada e variando-o de maneira a assumir a forma de sinais clássicos normalmente usados em sistemas de controle. Vale chamar a atenção, no entanto, para o fato de o fluxo de entrada em separadores submersos estar sujeito a tipos de escoamento comumente observados na produção de petróleo como o escoamento em golfadas. O fenômeno de golfadas caracteriza-se por um fluxo severo e irregular com oscilações de pressão e vazão [Conte 2014], esse fenômeno influencia o comportamento do sistema e deverá ser abordado no momento da verificação da capacidade de atuação do controlador a ser proposto.

Também não foi considerado em nenhum momento do desenvolvimento do modelo teórico o escoamento multifásico próprio desse tipo de sistema. Tanto o nível do líquido no interior do separador quanto os valores de pressão e vazão nele e nas tubulações de líquido e gás podem ser afetados se houver uma quantidade de gás escoando com o líquido ou do líquido escoando na parte do sistema destinado ao escoamento de gás. Para fins do presente trabalho, esses fenômenos serão considerados insignificantes admitindo-se que todo gás tenha sido retirado do líquido pelas etapas de separação. Espera-se que essa simplificação não inviabilize o modelo teórico adotado deixando para trabalhos futuros a inclusão de possíveis efeitos significativos através de adaptações do modelo.

\subsubsection{Explicitando o modelo em termos do nível}

Da relação entre a altura piezométrica no ponto $N S$ (ver Figura 5.2) no interior do recipiente identificado pelo índice $1\left(H_{P 1}(N S)\right)$ e a pressão do líquido neste ponto, pode-se explicitar a altura piezométrica em função da pressão: 


$$
H_{P 1}(N S)=\frac{p}{\rho g}
$$

onde $p$ é a pressão do líquido na altura da bomba, logo, a partir da equação 5.5 tem-se:

$$
H_{P 2}(1)=\frac{p}{\rho g}+\gamma^{2} H_{s}+a_{1} \gamma Q_{P 1}(N S)+a_{2} Q_{P 1}^{2}(N S)
$$

A pressão do líquido na altura da bomba é calculada pela equação 5.7 sendo uma função da pressão do gás, $p_{G}$, sobre a coluna de líquido no interior do recipiente e da altura ou nível $l$ do líquido de forma que, substituindo-se esse valor na equação 5.14:

$$
H_{P 2}(1)=\frac{p_{G}}{\rho g}+l-l_{c}+\gamma^{2} H_{s}+a_{1} \gamma Q_{P 1}(N S)+a_{2} Q_{P 1}^{2}(N S)
$$

A vazão de líquido que entra na bomba é a mesma que sai, logo, a vazão medida no ponto $N S$, no interior do recipiente, deverá ser a mesma medida no ponto 1 (ver Figura 5.3), início da tubulação de escoamento do líquido ou seja:

$$
Q_{P 2}(1)=Q_{P 1}(N S)
$$

Essa vazão é calculada pela equação 5.6. No entanto, algumas observações devem ser levadas em conta. O termo $C_{P 1}$ dessa equação foi discutido na apresentação do método das equações características para solução do transiente nas tubulações, $C_{P 1}$ contém dois termos $B$ e $R$, que estão relacionados ao transiente gerado pela obstrução parcial ou total do fluxo no interior da tubulação. No entanto, os efeitos de transientes no interior do separador centrífugo são insignificantes dado suas dimensões, $\log C_{P 1}$ dado por:

$$
C_{P 1}=H+B Q-R Q|Q|
$$

pode ser reduzido para:

$$
C_{P 1}=H_{1}(N S)
$$

Para determinação da vazão ainda faz-se necessário a determinação do valor de $C_{M 2}$, termo que aparece na equação 5.6. Assim como $C_{P 1}$, esse termo foi discutido no Capítulo 4 e deriva da aplicação do método de equações características para solução das equações de transientes em fluidos. No caso de $C_{M 2}$, como indicado pelo índice 2 (ver Figura 5.3), está sendo computado um valor no interior da tubulação de líquido, esse valor está sujeito à fenômenos de transientes que podem ser gerados, por exemplo, pelo acionamento da bomba. Neste caso devem ser levados em consideração os valores de $B$ e $R$ que computam esses efeitos. Lembrando que a equação de $C_{M 2}$, deriva de uma abordagem numérica para solução de transientes no interior da tubulação. Pode-se verificar que a vazão $Q_{P 2}$ (com a tubulação identificada pelo índice 2 e o tempo posterior indicado 
pelo índice p) no início da tubulação, ponto 1 , depende do valor da vazão e altura piezométrica num ponto adjacente, ponto 2 , que foram computados para um tempo imediatamente anterior, logo:

$$
C_{M 2}=H(2)+B Q(2)-R Q(2)|Q(2)|
$$

Como os valores de $H$ e $Q$ no ponto 2 no interior da tubulação também dependem dos valores de $H$ e de $Q$ em pontos adjacentes num tempo de computação imediatamente anterior com o tempo, o valor de $C_{M 2}$ será uma função do tempo dependente do histórico de escoamento (vazão e pressão) do fluido. Assim, a partir dos valores de $C_{P 1}$ e $C_{M 2}$ a equação 5.6 pode ser escrita da seguinte maneira:

$$
Q_{P 1}(N S)=\frac{B_{2}-a_{1} \gamma}{2 a_{2}}\left(1-\sqrt{1-\frac{4 a_{2}\left(\gamma^{2} H_{S}+H_{1}(N S)-C_{M 2}\right)}{\left(B_{2}-a_{1} \gamma\right)^{2}}}\right)
$$

Se o intervalo de tempo for suficientemente pequeno pode-se considerar $H_{1}(N S) \approx H_{P 1}(N S)$ de forma que a equação da vazão no ponto $N S$ torna-se:

$$
Q_{P 1}(N S)=\frac{B_{2}-a_{1} \gamma}{2 a_{2}}\left(1-\sqrt{1-\frac{4 a_{2}\left(\gamma^{2} H_{S}+\frac{p_{G}}{\rho g}+l-l_{c}-C_{M 2}\right)}{\left(B_{2}-\gamma_{1} a\right)^{2}}}\right)
$$

Como a vazão no ponto $N S$ é igual a vazão de líquido que sai do separador centrífugo, pode-se escrever o modelo do sistema que descreve o nível de líquido no interior do recipiente explicitamente:

$$
\frac{d l}{d t}=\frac{q_{i n}}{A}-\frac{B_{2}-a_{1} \gamma}{2 a_{2} A}\left(1-\sqrt{1-\frac{4 a_{2}\left(\gamma^{2} H_{S}+\frac{p_{G}}{\rho g}+l-l_{c}-C_{M 2}\right)}{\left(B_{2}-a_{1} \gamma\right)^{2}}}\right)
$$

\subsection{Comportamento do sistema do nível no interior do separador centrífugo}

Como já mencionado, a altura do nível de fluido no interior do separador é modelada por uma equação diferencial simples que relaciona a vazão de entrada com a vazão de saída no recipiente. A vazão de entrada no sistema será determinada pela a quantidade de fluido fornecida pelo poço de extração e que é lançado no separador ou de vários poços caso de a produção ser concentrada num mainfold e depois direcionada ao equipamento. O escoamento do fluido na entrada do separador muitas vezes se dá em regime de golfadas, fenômeno caracterizado por um fluxo severo e irregular com oscilações de pressão e vazão [Conte 2014]. Para se obter um panorama do comportamento do sistema, a vazão de entrada de líquido será considerada como sinal de entrada, de forma que se possa submeter o sistema a condições distintas de funcionamento. Uma boa forma de se analisar a estabilidade do sistema à submetê-lo a um sinal de entrada $\left(q_{i n}\right)$ do tipo degrau unitário, já que 
este é composto por inúmeros harmônicos. Outros sinais de entrada a serem aplicados ao sistema são sinais periódicos e sinais simuladores de golfadas.

O sistema do nível do líquido no interior do separador foi equacionado como um sistema nãolinear de primeira ordem conforme a equação 5.1. A considerações a cerca do escoamento das fases separadas em suas respectivas tubulações de gás e líquido, levaram à descrição do sistema na forma da equação 5.22, que será rearranjada como abaixo:

$$
\frac{d l}{d t}=\frac{q_{i n}}{A}-\frac{B_{2}-a_{1} \gamma}{2 a_{2} A}+\frac{1}{2 a_{2} A} \sqrt{\left(B_{2}-a_{1} \gamma\right)^{2}-4 a_{2}\left(\gamma^{2} H_{S}+\frac{p_{G}}{\rho g}-C_{M 2}\right)-4 a_{2}\left(l-l_{c}\right)}
$$

Para fins de simplificação de notação são introduzidas $q, \beta^{2}$ e $\Gamma^{2}$ de maneira que a equação 5.23 possa ser escrita da seguinte forma:

$$
\frac{d l}{d t}=q(t) \pm \sqrt{\beta^{2}-\Gamma^{2}\left(l-l_{c}\right)}
$$

onde

$$
\begin{gathered}
q(t)=\frac{q_{\text {in }}}{A}-\frac{B_{2}-a_{1} \gamma}{2 a_{2} A} \\
\beta^{2}=\frac{\left(B_{2}-a_{1} \gamma\right)^{2}}{4 a_{2}^{2} A^{2}}-\frac{\gamma^{2} H_{S}+\frac{p_{G}}{\rho g}-C_{M 2}}{a_{2} A^{2}} \\
\Gamma^{2}=\frac{1}{a_{2} A^{2}}
\end{gathered}
$$

O sinal que acompanha a raiz quadrada da equação 5.24 acompanhará o sinal de $a_{2}$. Os sinais atribuídos aos parâmetros $\beta, \Gamma$ e $q$ definirão o comportamento do sistema inclusive no que diz respeito à sua estabilidade. Portanto, a análise das possibilidades de descrição matemática da equação 5.24 será bastante útil para previsão do comportamento e o estabelecimento de limites de validade. Analisando a equação 5.23 pode-se inferir que:

1. O termo $\gamma H_{S}$ é um valor positivo já que a máxima elevação piezométrica $\left(H_{S}\right)$ alcançada bomba em condições normais de funcionamento é uma quantidade positiva e a fração $(\gamma)$ da velocidade de rotação da bomba também é um valor positivo.

2. O parâmetro $B_{2}$, advém da formulação numérica utilizada na solução da pressão e velocidade do fluido que escoa no interior das tubulação de líquido. O índice $2\left(\mathrm{em} B_{2}\right)$ é utilizado apenas para explicitar que esse termo refere-se à tubulação de escoamento do líquido, conforme ilustrado na Figura 5.2. Esse parâmetro é dado pela relação existente entre a velocidade do pulso transiente $(a)$, o valor da aceleração da gravidade $(g)$ e a área de seção transversal da tubulação $\left(A_{t u b}\right)$. O pulso transiente é gerado por uma perturbação do escoamento do 
fluido. $B$ será, então uma quantidade positiva dada pela expressão abaixo:

$$
B=\frac{a}{g A_{t u b}}
$$

3. A altura piezométrica dada pela pressão do gás acima da coluna de líquido no interior do separador centrífugo $\left(p_{G} \rho g\right)$ também é uma quantidade positiva. Ainda que sejam tomadas pressões relativas à pressão atmosférica quando da análise do sistema, não são esperadas pressões menores que esta em condições normais de funcionamento no interior do separador.

4. O parâmetro $C_{M 2}$ depende de valores de pressão e vazão no interior da tubulação de escoamento de líquido. Esse valor assumirá valor positivo ou negativo de acordo com o valor da vazão $(Q)$ e da altura piezométrica $(H)$, num dado instante, de acordo com a seguinte equação:

$$
C_{M 2}=H-B_{2} Q+R Q|Q|
$$

5. $A$ e $l_{c}$ são respectivamente a área de seção transversal do separador e a posição vertical da bomba em relação ao fundo do recipiente, portanto são valores positivos.

Restam os parâmetros $a_{1}$ e $a_{2}$ os quais descrevem a elevação da pressão da bomba em função de sua frequência de rotação e da vazão. Uma curva característica típica de uma bomba centrífuga é mostrado na Figura 5.4 [Volk 2013]. A curva da altura $H$ versus a vazão $Q$ mostrada é um parábola em $Q$ com inclinação negativa. Como o comportamento previsto para a curva é dado pela equação 5.30, com base na curva tipíca mostrada na Figura pode-se inferir que o parâmetro $a_{2}$ tem valor negativo. Para fins de simplificação da análise, a constante $a_{1}$ vinculada ao termo não quadrático da vazão será considerada como tendo um valor $a_{1} \leq 0$.

$$
\Delta H_{b o m b a}=\gamma^{2} H_{S}+a_{1} \gamma Q+a_{2} Q^{2}
$$

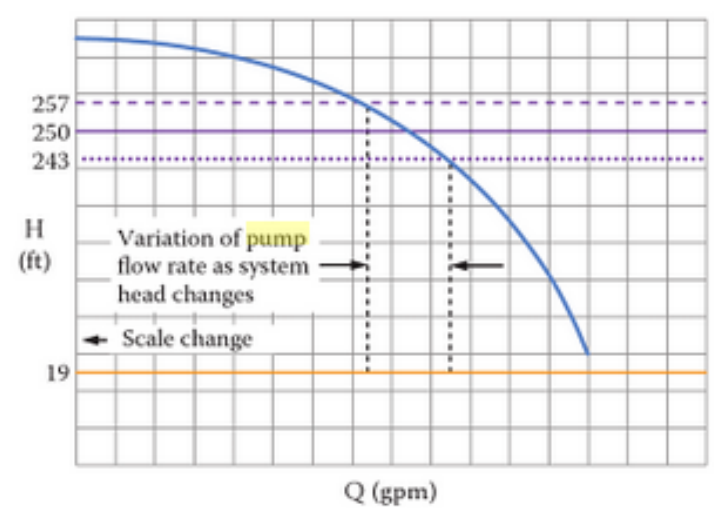

Figura 5.4: Curva característica típica (Hversus Q) de uma bomba centrífuga. Fonte: [Volk 2013]

Uma análise do sistema será realizada no seção subsequente, tomando os termos da equação 5.24 com sinais atribuídos apresentado. 


\subsubsection{Comportamento em Termos dos Parâmetros $\Gamma$ e $\beta$}

A equação 5.24 descreve o nível do líquido no interior do separador em termos das variáveis $\Gamma$ e $\beta$ definidas para a equação. O intuito da utilização desse tipo de notação é facilitar a visualização do sistema, facilitando a identificação de seus limites e comportamento característico. Considere a constante $a_{2}=-a_{b}$ um valor negativo (onde $a_{b}>0$ ), e $a_{1}=0$. O nível do líquido terá a seguinte equação:

$$
\frac{d l}{d t}=q(t)-\sqrt{\beta^{2}+\Gamma^{2}\left(l-l_{c}\right)}
$$

com as variáveis reescritas da seguinte forma:

$$
\begin{gathered}
q(t)=\frac{q_{\text {in }}}{A}+\frac{B}{2 a_{2} A} \\
\beta^{2}=\frac{B^{2}}{4 a_{b}^{2} A^{2}}+\frac{\gamma^{2} H_{S}+\frac{p_{G}}{\rho g}-C_{M 2}}{a_{b} A^{2}} \\
\Gamma^{2}=\frac{1}{a_{b} A^{2}}
\end{gathered}
$$

nas equações acima o subscrito de $B$ foi omitido para simplificar a notação.

Segundo essa equação, não haverá um limite de validade para os valores reais máximos que o nível no interior do separador poderá assumir sendo, no entanto, fixado um limite inferior para tais valores. São admitidos valores reais tais que $l>l_{c}-\frac{\beta^{2}}{\Gamma^{2}}$. Suponha uma tubulação de escoamento de líquido acoplada à base do separador, ter-se-á um nível inferior mínimo $\left(l_{m} i n\right)$ quando $l=l_{c}-\frac{\beta^{2}}{\Gamma^{2}}$. Esse nível mínimo não pode ser assumido como um limite fixo já que, como pode ser observado nas definições $\beta$ e $\Gamma$, há uma dependência de $\beta$ com a fração total da frequência de rotação da bomba $(\gamma)$ e com outros parâmetros do sistema como a pressão da gás acima da coluna de líquido e a pressão e vazão no interior da tubulação de escoamento do líquido. De modo geral, haverá uma relação de dependência do $l_{\text {min }} \operatorname{com} \gamma$ de modo a haver uma diminuição do seu valor à medida que se aumenta a velocidade de rotação da bomba, essa relação será uma reta de inclinação negativa. $\beta$, por sua vez, aumenta com o aumento da frequência de rotação da bomba $\gamma$. Essa previsão está de acordo com o comportamento físico intuitivamente esperado para o sistema já que é logico pensar que um aumento da velocidade de rotação da bomba torne o escoamento do líquido para o exterior do recipiente cada vez mais eficiente, assim, quanto mais fluido se retira do sistema menor o nível de líquido dentro do separador.

No intuito de se analisar a convergência do sistema seja, por exemplo, o comportamento do nível nas imediações de um ponto de referência $l=l_{0}$, em um intervalo suficientemente pequeno para que se admita a linearização da equação diferencial em torno desse ponto. Com base na série de Taylor:

$$
\left.f(x)\right|_{x=x_{0}}=f\left(x_{0}\right)+\frac{f^{\prime}\left(x_{0}\right)}{1 !}\left(x-x_{0}\right)+\frac{f^{\prime \prime}\left(x_{0}\right)}{2 !}\left(x-x_{0}\right)^{2}+\ldots+\frac{f^{n}\left(x_{0}\right)}{n !}\left(x-x_{0}\right)^{n}
$$


a equação 5.31 pode ser linearizada em torno da $l=l_{0}$, da seguinte maneira:

$$
i=q(t)-\sqrt{\left(\beta^{2}+\Gamma^{2} l_{0}\right)}-\frac{\Gamma^{2}}{2 \sqrt{\left(\beta^{2}+\Gamma^{2} l_{0}\right)}}\left(l-l_{0}\right)
$$

A equação homogênea acima determina a evolução temporal do nível do líquido a partir de condições iniciais especificadas e em torno de um ponto de equilíbrio determinado pelo ponto de referência $l_{0}$ essa equação é reescrita da seguinte forma:

$$
i+b l=q(t)
$$

onde $b=\frac{\Gamma^{2}}{2 \sqrt{\left(\beta^{2}+\Gamma^{2} l_{0}\right)}}$

Tem-se em mãos, uma equação diferencial linear de primeira ordem que pode ser facilmente analisada por técnicas tradicionais de engenharia de controle. Aplicando-se a transformada de laplace à equação chega-se à função de transferência abaixo

$$
\frac{L(s)}{Q(s)}=\frac{1}{s+b}
$$

Para essa função de transferência, $L(s)$ é a transformada de laplace e $l(t)$ e $Q(s)$, a transformada de $q(t)$. A convergência de um sistema está associada a existência de polos negativos [Ogata 2010], logo, para se satisfazer a exigência de que do nível no interior do separador convirja para certas condições de trabalho, sua equação correspondente deverá ser convergente para um, ou um conjunto de pontos de referência $l_{0}$, sob tais condições. Assim a convergência do sistema estará garantida quando $b$ tiver um valor real positivo. Observe que a raiz quadrada e o fato de $\Gamma$ ser um valor positivo, garantem que $b$ também será um valor positivo nesse caso.

Consideremos inicialmente o caso hipotético em que $p_{G}$ e $C_{M 2}$ são constantes ao longo do tempo. O retrato de fase do sistema, ou a relação entre a taxa de variação temporal do nível e o próprio nível, tem seu comportamento delimitado pela equação 5.31, o formato dessa equação guarda semelhanças com a equação de uma elipse a qual será utilizada como guia para análise do comportamento do sistema. Seja então a seguinte elipse:

$$
(i-q)^{2}+\Gamma^{2}\left(l-l_{c}\right)^{2}=\beta^{2}
$$

O retrato de fases do sistema atribuído à equação 5.31 bem como a elipse característica, dada pela equação 5.39 são mostrados na Figura 5.5. Observa-se na Figura, que a elipse característica do sistema tem origem no ponto $\left(l_{c}, q\right)$ plano cartesiano $i$ versus $l$. A Figura ainda assinala os tamanhos dos lados da elipse, tendo o maior, o valor dado por $\beta / \Gamma$, e o lado menor com valor dado por $\beta$. A circunferência característica descreve os traços gerais da lei que dita as possíveis velocidades $(i)$ assumidas em relação à posição do nível. A curva do retrato de fases mostrado na Figura intercepta essa elipse em, pelo menos, dois pontos. O mínimo ponto de valores reais do retrato de fases é assinalado como $X$ na Figura e corresponde a $\frac{\beta^{2}}{\Gamma^{2}}$ sendo que sua curva (em 
verde) intercepta a elipse nos pontos em que $l=l_{c}$.

Algumas características do sistema podem ser retiradas diretamente da leitura da Figura e da definição das variáveis simplificadas dadas pelas equações 5.34, 5.32 e 5.33. O valor mínimo nível de líquido no interior do separador (ponto $X$ na Figura 5.5) é uma função da velocidade de rotação, logo, da capacidade de elevação da bomba; da pressão do gás acima da coluna de líquido no interior do recipiente e dos valores de pressão e da vazão no início da tubulação de escoamento do líquido. Assim, uma elevação da velocidade de rotação da bomba ou de um desses valores implicará num aumento do valor de $\gamma$, aumentando $\beta$ e, consequente, deslocando o ponto assinalado como $X$ para esquerda. Dessa forma, quanto maior vazão de saída gerada pela bomba, mais líquido será lançado para o exterior do separador e menor será o nível mínimo que o sistema pode alcançar.

Uma maior vazão de entrada deslocará o ponto $q$ para cima, consequentemente, a elipse característica também será deslocada já que seu centro é determinado pelo ponto $q$. Observe que a curva característica é justamente denominada assim por que seu deslocamento é acompanhado pelo deslocado do retrato de fases, de forma que a relação entre as duas curvas sempre permanece como mostrado na Figura 5.5.

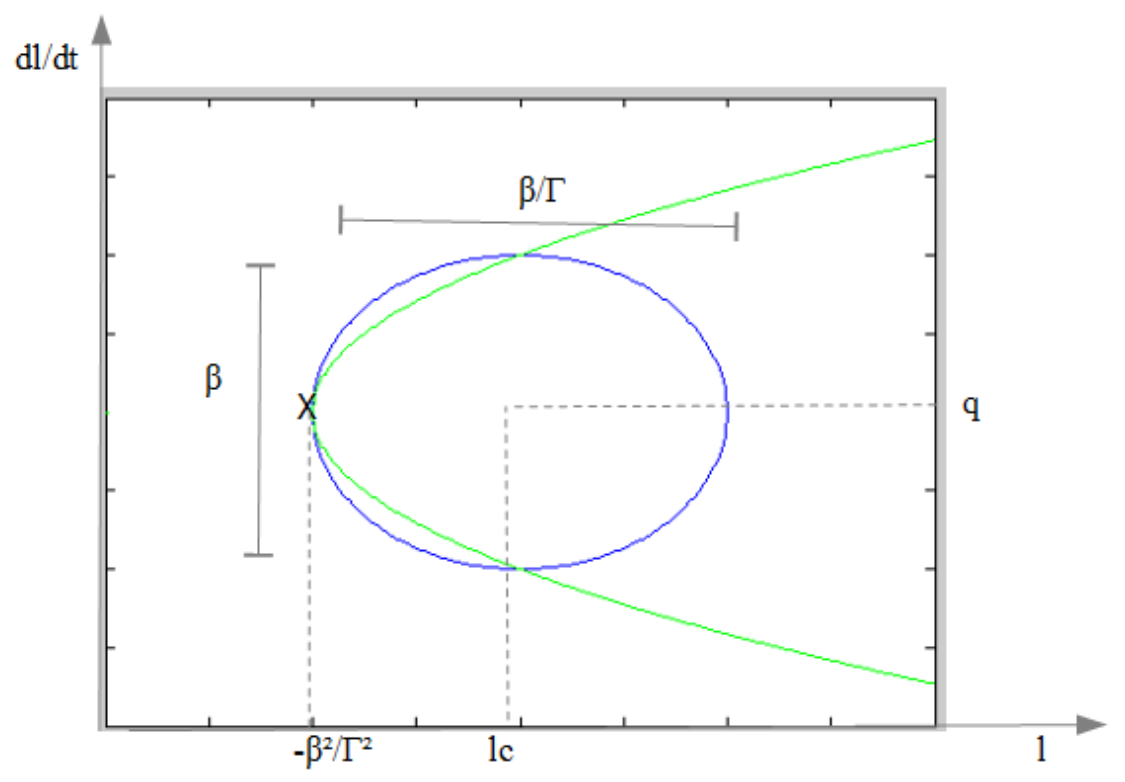

Figura 5.5: A parte real do retrato de fases do sistema intercepta a circunferência (em azul) em, pelo menos, dois pontos. A linha clara (em verde) mostra a curva de validade do retrato de fases do sistema

A pressão do gás acima do nível do líquido influencia no comportamento do sistema impondo uma diminuição do mínimo valor alcançado pelo nível $l$, com aumento do valor de $\beta$. Os resultados coincidem com o esperado intuitivamente do sistema físico já que quanto mais rápido a bomba extrai o fluido do interior do separador centrífugo, mais rápido o nível baixará. Da mesma forma, uma maior pressão sobre o líquido acaba por aumentar a velocidade de escoamento do fluido para fora do recipiente, já que a força por unidade de área exercida sobre o fluido aumentará. 
O parâmetro $C_{M 2}$ é uma medida da pressão e da vazão do fluido no interior da tubulação de escoamento do líquido num ponto que equivale ao início da tubulação, ou seja, o ponto da tubulação que está acoplado ao recipiente. Um aumento do valor desse parâmetro acarretará uma diminuição do valor de $\beta$ e um consequente deslocamento do ponto $X$ da Figura 5.5 para a direita. Para uma dada posição fixa na abcissa do plano cartesiano $i$ versus $l$, por exemplo $l_{c}$, se o retrato de fases for deslocado para esquerda, o valor de $i$ dado pela curva do retrato de fases (em verde) será maior para essa posição. Portanto, $l_{c}$ ficará mais próximo do nível mínimo permitido ao líquido, já que este foi deslocado para direita. Como $l_{c}$ é um ponto fixo no recipiente de separação, uma maior velocidade de variação do nível nesse ponto significa que o recipiente poderá encher mais.

O valor de $C_{M 2}$ aumenta com o aumento da pressão e, em geral, diminui com o aumento da vazão no ponto referente ao início da tubulação, esse resultado também concorda com o comportamento físico esperado já que uma menor vazão aliada a uma maior pressão nesse ponto indicam que uma quantidade menor do líquido que entra, consegue sair. O parâmetro é dado pela equação abaixo já discutida em Capítulos anteriores (ver Capítulo 4).

$$
C_{M 2}=H-B Q+R Q|Q|
$$

A equação polinomial de segunda ordem acima impõe um intervalo de valores de vazão $\mathrm{Q}$ para o qual $C_{M 2}$ pode assumir valores negativos. $Q$ na equação acima é a vazão do líquido no ponto equivalente ao início de tubulação de escoamento do líquido. Assim, uma vazão que aumente gradativamente a partir do zero irá inicialmente decrescer o valor de $\beta$ até um valor mínimo aumentando-o, a partir de então, sob um comportamento de uma curva polinomial de segunda ordem. Dessa forma, haverá uma vazão ótima para a qual $C_{M 2}$ será mínimo e "o trabalho da bomba será mais leve". Como Q é uma função da frequência de rotação da bomba esse ponto mínimo poderá ser alcançado com ajuste da rotação.

O parâmetro $B_{2}$ foi apresentado na seção 4.1 .2 e advém do comportamento transiente do fluido no interior da tubulação de escoamento do líquido com o aparecimento da um pulso de pressão que viaja a velocidade subsônica, gerado por uma perturbação do escoamento. $B_{2}$ é diretamente proporcional à velocidade desse pulso e pode ser visualizado como uma quantificação do resultado de uma perturbação sobre o escoamento do fluido no interior da tubulação. Um aumento do valor desse parâmetro aumenta $\beta$, desloca o ponto assinalado como X na Figura para esquerda o que pode ser visto como uma facilitação do escoamento do líquido para forma do recipiente. Por outro lado, esse mesmo aumento causa um aumento de $q$, que desloca a elipse característica para cima, assim haverá uma velocidade maior de subida do nível no interior do recipiente de separação, o que pode ser entendido como uma dificultação do escoamento do liquido para fora do recipiente. Dessa forma, tem-se um indicativo de que os efeitos de transientes gerados por perturbações no escoamento do fluido afetam a capacidade do sistema de escoar o líquido para o exterior do separador. Isso pode gerar complicações ao controle do fluxo e, consequentemente, do nível de líquido no interior do recipiente. 
A eficiência da bomba centrífuga aumenta com $a_{2}$, já que a diferença de pressão entre a saída e a entrada da bomba é proporcional ao quadrado da vazão na tubulação vezes $a_{2}$ (ver equação 5.30). Esse é um parâmetro de adequação da curva de desempenho da bomba que deve ser obtido experimentalmente e que foi discutido na seção 4.3. Um aumento de $a_{2}$ diminui $\beta$ e deslocado o ponto $X$ para direita. Esse resultado também coincide com o intuitivamente, esperado já que uma bomba mais eficiente imprimirá uma maior vazão ao sistema permitindo menores alturas mínimas do nível de líquido.

\subsection{Reposta do Sistema a Sinais de Entrada Clássicos}

Para se ter uma ideia qualitativa do comportamento, o sistema foi submetido a sinais de entrada clássicos como degrau unitário, sinal sinusoidal e sinal em forma de onda quadrada. Um sinal tipo degrau unitário, pode ser usado para representar uma vazão contínua na entrada do separador submerso enquanto um sinal sinusoidal pode ser usado para simular um vazão de entrada oscilatória. O sinal de onda quadrada será útil para simular uma vazão de entrada que se desenvolva em forma de golfadas. Nesta seção, são apresentadas as curvas de retrato de fase e da variação do nível do líquido em função do tempo para os três tipos de sinal de entrada. As respostas apresentadas foram obtidas a partir da aplicação de cada sinal ao sistema conforme descrito pela equação 5.31, por período de tempo necessário à estabilização do sinal de resposta com intuito principal de mostrar que há estabilização.

Além disso, o sistema foi submetido à variação do parâmetro $(\gamma)$ que representa a frequência de rotação da bomba, estando sujeito a uma vazão de entrada contínua (entrada em sinal degrau). Assim, é possível observar o efeito da variação da velocidade de rotação do atuador (uma bomba submersa no separador submerso) sobre o sistema.

\subsubsection{Resposta a uma entrada em sinal de degrau unitário}

A Figura 5.6 apresenta o retrato de fases que explicita o comportamento convergente. O gráfico de $d l / d t$ versus $l$, para a dada condição inicial, caminha direção do ponto de equilíbrio onde $l=0$ e $d l / d t=0$. 


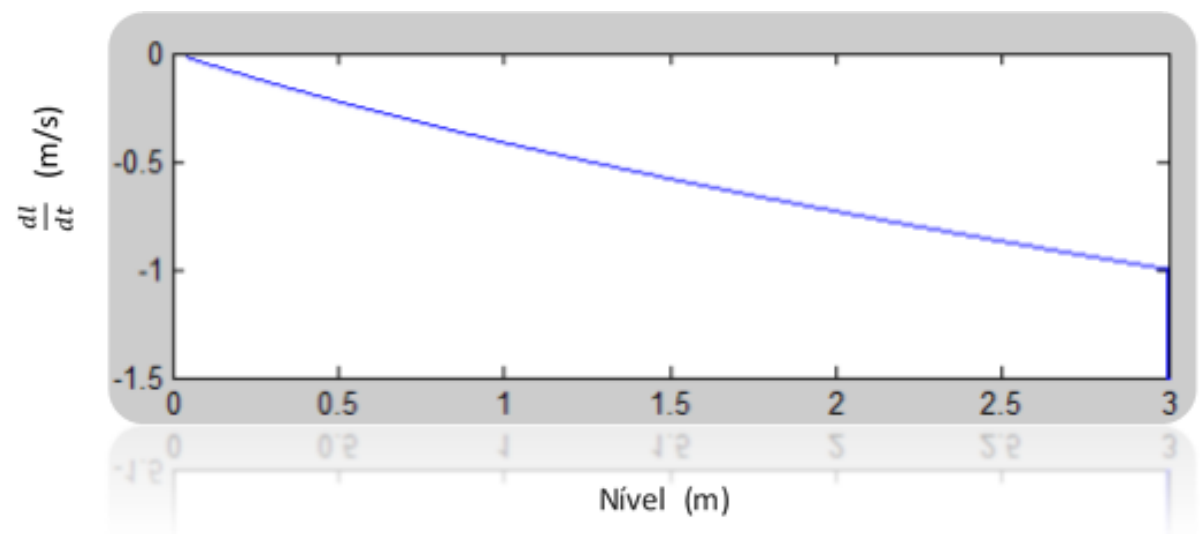

Figura 5.6: Retrato de fases para entrada em sinal unitário.

A Figura 5.7 apresenta as curvas da velocidade (verde) e do nível do líquido (azul) em relação ao tempo, para uma entrada em sinal de degrau unitário. Foram estabelecidas condições inicias tais que o nível estivesse a uma altura acima do ponto de equilíbrio. Por se tratar de um sistema descrito por uma equação diferencial de primeira ordem, a condição inicial de velocidade do nível é função da posição inicial do nível. Como mostrado na Figura a velocidade inicialmente negativa decresce em módulo até ponto em que se iguala a zero enquanto o nível reduz ao longo do tempo até chegar à posição de equilíbrio do sistema representado, nesse caso, por $l=0$.

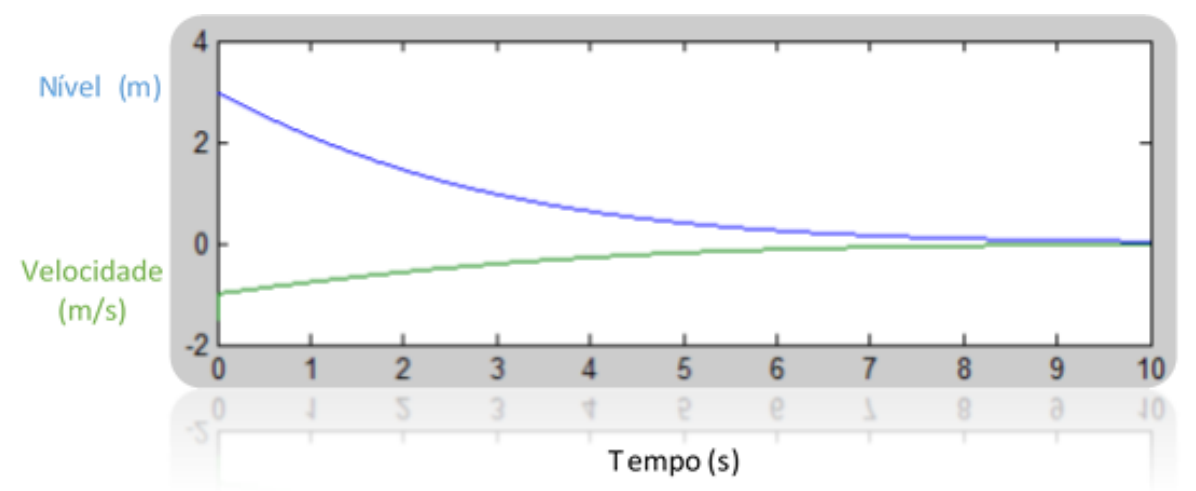

Figura 5.7: Curva do nível com o tempo (em azul) e da velocidade do nível (em verde) para uma condição inicial de nível acima da posição de equilíbrio.

\subsubsection{Resposta a uma entrada em sinal senoidal}

O comportamento do sistema se assemelha ao de um sistema linear de primeira ordem. Quando aplicado uma entrada senoidal, o nível no interior do recipiente apresenta uma variação periódica tanto na posição quanto da velocidade formando o ciclo limite característico também semelhante aos apresentados por sistemas lineares nessas condições. $O$ ciclo limite forçado pela entrada senoidal pode ser observado na Figura 5.8 enquanto o nível e a velocidade do nível, na Figura 5.9. 


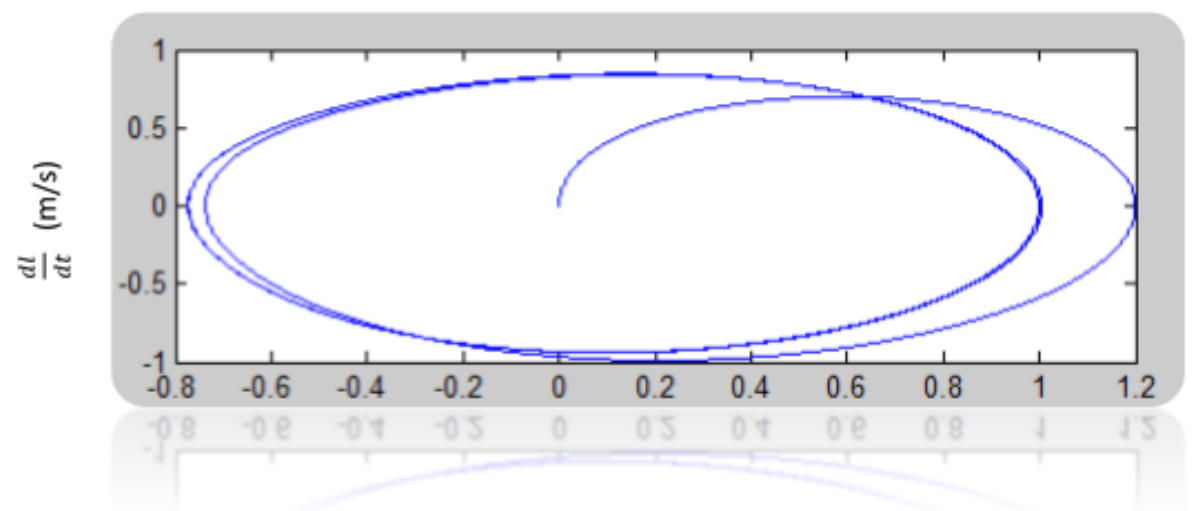

Nível (m)

Figura 5.8: Retrato de fases para entrada em sinal senoidal.

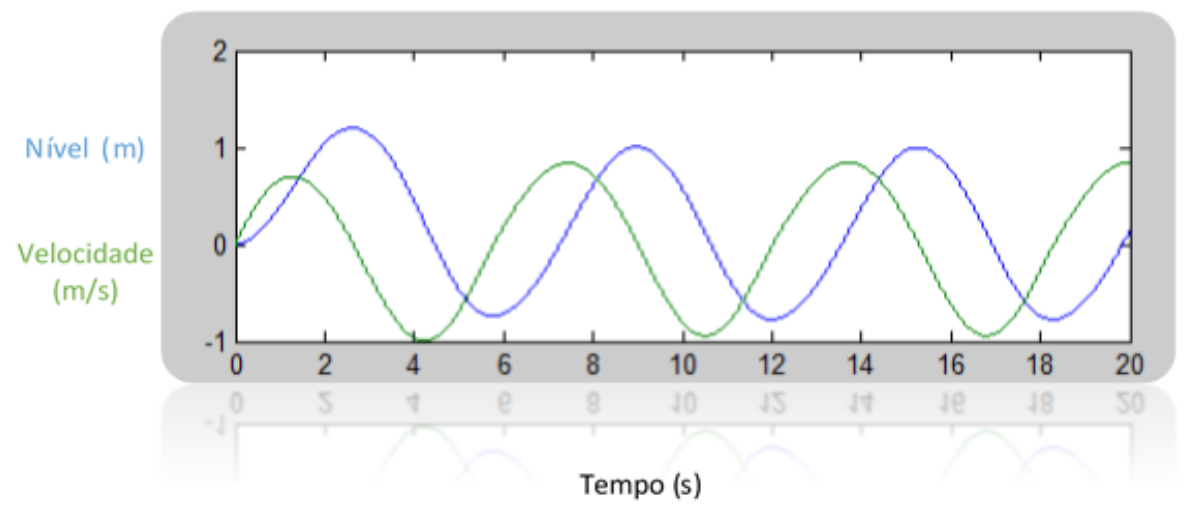

Figura 5.9: Gráfico do nível em relação ao tempo (em azul) e da velocidade do nível (em verde) para uma entrada sinusoidal

\subsubsection{Resposta a uma entrada em sinal de onda quadrada}

Um sinal de onda quadrada aplicada à entrada do sistema, como feito anteriormente, serve para se obter uma ideia do comportamento do sistema frente a sinais que representam uma vazão de entrada típica aplicada a separadores centrífugos submersos, ou seja, uma vazão em golfadas. Aqui também a resposta é semelhante à resposta de um sistema linear. Há um período de carregamento onde o nível se eleva acompanhado por um decréscimo da velocidade seguido por um período de descarregamento para o qual a velocidade aumente. Esse padrão se repete periodicamente enquanto é aplicada um sinal de onda quadrada à entrada do sistema. O gráfico da Figura 5.10 mostra a variação do nível (em azul) e da velocidade do nível (em verde) com o tempo. As descontinuidades da curva de velocidade evidenciada na Figura 5.10, são típicas de um sistema de primeira ordem como o proposto até o momento. Não se espera, no entanto, que no histórico de comportamento do sistema real haja saltos da velocidade como os que aparecem no gráfico. 


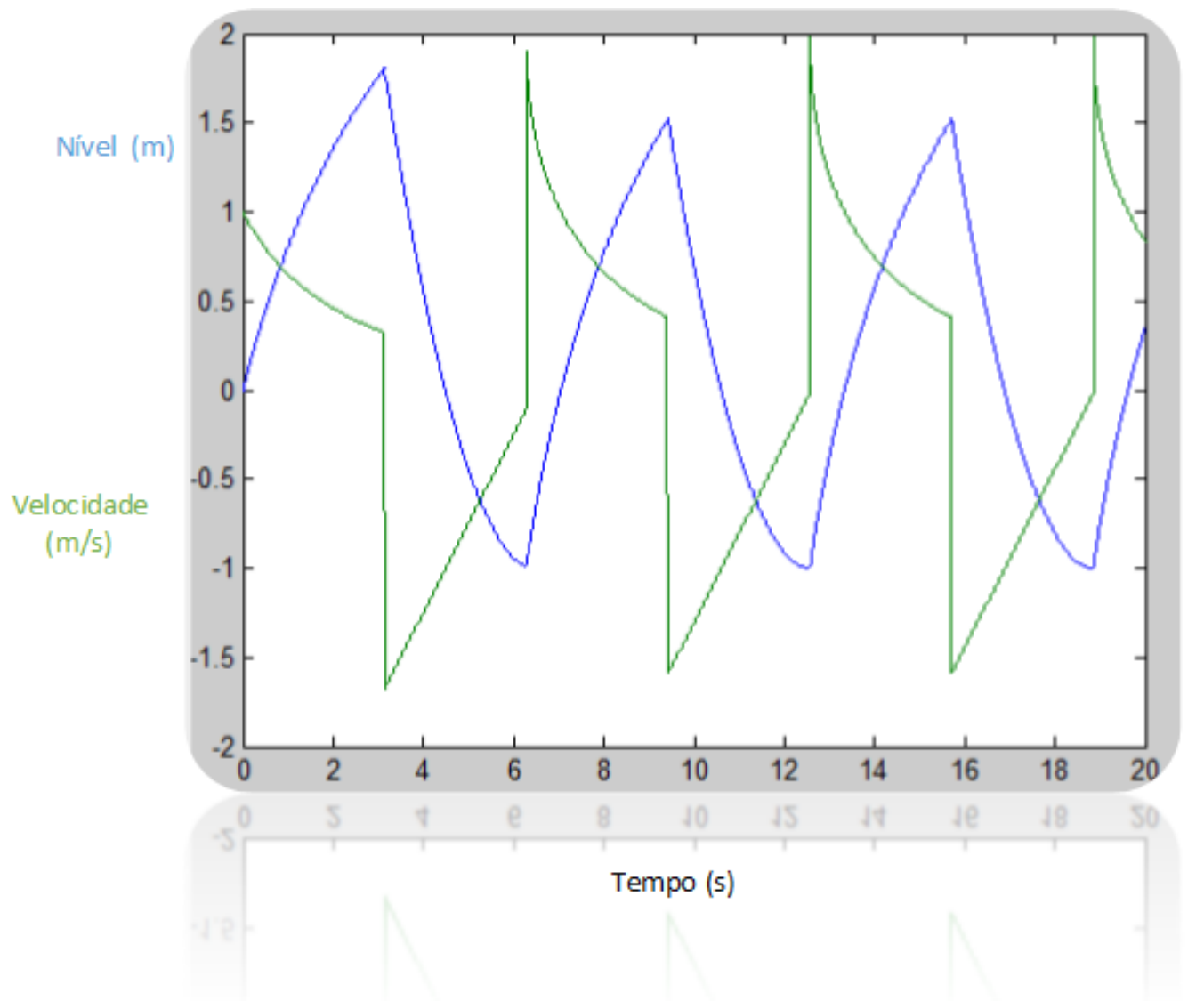

Figura 5.10: Gráfico do nível em relação ao tempo (em azul) e da velocidade do nível (em verde) para uma entrada um sinal de onda quadrada.

\subsubsection{Efeito da variação de velocidade de rotação da bomba}

A Figura 5.11, apresenta alguns gráficos do histórico temporal do nível para diferentes velocidades de rotação da bomba de escoamento do líquido. Assim como esperado, velocidades maiores de rotação levam o nível a se estabilizar em posições cada vez mais baixas. Num caso prático hipotético em que a bomba estivesse localizada no fundo do recipiente, $l_{c}=0$, aplicada uma vazão de entrada descrita por um degrau unitário, o nível do líquido,inicialmente igual a uma unidade, se estabilizaria no fundo do recipiente para uma dada velocidade de rotação (curva em azul). Velocidades de rotação menores fariam com que o nível se estabilizasse em alturas cada vez maiores como mostrado nas curvas em verde e vermelho da Figura. 


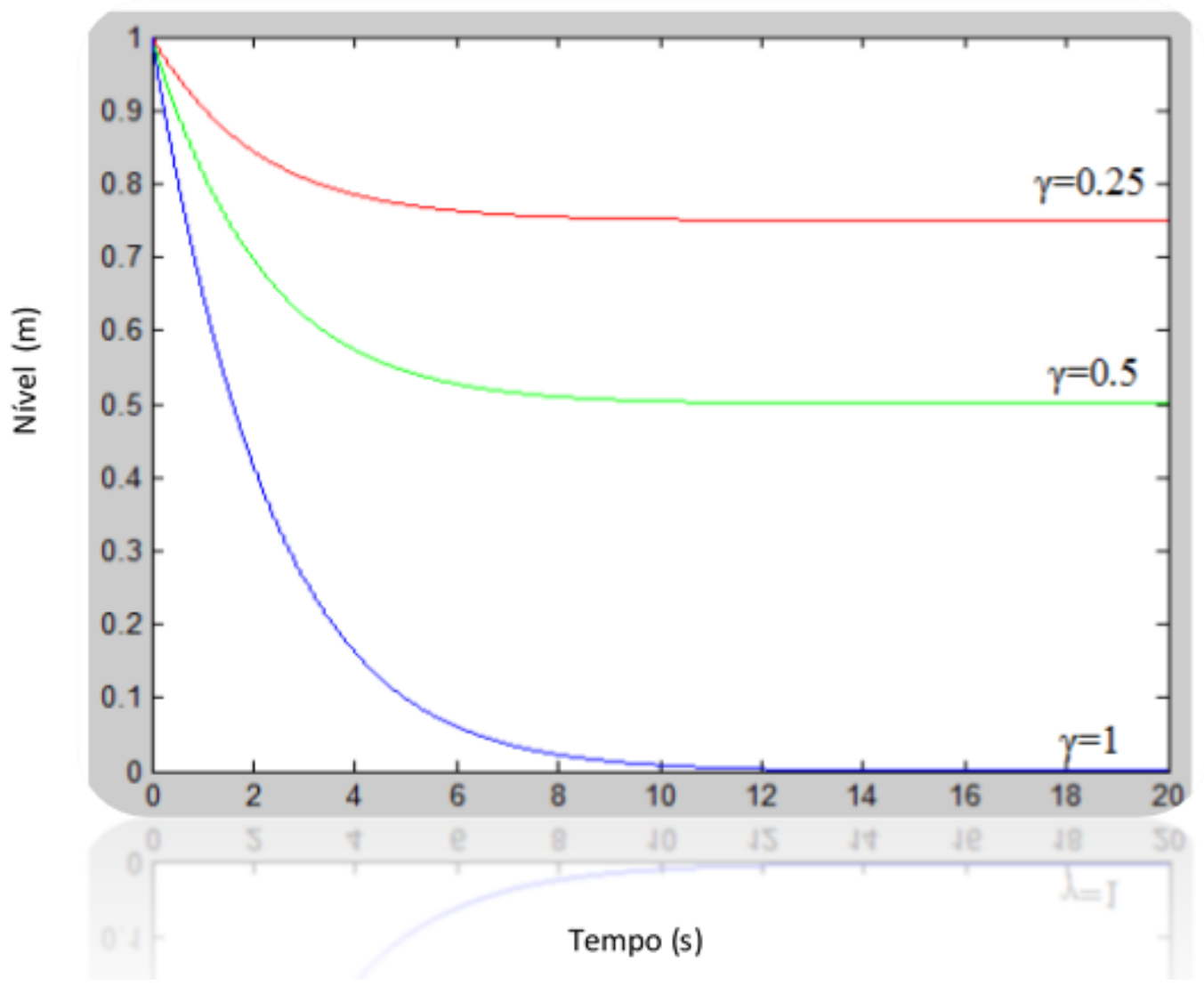

Figura 5.11: Histórico temporal do nível para diferentes velocidades de rotação da bomba. Quando $\gamma=1$ a bomba trabalha em sua capacidade de rotação máxima.

A curvas apresentadas não ilustram um caso prático com valores de todos os parâmetros do sistema meticulosamente quantificados, mas o comportamento qualitativo frente a diferentes valores de operação da bomba. Vale ainda salientar que até o momento, nas respostas encontradas para diferentes sinais de entrada, não foram considerados os efeitos advindos do escoamento do líquido no interior da sua tubulação de saída, esses efeitos influenciam e são influenciados pelo nível no interior do separador centrífugo. Não se espera no entanto, como será mostrado em análises posteriores, que esse tipo de fator force desvios de comportamento que se distanciem muito ou invalidem os resultados apresentados até o momento.

A contabilização dos efeitos da pressão e da vazão no interior da tubulação é feita pelo parâmetro $C_{M 2}$ da equação 5.23 , e analisando-se a circunferência de referência apresentada na Figura 5.5 e a definição de $\beta^{2}$ percebe-se que um aumento de $C_{M 2}$ leva a uma diminuição do valor de $\beta^{2}$ com consequente deslocamento do ponto de mínimo valor do nível para direita. Em outras palavras, quanto maior a pressão no início da tubulação de escoamento do líquido mais elevado é o ponto mínimo que o nível pode alcançar, uma situação esperada já que a bomba teria mais dificuldade para vencer uma maior pressão no início da tubulação de líquido. Uma variação oscilatória em relação ao tempo do parâmetro $C_{M 2}$ levaria a um aumento oscilatório dos limites da circunferência. Em casos como esse, o histórico do nível em relação ao tempo pode apresentar cuvas distintas das apresentadas até o momento, mas ainda assim explicáveis sob a ótica da teoria 
apresentada com a curva de retrato de fases e a circunferência de referência.

\subsection{Resposta a Variação da Frequência de Sinal de Entrada Os- cilatório}

Como pode ser observado no diagrama de bode traçado na Figura 5.12, o sistema se comporta como um filtro passa baixa. Quando submetido a um sinal sinusoidal o sistema comporta-se de forma a não apresentar regiões de amplificação da amplitude do sinal de entrada para frequências baixas. Enquanto reponde de forma a suprimir sinais com frequência alta a medida que a amplitude do sinal de saída decresce rapidamente com o aumento da frequência do sinal de entrada. Não há redução significativa da amplitude da saída até frequências próximas a unidade, ponto a partir do qual os efeitos do sinal de entrada são cada vez menos significativos e a saída dos sistema passa a ser cada vez menos sensível a variações sinusoidais.

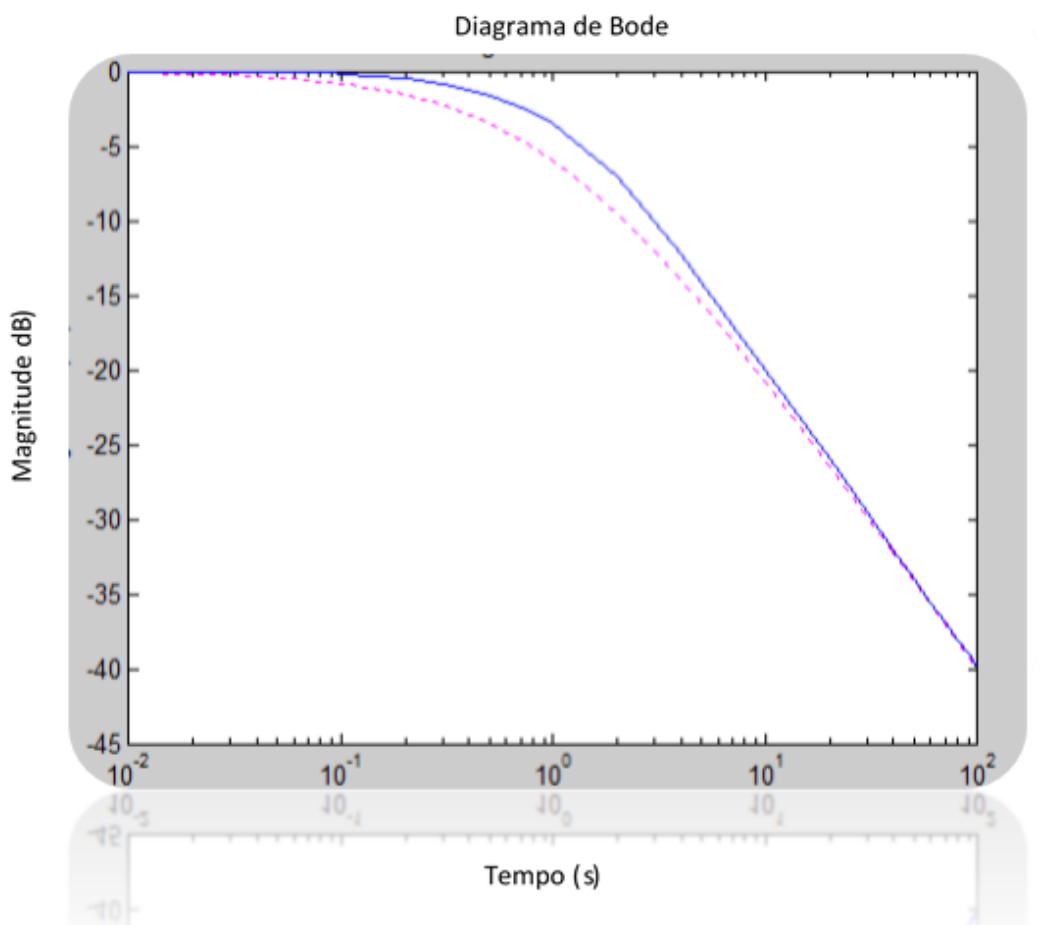

Figura 5.12: Diagrama de bode do sistema estudado (linha contínua). Diagrama de bode para uma sistema linear equivalente (linha tracejada).

A resposta a variação da frequência assim como a resposta a um degrau unitário desenvolve uma curva semelhante a um sistema de primeira ordem equivalente configurando. O gráfico do sistema de primeira ordem está impresso em linha tracejada na Figura 5.12.

Na prática, a vazão de líquido que entra no separador centrífugo pode ser representada, em alguns casos como uma composição de um sinal básico que descreve a vazão média ao longo do tempo modulada por um ruído descrito por uma curva composta por vários harmônicos. A resposta a variação de frequência apresentada no diagrama de bode permite prever que para o caso 
em estudo, os efeitos de pequenas variações, ou mesmo, grandes variações de vazão de entrada que ocorram rapidamente, não terão efeito significativo sobre a variação do nível do líquido dentro do separador. De fato, esses efeitos serão tão menos significativos quanto menor o for tempo que a vazão de entrada leva para variar.

Uma variação lenta da quantidade de líquido que entra no separador por unidade de tempo levará, por outro lado, a uma variação correspondente do nível de líquido no interior do recipiente. Esses casos deverão ser considerados no momento da elaboração de uma lei de controle, uma vez que o sistema de bombeamento deverá responder prontamente às demandas exigidas como manutenção de nível do líquido entre certos limites de altura, sem submeter o atuador a esforços desnecessários que acabariam por diminuir sua vida útil. Sabendo-se que frequências altas são naturalmente filtradas pode-se otimizar a resposta do atuador, neste caso a bomba, de forma a compensar gradativamente, cada vez menos, uma entrada com prevista tendência a aumento da frequência de oscilação da vazão de entrada.

\subsection{Estudo do sistema não-linear}

Nesta seção serão aplicados conceitos próprios do estudo de sistemas não lineares ao modelo dinâmico proposto para o separador submerso. Esse tipo de estudo se justifica uma vez que o modelo que descreve o comportamento do separador é um modelo não-linear, assim conceitos como autonomia, ponto de equilíbrio, movimento nominal e estabilidade devem ser abordados para que se conheça satisfatoriamente o sistema estudado.

\subsubsection{Autonomia}

Slotine e LI 1991, classificam sistemas não lineares como invariantes com tempo ou autônomo, quando o sistema não depende explicitamente do tempo e variantes com o tempo ou não-autônomo quando o sistema depende explicitamente do tempo. Um sistema invariante (autônomo) pode ser representado em espaço de estados da seguinte forma:

$$
\dot{\mathbf{x}}=f(\mathbf{x})
$$

enquanto um sistema variante (não-autônomo) pode ser representado em espaço de estados da seguinte forma

$$
\dot{\mathbf{x}}=f(\mathbf{x}, t)
$$

[Slotine e LI 1991], chamam atenção para o fato de que nenhum sistema físico é invariante com o tempo no sentido estrito, já suas propriedade variam com temo, por outro lado, a classificação de autonomia pode ser convenientemente aplicada quando o tempo de variação dessas propriedades é tão grande que essas variações podem ser negligenciadas. Como ilustração, é apresentado abaixo dois sistemas, um com dependência explicita do tempo (não-autônomo) e o outro invariante com 
o tempo (autônomo)

$$
\begin{gathered}
\dot{x}=-x^{2} \sin (t) \quad \text { sistema não-autônomo } \\
m \ddot{x}=-b \dot{x}-k x \quad \text { sistema autônomo }
\end{gathered}
$$

Uma lei de controle aplicada ao sistema também deve ser considerada no momento de sua classificação. O que se têm em mãos nesse caso é um sistema global composto da planta e de uma lei de controle, portanto, o sistema será dito autônomo apenas se ambos o forem.

Para classificação do sistema proposto no presente estudo quanto a sua autonomia deve levar em conta as suas variáveis. O nível $l$ é a variável de posição, portanto, para que o sistema seja considerado autônomo deve-se haver dependência direta apenas de $l$. Observemos, então, outras quantidades que variam com o estado do sistema. O parâmetro $C_{M 2}$ é uma medida que depende da pressão (ou altura piezométrica) e da vazão (ou velocidade) do fluido no interior da tubulação de escoamento de líquido num ponto da tubulação próximo a conexão com o separador centrífugo. Como tanto pressão quanto vazão são funções do tempo e da posição ao longo do comprimento da tubulação é possível descaracterizar a autonomia do sistema.

A pressão do gás $\left(p_{G}\right)$ acima da coluna de líquido dentro do separador também é uma variável que depende explicitamente do tempo uma vez que o comportamento da pressão no interior da tubulação de escoamento de gás é uma função do tempo e da posição ao longo da respectiva tubulação. A operação rotineira do separador centrífugo pode exigir o acionamento e variação de rotação da bomba, neste caso a velocidade de rotação da bomba, representada pelo parâmetro $\gamma$, poderá ser representado por uma função temporal. Explicitando a dependência das variáveis do sistema em relação ao tempo, o sistema pode ser apresentado na forma abaixo:

$$
\frac{d l}{d t}=\frac{q_{i n}}{A}-\frac{B-a_{1} \gamma(t)}{2 a_{2} A}\left(1-\sqrt{1-\frac{4 a_{2}\left(\gamma^{2}(t) H_{S}+\frac{p_{G}\left(x_{G}, t\right)}{\rho g}+l-l_{c}-C_{M 2}\left(H\left(x_{L}, t\right), Q\left(x_{L}, t\right)\right)\right)}{\left(B-a_{1} \gamma(t)\right)^{2}}}\right)
$$

$x_{G}$ é a posição da tubulação de escoamento de gás próxima ao separador. $x_{L}$ é a posição da tubulação de escoamento de líquido próxima ao separador.

Trata-se, então, de um sistema não autônomo dada a dependência explicita com tempo. A trajetória do sistema será determinada pela condição do tempo inicial, o que traz a necessidade da consideração desse tempo na definição de estabilidade tornando a análise mais complicada que no caso de um sistema autônomo.

Existem casos abrangidos pela equação do sistema de nível, para os quais o sistema torna-se autônomo. Caso o recipiente não tenha tubulações de escoamento de gás ou líquido, tanto $p_{G}$ quanto $C_{M 2}$ serão constantes. Nesse caso se a velocidade de rotação da bomba descrever uma curva em função da posição ou se permanecer constante ao longo do tempo, ter-se-á um sistema 
autônomo. Um sistema com essas características pode ajudar a compreender o comportamento geral do problema estudado, mas não será de grande utilidade na descrição de sua evolução já que o objetivo é a descrição de um recipiente submerso com fluidos canalizados escoando para superfície.

\subsubsection{Ponto de equilíbrio}

É razoável admitir-se que num separador centrífugo submerso, mantendo-se a velocidade de rotação da bomba constante, após um certo período as perturbações geradas por transientes sejam pequenas. Nesse, ou para qualquer caso hipotético em que se possa considerar $p_{G}$ e $C_{M 2}$ aproximadamente constantes, é possível se estabelecer um ponto de equilíbrio. O ponto de equilíbrio é definido como ponto que uma vez sendo alcançado, o sistema permanecerá nele para todo tempo futuro [Slotine e LI 1991]. Um sistema representado em espaço de estados terá $\mathbf{x}_{e q}$ como ponto de equilíbrio se:

$$
f\left(\mathbf{x}_{e q}\right)=0
$$

O ponto que satisfaz essa condição para a equação não forçada, com sinal de entrada igual zero, será o ponto em que a velocidade do sistema for igual a zero. Resolvendo a equação 5.44 para taxa de temporal do nível igual a zero chega-se ao valor de $\mathbf{x}_{e q}$ :

$$
l_{e q}=C_{M 2}-\gamma^{2} H_{s}-\frac{p_{G}}{\rho g}
$$

\subsubsection{Movimento nominal}

Para o caso em que parâmetros como $p_{G}, C_{M 2}$ ou $\gamma$ são função do tempo é mais produtivo analisar a estabilidade não em torno de um ponto, mas em relação a uma trajetória ou movimento, ou seja, se o sistema irá permanecer com uma trajetória próxima à sua trajetória inicial. Seja um vetor espaço de estados $\mathbf{x}(t)$, a solução da equação 5.41 correspondente à condição inicial:

$$
\mathbf{x}_{\text {ini }}(0)=\mathbf{x}_{0}
$$

A estabilidade do sistema em relação ao movimento nominal ( $\mathbf{x}_{\text {ini }}(t)$ ) [Slotine e LI 1991] pode ser estudada a partir de consideração de uma perturbação que desloca o sistema para um movimento resultante chamado, aqui, de $\mathbf{x}(t)$. Haverá um erro associado entre as duas trajetórias o qual pode ser descrito por:

$$
\mathbf{e}(t)=\mathbf{x}(t)-\mathbf{x}_{\text {ini }}(t)
$$

derivando a equação acima, obtém-se o vetor velocidade do erro: 


$$
\dot{\mathbf{e}}(t)=\dot{\mathbf{x}}(t)-\dot{\mathbf{x}}_{i n i}(t)
$$

o qual pode ser reescrito a partir da equação 5.41 como:

$$
\dot{\mathbf{e}}(t)=f(\mathbf{x}, t)-f\left(\mathbf{x}_{i n i}, t\right)
$$

substituindo-se o valor de $\mathbf{x}(t)$ da equação 5.48 na equação acima:

$$
\dot{\mathbf{e}}(t)=f\left(\mathbf{x}_{i n i}+\mathbf{e}, t\right)-f\left(\mathbf{x}_{i n i}, t\right)
$$

Considere então, o caso em que o nível no interior do separador tenha uma trajetória inicialmente determinada ou um movimento nominal $l_{\text {ini }}(t)$ que está associado a um $\beta_{\text {ini }}(t)$. A representação do sistema não-autônomo não forçado com $p_{G}, C_{M 2}$ ou $\gamma$ variando explicitamente com o tempo (seja $\left.a_{1}=0\right)$ será:

$$
i+\sqrt{\beta^{2}(t)+\Gamma^{2}\left(l-l_{c}\right)}=0
$$

o erro em relação a trajetória inicial será:

$$
\mathbf{e}(t)=\mathbf{l}(t)-\mathbf{l}_{\text {ini }}(t)
$$

logo, aplicando-se a equação 5.51 chega-se à uma lei de erro do movimento (trajetória inicial) em relação ao movimento nominal:

$$
\dot{e}+\sqrt{\beta_{i n i}^{2}(t)+\Gamma^{2} e+\Gamma^{2}\left(l_{i n i}(t)-l_{c}\right)}=\sqrt{\beta^{2}(t)+\Gamma^{2}\left(l_{i n i}(t)-l_{c}\right)}
$$

A lei de erro do movimento pode ser muito útil caso se queira formular um controlador que imponha certa trajetória ao sistema. Pela observação do comportamento do erro e com a aplicação de um controlador adequado pode-se fazer com que o nível no interior do separador siga uma trajetória periódica previamente planejada, por exemplo, alcançando um nível máximo que não atrapalhe no processo de separação gás/líquido e um mínimo que não permita entrada do gás separado na bomba ou na tubulação de escoamento de saída do líquido, dois cenários a serem evitados. Um ambiente de trabalho como esse seria de grande utilidade prática, já que a partir de um comportamento preestabelecido do sistema e, conhecendo-se o comportamento típico das vazões de entrada, é possível planejar rotinas de trabalho que visem minimizar os esforços do atuador, nesse caso a bomba centrífuga, aumentando sua vida útil.

\subsubsection{Estabilidade}

Um dado ponto de equilíbrio, representado em espaço de estados por $\mathbf{x}=0$ é dito estável, se para qualquer região esférica $\mathbf{R}>0$, houver uma região $\mathbf{r}>0$ tal que, se o estado inicial do sistema 
estiver contido em $\mathbf{r},\|\mathbf{x}(0)\|<\mathbf{r}$, então o estado dos sistema ficará contido em $\mathbf{R},\|\mathbf{x}(t)\|<\mathbf{R}$, para qualquer tempo $t=0$. [Slotine e LI 1991]

Logo, um sistema com ponto de equilíbrio estável terá uma trajetória arbitrariamente próxima da origem se seu estado inicial for um ponto arbitrariamente próximo da origem. Três hipóteses podem ser formuladas em relação a estabilidade:

1. Uma trajetória que se inicia num ponto de estado contido pela esfera $\mathbf{r},\|\mathbf{x}(0)\|<\mathbf{r}$, e que ultrapassa as fronteiras da região delimitada pela esfera $\mathbf{R}$. Trajetória 1 mostrada na Figura 5.13.

2. Uma trajetória que se inicia num ponto de estado contido pela esfera $\mathbf{r},\|\mathbf{x}(0)\|<\mathbf{r}$, mas que tem trajetória com início e fim contidos pela região delimitada pela esfera $\mathbf{R}$. Mostrado na 5.13 pela trajetória 2 .

3. Uma trajetória que se inicia num ponto de estado contido pela esfera $\mathbf{r},\|\mathbf{x}(0)\|<\mathbf{r}$, mas que tem trajetória com início e fim contidos pela região delimitada pela esfera $\mathbf{r}$. Mostrado na 5.13 pela trajetória 3 .

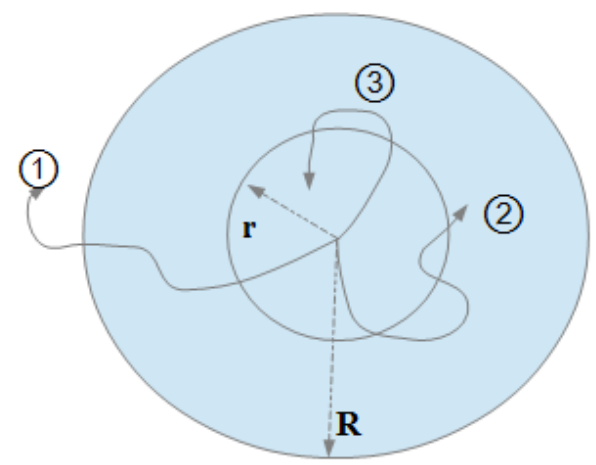

Figura 5.13: Trajetória 1: instável. Trajetória 2: marginalmente estável. Trajetória 3: assintoticamente estável

\subsubsection{Estabilidade assintótica}

Por definição, um ponto de estado $\mathbf{x}=\mathbf{0}$ é assintoticamente estável, se esse ponto for estável e houver uma região $\mathbf{r}>\mathbf{0}$ tal que a trajetória do sistema se inicia dentro dela, $\|\mathbf{x}(0)\|<\mathbf{r}$, e tende para o ponto $\mathbf{0}$ quando $t$ tende ao infinito $(\mathbf{x}(t) \rightarrow \mathbf{0}$ quando $t \rightarrow \infty)$.

A definição de estabilidade assintótica implica que trajetórias iniciadas arbitrariamente próximas ao ponto $\mathbf{0}$ convergirão para ele quando o tempo tender ao infinito. Seja o modelo do separador centrífugo: se os parâmetros $p_{G}, C_{M 2}$ ou $\gamma$ forem funções do tempo o sistema poderá ser descrito pela equação 5.52. Com esses parâmetros variáveis, pode-se se atribuir uma trajetória de $\beta$ com tempo. As dimensões da circunferência de referência mostrada da Figura 5.5 mudariam com o tempo de acordo com a trajetória imposta por $\beta$. Como resultado, ter-se-ia uma posição 
do ponto mínimo assumido pelo sistema variando com o tempo assim como a inclinação e posição da curva de retrato de fases.

Da mesma forma, como qualquer ponto de estabilidade estará necessariamente sobre a curva de retrato de fases, ter-se-ia uma posição variável para o ponto de convergência. Não seria possível, como impõe a definição de estabilidade assintótica, se estabelecer uma região no espaço de estados de raio arbitrariamente pequeno para a qual, iniciada a trajetória do nível dentro dessa região, o sistema convergisse para o dado ponto com o decorrer do tempo, já que tendo $\beta=\beta(t)$ uma trajetória, o ponto de convergência também teria.

Observe a Figura 5.14. Pela circunferência de referência (em azul) percebe-se que há um descolamento dos pontos do retrato de fases à medida que $\beta$ avança em sua trajetória. $\mathrm{O}$ ponto mínimo do retrato de fases, inicialmente na posição $p_{1}$ passará para posição $p_{2}$ ao final da trajetória. O mesmo comportamento será observado para um dado ponto de convergência já que este estará sobre a curva de retrato de fases (curva verde). Assim, não há como se afirmar uma estabilidade assintótica para o ponto de convergência. De fato, faz mais sentido estabelecer uma convergência em relação a uma trajetória e não a um ponto.

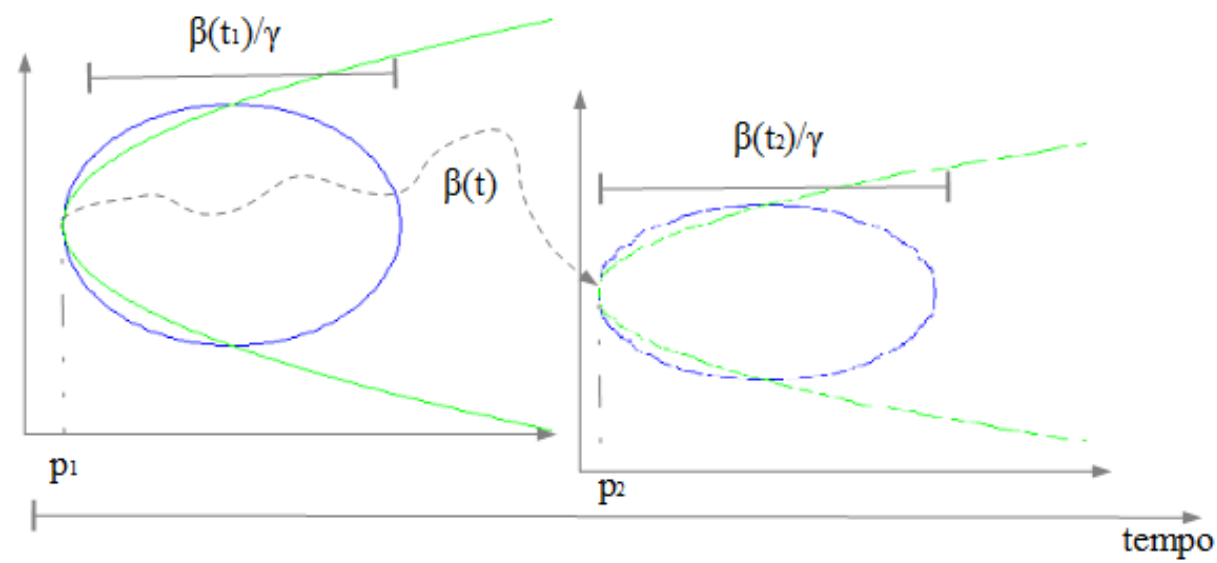

Figura 5.14: Com $\beta$ variável com o tempo há uma mudança no retrato de fases do sistema. Pode ser observado pela circunferência de referência (em azul) há um descolamento dos pontos do retrato de fases à medida que $\beta$ avança em sua trajetória. Como consequência, um ponto (como o ponto mínimo) inicialmente na posição $p_{1}$ passará para posição $p_{2}$ ao final da trajetória.

Não é difícil porém, estabelecer hipóteses em que a pressão do gás acima da coluna de líquido no interior do separador tenha uma variação com o tempo que possa ser negligenciada ou uma hipótese em que a pressão e a vazão na tubulação de escoamento de líquido alcancem um estado estacionário, cessados os efeitos de perturbações geradoras de transientes ou ainda, uma situação e que a velocidade de rotação da bomba possa permanecer constante por um longo período de tempo. A combinação desses casos levaria a um $\beta$ aproximadamente constante. Nesse caso dado o retrato de fases do sistema, é possível se estabelecer uma região no espaço ou um intervalo de níveis arbitrariamente pequeno dentro do qual o nível começaria (num ponto de equilíbrio) e terminaria sua trajetória temporal. 


\subsubsection{Estabilidade exponencial}

Nos casos em que $\beta$ é uma função do tempo não há de se falar em estabilidade exponencial já que esta depende da condição de estabilidade assintótica. Observemos, então, o caso em que $\beta$ é aproximadamente constante. Por definição um ponto em espaço de estados é exponencialmente estável se existir dois números estritamente positivos tais que $\|\mathbf{x}(t)\| \leq \epsilon\|\mathbf{x}(0)\| e^{-\lambda t}$ para todo $t>0$. [Slotine e LI 1991]. O sistema alcançará o ponto de convergência mais rápido que uma função exponencial. Derivando a condição de estabilidade exponencial em relação ao tempo:

$$
\|\dot{x}(t)\| \leq-\lambda \epsilon\|x(0)\| e^{-\lambda t}
$$

aplicando-se as desigualdades a equação do sistema de nível do separador

$$
i(t)+\sqrt{\beta^{2}+\Gamma^{2}\left(l-l_{c}\right)}=0 \leq-\lambda \epsilon l_{0} e^{-\lambda t}+\sqrt{\beta^{2}+\Gamma^{2}\left(\epsilon l_{0} e^{-\lambda t}-l_{c}\right)}
$$

de forma que haverá estabilidade exponencial para um dado valor de nível $l_{0}$ quando

$$
-\lambda \epsilon l_{0} e^{-\lambda t}+\sqrt{\beta^{2}+\Gamma^{2}\left(\epsilon l_{0} e^{-\lambda t}-l_{c}\right)} \geq 0
$$

A essa altura, dada a complexidade de formas que o modelo do sistema de nível do separador centrífugo pode assumir, optou-se apenas por mostrar a existência de pontos para os quais o sistema apresenta estabilidade exponencial. Da manipulação algébrica da desigualdade acima chega-se a

$$
\epsilon l_{0} e^{-\lambda t}\left(\lambda^{2} \epsilon l_{0} e^{-\lambda t}-\Gamma^{2}\right) \leq \beta^{2}-\Gamma^{2} l_{c}
$$

Para muitos casos $\beta^{2}-\gamma^{2} l_{c}$ é um valor positivo já que essa condição garante que a equação 5.11 conduza a uma valor não-imaginário quando o nível estiver na posição $l=0$. Assumindo-se essa condição, pode-se afirmar que a desigualdade será válida para qualquer valor que satisfaça a desigualdade abaixo

$$
\lambda^{2} \epsilon l_{0} e^{-\lambda t}-\Gamma^{2} \leq 0
$$

$\mathrm{ou}$

$$
\lambda^{2} \epsilon l_{0} e^{-\lambda t} \leq \Gamma^{2}
$$

Esta última desigualdade será verdadeira para qualquer tempo sempre que $\lambda^{2} \epsilon l_{0} \leq \Gamma^{2}$, o que é facilmente conseguido para pequenos valores de $\epsilon$ ou $l_{0}$. Verifica-se que há a possibilidade de convergência exponencial sob certas condições de funcionamento do separador. É importante lembrar que além das exigências admitidas até aqui, não foram consideradas possíveis sinais sendo aplicados à entrada do sistema. Não é difícil se imaginar, no entanto, situações em que a en- 
trada possa ser considerada aproximadamente constante por um período de tempo suficiente para que se encontre condições semelhantes às discutidas e que possibilitem pontos de convergência exponencial.

\subsection{Efeito do acoplamento da tubulação de líquido}

Como já enfatizado neste Capítulo, o nível no interior do separador está sujeito à ação do escoamento do líquido no interior da tubulação pertinente, isso ocorre pelo fato do nível ser uma função da pressão e da velocidade de escoamento no ponto próximo à junção da tubulação com o separador. Essa dependência é quantificada pelo parâmetro $\mathrm{C}_{M 2}$. O nível é modelado pela equação 5.23 enquanto a pressão e a velocidade do líquido na tubulação são determinados pelos métodos desenvolvidos no Capítulo 4. $\mathrm{C}_{M 2}$ dependerá do histórico de vazão e pressão os quais são largamente influenciados por perturbações próprias da operação do sistema como acionamento de bomba de escoamento do líquido ou fechamento de válvula para diminuir seu fluxo.

Nesta seção são analisados, por meio de um estudo de caso, alguns casos para os quais considera-se a pressão do gás acima da coluna de líquido no interior do separador como sendo constante e observa-se o efeito de perturbações sobre nível. No caso mais geral, a ser discutido posteriormente, deve-se considerar também os efeitos da pressão do gás, estes são efeitos do histórico de escoamento do gás em sua tubulação respectiva e têm comportamento descrito pelas equações apresentadas na seção 3.3 .

O sistema é resolvido numericamente pelas técnicas de equações características, para o caso da tubulação de líquido e pela discretização da equação do nível para o interior do separador. Foram elaborados algorítimos em linguagem MATLAB* utilizando-se uma estrutura de programação orientada a objetos, de forma a se criar uma classe de objetos referente à tubulação de líquido que pudesse ser referenciada e utilizada por um algorítimo responsável pela computação numérica do nível no separador centrífugo.

\subsubsection{Estudo de caso}

Seja um separador centrífugo que trabalha com um bomba escoando em estado estacionário $0.1 \mathrm{~m}^{3} / \mathrm{s}\left(Q_{0}\right)$ de um dado líquido a uma pressão equivalente a uma altura piezométrica de $50 \mathrm{~m}\left(H_{r}\right)$. O líquido é escoado por uma tubulação com $0.25 \mathrm{~m}$ de diâmetro $(D)$ e $400 \mathrm{~m}$ de comprimento $(L)$ com ângulo de inclinação em relação à horizontal $\beta=0$. A bomba tem capacidade máxima de elevação de pressão equivalente a $70 \mathrm{~m}\left(H_{S}\right)$. O modelo da variação da altura piezométrica da bomba é suficientemente descrito pela equação 4.38 apresentada na seção 4.3, com $a_{1}=0$. Na ponta da tubulação é acoplada uma válvula através da qual o líquido é descarregado na atmosfera. Num dado instante de tempo chamado tempo crítico $\left(t_{c}\right)$, a abertura da válvula sai de $100 \%$, ou totalmente aberta, para $50 \%$, aberta pela metade. A condição de contorno imposta pela válvula é modelada pela equação 4.33, discutida na seção 4.2.3, onde foi introduzida a variável $\tau$ que determina a fração de abertura da válvula. Para este exemplo tem-se $\tau=1$ quando o tempo 
for menor que $t_{c}$ e $\tau=0.5$ quando o tempo for maior.

As condições de contorno para ponta da tubulação onde é acoplada a válvula ficam estabelecidas da seguinte forma:

Para tempo $t>t c$ (equações discutidas na seção 4.2.3):

$$
\begin{gathered}
C_{v}=\frac{\left(0.5 Q_{0}\right)^{2}}{2 H_{0}} \\
Q_{P}(n+1)=-B C_{v}+\sqrt{\left(B C_{v}\right)^{2}+2 C_{v} C_{P}} \\
H_{P}(n+1)=C_{P}-B Q_{P}(n+1)
\end{gathered}
$$

$C_{p}$ foi calculado levando pelo método das equações características com interpolação por intervalo de tempos especificados, método discutido na seção 4.4.1.

$$
C_{P}=H_{R}+Q_{R}\left(B+\frac{\Delta t}{A} \operatorname{sen} \beta-\frac{f a \Delta t}{2 g D A^{2}}\left|Q_{R}\right|\right)
$$

onde

$$
H_{R}=H(n)-\left(\frac{Q_{R} \theta}{A}+\zeta\right)(H(n)-H(n-1))
$$

$\mathrm{e}$

$$
Q_{R}=\frac{Q(n)-\zeta(Q(n)-Q(n-1))}{1+\frac{\theta}{A}(Q(n)-Q(n-1))}
$$

com

$\theta=\frac{\Delta t}{\Delta x}$ e $\zeta=\theta a$ Para o tempo $t=t c:$

$$
Q_{P}(n+1)=Q_{0} H_{P}(n+1)=H_{0}
$$

onde

$$
H_{0}=H_{r}+\left(\operatorname{sen} \beta-\frac{f a Q_{0}}{2 g D A^{2}}\right) \frac{A Q_{0} L}{Q_{0}+a A}
$$

As condições de contorno para ponta da tubulação adjacente ao separador, onde a bomba é acoplada, ficam estabelecidas da seguinte forma:

$$
H_{S}=70
$$

o parâmetro $a_{2}$ pode ser estimado conforme discussão da seção 4.3:

$$
\begin{gathered}
a_{2}=\frac{H_{S}-H_{r}}{Q_{0}^{2}}=-2000 \\
B=\frac{a}{g A} R=\frac{f \Delta x}{2 \mathrm{~g} D A^{2}}
\end{gathered}
$$


A vazão de saída do recipiente de separação é dada pelo valor $q_{\text {out }}$, explicitado na equação 5.21 da seguinte forma:

$$
Q_{P}(1)=q_{\text {out }}=\frac{-B}{2 a_{2}}+\frac{1}{2 a_{2}} \sqrt{B^{2}+4 a_{2}\left(\gamma^{2} H_{S}+\frac{p_{G}}{\rho g}-C_{M 2}\right)+4 a_{2}\left(l-l_{c}\right)}
$$

e pela equação de elevação de altura da bomba

$$
H_{P}(1)-H_{l}=\gamma H_{S}-a_{2} Q_{P}(1)^{2}
$$

A fórmula acima equaciona a pressão provocada pelo trabalho da bomba entre seus pontos de tomada e de expulsão do líquido. $H_{P}(1)$ é o ponto de expulsão enquanto $H_{l}$ é a altura correspondente à pressão na entrada da bomba. Essa pressão, como estabelecido no momento da modelagem do nível, é a soma da pressão do gás acima da coluna de líquido e da pressão causada pela própria coluna do líquido acima do ponto de entrada da bomba, ou seja:

$$
H_{l}=\frac{p_{G}}{\rho g}+l-l_{c}
$$

$C_{M 2}$ é também é obtido pelo método de interpolação por tempos especificados e é dado por:

$$
C_{M 2}=H_{S}-Q_{S}\left(B-\frac{\Delta t}{A} \operatorname{sen} \beta-\frac{f a \Delta t}{2 g D A^{2}}\left|Q_{S}\right|\right)
$$

onde

$$
H_{S}=H_{C}+\left(\frac{Q_{S} \theta}{A}-\zeta_{S}\right)\left(H_{C}-H_{B}\right)
$$

e

$$
Q_{S}=\frac{Q(1)-\zeta_{S}(Q(1)-Q(2))}{1-\frac{\theta}{A}(Q(1)-Q(2))}
$$

com

$$
\theta=\frac{\Delta t}{\Delta x} \text { e } \zeta=\theta a
$$

Os valores da vazão e altura piezométrica no interior da tubulação são calculados pelo método das equações características com interpolação por tempos especificados. Uma vez estabelecido o comportamento de escoamento do líquido, calcula-se o nível no interior do separador pela equação 5.1 apresentada no início do Capítulo

$$
\frac{d l}{d t}=\frac{q_{\text {in }}}{\text { Area }}-\frac{q_{\text {out }}}{\text { Area }}
$$

onde Area na equação diferencial acima refere-se à área de secção transversal do separador centrífugo.

Seja uma entrada constante com vazão igual a vazão de saída $q_{o u t}$ e com nível inicialmente na posição zero. O comportamento do sistema pode ser observado na Figura 5.15. 

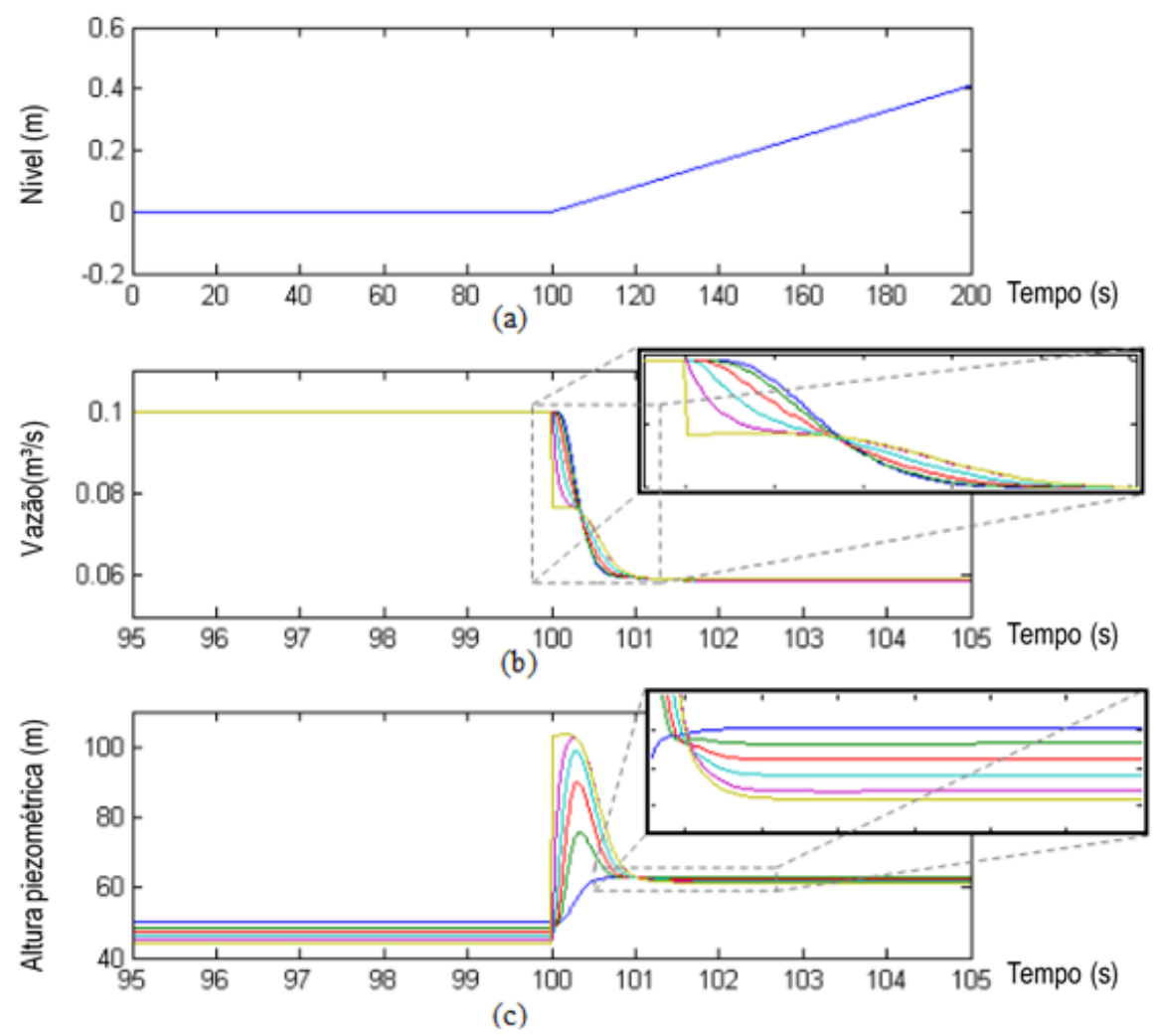

Figura 5.15: Separador Centrífugo com nível inicial igual a zero e com vazão de entrada constante igual à vazão inicial de saída. No tempo $t=t_{c}$ a válvula é subitamente fechada pela metade . (a) Nível do líquido no interior do separador. (b) vazão para vários pontos ao longo do comprimento da tubo. (c) pressão em termos da altura piezométrica ao longo do comprimento da tubulação.

Foi admitido inicialmente uma vazão constante $\left(Q_{0}=0.1\right)$ de líquido entrando no separador e o sistema operando de forma a gerar a mesma vazão de saída. O nível de líquido que havia inicialmente no recipiente era $l_{0}=0$. Num dado instante $\left(t_{c}=100\right)$ a válvula na extremidade da tubulação que se encontrava totalmente aberta é fechada pela metade. A Figura 5.15(a) mostra a curva do nível do separador ao longo do tempo onde é possível observar que no momento em que a válvula é parcialmente fechada a curva ganha uma inclinação positiva e o nível começa a aumentar. Esse resultado pode ser explicado pelo fato de haver mais fluido entrando do recipiente do que saindo, já que a obstrução do fluxo leva a diminuição da vazão de saída.

As Figuras 5.15(b) e 5.15(c) mostram, respectivamente, as curvas da vazão e da altura piezométrica para vários pontos ao longo do comprimento da tubulação, em ordem crescente de distância a partir da base da tubulação (seja a base o ponto conectado ao separador através da bomba) as curvas estão dispostas da seguinte maneira:

1. curva na cor azul: ponto 1 (conectado ao separador);

2. curva na cor verde: ponto 2 ;

3. curva em vermelho: ponto 3 ; 
4. curva em ciano: ponto 4;

5. curva na cor magenta: ponto 5 ;

6. curva em amarelo: ponto 6 (extremidade oposta, onde é acoplada a válvula).

Uma ilustração da numeração dos pontos ao longo da tubulação é mostrada na figura 5.16

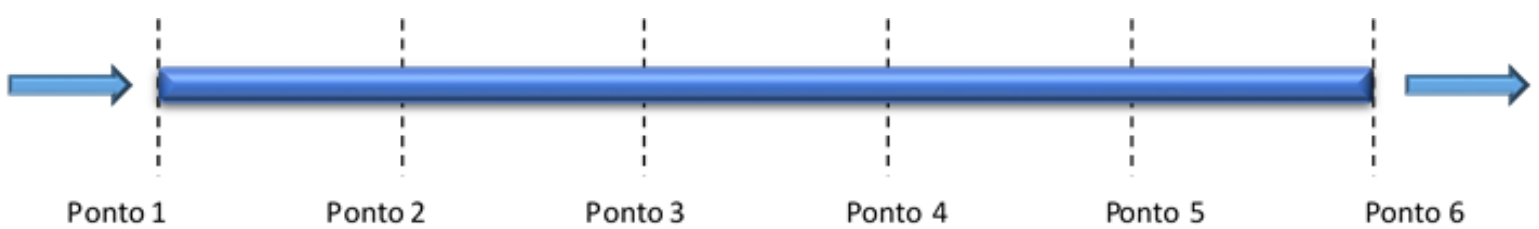

Figura 5.16: Numeração dos pontos ao longo da tubulação.

Para tempos menores que o tempo crítico, as vazões previstas pela simulação para cada ponto ao longo da tubulação têm praticamente o mesmo valor e permanecem contantes em todo o intervalo $0<t<t_{c}$. As curvas correspondentes às pressões em cada ponto analisado, também se mostraram bem comportadas para um tempo menor que o tempo crítico com valores diminuindo gradativamente a partir da base da tubulação, ponto 1, até a extremidade oposta. Quando a válvula é fechada, impõe-se um súbito aumento da pressão no ponto 6 acompanhado de uma queda de vazão brusca, como resultado há um pronunciamento do efeitos de transientes os quais se mostram significativos durante um curto intervalo de tempo. As pressões ao longo do comprimento da tubulação, Figura 5.15(c), aumentam rapidamente de forma a acompanhar o valor de contorno imposto pela válvula, esse aumento de pressão é tão menor quanto mais próximo da base está o ponto analisado sendo que para o presente caso não se observou um sobressinal no ponto 1, acima da pressão na qual o sistema se estabiliza passado os efeitos de transiente.

A Figura 5.15(b), mostra os efeitos dos transientes sobre as curvas de vazão de cada ponto analisado ao longo do comprimento da tubulação. Há uma diminuição dos valores da vazão que ocorrem mais pronunciadamente o quão mais próximo o ponto se está do ponto 6 , sendo a base da tubulação a última a acompanhar a súbita queda na vazão imposta pela válvula durante o intervalo de tempo em que esses efeitos são significativos $(100<t<101)$. Durante um pequeno intervalo de tempo, mostrado no detalhe da Figura, as vazões dos pontos mais próximos a base são maiores que as dos pontos mais próximos a válvula, essa inversão pode ser explicada pelo fato de os pontos adjacentes à extremidade oposta, estarem mais suscetíveis aos efeitos do contorno. Essa inversão cessa a medida em que o sistema tende a se estabilizar e os pontos mais próximos à base passam a ter vazão menor. Cessado os efeitos de transientes, o sistema tende a se estabilizar e apresenta, assim como quando $t<t c$, valores de vazão praticamente iguais para todos os pontos ao longo do tubo com a diferença que o valor global da vazão foi abaixado.

A pressão também se estabiliza ao longo do comprimento da tubulação passado os efeitos de transientes, como pode ser visto na Figura 5.15(c). O detalhe da Figura mostra que o padrão de distribuição das pressões continua o mesmo, com a pressão mais alta na base da tubulação diminuindo gradativamente ao longo do seu comprimento. O encurtamento da distância entre as 
curvas correspondentes à pressão em cada ponto se deve ao fato de se haver diminuído a diferença de pressão entre a base e a extremidade oposta, o que força as pressões nos pontos intermediários a se distribuírem em um intervalo menor.

Um pequeno tempo de simulação como o apresentado na Figura 5.15 pode sugerir a estabilização do sistema com valores de pressão e vazão bastante aquém da realidade. Basta observar, no entanto, a lei de velocidade do nível que corresponde ao próprio modelo do sistema para chegar-se a conclusão de que o ponto de equilíbrio não foi alcançado, portanto, não há de se falar a esse tempo, em estabilização. A definição de ponto de equilíbrio impõe uma velocidade zero no momento em que este seja alcançado. Não havendo grandes variações com o tempo do parâmetro $C_{M 2}$ do modelo descrito pela equação 5.23, é possível se prever a convergência do nível para seu ponto de equilíbrio característico. De fato, para um tempo maior de simulação o parâmetro $C_{M 2}$ tende a atingir um valor constante, o que confere ao sistema sua capacidade de convergência. Na medida em que se faz necessário uma velocidade de nível zero para o ponto de equilíbrio, a lei da velocidade do nível impõe que haja uma vazão de saída igual a vazão de entrada, e observa-se, sob um tempo de simulação maior, uma gradual elevação da vazão de saída de forma a se atingir essa condição.

O comportamento do parâmetro $C_{M 2}$ ao longo do tempo é mostrado na Figura 5.17. Na Figura, o tempo correspondente ao fechamento da válvula é marcado por uma súbita elevação do seu valor que tende a se estabilizar com a evolução do tempo. Os gráficos mostrados na Figura 5.15 são reapresentados na Figura 5.18, desta vez, para um tempo maior de simulação. Fica evidenciado a que a imposição de uma menor vazão de saída tende a ser compensada por uma elevação da pressão ao longo da tubulação, esse fato pode ser explicado na medida em que o aumento do nível do líquido no interior do separador centrífugo gerado pela diferença entre as vazões de entrada e saída, eleva a pressão na base da tubulação e nos demais pontos como consequência. Essa elevação da pressão acompanhada pelo aumento da vazão fica cada vez menos pronunciada até a que as pressões do conjunto são compensadas o sistema atinge o regime permanente. 


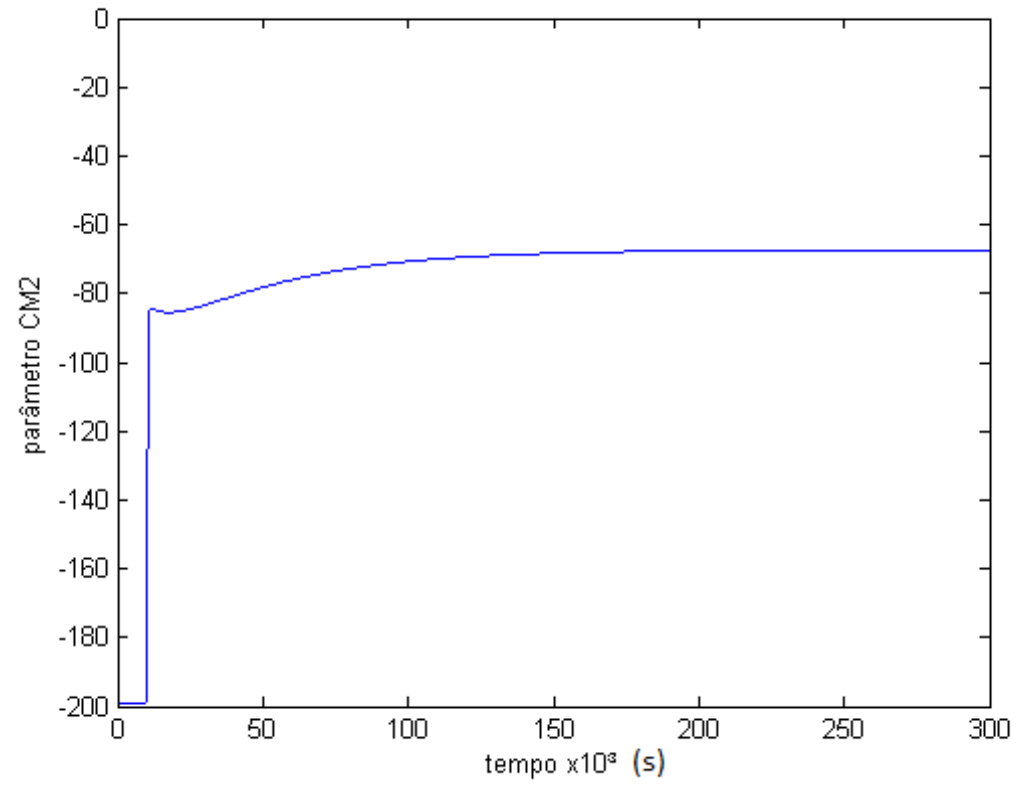

Figura 5.17: Parâmetro $C_{M 2}$ tende a ficar constante o que assegura a convergência do sistema. 

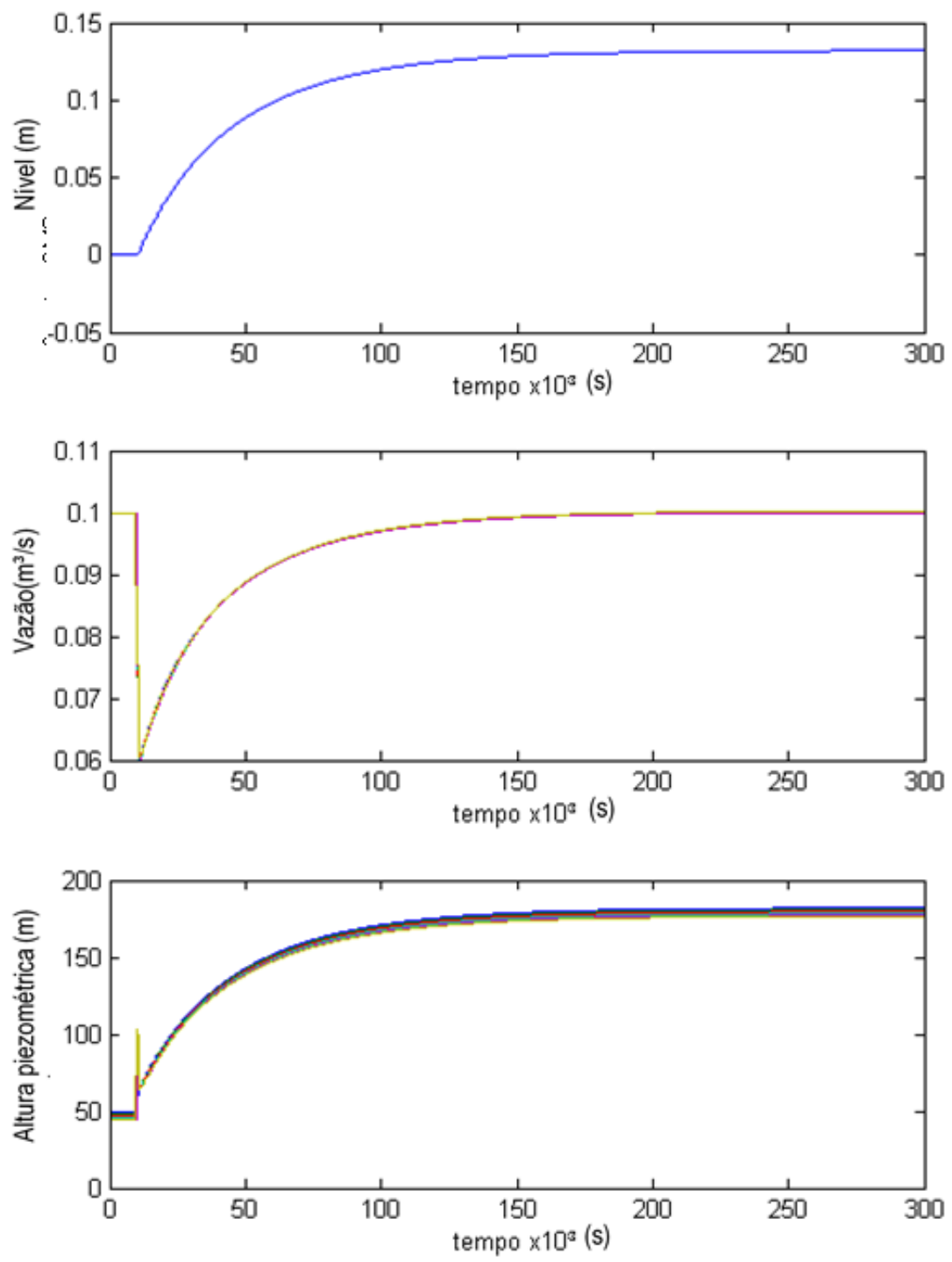

Figura 5.18: Gráficos mostrados na Figura 5.15 para um tempo de simulação maior. Percebe-se a convergência do sistema para o ponto de equilíbrio com o estabelecimento do regime permanente.

\subsubsection{Resposta a entrada degrau}

O modelo geral que descreve o nível no interior do separador, equação 5.22, quando submetido a um sinal de entrada tipo degrau sob as condições especificadas, apresentou um comportamento convergente como foi mostrado pelas figuras 5.6 e 5.7. Uma condição suficiente para que se pudesse afirmar a convergência do sistema seria que o parâmetro $C_{M 2}$, encapsulado na equação 5.24 por $\beta^{2}$, fosse constante. Essa condição foi utilizada no momento do estabelecimento das curvas de resposta a vários sinas de entrada discutidos para o modelo.

Situação semelhante foi observada no caso específico do sistema estudado do estudo de caso. O parâmetro $C_{M 2}$, tendeu a um valor constante com a evolução do tempo. Isso sugere um 
comportamento semelhantemente ao do modelo geral sob a condição suficiente à convergência quando este for submetido ao mesmo tipo de sinal de entrada. De fato, como mostrado na Figura 5.19 , quando aplicado uma entrada em sinal degrau o sistema responde tal qual o caso geral em condições semelhantes, com o nível convergindo para o ponto de equilíbrio em uma curva com características qualitativas semelhantes ao de um sistema de primeira ordem submetido ao mesmo tipo de entrada. Para que se tenha uma visão da resposta a uma perturbação advinda apenas do sinal de entrada a simulação foi rodada considerando a válvula aberta durante todo o tempo. A convergência, determinada pela lei de velocidade que é a própria equação do modelo, dita que a taxa de variação temporal do nível será zero, ou o sistema alcançará o equilíbrio, quando a vazão de saída for igual a de entrada. Após a aplicação do degrau a vazão de saída aumenta até atingir o mesmo valor da vazão de entrada como pode ser observado na Figura 5.19(b).

As vazões em cada ponto ao longo do comprimento da tubulação permaneceram com mesmo valor por todo o tempo da simulação como é esperado para um líquido incompressível, uma vez que os elementos de fluido viajando na tubulação não estão sujeitos a deformação longitudinal. Isso impõe a um dado volume de controle, tomado nas proximidades do ponto, a ter o mesmo volume entrando e saindo. O que se percebe é que todas as curvas na Figura 5.19(b) correspondentes à vazão em cada ponto estão sobrepostas. Além da sugerida incompressibilidade, faz-se necessário uma tubulação rígida já que sua deformação acarretaria um deslocamento dos pontos que geram as curvas da Figura os quais admitiriam velocidade relativa ao fluxo do fluido e vazões variando em função desse movimento.

A Figura 5.19(c), mostra as curvas das pressões de cada ponto ao longo do comprimento da tubulação. A convergência do sistema também é observada, em forma de pressões constantes, na medida em que é alcançado um escoamento permanente passado tempo suficiente para à equalização das vazões. Ao longo de todo o tempo as pressões em cada ponto se mostraram bem comportadas decrescendo gradativamente a partir da base da tubulação.

Vale ressaltar que enquanto o fechamento da válvula causa a diminuição da diferença de pressão entre a base e a extremidade oposta da tubulação e a diminuição da distância entre as curvas de pressão da Figura 5.15(c), no caso da Figura 5.19(c) houve um aumento da distância entre as curvas. Ocorre que aumentar o nível do recipiente implica em aumentar a pressão na entrada da bomba de evacuamento de líquido e, portanto, a diferença de pressão entre as duas extremidades e a diferença de pressão entre os pontos considerados. 

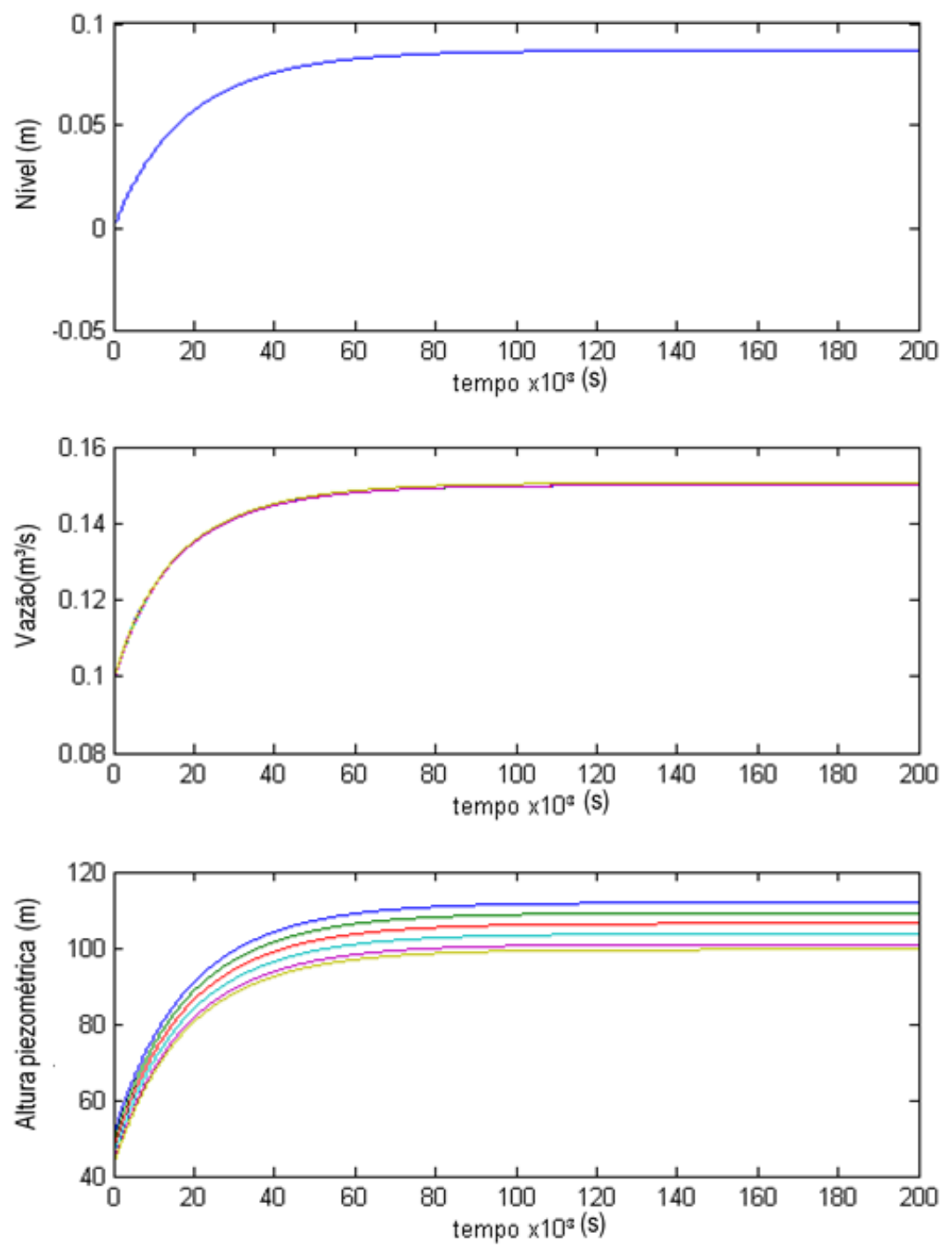

Figura 5.19: Sistema descrito pelo exemplo do estudo de caso, sob entrada em degrau unitário e com a válvula na extremidade oposta da tubulação aberta todo tempo. (a) Nível no interior do separador centrífugo. (b) vazões em cada ponto considerado. (c) pressão em termos da altura piezométrica ao longo do comprimento da tubulação.

\subsubsection{Resposta a entrada em sinal sinusoidal e onda quadrada}

As Figuras 5.20 e 5.21 mostram o sistema sob uma entrada sinusoidal e onda quadrada, respectivamente. Assim como na análise do caso geral modelado pela 5.22, particularizado e simplificado a partir da consideração do parâmetro $\beta^{2}$ constante, o sistema apresentou uma variação periódica do nível em resposta aos dois tipos de entrada periódica considerados. Apesar de $\beta^{2}$ não ser constante no modelo que resolve o exemplo do estudo, as curvas do comportamento do nível com o tempo se apresentaram qualitativamente bastante próximas das mostradas nas Figuras 5.20 e 
5.21 .

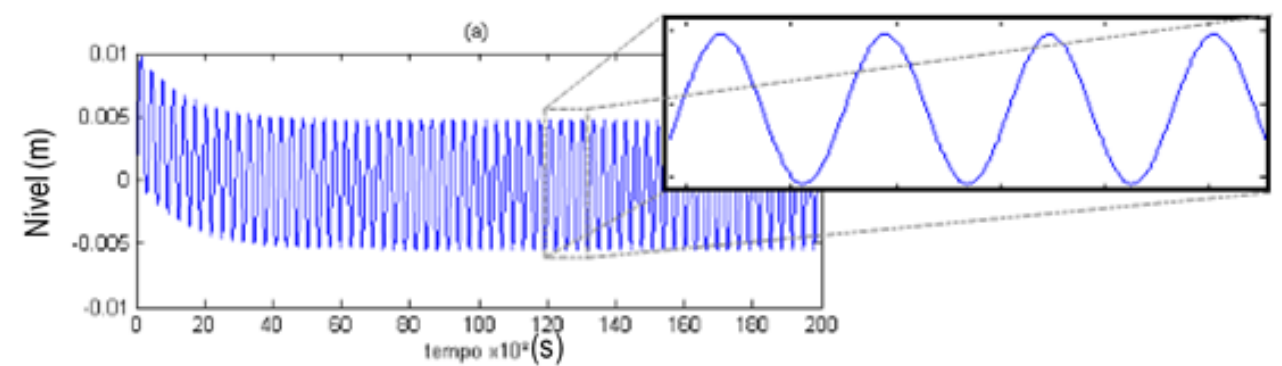

(b)
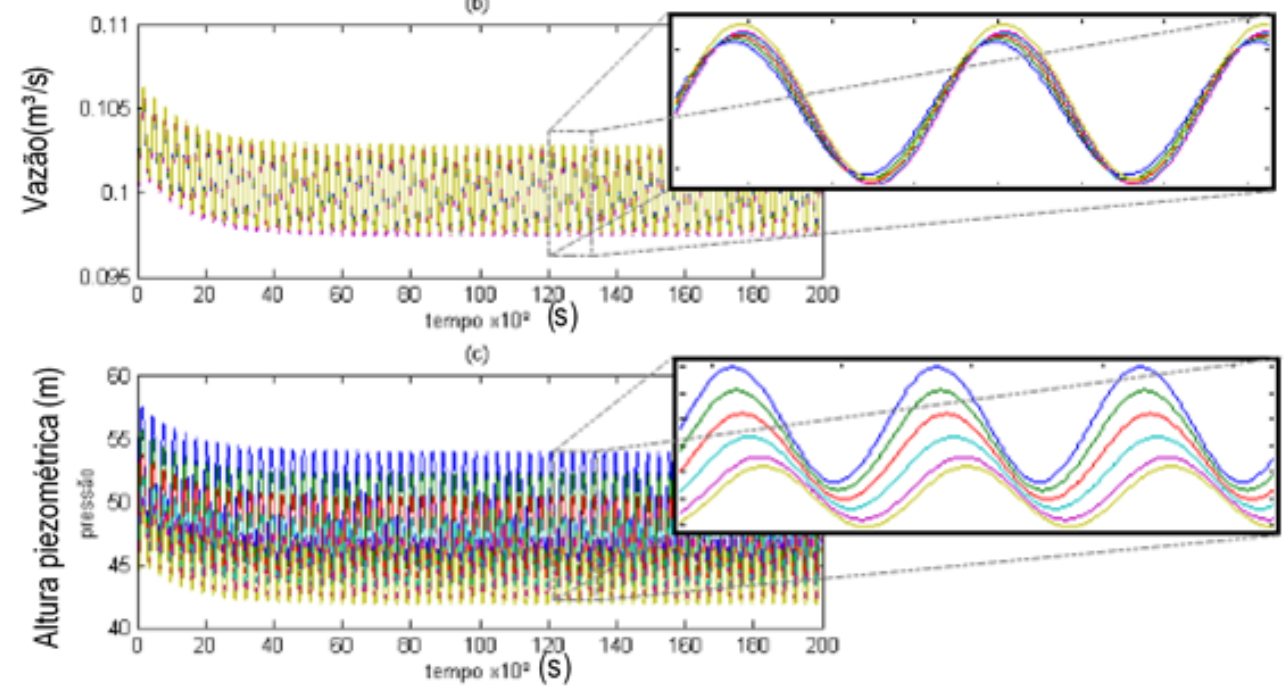

Figura 5.20: Sistema descrito pelo exemplo do estudo de caso, sob entrada sinusoidal e com a válvula na extremidade oposta da tubulação aberta todo tempo. (a) Nivel no interior do separador centrífugo. (b) vazões em cada ponto considerado. (c) pressão em termos da altura piezométrica ao longo do comprimento da tubulação.

Tanto a entrada sinusoidal quanto a entrada em onda quadrada foram implementadas de forma a se simular, minimamente, uma possível vazão de entrada de fluido no separador centrífugo. Dessa forma, foram admitidos sinais que representassem vazões variáveis com valores sempre maior ou igual a zero. À entrada sinusoidal, o sistema respondeu com a variação de nível também sinusoidal mostrada na Figura 5.20(a).

A amplitude do sinal de entrada utilizada na simulação foi 0.2 , enquanto da amplitude média da vazão em todos os pontos da tubulação é menor que 0.01 , ou $5 \%$ da entrada como pode ser observado na Figura 5.20(b). Essa amplitude predominante do sinal de entrada termina por dar forma à variação do nível. Comportamento semelhante, como esperado, é encontrado quando se impõe a onda quadrada, a mesma amplitude foi utilizada para a simulação e para esse caso também, as vazões na tubulação não passam de $5 \%$ da amplitude da vazão entrada, as vazões para esse caso são mostradas no Figura 5.21(b). A amplitude, vazão e nível médio têm um pequeno decréscimo nos primeiros instantes da simulação se estabilizando logo em seguida, apesar do deslocamentos das curvas nesses primeiros instantes não houve deformação das curvas em durante todo o intervalo de tempo. 
O nível, em resposta ao sinal de entrada degrau, apresentou curva semelhante a um sinal dente de serra como pode ser observado no detalhe da Figura 5.21(a). Esse comportamento também não difere do que foi obtido para o modelo geral descrito pela equação 5.22 sob as considerações que levaram à resposta mostrada na Figura 5.10. De maneira geral, este tipo de resposta é típico de sistemas de primeira ordem os quais alternam um intervalo de elevação do sinal de saída, que corresponderia, analogamente, ao período de carregamento de um capacitor num sistema eletrônico, com intervalo de diminuição, sendo a periodicidade da entrada a responsável pela periodicidade da saída.
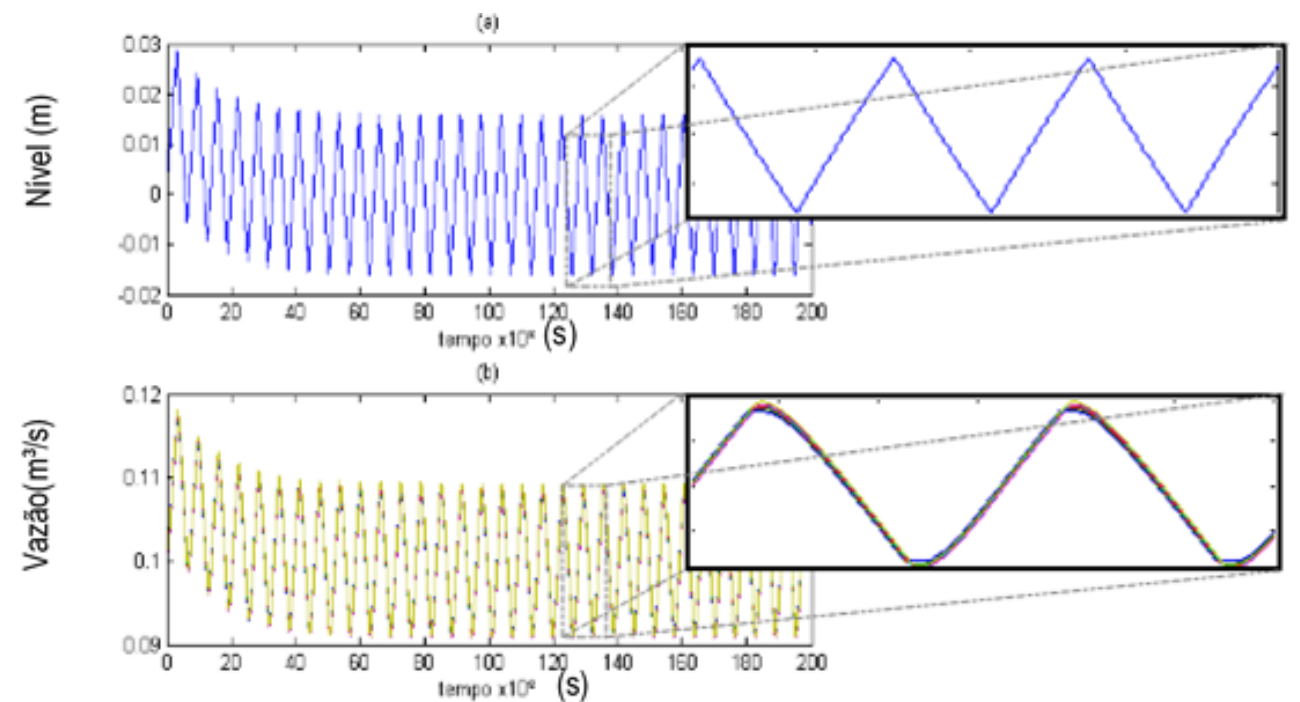

(c)

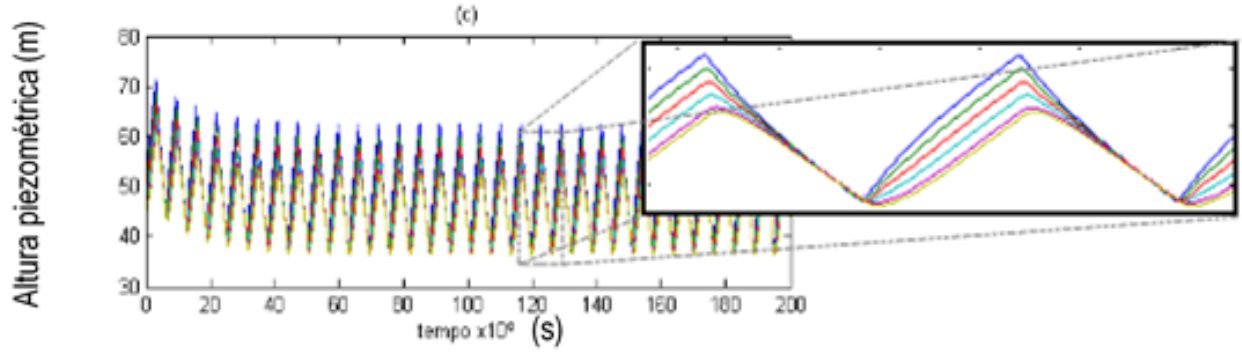

Figura 5.21: Sistema descrito pelo exemplo 1, sob entrada em sinal de onda quadrada e com a válvula na extremidade oposta da tubulação aberta to o tempo. (a) Nivel no interior do separador centrífugo. (b) vazões em cada ponto considerado. (c) pressões em cada ponto.

As pressões relativas as entradas periódicas mostradas nas Figuras 5.20(c) e 5.21(c) mostram uma defasagem do sinal periódico correspondente a cada ponto ao longo da tubulação de escoamento do líquido. O sinal de pressão é defasado com deslocamento para direita tão mais, quão mais próximo o ponto estiver da extremidade oposta da tubulação. O fato é que uma variação da pressão no ponto 1 leva um certo intervalo de tempo para ser sentido pelo ponto 2 , e assim sucessivamente.

O resultado dessa defasagem é que, como pode ser observado nos detalhes das Figuras 5.20(c) e 5.21(c), existirão determinados instantes para os quais a diferença de pressão ao longo da tubulação é maior o que facilita o escoamento do fluido, e instantes para os quais a diferença de pressão entre o 
pontos será menor e o líquido terá maior dificuldade de escoamento. Espera-se, portanto, que uma vazão de entrada em golfadas que não seja de alguma forma compensada, por exemplo variando-se a velocidade da bomba, termine por impor uma vazão periódica na extremidade da tubulação.

A Figura 5.22 mostra uma superfície gerada para pressão ao longo do comprimento da tubulação e ao longo do tempo. A superfície é referente a resposta do sistema a uma vazão de entrada sinusoidal. Esse resultado foi mostrado na Figura 5.20 em representação bidimensional.

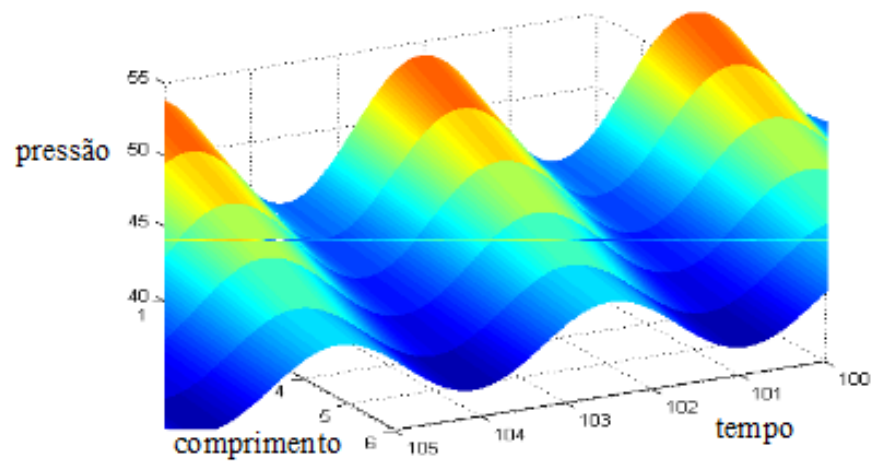

Figura 5.22: Superfície gerada para pressão ao longo do comprimento da tubulação e ao longo do tempo. A superfície é referente a resposta do sistema a uma vazão de entrada sinusoidal. Esse resultado foi mostrado na Figura 5.20 em representação bidimensional

\subsubsection{Influência da variação da velocidade de propagação do pulso de onda tran- siente}

Algumas propriedades do fluido e da tubulação são condensadas na definição da velocidade do pulso de pressão que aparece no momento em que os efeitos transientes são gerados. A velocidade do pulso, discutida na seção 3.1 foi definida, para o caso de uma tubulação fixada pela base, da seguinte forma:

$$
a=\sqrt{\frac{K / \rho}{1+\left(\frac{K}{E} \frac{D}{e}\right)(1-\mu / 2)}}
$$

onde $K$ é o módulo de elasticidade do fluido que mede a variação de pressão em relação a fração de variação do volume; $\rho$ é a densidade do fluido; $E$ o módulo de elasticidade da tubulação; $D$ é o diâmetro e $e$ a espessura da parede da tubulação; $\mu$ é o coeficiente de Poisson da tubulação.

De maneira geral, a velocidade do pulso de pressão tende a aumentar com o aumento dos módulos de elasticidade do fluido e da tubulação. Esse pulso pode ser visualizado como um pulso de pressão viajando à velocidade $a$ na direção contrária ao fluxo do fluido, com pressão suficiente para aplicar um impulso sobre ele de maneira a trazê-lo ao repouso. Quanto maior o módulo de elasticidade do fluido ou quanto menor a fração de deformação volumétrica para uma dada variação de pressão, mais rápido as camadas adjacentes chegarão ao repouso subsequentemente, e 
mais rápida será a velocidade da onda. Esse comportamento pode ser ilustrado pelo caso teórico limite em que não existe nenhuma variação de volume qualquer que seja a diferença de pressão aplicada, há então um líquido totalmente incompressível e a predominância do valor de $K$ na equação 5.75, impõe uma velocidade limite igual a:

$$
a=\sqrt{\frac{1}{\left(\frac{D \rho}{E e}\right)(1-\mu / 2)}}
$$

Para que se tenha a velocidade dada acima, considerando-se apenas fatores de compressibilidade do fluido, seria necessário uma fração de variação de volume tendendo a zero no cálculo do módulo de elasticidade do fluido. Pode-se considerar valores altos de $K$ para líquidos tidos normalmente como incompressíveis, valores que, no entanto, não são altos o suficiente para se sobrepor os valores das propriedades da tubulação dadas na equação 5.75, devendo essa ser considerada na sua forma mais geral para o cálculo da velocidade do pulso de pressão.

A mesma equação de velocidade será encontrada para tubulações muito flexíveis. Valores de $E$ muito pequenos em relação ao produto do diâmetro da tubulação pelo módulo de elasticidade do fluido, fazem $\left(\frac{D \rho}{E e}\right)(1-\mu / 2) \gg 1$ e reduzem a equação à forma 5.76.

Efeito semelhante, mais facilmente reproduzível na prática, ocorre quando se tem uma tubulação muito rígida com espessura das paredes muito alta em relação ao diâmetro. Ocorrerá pouca deformação transversal em virtude de um aumento de pressão. O pulso de onda de pressão tenderá a se deslocar mais rápido uma vez que haverá, predominantemente deslocamento longitudinal ao longo da tubulação. A velocidade será descrita pela equação 5.75, na forma:

$$
a=\sqrt{K / \rho}
$$

Como forma de se observar o impacto da mudança da velocidade $a$ sobre o sistema, o que equivale a testar diferentes tipos de fluido ou do material construtivo da tubulação, o modelo foi simulado para diferentes valores da velocidade do pulso de pressão. Para cada simulação, foi calculada a média aritmética da pressão no intervalo de tempo em que os efeitos transientes são mais pronunciados. Para o caso apresentado no estudo de caso, esse intervalo foi tomado a partir do momento em que há uma brusca mudança nos valores da pressão e vazão, resultado do fechamento parcial da válvula na extremidade da tubulação, até o momento em que esses efeitos tendem a se estabilizar. Na Figura 5.15, esse intervalo de tempo vai de 100 à aproximadamente 101.

De maneira geral, o aumento da velocidade do pulso de pressão a tem o efeito de aumentar a pressão média ao longo de todo o comprimento da tubulação. Como esperado, o aumento da pressão é mais pronunciado para os pontos da tubulação mais próximos da extremidade onde a válvula é acoplada. A Figura 5.23 mostra as pressões médias durante o intervalo de tempo especificado, para cada ponto analisado no interior da tubulação de escoamento do líquido, seguindo a especificação de cores adotada no estudo de caso, sendo azul a curva correspondente ao ponto próximo a base e amarelo, o ponto correspondente à extremidade oposta. 


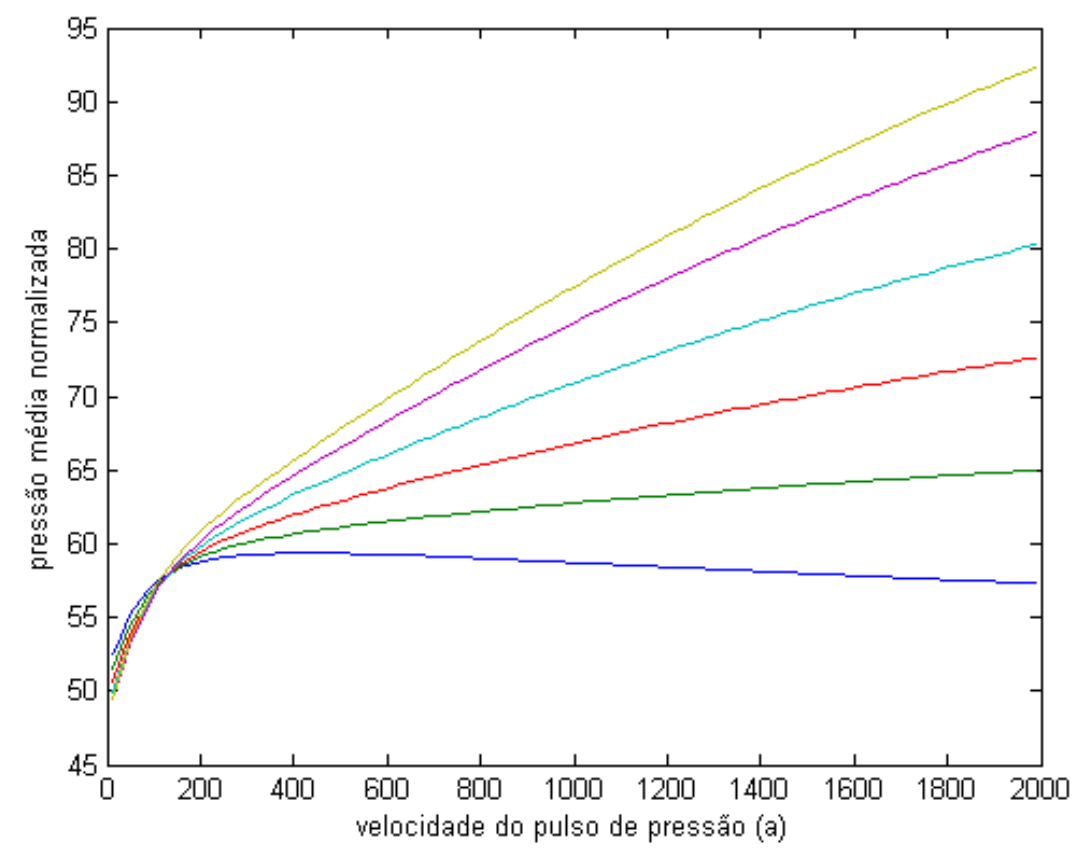

Figura 5.23: Pressões médias (em termos de altura piezométrica $(m)$ ) em cada ponto da tubulação para o intervalo de tempo em que os efeitos transientes são significativos variando com o aumento da velocidade do pulso de pressão a $(\mathrm{m} / \mathrm{s})$.

É sensato esperar, por exemplo, que tubulações mais rígidas respondam com pressões maiores quando submetidos a pertubações próprias daquelas que geram efeitos transientes. Um tubo mais rígido escoando líquido a uma dada velocidade, se fechada uma de suas extremidades imporá uma desaceleração maior ao fluido do que um tubo mais flexível, parte da energia utilizada na desaceleração do fluido será utilizada para expandir as paredes da tubulação permitindo que o fluido tome um maior intervalo de tempo até chegar ao repouso. O resultado é que toda a energia gerada pelo movimento do fluido será transmitida às paredes da tubulação, no caso de tubo rígido o que aumenta a pressão. Efeito semelhante ocorre na consideração de fluidos menos suscetíveis à variação do volume em virtude de variação de pressão. Maiores pressões são observadas quanto menor for a suscetibilidade do fluido. Tanto a rigidez da tubulação quanto do fluido são medidas que influenciam diretamente na velocidade do pulso de pressão de forma que a mesma análise pode ser feita para os dois casos, a partir das curvas do gráfico da Figura 5.23 .

O aumento da pressão com a velocidade do pulso de pressão é tão menos pronunciado quanto maior a proximidade com a base da tubulação o que significa que os pontos mais próximos da base sofrerão menor variação da pressão transiente em virtude de mudanças de características físicas do sistema. Em outras palavras, dois sistemas distintos com rigidez do fluido ou da tubulação diferentes, quando submetidos às mesmas condições e perturbações, deferirão mais nos resultados obtidos para pontos próximos a extremidade do que próximos à base da tubulação.

Observando a Figura 5.23 , percebe-se que para velocidades de $a$ menores que $200 \mathrm{~m} / \mathrm{s}$, as pressões nos pontos mais próximos à base da tubulação são maiores, após essa velocidade, esse 
comportamento se inverte ficando mais altas as pressões dos pontos mais próximos à extremidade oposta. Esse resultado pode ser entendido da seguinte forma, observe as curvas de pressão ao longo do comprimento da tubulação mostrados na Figura 5.15. Passado os efeitos transientes onde há uma elevação pronunciada dos valores de pressão inclusive com inversão das alturas relativas das curvas, o sistema tende a se estabilizar em valores de pressão mais altos do que aqueles inicialmente previstos para o tempo anterior à perturbação que causou o transiente. É possível se identificar um sobressinal transiente referente à elevação das curvas de pressão acima dos valores apresentados logo que passados os efeitos transientes mais pronunciados. Nos casos em que a velocidade do pulso de pressão $a$ é menor que $200 \mathrm{~m} / \mathrm{s}$, esse sobressinal não é observado, portanto não há inversão das alturas relativas das curvas de pressão em nenhum momento. Ultrapassado esse valor da velocidade $a$, o sobressinal fica cada vez mais pronunciado, o resultado é o aumento da pressão observado nas curvas da Figura 5.23 . 


\section{Capítulo 6}

\section{Controle Deslizante}

O controle deslizante (Sliding Control) é um método de controle não linear que altera a dinâmica de um sistema não linear pela aplicação de um sinal de controle descontínuo que força o sistema a se manter sobre uma superfície (sliding surface), que dá as condições para que a variável controlada do sistema mantenha um erro próximo a zero em relação a uma variável predeterminada. Slotine [Slotine e LI 1991] classifica o controle deslizante como robusto, apropriado a tratar sistemas não lineares que tenham incertezas em seu modelo. Segundo o autor, incertezas associadas podem ser estruturadas, advindas de incertezas associadas a parâmetros não conhecidos do modelo que descreve o sistema, ou não estruturadas advindas da simplificação de representação de um dado modelo que negligencia partes da dinâmica do sistema. Na estrutura típica do controlador robusto há uma parte nominal similar a realimentação linearizante e termos adicionais que lidarão com as incertezas do modelo dinâmico.

O modelo dinâmico adotado para determinação do nível do líquido no interior do separador apresenta incertezas associadas a partes que são tratadas como não modeladas. Essas incertezas advêm de variáveis que são obtidas pela solução dos dois conjuntos de equações que descrevem o comportamento do escoamento do gás e do líquido em suas respectivas tubulações e que foram discutidos no Capítulo 3, levantados pela teoria de transientes em fluidos. A vantagem de se tratar essas variáveis como incertezas do sistema é que é possível representar sua dinâmica por uma equação de primeira ordem, apesar de se estar lidando com uma dinâmica de ordem superior fortemente não linear já que as equações que governam o escoamento do líquido dentro das tubulações de saída são equações diferenciais não lineares no tempo e no espaço. Assim, visualizando-se o separador ciclônico submerso como um sistema dinâmico com incertezas não estruturadas associadas, o controle deslizante torna-se um excelente candidato à lei de controle.

$\mathrm{Na}$ implementação do controlador baseado na teoria de controle deslizante uma dificuldade emerge. Esse tipo de controlador utiliza um sinal descontínuo. No caso do sistema estudado o atuador responsável por desenvolver o sinal de controle é uma bomba ESP ${ }^{1}$. Assim, uma preocupação surge quanto ao controlador utilizado. As variações bruscas do sinal de controle impostas pela natureza descontínua de um controle deslizante seriam refletidas em variações bruscas da

\footnotetext{
${ }^{1}$ Vale et al. 2002 discute a instalação de um separador VASPS
} 
frequência de rotação da bomba, isso poderia causar um esforço excessivo do atuador diminuindo sua vida útil. Uma forma de contornar esse problema é através da aplicação de um filtro ao sinal de controle, de forma que as descontinuidades sejam eliminadas. A aplicação do filtro, no entanto, leva a diminuição do tempo de resposta do atuador o que não será um grande problema já que o papel do controlador não é manter o nível do líquido no interior do separador num valor exato sob uma tolerância exigente, mas mantê-lo dentro de um intervalo de valores que permitam que haja espaço suficiente para a separação das fases, não ultrapassando um valor superior e que imponham que o nível não seja baixo o suficiente para alcançar a bomba.

Ao longo do Capítulo é utilizada a expressão projetista do controlador, que refere-se ao fato de que a lei de controle apresentado no presente estudo não é elaborado para um caso prático particular. Dessa forma, a adaptação do controlador para um caso particular, com a determinação de valores dos parâmetros fica a cargo do projetista.

Neste Capítulo é discutido o controlador proposto para controlar o nível do líquido no interior do separador ciclônico submerso (seções de 6.1 e 6.2) bem como o filtro a ser aplicado ao sinal de controle obtido (seções 6.3 6.4) e as condições necessárias esperadas para o sistema a fim de que o controlador possa ser aplicado (seção 6.5).

\subsection{Superfície Deslizante}

Considere o sistema dinâmico de, apenas, uma entrada mostrado abaixo:

$$
\mathbf{x}^{n}=f(\mathbf{x})+b(\mathbf{x}) u
$$

a equação é composta por uma parte, $f(\mathbf{x})$ que não é exatamente conhecida. Apesar de não ser determinada a função $f$ tem limites bem determinados que podem ser descritos como uma função conhecida de $\mathbf{x}$. Na equação $6.1, b$ é o ganho de controlador, $u$ é o sinal utilizado para controle do sistema e $\mathbf{x}$ é o vetor de estados do sistema, geralmente, não linear.

Assim como a primeira parcela da equação 6.1, o ganho do sinal de controle não tem, necessariamente, uma valor conhecido [Slotine e LI 1991], mas seus valores máximos e mínimos estão limitados por funções de $\mathbf{x}$ bem definidas. Dada as incertezas do sistema dinâmico advindas da imprecisão do modelo tanto em $f(\mathbf{x})$ quanto em $b(\mathbf{x})$, o problema relacionado ao controle tornase determinar um dado estado $\mathbf{x}$ que faça o sistema rastrear e seguir uma trajetória desejada previamente definida pelo estado $\mathbf{x}_{d}$, sendo este, variante no tempo. [Slotine e LI 1991]

Para que a trajetória desejada seja seguida por um sinal de controle finito $u$, a condição inicial do estado a ser seguido deve será tal que:

$$
\mathbf{x}_{d}(0)=\mathbf{x}(0)
$$

Defini-se, então um erro de estado $\hat{\mathbf{x}}=\mathbf{x}-\mathbf{x}_{d}$ como uma função da do estado $\mathbf{x}$. Dessa forma é possível definir-se uma superfície $s$ variante no tempo, tal que: 


$$
s(\mathbf{x}, t)=\left(\frac{d}{d t}+\lambda\right)^{n-1} \hat{\mathbf{x}}
$$

onde $\lambda$ é um valor estritamente positivo.

Assim, dada a condição inicial da equação 6.2, o problema é fazer com que o sistema siga a trajetória desejada $\left(\mathbf{x}=\mathbf{x}_{d}\right)$ torna-se um problema equivalente ao problema de se permanecer sobre a superfície $s(t)$, ou seja, fazer com que a equação da superfície seja igual a zero para qualquer tempo $t>0$.

A superfície $s$ tal qual definida na equação 6.3, representa uma equação diferencial linear para qual a única solução é $\hat{\mathbf{x}}=0$. Dessa forma, o problema de fazer o sistema seguir a trajetória desejada, $\mathbf{x} \rightarrow \mathbf{x}_{d}$, é reduzido ao problema de se manter a quantidade escalar $s$ igual a zero, ao longo do tempo. Em outras palavras, a implementação da superfície $s$ permite transformar o problema de se rastrear o vetor n-dimensional $\mathbf{x}_{d}$, em um problema de estabilização de uma equação de primeira ordem em termos de $s$, já que a primeira derivada de $s$ explicita do sinal de controle $u$.

\subsubsection{Relação entre os Limites dos Valores do Erro de Posição e os Limites impostos à Superfície}

Para ilustrar o rastreamento de uma dada trajetória desejada pela solução da equação de primeira ordem, seja um sistema de quarta ordem $(n=4)$ nos moldes da equação 6.1. Assumindo $\hat{\mathbf{x}}(0)=0$, ou seja, que o vetor erro está na posição de equilíbrio no momento inicial $t=0$, pode-se escrever:

$$
\forall t>0, \quad|s(t)| \leq \Phi
$$

Tem-se, então, a quantidade escalar $s(t)$ limitada por $\Phi$ conforme mostrado na Figura 6.1.

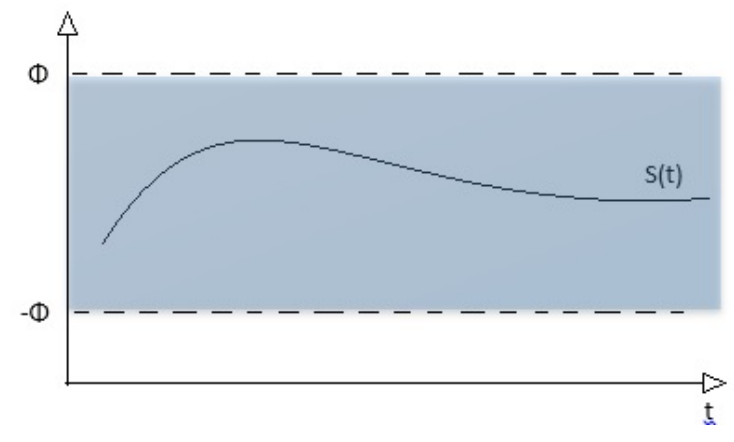

Figura 6.1: região de contenção de $s(t)$

Com base nos limites de $s(t)$ a inequação 6.4 do sistema de quarta ordem pode ser reescrita da seguinte forma: 


$$
|s|=\left|\left(\frac{d}{d t}+\lambda\right)^{4-1} \hat{x}\right| \leq \Phi
$$

expandindo a equação 6.5 :

$$
\left|\dddot{\hat{x}}+3 \lambda \ddot{\hat{x}}+3 \lambda^{2} \dot{\hat{x}}+\lambda^{3} \hat{x}\right| \leq \Phi
$$

Estando os valores de $s(t)$ estabelecidos entre limites $\pm \Phi$ para todo tempo $t \geq 0$, pode-se afirmar [Slotine e LI 1991] que os elementos de vetor erro de estados $\hat{\mathbf{x}}$, também estarão limitados, mas por um valor proporcional a $\Phi$ tal que :

$$
\forall t \geq 0, \quad\left|\hat{x}^{(i)}(t)\right| \leq(2 \lambda)^{i} \frac{\Phi}{\lambda^{4-1}}
$$

onde $i=0,1,2,3$.

Os limites impostos a $s(t)$ implicam diretamente em limites do vetor erro segundo a equação 6.6. Nesses termos, $s$ pode ser interpretado como uma medida da performance do controlador no que tange à convergência do estado atual do sistema num dado instante $t$, para o estado desejado $\mathbf{x}_{d}$.

Para visualização da limitação dos elementos do vetor erro em termos dos limites imposto a $s$, considere o diagrama de blocos mostrado na Figura 6.2 que representa um filtro de primeira ordem aplicado a $s$.

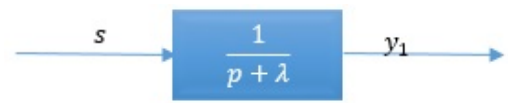

Figura 6.2: Diagrama de blocos de filtro de primeira ordem onde p é o operador laplaciano

A partir do diagrama obtém-se o valor do sinal $y_{1}$ no domínio de laplace pela equação 6.7

$$
\frac{Y_{1}(p)}{S(p)}=\frac{1}{p+\lambda}=G(p)
$$

$p$ é o operador laplaciano da equação.

Aplicando sucessivos filtros de primeira ordem a $s$ chega-se ao seu valor em termos dos elementos de vetor erro $\hat{\mathbf{x}}$ conforme a equação anunciada na primeira parte da inequação 6.5 , de modo que o sinal de erro de trajetória $\hat{x}$ pode ser obtido a partir do diagrama da Figura 6.3 


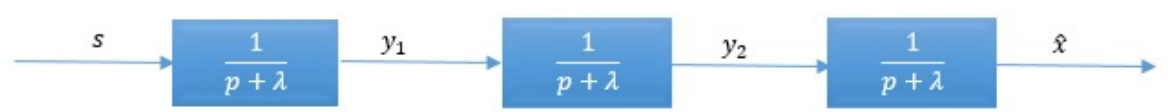

Figura 6.3: Diagrama de blocos com sucessivos filtros passa-baixa aplicados a s. O erro de trajetória é a saída do sistema descrito pelo diagrama. p é o operador laplaciano

$$
\frac{\hat{X}(p)}{S(p)}=\frac{1}{p^{3}+3 \lambda p^{2}+3 \lambda^{2} p+p^{3}}
$$

O sinal intermediário $y_{1}$ no domínio do tempo pode ser recuperado aplicando-se a transformada inversa de laplace ao respectivo sistema (eq. 6.7):

$$
y_{1}(t)=\mathcal{L}^{-1}(t)\{G(p) S(p)\}
$$

onde $\mathcal{L}^{-1}(t)\{F(p)\}$ representa da forma geral da transformada inversa de laplace de uma função $F(p)$, no domínio de laplace, para sua forma $f(t)$ no domínio do tempo.

Utilizando a propriedade do produto da transformada da convolução a equação 6.7 é reescrita na seguinte forma:

$$
y_{1}(t)=\mathcal{L}^{-1}(t)\{\mathcal{L}(p)\{g(t) * s(t)\}\}
$$

Admitindo-se a propriedade da transformada inversa de laplace aplicada à transformada direta, que resulta na própria função original, a admitindo-se a definição de convolução, chega-se a:

$$
y_{1}(t)=\int_{0}^{t} g(t-\tau) s(\tau) d \tau=\int_{0}^{t} e^{-\lambda(t-\tau)} s(\tau) d \tau
$$

onde $g(t)$ é dada pela inversa de $G(p)$ em 6.7

Os limites inicialmente assumidos, $|s|<\Phi$, permitem afirmar-se que $y_{1}$ também estrá limitado uma vez que:

$$
\left|y_{1}(t)\right| \leq \int_{0}^{t} e^{-\lambda(t-\tau)} \Phi d \tau
$$

sendo $\Phi$ independente do tempo, a solução da integral definida leva a:

$$
\left|y_{1}(t)\right| \leq \frac{\Phi}{\lambda}
$$

O valor do sinal intermediário $y_{2}$ pode ser encontrado, seguindo a lógica aplicada ao sinal $y_{1}$, pela transformação inversa do produto de sua respectiva função de transferência com $Y_{1}(p)$ conforme o diagrama da Figura 6.3, logo: 


$$
y_{2}(t)=\int_{0}^{t} g(t-\tau) y_{1}(\tau) d \tau=\int_{0}^{t} e^{-\lambda(t-\tau)} y_{1}(\tau) d \tau
$$

A partir da equação 6.13 e resolvendo a integral definida apresentada na equação 6.11 , chega-se ao valor do limite imposto ao sinal intermediário $y_{2}$ :

$$
\left|y_{2}(t)\right| \leq \frac{\Phi}{\lambda^{2}}
$$

Por fim, o mesmo desenvolvimento que levou a inequação 6.15 é aplicado ao erro de trajetória $\hat{x}$. O resultado é que $\hat{x}$ terá um valor circunscrito a uma região também limitada, uma vez impostos os limites de $s$.

$$
|\hat{x}(t)| \leq \frac{\Phi}{\lambda^{3}}
$$

Em geral, dado um sistema de ordem $n$, o erro associado a trajetória respeitará a seguinte relação:

$$
|\hat{x}(t)| \leq \frac{\Phi}{\lambda^{n-1}}
$$

\subsubsection{Limites Impostos aos Elementos do Vetor Erro}

Assim como no caso da posição do erro associado à trajetória do sistema, a imposição de limites à superfície deslizante descrita em termos do valor $s$ (ver equação 6.4) acaba por impor que os valores dos elementos do vetor erro de estado $\hat{\mathbf{x}}$ também estarão limitados proporcionalmente ao valor do limite imposto a $s$. Para se chegar a relação entre dos limites impostos aos elementos de $\hat{\mathbf{x}}$, considere os diagramas de blocos mostrados na Figura 6.4 que levam aos elementos do vetor erro de estado $\left[\begin{array}{llll}\hat{x} & \ddot{\hat{x}} & \ddot{\hat{x}} & \ddot{\hat{x}}\end{array}\right]^{T}$ de um sistema de quarta ordem $(n-1=3)$.

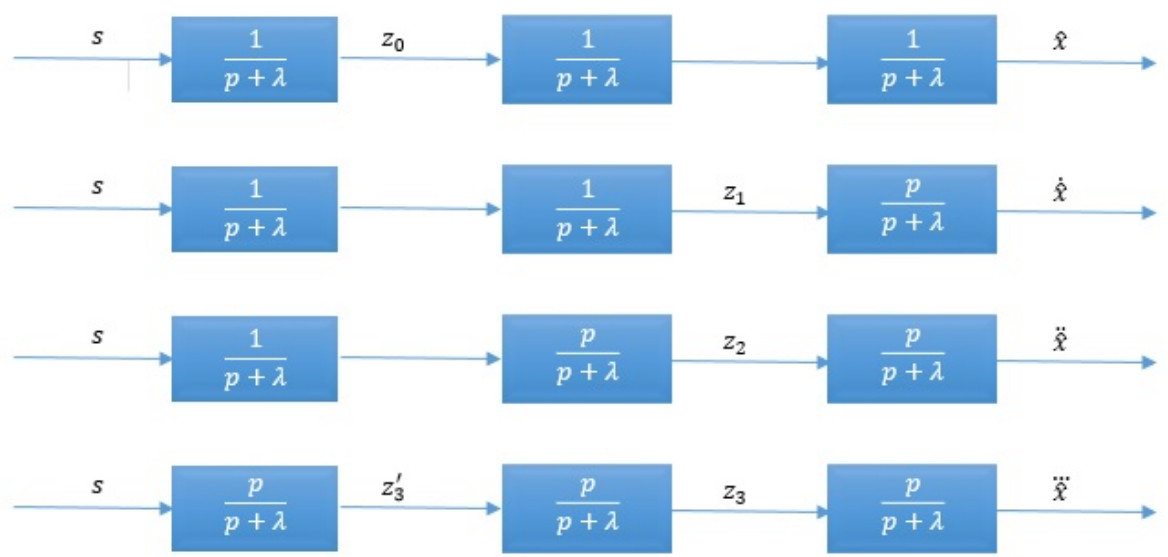

Figura 6.4: diagramas de blocos dos elementos do vetor $\hat{\boldsymbol{x}}$.

A partir dos diagramas de blocos pode se escrever as respectivas funções de transferências. A função de transferência da para a primeira derivada temporal do erro de posição $\dot{\hat{x}}$ será: 


$$
\frac{\hat{X}^{(1)}(p)}{S(p)}=\frac{1}{p+\lambda} \frac{1}{p+\lambda} \frac{p}{p+\lambda}
$$

Como a função de transferência do sinal intermediário $z_{1}$ é:

$$
\frac{Z_{1}(p)}{S(p)}=\frac{1}{p+\lambda} \frac{1}{p+\lambda}
$$

pode-se escrever:

$$
\hat{X}^{(1)}(p)=\left(1-\frac{\lambda}{p+\lambda}\right) Z_{1}(p)
$$

A esse ponto o mesmo procedimento adotado na seção 6.1.1 é utilizado para se obter os limites de $\dot{\hat{x}}$. Assim, a transformada inversa de laplace da equação 6.20 leva a:

$$
\dot{\hat{x}}(t)=z_{1}(t)-\mathcal{L}^{-1}(t)\left\{G_{1}(p) Z_{1}(p)\right\}
$$

onde $G_{1}(p)=\frac{1}{p+\lambda}$. Da propriedade da transformada de laplace da convolução chega-se a:

$$
\dot{\hat{x}}(t)=z_{1}(t)-\int_{0}^{t} g_{1}(t-\tau) z_{1}(\tau) d \tau
$$

onde $g_{1}(t)=\mathcal{L}^{-1}(t)\left\{G_{1}(p)\right\}$

Os limites do sinal intermediário $z_{1}(t)$ podem ser obtidos pela inequação geral 6.17. Logo Sendo $\left|z_{1}\right| \leq \frac{\Phi}{\lambda^{2}}$, os limites de $\dot{\hat{x}}$ podem ser descritos da seguinte forma:

$$
|\dot{\hat{x}}(t)| \leq\left(1+\int_{0}^{t} g_{1}(t-\tau) d \tau\right) \frac{\Phi}{\lambda^{2}}
$$

Por fim, a transformada inversa de laplace de $G_{1}(p)$ leva a $g_{1}(t)=\lambda e^{-\lambda t}$ o que permite achar os limites de $\dot{\hat{x}}$ em termos dos limites impostos a $s$ :

$$
|\dot{\hat{x}}(t)| \leq\left(1+\frac{\lambda}{\lambda}\left(1-e^{-\lambda t}\right)\right) \leq 2 \frac{\Phi}{\lambda^{2}}
$$

De maneira semelhante, é possível chegar-se aos limites de $\dot{\hat{x}}$. Do respectivo diagrama na Figura 6.4, obtém-se a função transferência relativa à segunda derivada de $\hat{x}$ :

$$
\frac{\hat{X}^{(2)}(p)}{S(p)}=\frac{1}{p+\lambda} \frac{p}{p+\lambda} \frac{p}{p+\lambda}
$$

Considere, então, a função de transferência da transformada de laplace de $z_{2}$ (ver Figura 6.4) em termos do sinal intermediário $z_{0}$ : 


$$
Z_{2}(p)=\frac{p}{p+\lambda} Z_{0}(p)
$$

$Z_{2}$ e $Z_{0}$, são as transformadas de $z_{2}$ e $z_{0}$, respectivamente.

A transformada inversa da equação 6.25

$$
z_{2}(t)=z_{0}(t)-\int_{0}^{t} g_{0}(t-\tau) z_{0}(\tau) d \tau
$$

onde $g_{0}=\mathcal{L}^{-1}(t)\left\{G_{0}(p)\right\}$

O sinal $z_{0}$ é a saída de um sistema linear de primeira ordem, portanto, quando submetido a inequação 6.17 , fica limitado por $\left|z_{0}\right| \leq \frac{\Phi}{\lambda}$. Logo, a partir dos limites de $z_{0}$ chega-se aos limites de $z_{2}$ :

$$
\left|z_{2}\right| \leq\left(1+\frac{\lambda}{\lambda}\right) \frac{\Phi}{\lambda}
$$

A partir dos limites encontrados para $z_{2}$ e aplicando a transformada inversa à transformada de laplace da função $\ddot{\hat{x}}$ dada por $X^{(2)}(p)=\frac{p}{p+\lambda} Z_{2}(p)$ chega-se ao limites impostos a $\ddot{\hat{x}}$ em termos do limite $\Phi$ imposto a $s$

$$
|\ddot{\hat{x}}| \leq\left(1+\frac{\lambda}{\lambda}\right)\left(1+\frac{\lambda}{\lambda}\right) \frac{\Phi}{\lambda}=\frac{4}{\lambda} \Phi
$$

O mesmo raciocínio é usado para determinar os limites de $\dddot{\hat{x}}$. A função de transferência do sinal intermediário $z_{3}$ em função do sinal $z_{3}^{\prime}, Z_{3}=\frac{p}{p+\lambda} Z_{3}^{\prime}$ (ver o respectivo diagrama na Figura 6.1), quando submetida à transformação inversa de laplace, sabendo-se que $\left|z_{3}^{\prime}\right| \leq \Phi\left(1+\frac{\lambda}{\lambda}\right)$, leva aos limites de $\dddot{x}$ segundo a seguinte inequação:

$$
|\dddot{x}| \leq\left(1+\frac{\lambda}{\lambda}\right)\left(1+\frac{\lambda}{\lambda}\right)\left(1+\frac{\lambda}{\lambda}\right) \Phi=8 \Phi
$$

Os limites do sinal $z_{3}^{\prime}$ foram obtidos aplicando-se a transforma da inversa de laplace à sua função de transferência $\frac{Z_{3}^{\prime}(p)}{S(p)}=1-\frac{\lambda}{p+\lambda}$.

A relação geral entre os limites impostos a $s$ e os limites impostos aos elementos do vetor erro $\hat{\mathbf{x}}$, é dada pela seguinte inequação:

$$
\left|\hat{x}^{(i)}\right| \leq\left(1+\frac{\lambda}{\lambda}\right)^{i}\left(\frac{\Phi}{\lambda^{n-1-i}}\right)=(2 \lambda)^{i} \frac{\Phi}{\lambda^{n-1}}
$$

Esta última inequação explicita o fato de que um vez que a quantidade escalar $s$ convirja para zero, o vetor erro de estado $\hat{\mathbf{x}}$ também convergirá, de modo que a trajetória seguida pelo sistema coincidirá com a trajetória desejada previamente determinada. É possível, então, estabelecer critérios de convergência específicos que se ajustem a uma dada necessidade ou vontade do projetista de um controlador particular. Por exemplo, num caso hipotético em que se deseje que o sistema 
controlado deva apresentar comportamento tal que, um dado elemento do vetor erro de estado $\hat{\mathbf{x}}$ de ordem superior convirja mais rapidamente que um elemento de ordem inferior do mesmo vetor, basta garantir que o intervalo de valores o primeiro pode assumir em relação ao limite imposto a $s$, seja menor que o intervalo de valores assumíveis pelo segundo. Para clarear a ideia, suponha que se deseje que um dado sistema de ordem superior $(n \geq 4)$, tenha o elemento de quarta ordem do vetor $\hat{\mathbf{x}}$ limitado por um intervalo de valores menor que o intervalo limitador do elemento de segunda ordem. A inequação 6.30 resulta em $|\dddot{\widehat{x}}| \leq \frac{16 \Phi}{\lambda^{4-n+1}}$, e $|\ddot{\hat{x}}| \leq \frac{4 \Phi}{\lambda^{2-n+1}}$, assim para que $\dddot{\widehat{x}} \leq \ddot{\hat{x}}$, basta que $\lambda \geq 4$.

\subsection{Lei de Convergência Aplicada e Controle do Separador Sub- merso}

O controlador a ser aplicado será estabelecido a partir de uma lei de convergência a ser aplicada de acordo com o método do Sliding Control, de forma a fazer com que o sistema controlado convirja. Descrito o controlador será possível apresentar um exemplo de um sistema controlado. Nesse ponto, ainda não são realizadas considerações a cerca da adequação da lei de controle para que se consiga preservar o atuador. Isso será feito a partir da adoção de um filtro, uma vez que o sinal de controle esteja estabelecido.

\subsubsection{Determinação da Lei da Controle a partir da Lei de Convergência}

A convergência do estado de um dado sistema, sob ação de um controle deslizante (seção 6.1), para um estado desejado, passa pela assunção de que, para todo $t \geq 0$ o sistema controlado permanecerá sobre a superfície deslizante. Permanecer sobre a superfície significa que a quantidade escalar $s$ que a define, dada pela equação 6.3, deverá ser zero no mesmo intervalo de tempo. Faz-se necessário, então, a imposição de uma lei de convergência que garanta que o sistema controlado permaneça sobre a superfície deslizante de modo a se conseguir a convergência de sua trajetória para a trajetória desejada. Em concordância com o trabalho de referência para o controlador [Slotine e LI 1991], assumiu-se para o presente trabalho uma lei básica de controle tal que a taxa de variação temporal de $s$ seja menor que uma quantidade proporcional ao seu sentido negativo:

$$
\dot{s}=-\eta \frac{|s|}{s}
$$

A equação 6.31 implica num erro de trajetória sempre decrescente de que modo que o intervalo dentro do qual erro está circunscrito tende a se estabilizar em valores próximos a zero.

Seja o exemplo de um sistema de segunda ordem descrito por uma função geral $f$ variante no tempo, linear ou não, na seguinte forma:

$$
\ddot{x}=f+u
$$


$x$ é o sinal da saída do sistema e $u$ o sinal de controle.

A aplicação de um controlador nos moldes do discutido na seção 6.1, pressupõe o conhecimento dos limites máximos e mínimos que a função pode assumir apesar de não haver a necessidade de se conhecer seu comportamento ao longo do tempo. Considerando que $f$ seja um função não determinada mas passível de ser estimada por um função $\hat{f}$ e que o erro associado à essa estimativa não seja maior que uma função conhecida $F(x, \dot{x})$, pode-se determinar um sinal de controle $(u)$ que obedeça a lei de convergência 6.31. A Figura 6.5, mostra uma representação gráfica dos possíveis valores de $f$, bem como de sua melhor estimativa e limites de circunscrição sendo esses limites descritos na forma:

$$
|\hat{f}-f| \leq F(x, \dot{x})
$$

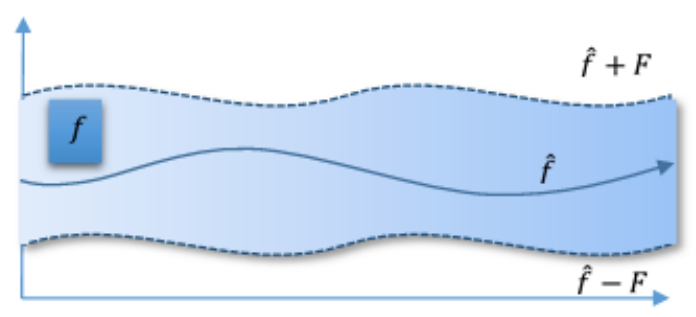

Figura 6.5: limites da função desconhecida $f$.

Os limites de circunscrição de $f$, em termos de sua melhor estimativa, podem ser escritos na seguinte forma:

$$
\ddot{x}=f+u
$$

O sinal de controle será obtido a partir da definição da superfície aplicável ao sistema, com base na definição dada pela equação 6.3 , logo:

$$
s=\dot{\hat{x}}+\lambda \hat{x}
$$

Da equação 6.35, obtém-se a taxa de variação temporal de $s$ :

$$
\dot{s}=\ddot{\hat{x}}+\lambda \dot{\hat{x}}
$$

A variável $\hat{x}$ nas equações 6.35 e 6.36 , corresponde à definição do erro de trajetória do sistema em relação à trajetória desejada, $\hat{x}=x-x_{d}$. Do valor do erro $\hat{x}$, bem como da dinâmica do sistema em 6.32, chega-se à seguinte forma para taxa de variação temporal de $s$ :

$$
\dot{s}=f+u-\ddot{x}_{d}+\lambda \dot{\hat{x}}
$$


Dada a equação 6.37, a melhor aproximação para o sinal de controle $\hat{u}$, será aquela que fará a taxa temporal de $s$ se igualar a zero [Slotine e LI 1991], uma vez que a melhor estimativa da parte não conhecida da dinâmica do sistema coincida com seu valor, ou seja, quando $\hat{f}=f$. Assim para o sistema da equação 6.32, propõe-se o seguinte controlador:

$$
\hat{u}=-\hat{f}+\ddot{x}_{d}-\lambda \dot{\hat{x}}
$$

Para que o controlador consiga satisfazer a lei de convergência 6.31, faz-se necessário a adoção de um termo descontínuo sobre no sinal de controle, sobre a superfície $s$. O sinal de controle assumirá, então a seguinte forma:

$$
u=\hat{u}-k \operatorname{sign}(s)
$$

onde $k$ é uma função de $\mathbf{x}$ tal que $k=k(x, \dot{x})$, e sign é um função definida da seguinte forma:

$$
\operatorname{sign}(s)=\left\{\begin{array}{l}
+1, \text { se } s \geq 0 \\
-1, \text { se } s<0
\end{array}\right.
$$

Projetado o controlador, o próximo passo é escolher a função $k(x, \dot{x})$ com valor suficiente para garantir que a lei de convergência seja verificada, o que pode ser conseguido assumindo a seguinte para função $k$ :

$$
k=F+\eta
$$

Pode-se provar que $k$ é suficiente, a partir de seu valor e das equações 6.31 e 6.32, tem-se, então:

$$
\dot{s} s=\left(f+u-\ddot{x}_{d}+\lambda \dot{\hat{x}}\right) s
$$

Da equação 6.39:

$$
\dot{s} s=\left(f+\hat{u}-k \operatorname{sign}(s)-\ddot{x}_{d}+\lambda \dot{\hat{x}}\right) s
$$

Dos valores de $\hat{u}$ e $k$ aplicados à equação 6.43 acima:

$$
\dot{s} s=(f-\hat{f}) s-F|s|-\eta|s|
$$

Como $(f-\hat{f}) s \leq|f-\hat{f}||s|$, pode-se escrever:

$$
\dot{s} s \leq|f-\hat{f}||s|-F|s|-\eta|s|
$$


Assim, através definição de $F$, dada em 6.33, chega-se à própria lei de convergência:

$$
\dot{s} s \leq-\eta|s|
$$

Dessa forma, o controlador garante que o estado desejado $\hat{\mathbf{x}}$ seja rastreado de maneira que a esperada convergência da trajetória do sistema à trajetória desejada é alcançada.

\subsubsection{Controle do Separador Ciclônico}

Considere agora, o sistema dinâmico que descreve o comportamento do nível do líquido no interior do separador ciclônico submerso, alvo do presente trabalho. Trata-se de um sistema que pode ser representado por uma função não linear de primeira ordem na seguinte forma geral:

$$
i=f(\gamma, l)
$$

A variável $l$ é a saída do sistema e $\gamma$ é o sinal de controle usado para estabelecer o nível do líquido no interior do separador, no valor desejado de acordo com as características do sistema. O projeto de controle deslizante começa pelo estabelecimento da superfície $s$ correspondente. Esta pode ser obtida a partir de sua definição, na equação 6.3. Tratando-se de um sistema de primeira ordem, a definição da superfície leva a um valor coincidente com o erro de posição. O erro de posição para o separador submerso será dado pela posição do nível de líquido $(l)$ em seu interior num dado tempo, menos a posição desejada $\left(l_{d}\right)$ no mesmo instante. Logo, a superfície $s$, ou erro de trajetória $\hat{x}$ terá a seguinte forma:

$$
s=\hat{x}=l-l_{d}
$$

Com base em 6.48 , a taxa de variação temporal de $s$ é facilmente obtida:

$$
\dot{s}=\dot{l}-i_{d}
$$

Para que a trajetória do nível de líquido no interior do separador convirja para desejada $\left(l \rightarrow l_{d}\right)$, faz-se necessária a assunção da lei de convergência e a determinação de um sinal de controle que force o sistema a respeitá-la. Então, para se alcançar um controlador apropriado deve-se observar a dinâmica do sistema mais detalhadamente. Como já descrito em Capítulos anteriores, o nível do líquido pode ser descrito como se segue:

$$
\frac{d l}{d t}=\frac{q_{\text {in }}}{A}-\frac{q_{\text {out }}}{A}
$$

Na equação 6.50, $A$ é a área transversal do recipiente de separação, qin é o sinal de entrada correspondente à vazão de entrada de líquido no separador e $q_{\text {out }}$ é a vazão de saída do líquido. A vazão de saída em termos dos parâmetros de sistema discutidos no Capítulo 5, é descrita por: 


$$
q_{\text {out }}=\frac{B}{2 a_{2}}\left[1-\sqrt{1-\frac{4 a_{2}}{B^{2}}\left(\gamma^{2} H_{s}+\frac{p_{L}}{\rho g}-C_{M}\right)}\right]
$$

A pressão da coluna de líquido no ponto de saída do líquido é uma função da altura da coluna e da pressão do gás acima dela:

$$
p_{L}=p_{G}+\rho g\left(l-l_{0}\right)
$$

onde $l_{0}$ é a altura onde o líquido é bombeado.

Para fins de simplificação, o ponto de bombeamento do líquido será tomado como estando na base do separador de forma que $l_{0}=0$. Uma ilustração do separador com os referidos parâmetros é apresentado na Figura 6.6

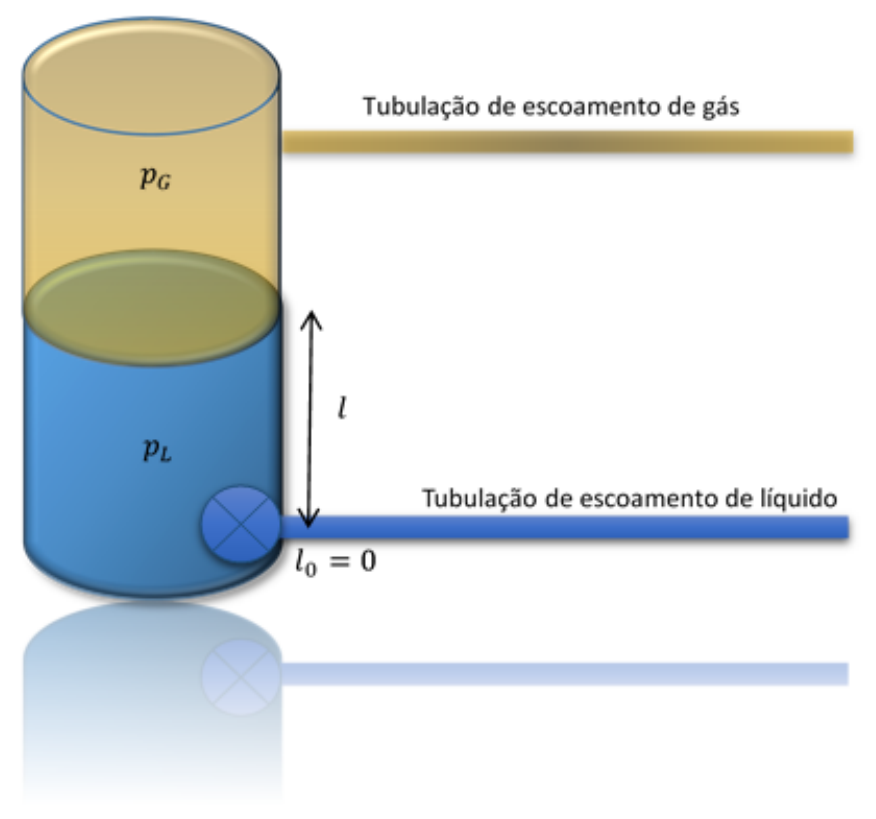

Figura 6.6: Pressões da coluna de líquido $p_{L}$ e do gás acima da coluna $p_{G}$ no interior do separador ciclônico. l é o nível do líquido no interior do separador e o ponto de bombeamento é fixado na base do recipiente, $l_{0}=0$

Duas variáveis destacam-se na equação do nível de líquido: a pressão do gás $p_{G}$ e o parâmetro $C_{M}$. A pressão $p_{G}$ é uma função da pressão de vazão do gás ao longo do comprimento da respectiva tubulação ao longo do tempo, enquanto o parâmetro $C_{M}$ é uma função da altura piezométrica e da vazão do líquido na saída da bomba, ou no ponto de intersecção entre o separador e a tubulação de escoamento do líquido. Este parâmetro é determinado a partir do histórico do comportamento da pressão e vazão do líquido em pontos adjacentes da tubulação de escoamento do líquido, para um tempo $t_{n-1}$ anterior ao medido num dado instante $t_{n}$. Uma maneira de se tratar esses parâmetros, dadas suas complexidades inerentes e método de determinação fatigante, é considerálos como funções de comportamento incerto, mas com limites de valores bem determinados. É razoável esperar que num ambiente de operação real, tanto a pressão $p_{G}$ quanto o parâmetro $C_{M}$ 
sejam limitados por valores típicos de um caso particular, sendo esses valores determinados por um estudo específico a ser realizado para cada caso.

Considere, então, $p_{G}$ e $C_{M}$ limitados por funções temporais de comportamento bem definido, tais que:

$$
p_{G} \leq \hat{p}_{G}(t) \quad, \quad C_{M} \leq \hat{C}_{M}(t)
$$

Como tanto $\hat{p}_{G}(t)$ quanto $\hat{C}_{M}(t)$ são funções conhecidas, é possível prever o exato comportamento do sistema no caso limite em que a pressão no interior do separador e o parâmetro $C_{M}$ se aproximam de seus valores balizadores num determinado instante $\left(p_{G}(t) \rightarrow \hat{p}_{G}(t)\right.$, $\left.C_{M}(t) \rightarrow \hat{C}_{M}(t)\right)$. O desafio, então surge da necessidade de se projetar um controlador robusto suficiente para forçar a superfície $s$, nesse caso o próprio erro de trajetória, a se igualar a zero quando $p_{G}$ e $C_{M}$ assumirem valores conforme as inequações 6.53. Para tanto, faz-se produtivo formular o controlador a partir da determinação da taxa temporal de variação da superfície $s$, utilizando procedimento semelhado ao da seção 6.2.1.

O valor de $\dot{s}$ para o sistema dinâmico que descreve o separador submerso é obtido das equações 6.49 e 6.50 :

$$
\dot{s}=q-\beta_{1}\left[1-\sqrt{1-\beta_{2}\left(\gamma^{2} H_{s}+\beta_{3} p_{G}-C_{M}+l\right)}\right]
$$

onde $q=\frac{q_{i n}}{A}, \beta_{1}=\frac{B}{2 A a_{2}}, \beta_{2}=\frac{4 a_{2}}{B^{2}}$ e $\beta_{3}=\frac{1}{\rho g}$.

A questão a esse ponto, é encontrar um sinal de controle capaz de anular o erro de trajetória. Como feito anteriormente na seção 6.2, esse sinal de controle pode ser obtido igualando a taxa de variação temporal de $s$ a zero. Uma boa estimativa do sinal de controle será a função que consegue igualar a $\dot{s}$ a zero quando as variáveis incertas do sistema têm seus valores determinados. Para o modelo dinâmico do separador ciclônico submerso, suponha o seguinte sinal de controle obtido do caso em que o comportamento do sistema coincide com sua melhor estimativa:

$$
\hat{\gamma}^{2}=\frac{1}{H_{s}}\left(\hat{C}_{M}(t)-\beta_{3} \hat{p}_{G}(t)-l+\frac{1-\varphi^{2}}{\beta_{2}}\right)
$$

O termo $\varphi$, pode ser obtido substituindo-se a equação 6.55 na equação 6.54 , considerando $\gamma=\hat{\gamma}$ e impondo-se que $s$ não varie com o tempo, logo:

$$
\varphi=\frac{1}{\beta_{1}}\left(i_{d}-q\right)+1
$$

O controlador proposto na equação 6.55 pode ser visto, em alusão à nomenclatura usada em literatura especializada [Slotine e LI 1991], como a melhor estimativa de um controlador equivalente. O procedimento utilizado para se chegar em $\hat{\gamma}^{2}$ configura um procedimento geral em que o controlador equivalente é obtido resolvendo-se a equação da taxa de variação temporal de $s$ igualada a zero. Observe que $s$, no presente estudo, coincide com o erro de trajetória. O controlador 
equivalente será, então, a função capaz de zerar a taxa de erro de trajetória $(\dot{s}=0)$ quando a dinâmica do sistema for completamente determinada. Um ajuste ainda se faz necessário, para que a condição imposta pela lei de convergência (inequação 6.31) seja respeitada independentemente das incertezas de $p_{G}$ e $C_{M}$. É adicionado ao controlador equivalente um parâmetro descontínuo em função da superfície $s$, procedendo-se semelhantemente ao procedimento que levou a equação 6.39. O sinal, ou lei, de controle assumirá a seguinte forma:

$$
\gamma^{2}=\frac{1}{H_{s}}\left(\hat{C}_{M}(t)-\beta_{3} \hat{p}_{G}(t)-l+\frac{1-\varphi^{2}}{\beta_{2}}\right)
$$

onde

$$
\varphi=\frac{1}{\beta_{1}}\left(i_{d}-q\right)+1+k \operatorname{sign}(s)
$$

O próximo passo é determinar o valor de $k$ que faça com que o sinal de controle cumpra sua função, ou seja, impor à trajetória do sistema um comportamento coincidente ao da trajetória desejada. Isso é conseguido garantindo-se $s=0 \mathrm{ou}$, equivalentemente, que o erro de trajetória seja zero. Considere, outra vez, o sistema totalmente conhecido $\left(p_{G}(t)=\hat{p}_{G}(t)\right.$ e $\left.C_{M}(t)=\hat{C}_{M}(t)\right)$, com base nas equações 6.49 e 6.54 a lei de convergência para o sistema do separador submerso poderá ser escrita:

$$
\dot{s} s=\left(q-\beta_{1}\left[1-\sqrt{1-\beta_{2}\left(\gamma^{2} H_{s}+\beta_{3} p_{G}-C_{M}+l\right)}\right]-i_{d}\right) s \leq-\eta|s|
$$

Substituindo o valor do sinal de controle 6.57 na equação 6.59 :

$$
\dot{s} s=\left(q-\beta_{1}(1-\varphi)-\dot{l}_{d}\right) s \leq-\eta|s|
$$

do valor de $\varphi$ chega-se a:

$$
\dot{s} s=k \operatorname{sign}(s) s \leq-\eta|s|
$$

$\mathrm{Ou}$

$$
\dot{s} s=k|s| \leq-\eta|s|
$$

Logo, para que a lei de convergência seja respeitada basta que

$$
k=-\eta
$$

O controlador para o caso prático em que tanto $p_{G}$ quanto $C_{M}$ representam incertezas do sistema, será obtido pela implementação de algumas modificações no controlador proposto pela equação 6.57. Considere o máximo erro absoluto dos parâmetros incertos da dinâmica do sistema balizado por valores determinados. De forma que se tenha $\bar{p}$ e $\bar{C}$, como valores balizadores das incertezas do sistema de forma que: 


$$
\left|\hat{p}_{G}-p_{G}\right| \leq \bar{p} \quad, \quad\left|\hat{C}_{M}-C_{M}\right| \leq \bar{C}
$$

Das inequações 6.64 depreende-se que uma vez estimados a pressão do gás acima da coluna de líquido no interior do separador e o parâmetro $C_{M}$ no ponto de intersecção entre a saída da bomba submersa e a tubulação de escoamento de líquido, espera-se que o sistema se comporte de maneira que o erro associado à estimativa das incertezas não ultrapasse um valor absoluto máximo previamente conhecido. Os valores de $\bar{p}$ e de $\bar{C}$ são dados iniciais do problema de controle adquiridos pelo estudo das limitações do sistema já que, como discutido anteriormente, a implementação de um controle deslizante depende do conhecimento dos limites de valores aos quais os parâmetros que representam as incertezas do sistema estão sujeitos.

Introduzindo as funções $\bar{p}$ e $\bar{P}$ na equação do sinal de controle, 6.57 :

$$
\gamma^{2}=\frac{1}{H_{s}}\left(\hat{C}_{M}(t)+\bar{C}(t)-\beta_{3} \hat{p}_{G}(t)+\beta_{3} \bar{p}(t)-l+\frac{1-\varphi^{2}}{\beta_{2}}\right)
$$

O valor de $k$ foi encontrado na equação 6.63 para caso em que o sistema não apresenta incertezas em seu modelo dinâmico. Esse valor será adotado para o controlador geral dado em 6.65. Ressalvando-se que a validade do sinal controle precisará ser verificada uma vez que o valor de $k$ foi obtido para um caso específico. O valor de $\varphi$ será, então:

$$
\varphi=\frac{1}{\beta_{1}}\left(i_{d}-q\right)+1-\eta \operatorname{sign}(s)
$$

A equação 6.65 dá a forma geral da lei de controle, adotada no presente trabalho, a ser imposta ao separador ciclônico submerso. Como discutido em seções posteriores, esse controlador é robusto suficiente para garantir a convergência da trajetória do nível do líquido para uma trajetória desejada, previamente determinada. Na forma apresentada na equação 6.65, o sinal de controle consegue lidar não só com as incertezas do sistema como com possíveis efeitos transientes advindos do escoamento dos fluidos em suas respectivas tubulações. Esses transientes foram discutidos no Capítulo 3 e aparecem, por exemplo, no momento do acionamento do sistema de bombeamento ou no fechamento de uma válvula disposta num ponto ao longo da tubulação.

\subsubsection{Condição Parcial de Validade Segundo a Lei de Controle}

A Lei de controle apresentada pela equação 6.65, deve ser submetida a lei de convergência, dada pela inequação 6.31 , a fim de se verificar sua validade ou, em outras palavras, sua capacidade de atender a expectativa de forçar um comportamento pré definido a trajetória do nível líquido. Para proceder a verificação, seja o valor da taxa temporal da superfície corresponde ao controlador proposto $\left(\dot{s}=i-i_{d}\right)$ : 


$$
\dot{s}=q-\beta_{1}\left[1-\sqrt{1-\beta_{2}\left(\beta_{3} p_{G}-\beta_{3} \hat{p}_{G}+\beta_{3} \bar{p}-C_{M}+\hat{C}_{M}+\bar{C}_{M}+\frac{1-\varphi^{2}}{\beta_{2}}\right)}\right]-i_{d}
$$

Seja, ainda, a seguinte simplificação de notação:

$$
\delta=\delta_{p}+\delta_{C}
$$

onde

$$
\delta_{p}=\beta_{3}\left(p_{G}-\hat{p}_{G}+\bar{p}\right), \quad \delta_{C}=-C_{M}+\hat{C}_{M}+\bar{C}_{M}
$$

Os limites impostos em 6.64 garantem que tanto $\delta_{p}$ quanto $\delta_{C}$ sejam valores sempre positivos o que, por sua vez, implica $\delta \geq 0$ para todo $t \geq 0$. Dada as simplificações, a lei de convergência deverá ser verificada quando o sistema controlado atender a seguinte relação:

$$
f_{1}: \quad \dot{s} s=\left(q-\beta_{1}\left[1-\sqrt{1-\beta_{2}\left(\delta+\frac{1-\varphi^{2}}{\beta_{2}}\right)}\right]-i_{d}\right) s \leq-\eta|s|
$$

Observe que quando o modelo dinâmico do sistema não tem incertezas associadas, as variáveis $p_{G}$ e $C_{M}$ podem ser compensadas facilmente por sinal de controle projetado para esse fim. Para tanto, bastaria introduzir o valor das funções multiplicado por -1 , convenientemente. Para um modelo sem incertezas ter-se-ia as funções estimadas coincidentes com as reais $\left(\hat{p}_{G}=p_{G}\right.$ e $\hat{C}_{M}=$ $\left.C_{M}\right)$ e o máximos erros absolutos das estimativas iguais a zero $(\bar{p}=\bar{C}=0)$. A hipótese leva a $\delta=0$ de forma que a equação 6.70 pode seria levada a seguinte forma:

$$
f_{2}: \quad \dot{s} s=\left(q-\beta_{1}\left[1-\sqrt{1-\beta_{2}\left(\frac{1-\varphi^{2}}{\beta_{2}}\right)}\right]-i_{d}\right) s \leq-\eta|s|
$$

A simplificação da inequação anterior, rotulada como $f_{2}$ é a própria definição da lei de convergência. Assim, para que se tenha a equação rotulada por $f_{1}$ dentro dos limites impostos pela lei, basta garantir que $f_{1} \leq f_{2}$, logo:

$$
\delta+\frac{1-\varphi^{2}}{\beta_{2}} \geq \frac{1-\varphi^{2}}{\beta_{2}}
$$

$\mathrm{ou}$

$$
\delta \geq 0
$$

É evidente que a condição $\delta \geq 0$ não garante a convergência do sistema que descreve o separador submerso para todo intervalo de valores de $s$, refletindo uma condição parcial de validade segundo a lei de controle, ou seja, só há garantia de convergência da trajetória do nível do líquido para a trajetória desejada para um intervalo específico de $s$. A importância da apresentação desta 
condição justifica-se, no entanto, como será discutido na seção 6.3.3, pelo fato de que a região de $s$ para qual a condição 6.73 garante a convergência da trajetória é justamente a região de trabalho do controlador, assim, considerando-se restrições práticas de funcionamento do controlador, a condição será suficiente abarcar todo escopo de operação do sistema.

\subsubsection{Exemplo de um Sistema Controlado}

Para ilustrar o comportamento do controlador discutido, o exemplo a seguir submete-o ao sistema hipotético descrito pela seguinte equação:

$$
i=q+1-\sqrt{1+\gamma^{2} H_{s}+p_{G}-C_{M}+l}
$$

onde $H_{s}$ é uma constante; $p_{G}$ e $C_{M}$ são as funções que descrevem a parte incerta do sistema e $l$ é o sinal de saída ou o nível do líquido, em alusão ao sistema que descreve o separador ciclônico submerso dado pela equação 6.50

As variáveis $p_{G}$ e $C_{M}$ são funções do sinal $l$, bem como de sua taxa temporal dadas pelas seguintes equações:

$$
\begin{gathered}
p_{g}=5+l^{2}(1+a(t) \cos (3 l)) \\
C_{M}=i^{2}(1-b(t) \sin (2 l))
\end{gathered}
$$

Tanto $a(t)$ quanto $b(t)$, têm valores não determinados mas limitados segundo as seguintes relações:

$$
\begin{gathered}
1 \leq a(t) \leq 2 \\
0.5 \leq b(t) \leq 1
\end{gathered}
$$

Com base nos limites impostos a $a$ e $b$ pode-se inferir a melhor estimativa para as funções não determinadas:

$$
\begin{gathered}
\hat{p}_{g}=5+l^{2}(1+1,5 \cos (3 l)) \\
\hat{C}_{M}=i^{2}(1-0,75 \sin (2 l))
\end{gathered}
$$

O máximo erro absoluto entre os valores das funções estimadas e seus valores originais, é obtido aplicando-se as relações dadas em 6.64, de onde obtém-se:

$$
\begin{aligned}
\bar{p} & =0,5 l^{2}|\cos (3 l)| \\
\bar{C} & =0,25 \dot{l}^{2}|\sin (2 l)|
\end{aligned}
$$

O sinal de controle será o obtido na pela equação 6.65 , de forma que: 


$$
\gamma^{2}=\frac{1}{H_{s}}\left(\hat{C}_{M}(t)+\bar{C}(t)-\hat{p}_{G}(t)+\bar{p}(t)-l+1-\varphi^{2}\right)
$$

onde

$$
\varphi=1+q-i_{d}+\eta \operatorname{sign}(s)
$$

A superfície $s$ coincide neste caso, coincidirá com o erro de trajetória do sistema. Considerando que o sistema deva seguir a trajetória pre determinada $l_{d}, s$ terá o valor dado pela equação 6.48.

A Figura 6.7 mostra a resposta do sistema controlado submetido a uma entrada $q(t)$ descrita por um sinal degrau tal que $q(t)=2(t)$, sendo que para simulação considerou-se $H_{s}=1$. Como trajetória desejada, foi imposta uma função exponencial:

$$
l_{d}=1-e^{-t}
$$

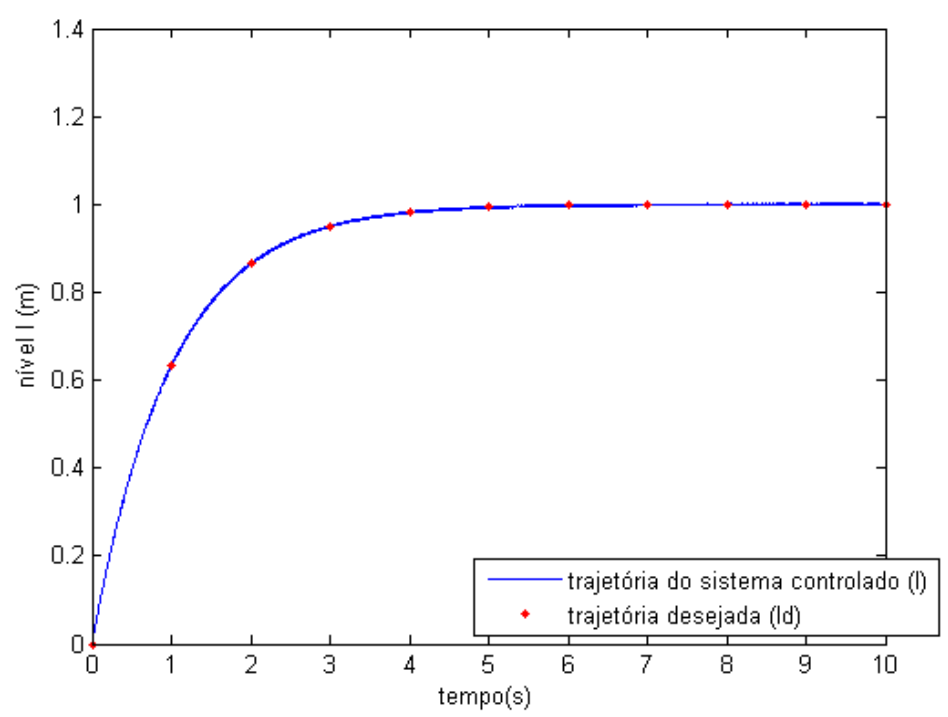

Figura 6.7: Sistema do exemplo, controlado. A trajetória do sinal de l acompanha a trajetória $l_{d}$

A Figura 6.7 mostra uma relação bastante satisfatória entre a trajetória seguida pelo sistema controlado e a trajetória desejada. Esse resultado é obtido mesmo sob o comportamento fortemente não linear imposto ao nível $l$ pelas equações 6.75 e 6.76. A simulação que resulta na trajetória mostrada foi obtida fazendo-se as funções $a(t)$ e $b(t)$ assumirem valores randômicos limitados por 6.77. A Figura 6.8 mostra a oscilação da pressão $p_{G}$ com aumento de $l$ enquanto a Figura 6.9 mostra a superfície $C_{M}(l, i)$ que mostra os valores assumido por $C_{M}$ de acordo com a posição do vetor $\mathbf{l}=\left[\begin{array}{ll}l & l\end{array}\right]^{T}$ 


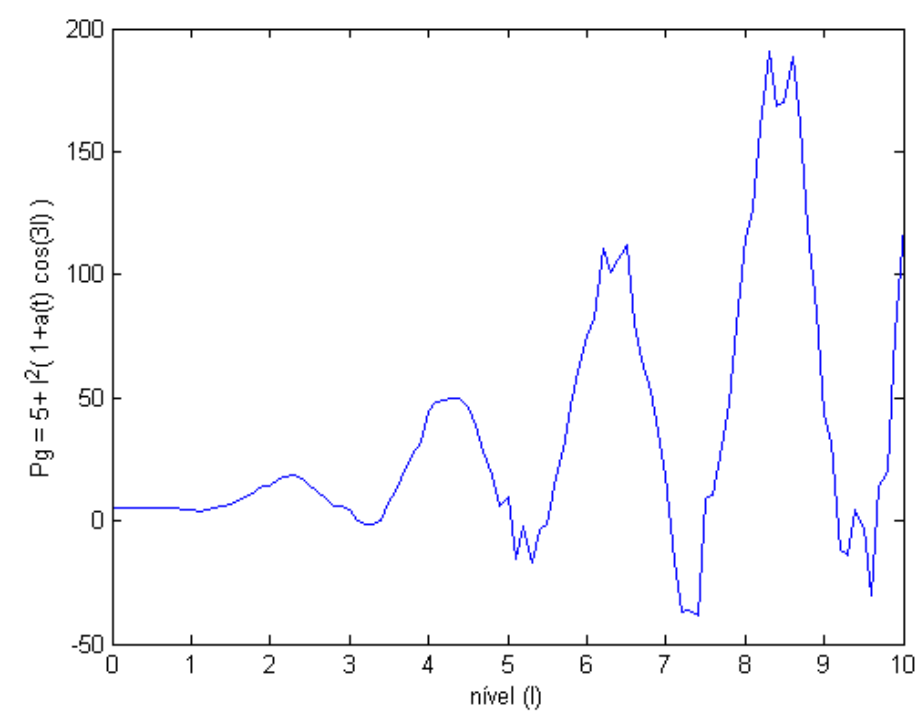

Figura 6.8: Oscilação da pressão $p_{G}$ com aumento de $l$

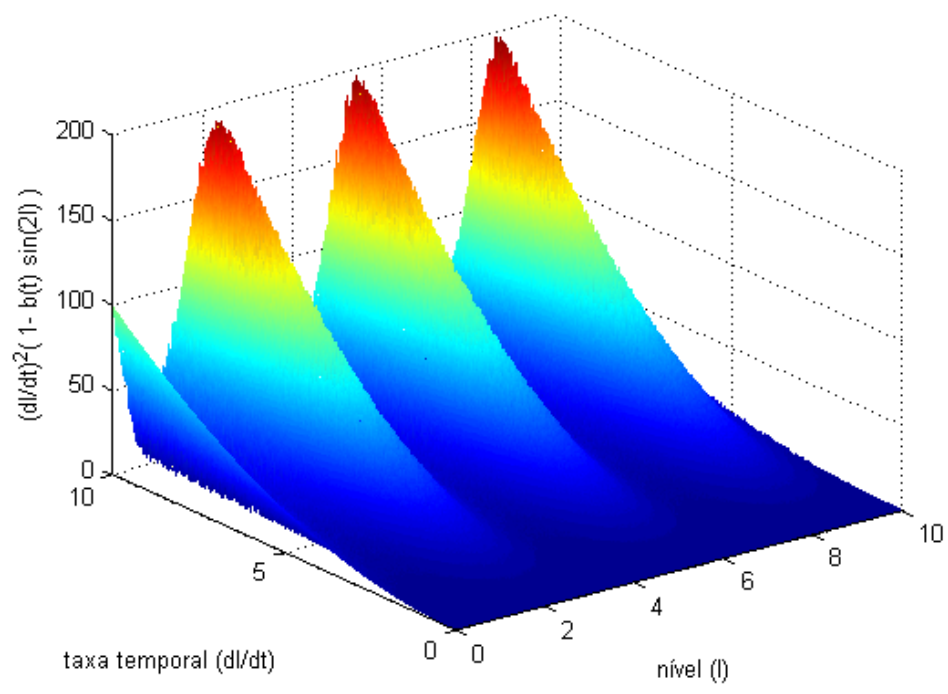

Figura 6.9: Superfície $C_{M}(l, i)$

\subsection{Filtragem do Sinal de Controle}

A ideia de forçar o sistema a seguir um trajetória pré determinada, advém da expectativa de se conseguir um comportamento adequado da trajetória do nível do líquido no interior do separador, que respeite condições específicas do sistema, como limitação dos valores do nível ao longo do tempo, ao mesmo tempo que lide com outros aspectos importantes do funcionamento do sistema como a ação do atuador. A utilização da trajetória pré definida apresenta a vantagem de, não só se controlar o nível do líquido, mas fazê-lo através de um caminho controlado que servirá 
para que se consiga aliviar o esforço do atuador de modo a aumentar sua vida útil e diminuir a probabilidade de falhas. A imposição de uma trajetória suave, quando possível, agirá de forma a atrasar o alcance de um determinado valor do nível de líquido, de maneira que a convergência do valor do nível do líquido para um determinado ponto, demandará intervalo de tempo maior. Em contrapartida, pode-se alcançar o ponto desejado submetendo a bomba submersa a uma menor variação da frequência de rotação da bomba o que implicará em menor desgaste de seus componentes. Esse tipo de abordagem possibilita, ainda, adoção de trajetórias diferentes para diferentes necessidades práticas, bastando escolher um caminho que o nível deverá seguir $(l(t))$ e traduzi-lo em termos de uma trajetória desejada pré determinada $\left(l_{d}(t)\right)$, o controlador forçará o sistema a segui-la. Por exemplo, é possível adotar-se diferentes estratégias com diferentes curvas $l_{d}(t)$ utilizadas em ocasiões distintas como horários ou outras necessidades impostas por um caso particular. Outro exemplo de utilização de diferentes curvas para trajetória desejada é a divisão do interior do recipiente de separação em intervalos de valores para os quais se espera respostas diferentes do sistema controlado. As diferentes curvas da trajetória do nível do líquido no interior do separador seriam acomodadas da seguinte forma:

$$
\left\{\begin{array}{c}
l_{d}(t)=f_{1}(t) \quad \text { se } \quad-\delta \leq l \leq \delta \\
l_{d}(t)=f_{2}(t) \quad \text { se } \quad-2 \delta \leq l \leq 2 \delta \\
\ddots
\end{array}\right.
$$

$\operatorname{com} n=1,2,3 \ldots n$

No exemplo, $f_{n}(t)$ são trajetórias escolhidas arbitrariamente pelo projetista do controlador. $\delta$ é um número real positivo que representa um intervalo de valores do interior do separador equivalente a uma altura que o nível do líquido pode assumir. Assim, para diferentes intervalos ter-se-ia diferentes trajetórias a serem seguidas. Isso possibilitaria aumentar, ou diminuir, a velocidade de convergência da variável controlada, $l(t)$, para um determinado ponto a depender das necessidades catalogadas a partir do estudo de um caso prático. Uma ideia seria admitir-se trajetórias cada vez mais suaves para intervalos de $\delta$ cada vez menores, em torno do ponto em que se deseja que o nível permaneça.

Apesar da gama de possibilidades apresentada pelo controlador proposto, há uma questão intrínseca a ser discutida. O controle deslizante é, por natureza, um controle descontínuo. Isso acaba por impor um comportamento também descontínuo tanto à trajetória do sistema quanto à função que descreve a ação do atuador ao longo do tempo. Nesse caso, o esforço do atuador será tão maior, quão maior for a frequência de rotação da bomba submersa utilizada para elevação do líquido em direção à plataforma em superfície. A tentativa de imposição de um comportamento descontínuo ao atuador não parece, à priori, uma boa escolha já que não é razoável esperar que a bomba submersa mude sua frequência de rotação instantaneamente. Além disso, qualquer tentativa de imposição de um comportamento descontínuo poderia levar a mudanças abruptas da frequência de rotação da bomba, levando a altas taxas de variação temporal da frequência e ocasionando, em última instância, o deterioramento prematuro dos componentes do atuador. 
Para solucionar o problema, propõe-se, neste trabalho, a adição de um filtro linear à planta do sistema controlado. Espera-se com isso, transformar o sinal de controle descontínuo em um sinal contínuo e suave o suficiente para que se possa preservar o atuador fazendo-o trabalhar de forma otimizada. Por outro lado, um efeito previsível da filtragem do sinal, é a diminuição do valor da taxa de convergência entre a trajetória desejada e a efetivamente seguida pelo sistema controlado, fazendo com que a trajetória a ser seguida $l_{d}(t)$ leve mais tempo para ser alcançada. No entanto, assume-se aqui, que os principais requisitos de funcionamento do separador submerso não estão relacionados a manutenção de um valor específico para o nível do líquido ao longo do tempo. Basta que o nível seja mantido dentro de um intervalo de valores que, como dito em Capítulos anteriores, seja suficientemente adequados para que não se perca capacidade de separação, como o líquido invadindo espaço no interior do equipamento destinado a separação gás/líquido e para que não haja entrada de gás na bomba, o que poderia danificá-la.

A descontinuidade do sinal de controle vem do termo $\operatorname{sign}(s)$, dado pela equação 6.40 que muda de sinal quando o sistema atravessa a superfície $s$. Aplicando-se um filtro linear ao sinal de controle consegue-se a transformação do sinal em um sinal contínuo conforme esquematizado na Figura 6.10. Supõe-se, a este ponto, que a perda de velocidade na convergência das trajetórias seja vantajosamente compensada pelo alívio do atuador, desde que o nível permaneça dentro de um intervalo de valores operacionais pré especificados. A proposta, então, é assumir que o sinal de controle dado pela equação 6.65 como entrada do filtro, fazendo a lei de controle propriamente dita $(\gamma)$ seja seu valor de saída. Explicitamente, a lei de controle assumirá a seguinte forma:

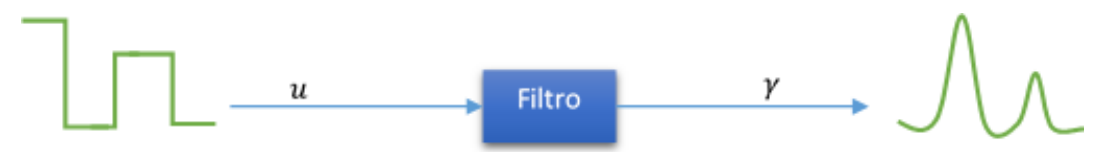

Figura 6.10: sinal de controle descontínuo u após filtragem torna-se um sinal contínuo $\gamma$

$$
u^{2}=\frac{1}{H_{s}}\left(\hat{C}_{M}(t)+\bar{C}(t)-\beta_{3} \hat{p}_{G}(t)+\beta_{3} \bar{p}(t)-l+\frac{1-\varphi^{2}}{\beta_{2}}\right)
$$

Com $\varphi$ dado pela equação 6.66 e a nova lei de controle $\gamma$ obtida conforme o diagrama de blocos mostrado na Figura 6.11, onde $C(p)$ é a função que descreve o filtro aplicado no domínio de laplace, e $p$ é o operador laplaciano.

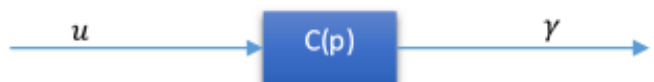

Figura 6.11: $C(p)$ é a função que descreve o filtro aplicado no domínio de laplace, e p é o operador laplaciano 


\subsubsection{Filtro de Primeira Ordem}

O primeiro filtro a ser considerado e que servirá de guia para estudo do comportamento do sistema controlado sob ação de atenuação da descontinuidade conforme proposto, será um filtro, descrito por uma função linear de primeira ordem. Seja o filtro tal qual apresentado na Figura 6.12. Para facilitar a análise da introdução do filtro são considerados, inicialmente, valores $k$, $T$ e $a$ que resultem em uma amplificação máxima unitária do sinal de controle. Um importante parâmetro associado a ser considerado é a diferença entre ao sinal de controle $u$ previsto pela teoria de controle deslizante, e o sinal efetivamente utilizado $\gamma$ para o controle do sistema que descreve o separador. Essa diferença definida, aqui, como erro do sinal de controle $e(t)$ aparece em razão das diferenças que surgem entre os valores de $u$ e $\gamma$ para estados transitórios associados à transformação do sinal conforme diagrama da Figura $6.12 \mathrm{ou}$, mesmo, a estados estacionários após filtragem a depender da forma do sinal $u$.

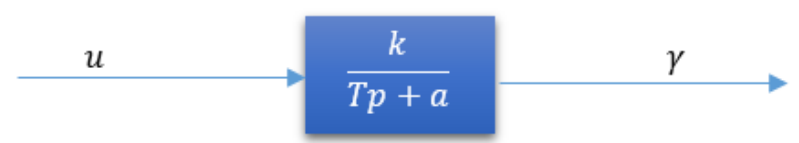

Figura 6.12: Sinal de controle passa por um filtro de primeira ordem. $k, T$ e a são constantes e $p$ é o operador laplaciano

O erro do sinal de controle é definido da seguinte forma:

$$
e(t)=u(t)-\gamma(t)
$$

Supondo que não haja amplificação do sinal $u$ do filtro, admite-se que o erro tenha valor limitado $0 \leq e(t) \leq 1$. Para simplificação das discussões, seja o sistema que descreve o comportamento do nível $l$ no interior do separador ciclônico, dado pela equação 6.50 , descrito pela notação simplificada dada na equação 6.88. Valores das constantes associadas foram atribuídas apenas no intuito de facilitar a análise qualitativa do comportamento do sistema.

$$
i=q-\sqrt{f(t)+l+\gamma^{2}}
$$

onde $\left\{\begin{array}{c}q=\frac{q_{i n}}{A} \\ \frac{B}{2 A a_{2}}=-1 \\ \frac{4 a_{2}}{B^{2}}=-1 \\ \rho g=1 \\ f(t)=1+p_{G}-C_{M} \\ H_{s}=1\end{array}\right.$

O sinal de controle tomará a seguinte forma:

$$
u^{2}=F-l+\varphi^{2}
$$


com $F=\bar{f}-\hat{f}, \varphi$ dado por:

$$
\varphi=q+\eta \operatorname{sign}(s)-i_{d}
$$

e onde $\hat{f}$ é a melhor estimativa da função $f$, sendo obtido conforme procedimento apresentado na seção 6.2. $\bar{f}$ é um função conhecida que obedece a seguinte relação:

$$
|f(t)-\hat{f}(t)| \leq \bar{f}(t)
$$

O erro do sinal de controle associado à filtragem de $u$ é descrito em termos de frações de suas parcelas individuais que permanecem após atenuação de amplitude com o processo de filtragem. Define-se então:

$$
e(t)=\left(1-\epsilon_{F}\right) F-\left(1-\epsilon_{l}\right) l+(1-\epsilon) \varphi^{2}
$$

Na equação $6.92, \epsilon_{F}, \epsilon_{l}$ e $\epsilon$ são parâmetros que descrevem as frações parciais de seus respectivos termos $F, l$ e $\varphi$ de forma que quando $\epsilon_{F}$ é igual a zero, não há atenuação de sinal e amplitude do termo $F$ do sinal de controle $u$ obtido pela teoria de controle deslizante, não é atenuado. Por outro lado, quando $\epsilon_{F}$ é igual a unidade, o termo $F$ é totalmente atenuado e a saída do filtro resulta em um sinal que não tem influência dessa função. O mesma relação de observada para os termos $l$ e $\varphi$ quanto ao comportamento de $\epsilon_{l}$ e $\epsilon$, respectivamente. Por tratar-se de um filtro linear de primeira ordem, um atenuação total de uma dada parcela do sinal de controle, é esperada para os casos em que esse sinal for oscilatório, com altas frequência de oscilação, lembrando que o filtro adotado é um típico passa-baixa.

Considere, ainda, a introdução de uma nova variável simplificativa que engloba parte das termos do controlador $u$, definida da seguinte forma:

$$
\delta(t)=f+\epsilon_{F} F+l-\epsilon_{l} l
$$

Admitindo-se que $\epsilon_{F}$ e $\epsilon_{l}$ são valores positivos, o valor de $\delta$ será zero quando o sinal de controle não sofrer atenuação da amplitude do seu sinal após passar pelo filtro. Isso acontece quando $\epsilon_{F}$ e $\epsilon_{l}$ forem iguais a zero, no caso de uma dinâmica do sistema determinada, ou seja, a melhor estimativa $\hat{f}$ coincide com $f$, e de modo a se conseguir $\bar{f}=0$.

Quando há atenuação do sinal de controle após a sua passagem pelo filtro, a submissão do sistema à lei de convergência, dada pela equação 6.31, ficará condicionada à capacidade de compensação que o sinal de controle é capaz de impor sobre o sistema. Assim, se $\epsilon_{F}=\epsilon_{l}=\epsilon=0$, a convergência do sistema estará garantida nos termos de lei de convergência já que, essencialmente, o sistema controlado se reduz ao sistema estudado na seção 6.2.2, uma vez que não há ação do filtro sobre o sinal de controle $u$ e ele é usado em sua forma original no controle do sistema.

Por outro lado, quando todas as parcelas do sinal de controle têm suas amplitudes totalmente atenuadas, ou seja, quando $\epsilon_{F}=\epsilon_{l}=\epsilon=1$, o sinal de controle será totalmente suprimido e o sistema ficará à deriva já que não haverá ação do controlador sobre o sistema. Essa, se configura 
uma situação crítica em que o sistema simplesmente não está sob ação do controlador. Um caso assim pode, à princípio, parecer preocupante, no entanto, como será abordado em discussões subsequentes, uma vez estabelecidas condições básicas de operação do sistema e após algumas adaptações do controlador, é possível garantir que o controlador atue satisfatoriamente sobre o sistema.

\subsubsection{Sinal de Controle Filtrado frente a Lei de Convergência}

O principal problema posto pela introdução do filtro ao sinal de controle é a identificação da capacidade do controlador impor um determinado comportamento esperado ao sistema. Essa capacidade pode ser mensurada em termos da adequação do sistema à lei de convergência, onde pode-se delimitar as condições para as quais a lei de controle terá ingerência sobre o sistema. Para delimitação dessas condições considere, primeiramente, o caso em que $\delta(t)$ seja igual zero, a equação 6.88 poderá ser reescrita na forma:

$$
\dot{l}=q-\sqrt{\epsilon} \varphi
$$

A lei de convergência aplicada a essa equação leva a:

$$
\dot{s} s=\left(q-\sqrt{\epsilon} \varphi-\dot{l}_{d}\right) s \leq-\eta|s|
$$

Expandindo a equação a a partir do valor de $\varphi$ dado pela equação 6.90 :

$$
(1-\sqrt{\epsilon})\left(\left(q-\dot{l}_{d}\right) s+\eta|s|\right) \leq 0
$$

A convergência da trajetória para a trajetória desejada esterá garantida quando a equação 6.95 for respeitada. Como $1-\sqrt{\epsilon}$ é um valor real positivo, a validade a submissão do controlador a lei de convergência estará condicionada a

$$
q-i_{d} \leq-\eta \operatorname{sign}(s)
$$

Apesar de $\dot{l_{d}}$ e $\eta$ serem valores escolhidos arbitrariamente a depender do comportamento que se queira impor ao sistema, a relação 6.97 não parece razoável para todos os valores de operação do sistema, sendo fácil identificar hipóteses capazes de infringi-la. Não há, portanto, para esse caso particular garantia de que o sistema controlado se submeterá a lei de controle, logo, não há, à princípio, garantia da convergência da trajetória do sistema para trajetória desejada. Isso, não configura uma ameaça à estratégia de utilização do controle deslizante filtrado uma vez que, como será apresentado mais adiante (ver seção 6.3.3) ainda é possível garantir a convergência do sistema em termos da mesma lei para certas regiões de operação.

A importância de apresentar o caso específico que leva à equação 6.94 é eminentemente didática. É fácil visualizar o comportamento do sistema frente a variação de $\epsilon$ a partir da inequação 6.96 
de onde verifica-se que a lei de convergência e, portanto, a própria convergência da trajetória do sistema para trajetória desejada será garantido quando $\epsilon=1$. Essa hipótese ocorre quando os termos do sinal ao qual $\epsilon$ está atrelado $(\varphi)$, ou seja, do sinal do qual $\epsilon$ representa fração de amplificação, não sofrem atenuação de suas amplitudes o que resulta na mesma amplitude do sinal de controle que entra e que sai do filtro. O resultado é que o lado esquerdo da inequação 6.96 será igual a zero, portanto, a convergência da trajetória estará assegurada. Por outro lado, quanto maior for a atenuação da amplitude do sinal de controle após passagem pelo filtro mais próximo da unidade estará o termo $1-\sqrt{\epsilon}$ e menor será a capacidade do controlador de se impor sobre o sistema. O mesmo raciocínio pode ser aplicado às outras frações representativas $\epsilon_{F}$ e $\epsilon_{l}$. O sistema estará mais fortemente controlado quanto mais próximo da unidade forem seus valores, ou seja, quanto menor for a atenuação a amplitude de seus sinais de origem, respectivamente, $F$ e $l$. Esses sinais estão definidos na seção 6.3.1

Considere, agora, o caso mais geral em que $\delta(t)$ é diferente de zero, a equação 6.88 tomará a seguinte forma:

$$
i=q-\sqrt{\delta(t)+\epsilon \varphi^{2}}
$$

A primeira condição que emerge do sistema é:

$$
\delta(t) \geq-\epsilon \varphi^{2}
$$

para todo tempo $t$ maior que zero. A lei de convergência aplicada ao sistema resulta em:

$$
\dot{s} s=\left(q-\dot{l}_{d}-\sqrt{\delta(t)+\epsilon \varphi^{2}}\right) s \leq-\eta|s|
$$

Infere-se, a partir da definição de $\varphi$ dada pela equação 6.90 e da equação 6.95 um sistema que siga as condições impostas que culminaram na equação 6.95 terá convergência garantida nos termos da lei de convergência se além das condições discutidas, $\epsilon$ for igual a um. Pode-se garantir, então, que:

$$
\left(q-i_{d}-\sqrt{\varphi^{2}}\right) s \leq-\eta|s|
$$

Para que o sistema de que trata a equação 6.98 respeite a lei de convergência, basta garantir que o produto entre a taxa de variação temporal de sua superfície $\dot{s}$ associada e sua superfície $s$, seja menor que o produto $\dot{s} s$ que deu origem à inequação 6.101:

$$
\left(q-i_{d}-\sqrt{\delta+\epsilon \varphi^{2}}\right) s \leq\left(q-i_{d}-\sqrt{\varphi^{2}}\right) s
$$

Um caso significativo para ação do controlador ocorrer nas regiões da superfície $s$ em que esta é maior e igual a zero. Então, desde que seja suficiente a ação do controlador para essa região, a convergência das trajetórias estará garantida desde que: 


$$
\delta(t) \geq(1-\epsilon) \varphi^{2}
$$

Esse resultado acaba por impor um limite mínimo para $\delta$ de forma a ser garantir que a trajetória percorrida para o nível do líquido no interior do separador convirja para trajetória desejada. Apesar da imposição do filtro atenuar o sinal de controle, tornando-o inoperante em casos como o de um sinal puramente oscilatório de alta frequência, o sinal de controle é composto por termos que podem ser arbitrados pelo projetista do controlador, de modo que é possível impor-se um sinal de controle que não seja puramente oscilatório ou que, num caso mais geral, contenha parcelas que não sofram atenuação significativa de sua amplitude após passagem pelo filtro, de maneira que sempre se consiga manter a ação de controle sobre o sistema.

\subsubsection{Regiões de Convergência do Sistema Filtrado}

A condição apresentada pela inequação 6.103 não representa um condição de validade global para convergência do sistema. O resultado é especialmente útil quando o sistema controlado se encontra numa condição tal que a posição do nível de líquido é maior que a posição esperada pela trajetória desejada num determinado instante, $l>l_{d}$. Fora do escopo das condições que permitem escrever inequação 6.103 , não foi apresentado, até este ponto do trabalho, condições que garantam a aplicabilidade do controlador ao sistema do separador submerso. Isso levanta a necessidade de uma discussão sobre as regiões de convergência do sistema com sinal de controle filtrado, bem como das condições esperadas para que se possa garantir que o sistema não só se submeta à lei de convergência em sua forma original dada pela equação 6.31, ou em alguma forma equivalente, mas que garanta que o sistema não seja levado a divergir de um ponto ou trajetória ótima, o que poderia causar sérios danos ao separador. Vale, então, uma discussão sobre o caso mais geral em que a superfície deslizante $s$ assume valores positivos e negativos apontando as condições necessárias para que o controlador consiga agir adequadamente, fazendo a trajetória do nível convergir conforme esperado.

A primeira condição imposta ao sistema é o limite mínimo do valor que $\delta(t)$ pode assumir para que a taxa de variação temporal do nível seja um número real. Explicitando as regiões positiva e negativa da superfície $s$, a equação 6.99 dá os valores mínimos de $\delta$ como segue:

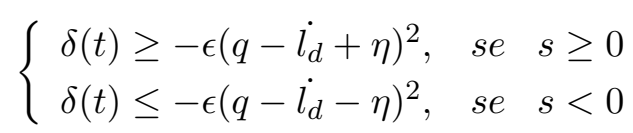

Além dos limites mínimos impostos, a submissão do sistema a lei de controle pode ser levantada. A partir da equação 6.102 e do valor de $\varphi$, dado pela equação 6.90 , as condições necessárias para que o sistema se submeta à lei de convergência são apresentadas da seguinte forma:

$$
\left\{\begin{array}{l}
\delta(t) \geq(1-\epsilon)\left(q-\dot{l_{d}}+\eta\right)^{2}, \quad \text { se } \quad s \geq 0 \\
\delta(t) \leq(1-\epsilon)\left(q-\dot{l_{d}}-\eta\right)^{2}, \quad \text { se } \quad s<0
\end{array}\right.
$$


Além do casos que dão os limites mínimos para que se trabalhe com valores reais, e que o sistema esteja sob a lei de convergência, existem outras condições que levam o sistema a se comportar de forma que, apesar de não submeter à lei de convergência conforme enunciada pela equação 6.31 ainda impõe um comportamento convergente à trajetória do nível de líquido no interior do separador. Essas condições aparecem quando as variáveis do sistema dinâmico que descrevem o separador apresentam um composição de valores tal que se consegue uma taxa de variação do erro de trajetória, ou $\dot{s}$, com sinal oposto ao erro de trajetória, ou $s$.

Sob essas condições o valor absoluto do erro de trajetória será sempre decrescente uma vez que quando o erro de trajetória tiver valor positivo, a taxa de variação temporal do erro terá um sinal negativo, forçando o erro do sistema a retornar ao ponto em que $s=0$. Da mesma forma, quando o erro de trajetória for negativo, a sua taxa de variação temporal será positiva, forçando, mais uma vez a restauração do sistema para o ponto em que o erro de trajetória é igual a zero, esse comportamento esperado é ilustrado na Figura 6.13. Essa é a própria dinâmica da lei de convergência, desde que o produto da taxa de variação temporal do erro de trajetória com o próprio valor do erro seja negativo, é possível enunciar condições de convergência equivalentes à inequação 6.31 mas com valores distintos de $\eta$.

Vale observar que, a lei de controle imposta ao separador submerso pressuporá uma convergência que respeite a lei de convergência segundo o valor inicialmente determinado pelo projetista para $\eta$. As condições em que o sistema se comporta de maneira a seguir uma lei equivalente, com valores diferentes de $\eta$ na equação 6.31, aparecem no decorrer do movimento do sistema. O importante, nessa discussão é o estabelecimento das condições em que o sistema converge de acordo com lei, apresentadas no conjunto de inequações 6.105 , bem como das condições para as quais o sistema converge fora da lei ou diverge, um caso a ser evitado.

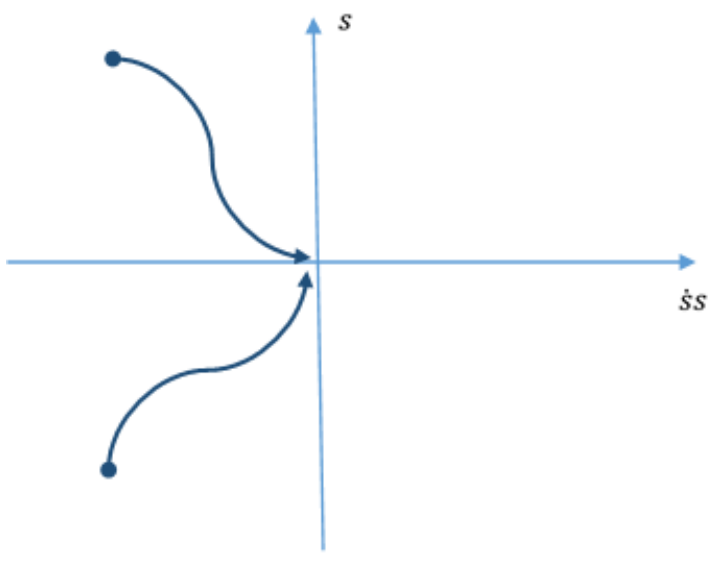

Figura 6.13: Quando o erro de trajetória s é negativo, a sua taxa de variação temporal será positiva, forçando, s para zero. Quando o erro de trajetória s é positivo, a sua taxa temporal será positiva, forçando, s também para zero. Nos dois casos, ṡs é menor que zero

O produto negativo da taxa de variação temporal do erro com o próprio erro de trajetória, $\dot{s} s<0$, impõe a seguintes inequações: 


$$
\left\{\begin{array}{l}
\dot{s} s=\left(q-i_{d}-\sqrt{\delta(t)+\epsilon\left(q-i_{d}+\eta\right)^{2}}\right) s \leq 0, \quad \text { se } s \geq 0 \\
\dot{s} s=\left(q-i_{d}-\sqrt{\delta(t)+\epsilon\left(q-i_{d}-\eta\right)^{2}}\right) s \leq 0, \quad \text { se } s<0
\end{array}\right.
$$

Com intuito de simplificação de notação, as relações acima são reescritas da seguinte maneira:

$$
\left\{\begin{array}{l}
\dot{s}=Q_{1} \leq 0, \quad \text { se } \quad s \geq 0 \\
\dot{s}=Q_{2} \leq 0, \quad \text { se } \quad s<0
\end{array}\right.
$$

onde $Q_{1}=q-i_{d}-\sqrt{\delta(t)+\epsilon\left(q-i_{d}+\eta\right)^{2}}$ e $Q_{2}=q-i_{d}-\sqrt{\delta(t)+\epsilon\left(q-i_{d}-\eta\right)^{2}}$

As inequações 6.107, dão as condições para que a taxa de variação temporal de $s$ tenha sempre sinal oposto ao próprio $s$, dessa forma espera-se que o valor do erro de trajetória decresça em módulo com o passar do tempo até que $s$ mude de sinal. Quando isso ocorre, haverá um transição descontínua da taxa de variação temporal, de $Q_{1}$ para $Q_{2}$, caso $s$ vá de positivo para negativo, ou de $Q_{2}$ para $Q_{1}$, no caso contrário. Sucessivas mudanças de sinal, ou em outras palavras, passagens através da superfície $s$ darão à curva que descreve a trajetória do sistema um formato que se assemelha a uma vibração em torno da trajetória desejada conforme é ilustrado na Figura 6.14. Quando $Q_{1}$ ou $Q_{2}$ são iguais a zero, a taxa de variação temporal do erro de trajetória também será igual a zero, neste caso não há diminuição do erro ao longo do tempo, o que significa que a trajetória do nível de líquido no interior do separador não convergirá para a desejada, mas estacionará sobre um curva com erro constante em relação a ela.

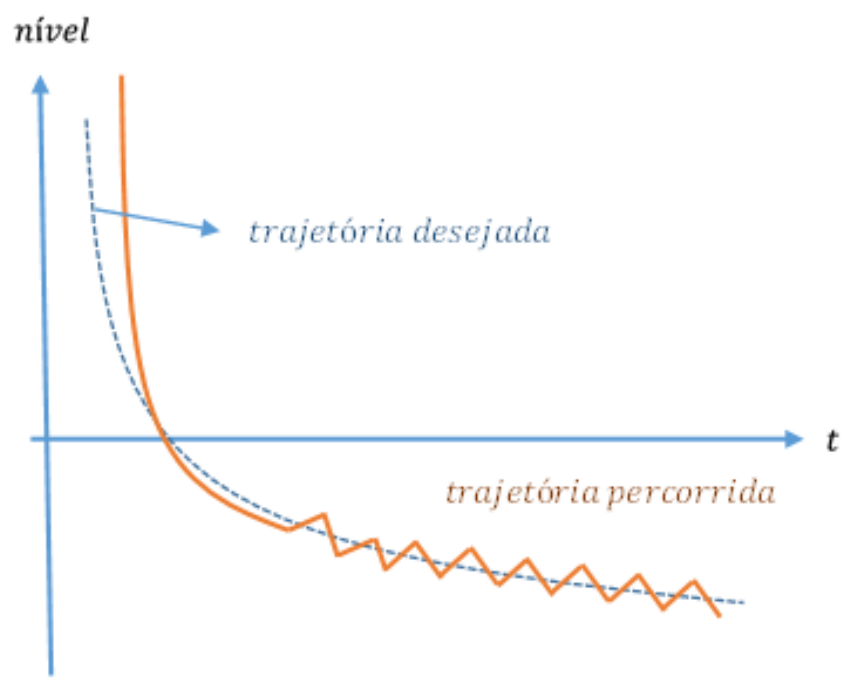

Figura 6.14: Sucessivas passagens através da superfície s darão à curva que descreve a trajetória do sistema um formato que se assemelha a a uma vibração em torno da trajetória desejada.

As condições necessárias para que haja convergência do sistema ainda que seja uma convergência fraca, são obtidas a partir das relações 6.106, de forma que: 


$$
\left\{\begin{array}{lll}
q-i_{d} \leq \sqrt{\delta(t)+\epsilon\left(q-i_{d}+\eta\right)^{2}}, & \text { se } & s \geq 0 \\
q-\dot{l}_{d} \geq \sqrt{\delta(t)+\epsilon\left(q-i_{d}-\eta\right)^{2}}, & \text { se } & s<0
\end{array}\right.
$$

Resolvendo as inequações para $\delta$ :

$$
\left\{\begin{array}{lll}
\delta \geq(1-\epsilon)\left(q-i_{d}\right)^{2}-\epsilon\left(\eta^{2}+2 \eta\left(q-i_{d}\right)\right), & \text { se } & s \geq 0 \\
\delta \leq(1-\epsilon)\left(q-i_{d}\right)^{2}-\epsilon\left(\eta^{2}-2 \eta\left(q-i_{d}\right)\right), & \text { se } & s<0
\end{array}\right.
$$

Por convergência fraca entende-se, para fins deste estudo, a situação para a qual o sistema que descreve o nível do líquido tem sua trajetória convergente para uma dada trajetória desejada, sendo submetida a uma lei de convergência equivalente a descrita pele equação 6.31 , mas com valor de $\eta_{f}$ menor que o valor de $\eta$ imposto inicialmente pela lei de convergência. Assim, o sistema se submeterá a equação 6.110 :

$$
\dot{s} s=-\eta_{f}|s|
$$

$\operatorname{com} \eta_{f}<\eta$.

As regiões de validade (onde $i_{d}$ apresenta valor real) e de convergência do sistema são sumarizadas nas Figuras 6.15 e 6.16 e a tabela 6.1, mostra os respectivos rótulos utilizados nas Figuras.

Tabela 6.1: rótulos das regiões de validade e convergência do sistema controlado

\begin{tabular}{|c|c|c|}
\hline (1) & $-\epsilon\left(q^{\prime}+\eta\right)^{2}$ & $s \geq 0$ \\
\hline (2) & $(1-\epsilon) q^{\prime 2}-\epsilon\left(\eta^{2}+2 \eta q^{\prime}\right)$ & $s \geq 0$ \\
\hline (3) & $(1-\epsilon)\left(q^{\prime}+\eta\right)^{2}$ & $s \geq 0$ \\
\hline (4) & $-\epsilon\left(q^{\prime}-\eta\right)^{2}$ & $s<0$ \\
\hline (5) & $(1-\epsilon)\left(q^{\prime}-\eta\right)^{2}$ & $s<0$ \\
\hline (6) & $(1-\epsilon) q^{\prime 2}-\epsilon\left(\eta^{2}-2 \eta q^{\prime}\right)$ & $s<0$ \\
\hline
\end{tabular}

A Figura 6.15 mostra que para valores de $s$ maiores ou iguais a zero. Da Figura, pode-se inferir que para valores de $\delta$ maiores que (1) (ver tabela 6.1), o sistema estará na região de validade, ou seja, a taxa de variação temporal da posição do nível $l$ terá valores reais. Quando $\delta$ tiver valor maior que $\mathcal{Q}$, o sistema estará na região de convergência fraca, onde a sua trajetória convergirá para desejada, mas a um taxa menor do que a observada quando o sistema estiver sob a lei de convergência. Quando $\delta$ é maior que (3), o sistema respeitará a lei de convergência, logo, a taxa de variação temporal do erro de trajetória será, seguramente, menor que o valor $-\eta$ imposto pelo projetista do controlador. 


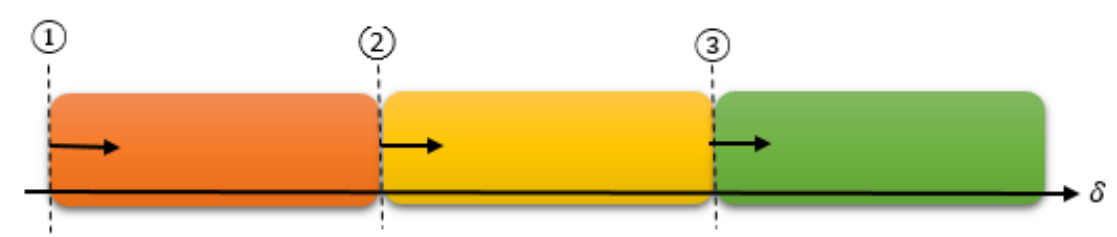

Figura 6.15: Condições de convergência para $s \geq 0$

A Figura 6.16, mostra as regiões características do comportamento do sistema quando $s$ é menor que zero. A convergência do sistema está encarcerada entre dois intervalos distintos. No primeiro, entre os pontos $(4$ e 5 , o sistema controlado terá sua validade assegurada além de ter a convergência de trajetórias regida pela lei de convergência. O segundo intervalo, com valores de $\delta$ entre os pontos $\left(4 \mathrm{e}\right.$ ( 6 , leva o sistema à condições em que a sua validade está assegurada, já que $\dot{l}_{d}$ terá valores reais, e apresentará convergência fraca, com a taxa de variação do erro de trajetória menor que a prevista pela lei de convergência. Vale lembrar que para o sistema dinâmico estudado no presente trabalho, a superfície $s$ e sua taxa $\dot{s}$ coincidem com o erro de trajetória e sua taxa temporal, respectivamente. Valores de $\delta$ maiores que 6 na Figura 6.16, quando $s<0$ e valores de $\delta$ entre $(1)$ e $(2)$ na Figura 6.15 , implicam em divergência de trajetória, de modo que a trajetória do percorrida pelo nível do líquido se distanciará da trajetória desejada com o passar do tempo, essa é um condição a ser evitada já que significaria grande risco ao sistema.

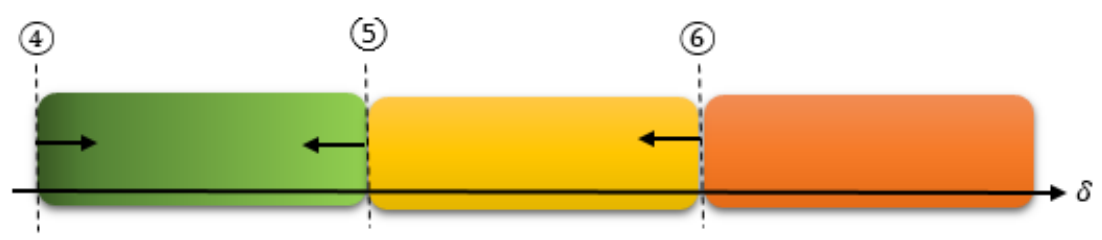

Figura 6.16: Condições de convergência para $s<0$.

A Figura 6.17 apresenta o plano cartesiano śs versus $s$, com alguns exemplos de condições aplicadas a $\delta$ que resultam em diferentes comportamentos do sistema. A curva pontilhada, na intersecção entre as regiões verde e amarelo, ilustra os limites superiores da lei de convergência, qualquer valor de $\delta$ que resulte em curvas dentro dessa região levará o sistema a convergir sua trajetória para a trajetória desejada, a uma taxa com valor absoluto maior que $\eta$. Duas curvas, em verde, exemplificam essa situação, uma quando os valores de $\delta$ são maiores que (3) para $s$ maior que zero e outra quando $\Phi<\delta<$ (5). Na região marcada em amarelo, o sistema também terá sua trajetória convergida para desejada. Essa é a região de convergência fraca onde o valor absoluto do erro de trajetória diminuirá a uma taxa menor que a mínima exigida pela lei de convergência. Duas curvas, em amarelo, exemplificam essa condição, uma para $s \geq 0$ com $\delta$ tendo valores contidos no intervalo $\mathbb{Q}<\delta<(\mathfrak{B})$, e outra, para $s<0$ com $\mathbb{6}<\delta<$ (פ).

As linhas pontilhadas na intersecção entre as regiões marcadas em amarelo e vermelho, dizem respeito a condição em que o sistema terá taxa de variação temporal do erro de trajetória igual a zero, sob essa condição não haverá convergência da trajetória do sistema para trajetória desejada 
e a curva descrita pela posição do nível do líquido ao longo do tempo manterá um erro constante em relação à curvas de trajetória desejada. Um exemplo desse caso é mostrado na Figura pela linha pontilhada correspondente a $\delta=2$.

Uma última região aparece em vermelho na Figura, nessa região śs é um valor positivo o que implica que a trajetória do sistema divergirá da trajetória desejada com erro aumentando ao longo do tempo. A Figura mostra dois exemplos de curvas, as duas mostradas em vermelho, em que o sistema terá comportamento divergente, uma $\operatorname{com} \delta>\mathbb{6}$ para $s>0$ e outra com valores de $\delta$ no intervalo $\mathbb{D}<\delta<\mathcal{Q}$, para $s \geq 0$.

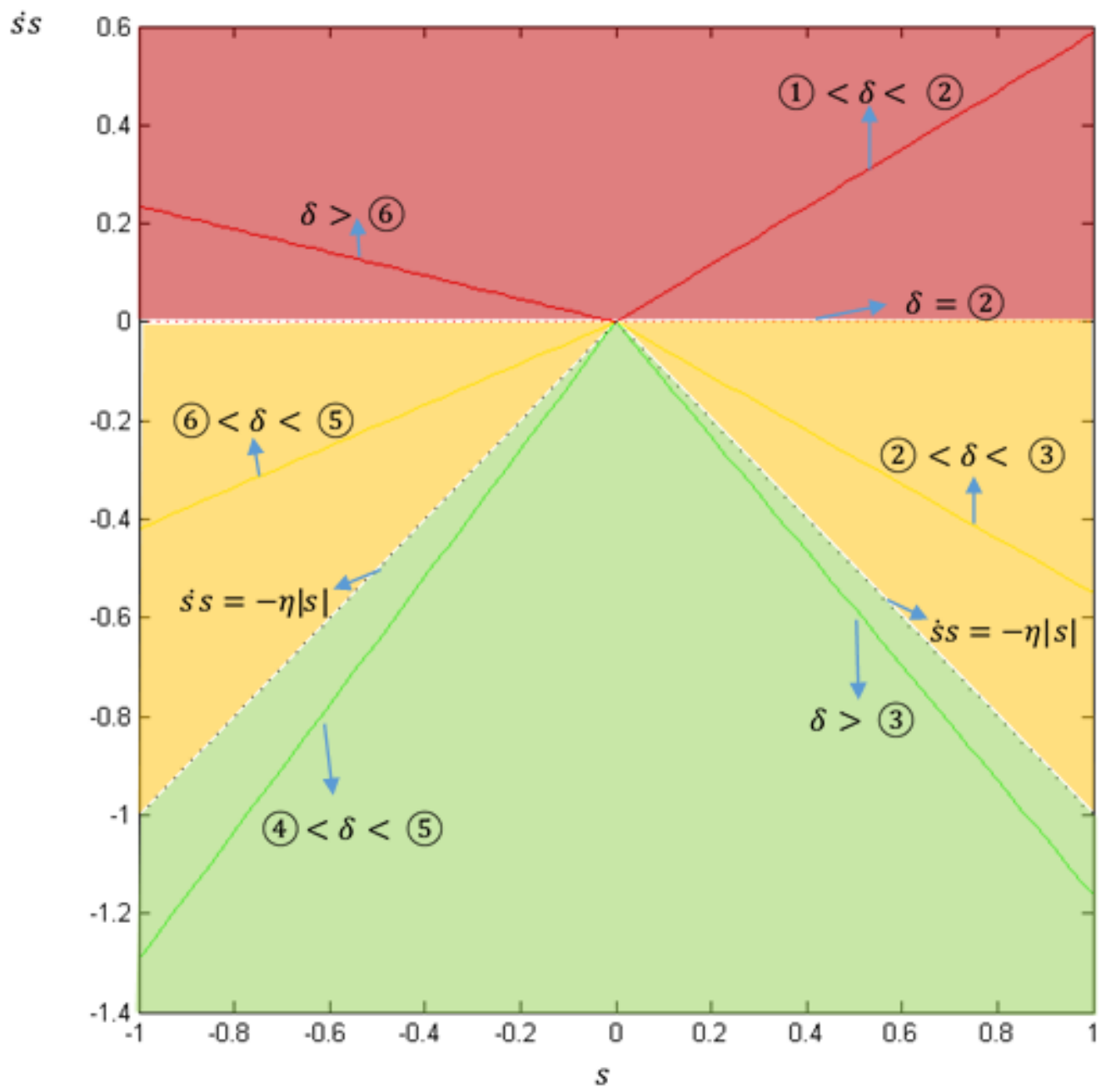

Figura 6.17: Plano ṡs versus s. Várias curvas para diferentes valores de delta são mostradas, em três regiões de comportamento distintos. Curvas em verde: região sob a lei de convergência. Curvas em amarelo: região em que há convergência, mas fora de lei de convergência. Curvas em vermelho: região de divergência.

A discussão das regiões de convergência foram realizadas, até o momento, para duas condições 
distintas: uma em que $s \geq 0$ e a outra em que $s<0$. As condições que levam à convergência global para qualquer valor de $s$ necessitam, o entanto, de uma análise um pouco mais criteriosa a ser realizada na seção 6.4. De antemão, observa-se que a submissão global do sistema à lei de convergência só será alcançada para as condições específicas em que $\epsilon=1$ e $\delta=0$. Essas duas condições implicam, respectivamente, que não haverá atenuação do sinal de controle após filtragem e que as estimativas das variáveis incertas coincidem com o caso real a ponto de poder assumir que a máxima diferença absoluta entre as duas seja zero. Um sistema que não apresente incertezas no seu modelo dinâmico seria um exemplo de sistema com essas características, uma hipótese que não justificaria a utilização de um controle deslizante.

Em favor da utilização do controle deslizante para o sistema estudado no presente trabalho, fazse necessário observar que ainda que, em geral, o sinal de controle não consiga manter o sistema sob ação da lei de controle para valores positivos e negativos de $s$ concomitantemente, é perfeitamente factível que o sistema esteja sob ação de uma forma equivalente da lei de convergência conforme a anunciada pela equação 6.110. Pode-se, então, ajustar o valor de $\delta$ de forma que o sinal de controle imponha um comportamento tal que o sistema seja regido pela lei de convergência quando o erro de trajetória tiver valores positivo, e seja regido por lei equivalente para valores de $s$ menores que zero. Assim, com a trajetória do nível do líquido sempre convergindo para desejada, garante-se que o sistema se comporte de maneira adequada.

Outra questão a ser observada a cerca das condições de convergência é que independentemente do valor atribuído a $\delta$, caso $s$ seja menor que zero e $q-i_{d}$ também seja menor que zero, o produto $\dot{s} s$ explicitado em 6.111 será sempre um valor positivo. Isso leva o sistema para a região marcada em vermelho na Figura 6.17 o que, como visto anteriormente, implica divergência de trajetórias. Como a divergência deve sempre ser evitada, faz-se necessário escolher uma trajetória a ser seguida de forma que a taxa $i_{d}$ não seja maior que o valor de $q$, o qual representa a vazão de entrada de líquido no separador submerso, conforme descrito na equação 6.88 .

$$
\dot{s} s=\left(q-i_{d}-\sqrt{\delta+\epsilon\left(q-i_{d}+\eta \operatorname{sign}(s)\right)^{2}}\right) s
$$

\subsection{Convergência sob Atenuação do Sinal de Controle}

Até agora, foram estudados os efeitos do controlador, levando em conta os termos do sinal de controle responsáveis por compensar as incertezas associadas ao sistema. Essas incertezas do modelo dinâmico surgem devido ao fato de não se conhecer exatamente os termos referentes a certas variáveis. No caso do presente estudo, tem-se como fonte de incertezas sobre o sistema, a pressão do gás acima da coluna de líquido no interior do separador e ao parâmetro que descreve a pressão e a vazão no ponto de intersecção entre o recipiente de separação e a tubulação de escoamento do líquido. Essas variáveis foram definidas como $p_{G}$ e $C_{M}$ e são mostradas na equação 6.51, no início deste Capítulo. Os termos $p_{G}$ e $C_{M}$, bem como os termos introduzidos para compensá-los, via sinal de controle, impondo o comportamento desejado, são sumarizados pela variável $\delta$, discutida inúmeras vezes ao longo das seções anteriores. Como visto, a depender do valor atribuído a $\delta$, a 
trajetória da variável controlada poderá convergir para a trajetória desejada respeitando a lei de convergência (equação 6.31), fora de seu escopo ou mesmo divergir da trajetória desejada, condição a ser evitada.

Outra questão importante a cerca das condições de validade e convergência da trajetória, diz respeito à atenuação sofrida pelo sinal de controle após passar pelo filtro. Por condição de validade, entende-se as condições que permitem a equação dinâmica 6.88 auferir valores reais. A variável $\epsilon$ apresentada em 6.92 configura uma clara indicação da atenuação que a amplitude do sinal de controle sofre após passar pelo filtro, sendo que para valores de $\epsilon=1$, não haverá atenuação e o sinal de controle permanecerá com a amplitude original. Valores de $\epsilon=0$, significam supressão total do sinal após passar pelo filtro. Um diagrama do processo de filtragem é mostrado na Figura 6.10. De fato, $\epsilon$ não representa uma medida direta da fração da amplitude do sinal de controle, mas de sua parcela correspondente conforme definido na equação 6.92 , onde define-se o erro do sinal de controle. Além de $\epsilon, \epsilon_{F}$ e $\epsilon_{l}$ são os parâmetros que descrevem a atenuação das respectivas parcelas do sinal de controle, conforme apresentado em 6.92 e discutido na explanação imediatamente subsequente.

Para se abordar o comportamento do sistema em relação às suas condições de validade e convergência, primeiramente será discutida a influência de $\epsilon$, dessa forma pretende-se estabelecer as condições de convergência do sistema controlado e sua relação com a atenuação da parcela do sinal de controle definida por $\varphi$ (ver equação 6.90). O estudo do comportamento do sistema frente a atenuação de $\varphi$, medida por $\epsilon$, dá uma ideia do comportamento geral do sistema frente a atenuação do sinal de controle. As Figuras 6.20 e 6.18 mostram o comportamento do sistema para dois casos extremos, quando $\epsilon=1$ e quando $\epsilon=0$. Nas Figuras são assinaladas três regiões distintas de comportamento do sistema controlado em razão do valor atribuído à variável $\delta$. A região marcada em verde corresponde aos valores de $\delta$ que levam a trajetória do líquido no interior do separador a convergir para trajetória desejada de acordo com a lei de convergência. Na região amarela, a trajetória descrita pelo sistema convergirá para a desejada, não de acordo com a lei de convergência mas submetendo-se à convergência fraca discutida a seção anterior. A região em vermelho mostra os valores de $\delta$ que farão com que o sistema descreva um trajetória divergente da desejada. Os valores de $\delta$ são mostrados em termos das variáveis $q^{\prime}$ e $\eta$, onde $\eta$ é um número real positivo apresentado pela equação 6.31 , enquanto $q^{\prime}$ é definido por:

$$
q^{\prime}=q-i_{d}
$$

o valor de $q$ é apresentado na equação 6.54 e $l_{d}(t)$ é a trajetória que se deseja que o sistema siga. 


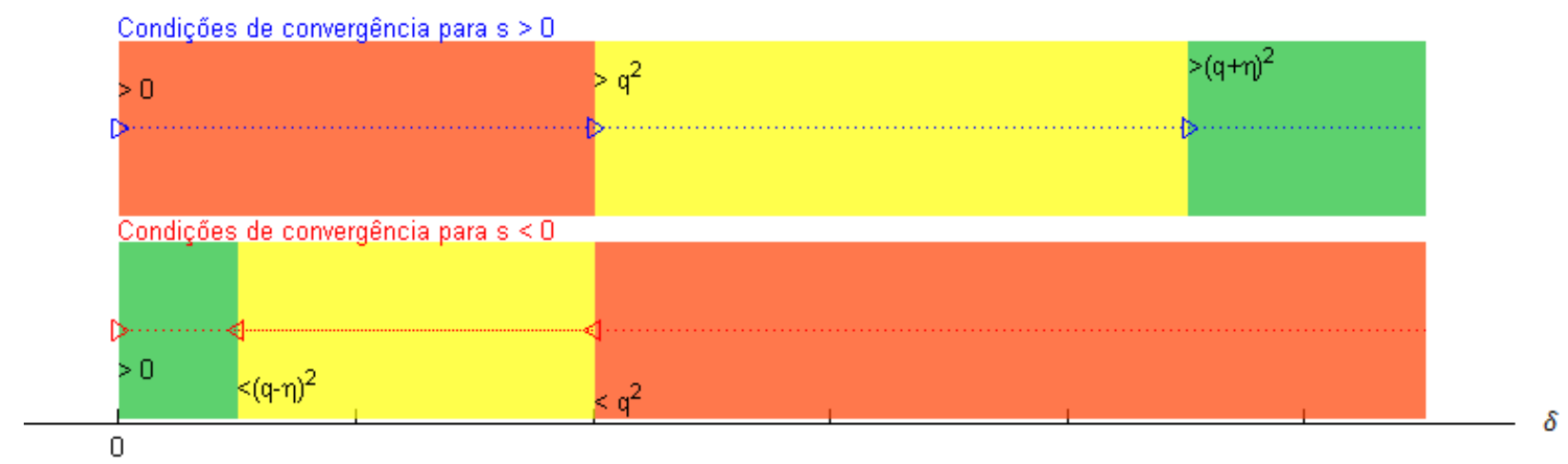

Figura 6.18: $\epsilon=0$. Condições de convergência para $s \geq 0$ parte superior da Figura e $s<0$ parte inferior. Região verde:sistema sob a lei convergência. Região amarela: convergência fraca. Região vermelha: trajetórias divergem

Na comparação entre os dois casos, chama atenção o fato de que no primeiro, em que $\epsilon=1$, existe um ampla faixa de valores de $\delta$ que permitem que o sistema convirja, ainda que sob convergência fraca, para qualquer valor do erro de trajetória medido por $s$, seja positivo ou negativo. Essa faixa enquadra $\delta$ dentro dos limites inscritos no intervalo 6.113 e é mostrada na Figura 6.19.

$$
-\left(\eta^{2}+2 q^{\prime} \eta\right)<\delta<-\left(\eta^{2}-2 q^{\prime} \eta\right)
$$

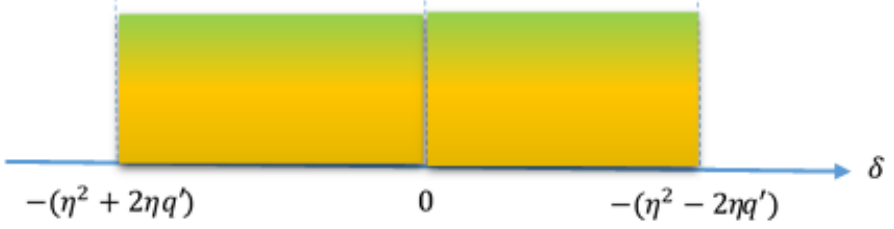

Figura 6.19: Intervalo de valores para os quais o sistema terá trajetórias convergentes independentemente do sinal de $s$

Não há qualquer intervalo de valores que faça com que o sistema descreva sua trajetória sob a lei de convergência simultaneamente para valores de $s$ positivos e negativos. Apenas um ponto, $\delta=0$, permitirá que a trajetória convirja para desejada independentemente do sinal do erro de trajetória. Esse ponto, no entanto, não representa uma condição prática implementável porque pressupõe que a melhor estimativa atribuída às variáveis incertas do sistema dinâmico, coincida com seus valores instantâneos. Isso significaria conhecer completamente o sistema, o que vai de encontro à premissa assumida ao longo deste trabalho de há incertezas associadas. 


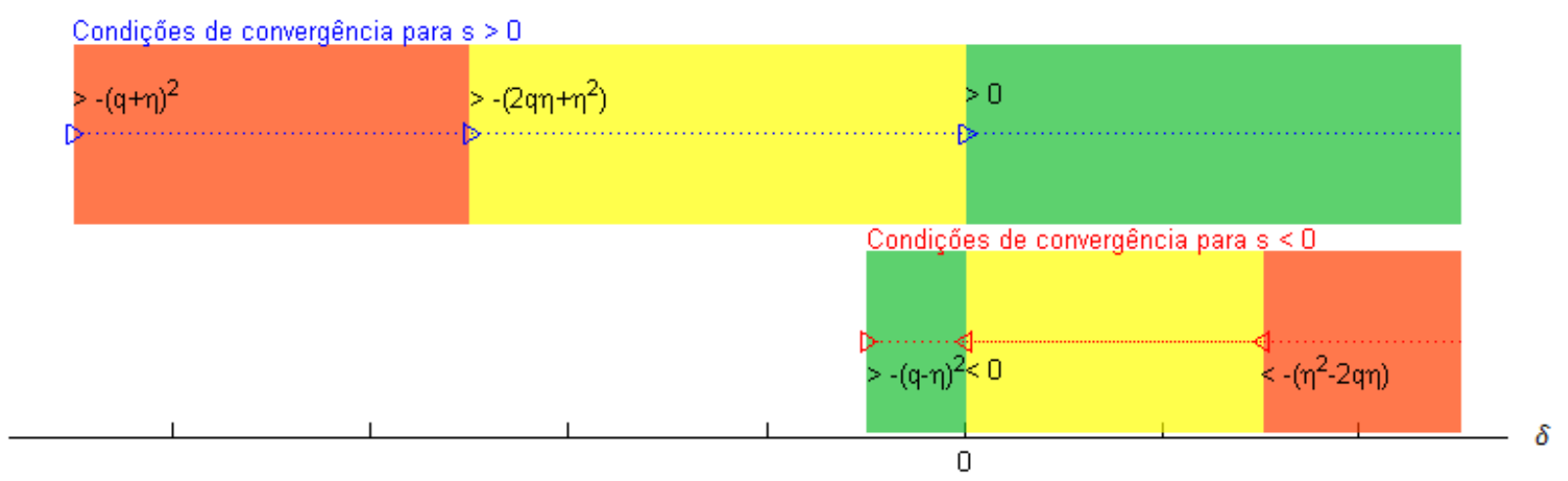

Figura 6.20: $\epsilon=1$. Condições de convergência para $s \geq 0$ parte superior da Figura e $s<0$ parte inferior. Região verde:sistema sob a lei convergência. Região amarela: convergência fraca. Região vermelha: trajetórias divergem

Já no segundo caso, em que $\epsilon=0$ (Figura 6.18), não haverá intervalo permitido a $\delta$ que levem o sistema a apresentar convergência global, ou seja, que permita a trajetória do sistema convergir para desejada, independentemente de $s$ ser positivo ou negativo. As regiões marcadas em verde na Figura estão diametralmente opostas, o que indica que não há intervalo de valores de $\delta$ que levem à um convergência global. A Figura 6.21 ilustra a interseção das regiões que representam as condições mostradas na Figura 6.18, onde observa-se que o sistema não apresenta, para este caso, condições de convergência. Algum mecanismo deverá ser implementado para que essa situação seja evitada, no entanto, faz-se necessário chamar a atenção para o fato de que as regiões de convergência e divergência foram apresentadas em relação à atenuação medida por $\epsilon$, que representa apenas uma das parcelas do sinal de controle. Além disso, várias parcelas do sinal de controle serão arbitradas pelo projetista do controlador, de forma que não será difícil implementar alguma condição que impeça o sistema controlado de atuar em regiões de divergência.

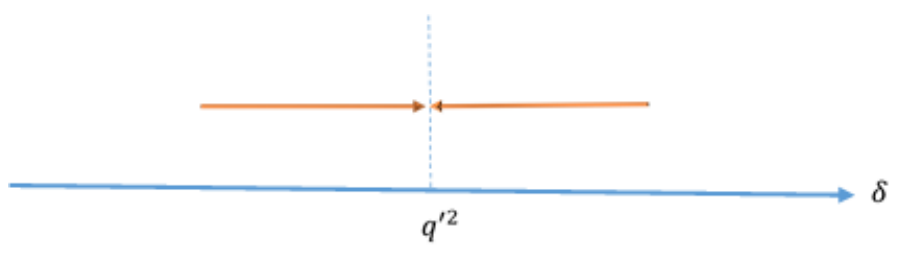

Figura 6.21: Se $\epsilon=0$, não intervalo de valores para os quais o sistema terá trajetórias convergentes independentemente do sinal de $s$

Sumarizando o comportamento de sistema para $\epsilon=0$ : se $\delta>q^{\prime 2}$, a trajetória do sistema divergirá da desejada para valores negativos de $s$; se $\delta<q^{\prime 2}$, a trajetória divergirá da desejada para valores positivos de $s$. No ponto em que $\delta=q^{\prime 2}$ a taxa de variação do erro de trajetória, medida por $\dot{s}$ será igual a zero, resultado que é obtido quando se substitui os valores $\delta=q^{\prime 2}$ e $\epsilon=0$ na equação 6.111. Sob essa hipótese, o sistema permanecerá com erro de trajetória constante. 


\subsubsection{Valores de $\epsilon$ Intermediários}

Valores intermediários de atenuação de $\epsilon$ resultarão em comportamento intermediário do sistema no que diz respeito à convergência do sistema, em relação ao dois casos apresentados $(\epsilon=0 \mathrm{e}$ $\epsilon=1)$. Quanto mais próximo de zero for o valor de $\epsilon$, menor será o intervalo de valores permitidos a $\delta$ para que haja garantia de que a trajetória do nível do líquido no interior do separador convirja para a trajetória desejada. Para ilustrar o efeito da atenuação parcela do sinal de controle medida pelo decréscimo do valor de $\epsilon$, considere a seguinte notação:

$$
\begin{aligned}
& a=q^{\prime 2}+2 \eta q^{\prime}+\eta^{2} \\
& b=q^{\prime 2}-2 \eta q^{\prime}+\eta^{2}
\end{aligned}
$$

A Figura 6.22 mostra o intervalo produtivo de $\delta$ para quatro valores diferentes de $\epsilon(\epsilon=1$, $\epsilon=0.9, \epsilon=0.5$ e $\epsilon=0)$. O intervalo produtivo de $\delta$ será caracterizado como aquele em que o sistema terá trajetórias convergentes ou, no mínimo, estabilidade de trajetória, de forma que o erro medido por $\dot{s}$ permaneça constante. Observa-se na Figura, que a medida que o valor de $\epsilon$ diminui, o intervalo produtivo de $\delta$ fica cada vez menor até que, em $\epsilon=0$ esse intervalo se reduz a apenas um valor, $\delta=q^{\prime 2}$.

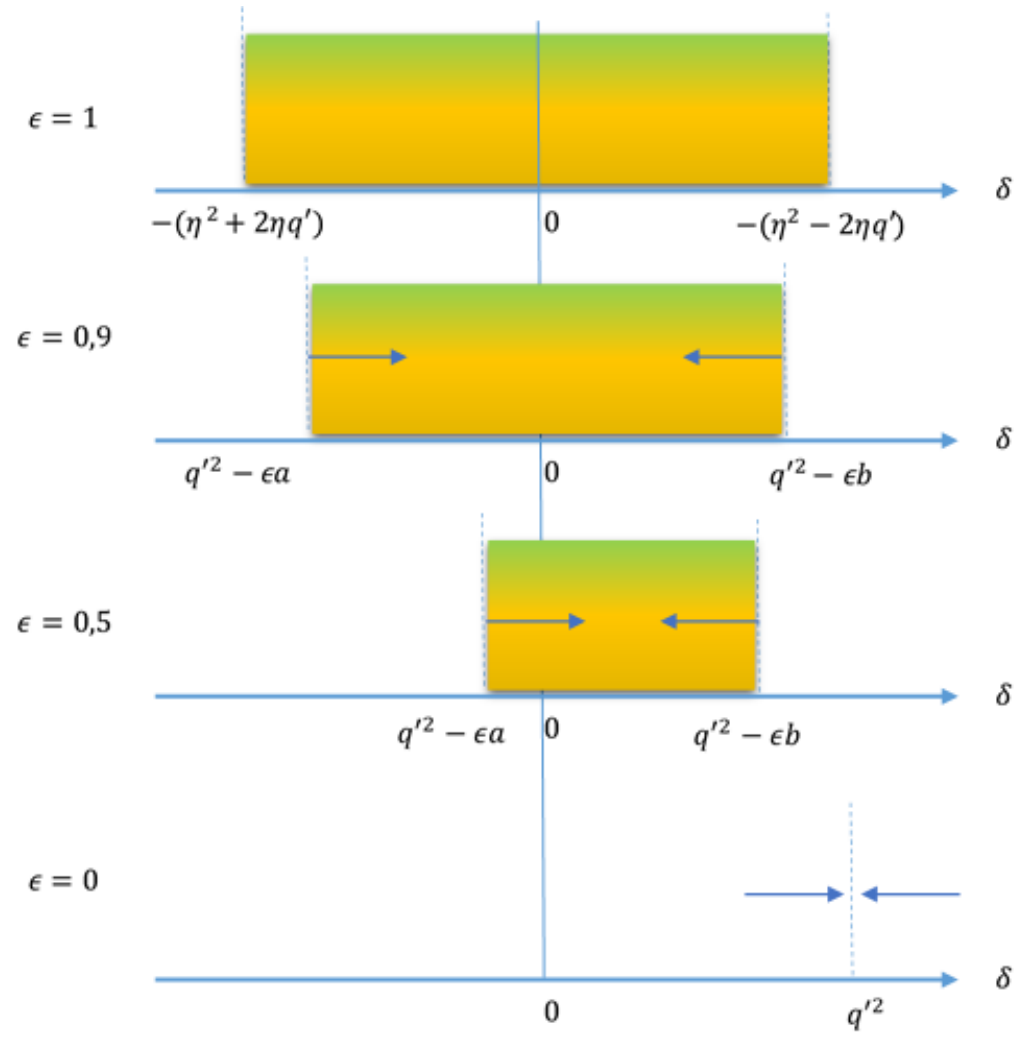

Figura 6.22: Intervalo produtivo de $\delta$ para quatro valores diferentes $(\epsilon=1, \epsilon=0.9, \epsilon=0.5 e$ $\epsilon=0)$

Em geral, o intervalo produtivo de $\delta$ circunscrito ao intervalo é descrito na relação 6.115 


$$
q^{\prime 2}-\epsilon a<\delta<q^{\prime 2}-\epsilon b
$$

\subsubsection{Efeitos da Atenuação do Sinal de Controle devido variação de $\epsilon_{f}$ e $\epsilon_{l}$}

Até agora, foram estudados os efeitos da atenuação da parcela do sinal de controle que corresponde a $\varphi$, definido na equação 6.90. Como visto, quando maior o valor da fração $\epsilon$, que mede a atenuação, maior será o intervalo de valores permitidos a $\delta$ que forçarão o sistema a descrever trajetórias convergentes. Por trajetórias convergentes entende-se, no escopo do presente trabalho, a situação em que a função da posição do nível do líquido no interior do separador $(l(t))$, converge para a função $l_{d}(t)$, uma função previamente determinada pelo projetista do controlador. Esta última função aparece diversas vezes ao longo do Capítulo, identificada como trajetória desejada.

Embora as condições convergência estejam exemplificadas na discussão realizada em termos de $\epsilon$, este não é o único parâmetro resultante da filtragem do sinal de controle que irá influenciar o comportamento do sistema controlado, quanto a sua convergência. Nessa discussão foram identificadas três regiões distintas:

- um intervalo de valores de $\delta$ que levará o sistema a apresentar comportamento convergente, respeitando a lei de convergência (equação 6.31);

- um intervalo de valores de $\delta$ que fará com que o sistema apresente comportamento convergente, respeitando uma lei equivalente à lei de convergência, nomeada de convergência fraca (equação 6.110);

- um intervalo de valores de $\delta$ que implicará em divergência de trajetórias.

Uma questão importante que surge na identificação desses intervalos é que o próprio valor de $\delta$ é uma composição de parcelas que englobam parte o sistema dinâmico que descreve o nível do líquido no separador submerso e de parcelas do sinal de controle aplicado ao sistema. Sendo assim, a variável $\delta$ também estará sujeita a modificação pelo processo de filtragem do sinal. Na prática, quando se considera que $\delta$ é uma soma de parcelas intrínsecas à dinâmica e introduzidas pelo sinal de controle, faz-se necessário considerar a atenuação dessas parcelas pertinentes pelo processo de filtragem, de modo a se obter um retrato amplo do comportamento do sistema. A variável $\delta$ não é uma variável advinda de características do sistema, uma simplificação notacional utilizada neste trabalho que foi definida pela equação 6.93. As parcelas de $\delta$ que representam parte do sinal de controle têm suas atenuações de amplitude medidas pelas variáveis $\epsilon_{F}$ e $\epsilon_{l}$, de forma que haverá necessidade de considerá-las para se estabelecer o comportamento do sistema e se propor a forma final da lei de controle a ser aplicada.

Considere, primeiramente, o caso hipotético no qual todo sinal de controle seja uma função sinusoidal de alta frequência, como ilustrado na Figura 6.23. Um filtro de linear de primeira ou segunda ordem, resultará na supressão do sinal de controle $u^{2}$, levando $\gamma^{2}$ a zero. O resultado seria que o sistema estaria à deriva já que não haveria ingerência do controlador sobre ele. Em termos 


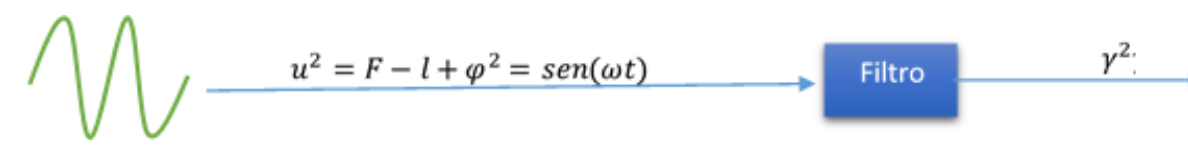

Figura 6.23: Sinal de controle u descrito por uma função sinusoidal sin( $\omega t)$ com frequência angular $\omega$

das variáveis que representam as frações de atenuação de amplitude, ter-se-ia $\epsilon_{F}=0$ e $\epsilon_{l}=0$. Apesar do sério problema associado ao caso dessa hipótese, um vez que suscita-se a possibilidade de total descontrole do sistema, vale a pena ressaltar que esse possível problema pode ser facilmente contornado. O valor de $F$ (ver equação 6.89) pode ser convenientemente arbitrado desde que retrate os máximos valores absolutos das variáveis incertas do sistema, de acordo com a equação 6.34

É possível, então, chegar-se a um valor de $F$ que seja minimamente impactado pela filtragem do sinal de controle, agindo de tal forma que $\epsilon_{F}$ sempre expresse valores significativos e o controlador não perca influência sobre o sistema. É evidente que independentemente do valor arbitrado para $F$, haverá um intervalo de tempo em que $\epsilon_{F}$ apresentará valores próximos de zero, esse intervalo corresponde ao intervalo de tempo inicial em que a saída do filtro está em regime transiente. Não se espera problemas relacionados à capacidade do controlador agir sobre o sistema desde que esse intervalo de tempo seja pequeno. Um sinal composto por uma variável $F$ descrita por uma função periódica de baixa frequência, ou que tenha parcelas com semelhante, como uma função constante no tempo, seria um bom candidato à lei de controle já que as parcelas constantes seriam pouco influenciadas pelo filtro uma vez alcançado o regime permanente. O referido regime permanente diz respeito ao sistema em malha aberta do conjunto sinal de controle/filtro, conforme mostrado na Figura 6.11, de forma que projetando convenientemente o filtro pode-se conseguir um regime transiente associado com um intervalo de tempo pequeno de forma que $\epsilon_{F}$ possa ser admitido como constante.

Explicitando o valor de $\delta$, a equação 6.115 que dá o intervalo em que sistema apresenta comportamento convergente (intervalo produtivo) poderá ser escrito na seguinte forma:

$$
q^{\prime 2}-\epsilon a<f+\epsilon_{F} F+l-\epsilon_{l} l<q^{\prime 2}-\epsilon b
$$

Caso o intervalo de tempo que $e_{F}$ leve para alcançar a unidade possa ser desprezado o intervalo produtivo será escrito na forma:

$$
q^{\prime 2}-\epsilon a<f+F+l-\epsilon_{l} l<q^{\prime 2}-\epsilon b
$$

Como a função $f(t)$ que descreve a parte incerta do sistema dinâmico tem seus limites superior $\left(f_{\text {sup }}\right)$ e inferior $\left(f_{\text {inf }}\right)$ determinados, a desigualdade 6.117 ainda estará satisfeita quando:

$$
q^{\prime 2}-\epsilon a-f_{\text {inf }}<F+\left(1-\epsilon_{l}\right) l<q^{\prime 2}-\epsilon b-f_{\text {inf }}
$$


onde $f_{\text {inf }} \leq f \leq f_{\text {sup }}$.

O que interessa, a esse ponto, é se determinar o comportamento do sistema que descreve a posição do nível do líquido no interior do separador em em relação aos valores assumidos pela variável $F$, a exemplo do discussão apresentada para variável $\delta$ na seção 6.4.1. A vantagem dessa análise está no fato de que $F$ é a parte manipulável do sistema controlado, portanto, o comportamento do sistema estará diretamente vinculado ao seu valor.

No intuito de se desenvolver um raciocínio que leve a determinação dos possíveis valores de $F$ que resultem em convergência de trajetórias do sistema, considere, primeiramente, a hipótese em que $\epsilon_{l}=1$, ou seja, o nível do líquido é constante ou oscila à baixas frequências. Nesse caso o sinal de controle previsto em 6.89 consegue compensar a variável $l$ (nível do líquido) e o intervalo 6.118 se torna:

$$
q^{\prime 2}-\epsilon a-f_{\text {inf }}<F<q^{\prime 2}-\epsilon b-f_{\text {inf }}
$$

O comportamento do sistema em relação à $F$ será semelhante ao comportamento apresentado em relação $\delta$ mostrado na Figura 6.22. Observe que $F$ está circunscrito pelo mesmo intervalo de valores atribuídos a $\delta$ em 6.115 , só que deslocado para esquerda por um valor constante $f_{\text {inf }}$. Assim, serão observados as mesmas regiões de valores que levam o sistema a divergir, convergir sob a lei de convergência, e convergir fora da lei de convergência (convergência fraca). A Figura 6.24 mostra os intervalos de $F$ para os quais o sistema terá a trajetórias convergentes, nesse assim como no caso da discussão feita em relação a $\delta$, quanto menor for o valor de $\epsilon$ menor será o intervalo de valores permitidos para $F$, quando $\epsilon=0$ esse intervalo se reduz ao ponto $F=q^{2}-f_{\text {inf }}$ 


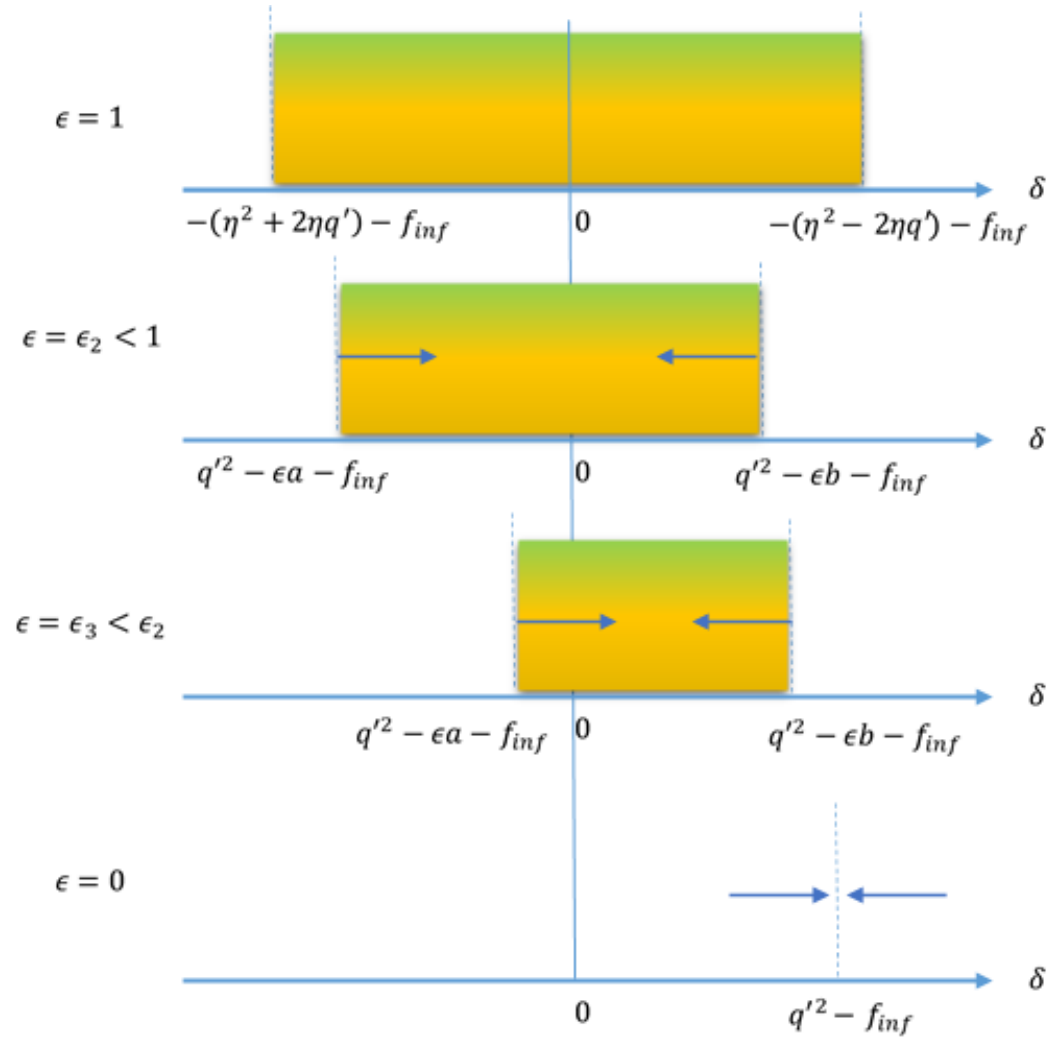

Figura 6.24: Intervalo produtivo de $F$ para quatro valores diferentes $\epsilon$

Semelhantemente ao intervalo 6.119, valores de $e_{l}$ diferentes de zero resultam em um descolamento do intervalo de valores produtivos de $F$. No entanto, esse tipo de análise suscita uma complicação. O intervalo de valores produtivos em relação a $F$, não será deslocado apenas por uma quantidade constante como é o caso da hipótese anterior (inequação 6.119), mas por uma função da variável a ser controlada: $(1-\epsilon) l$, o que pode dificultar o estabelecimento da parte manipulável do sinal de controle, ou seja, de $F$.

Como o sinal de controle, da forma como proposto, é inteiramente filtrado, faz-se necessário considerar o deslocamento do intervalo produtivo de $F$ ocasionado pela variação do nível $l$. Uma alternativa seria adotar uma modificação do sinal de controle em que a parcela referente a variável $l$ não fosse filtrada, dessa forma o intervalo de valores produtivos de $F$ já estaria estabelecido pela inequação 6.119, essa estratégia demandaria uma revisão do projeto do controlador o que deverá ser realizado em momento oportuno. Uma outra estratégia a ser aplicada ao controlador na forma como proposto, é o estabelecimento de valores de $F$ que sejam proporcionais a $\left(1-\epsilon_{l}\right) l$, valor disponível, já que é parte do sinal filtrado. No entanto, o valor efetivamente obtido após passar o sinal de controle $u^{2}$ pelo filtro é $\gamma^{2}$ (ver Figura 6.11 ), logo, a obtenção de $\left(1-\epsilon_{l}\right) l$ pode não ser uma tarefa simples.

No intuito de se estabelecer um intervalo de valores produtivos $F$, que suportem a variação de $\left(1-\epsilon_{l}\right) l$, alguns conceitos adicionais deveram ser abordados. Considere o intervalo 6.119 reescrito na seguinte forma: 


$$
A-\left(1-\epsilon_{l}\right) l<F<B-\left(1-\epsilon_{l}\right) l
$$

onde $A=q^{\prime 2}-\epsilon a-f_{\text {inf }}$ e $B=q^{2}-\epsilon b-f_{\text {inf }}$.

Suponha, adicionalmente, que num período de tempo o nível do líquido no interior do separador tenha se variado de um dado valor inicial $l_{0}$ para um valor final $l_{f}$. Nesse caso qualquer tentativa de estabelecimento de um valor para $F$ dentro do intervalo $A \leq F \leq B$, resultará em uma das seguintes hipóteses:

- o valor proposto para $F$ estará dentro de um intervalo acertadamente assumido

- o valor proposto para $F$ estará dentro de um intervalo erroneamente assumido

Por intervalo acertadamente assumido, entende-se o intervalo de valores para os quais $F$ estará contido, simultaneamente no intervalo $A \leq F \leq B$ e no intervalo 6.120. Por erroneamente assumido entende-se o valor de $F$ que caia na região fora dos limites de 6.120. Uma terceira hipótese ainda pode acontecer: $F$ dentro dos limites de 6.120, mas fora do intervalo $A \leq F \leq B$. Essa, porém, não seria facilmente implementável já que para tal seria necessário determinar o valor de $\left(1-\epsilon_{l}\right)$.

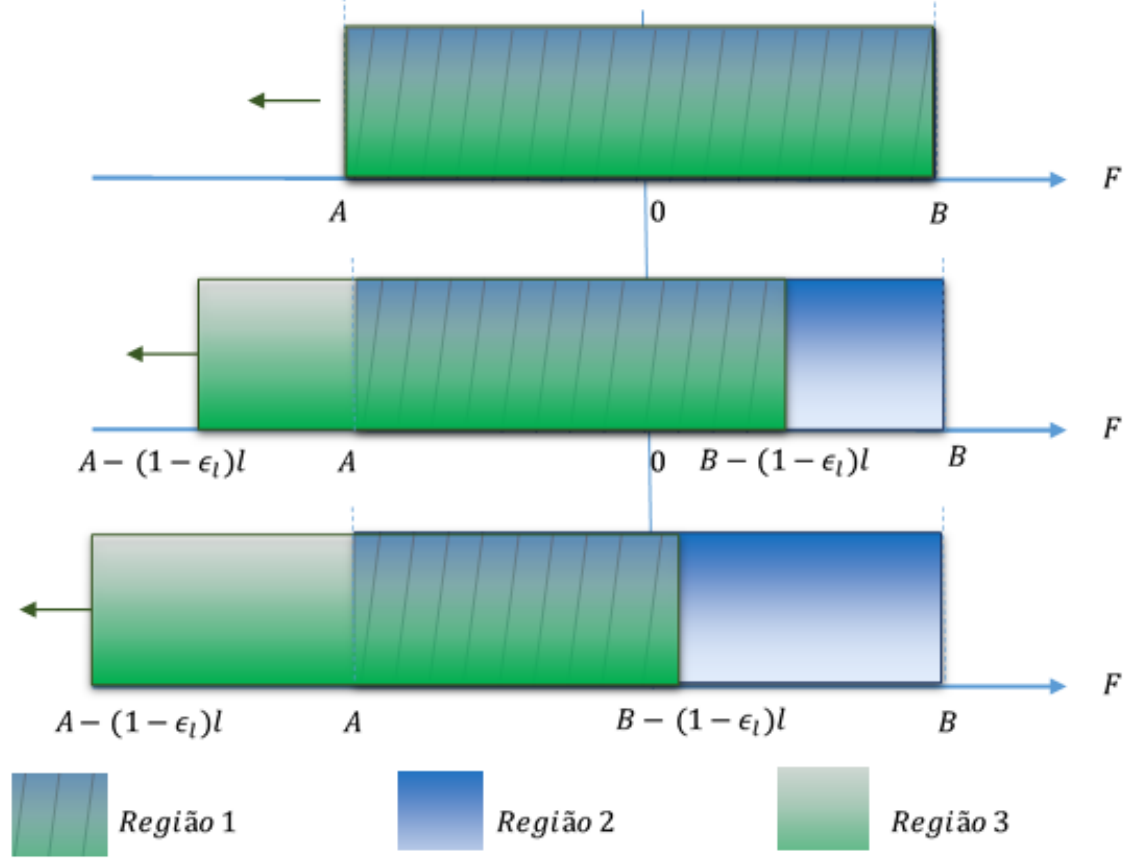

Figura 6.25: Regiões de comportamento do sistema em relação a F. Região 1: valor proposto para $F$ estará dentro de um intervalo acertadamente assumido. Região 2: valor proposto para $F$ estará dentro de um intervalo erroneamente assumido.Região 3: $F$ dentro dos limites do intervalo 6.120, mas fora do intervalo $A \leq F \leq B$.

O intervalos relativos às hipóteses levantadas são mostrados na Figura 6.25. Na Figura é ilustrado o estreitamento do intervalo acertadamente assumido à medida que o valor de $\left(1-\epsilon_{l}\right) l=0$ 
aumenta e desloca o intervalo de valores produtivos para esquerda. Esse deslocamento culminará no ponto em que não haverá nenhum valor que se possa atribuir a $F$ que o posicione dentro dos intervalos $A \leq F \leq B$ e 6.120 simultaneamente, o que acaba por impor um valor máximo ao nível $l$ para o qual o controlador conseguirá um ingerência segura sobre o sistema. A partir desse valor máximo em diante, tem-se:

$$
B-\left(1-\epsilon_{l}\right) l<A
$$

desenvolvendo a desigualdade chega-se a:

$$
q^{\prime 2}-\epsilon b-f_{\text {inf }}-\left(1-\epsilon_{l}\right) l<q^{2}-\epsilon a-f_{\text {inf }}
$$

assim, tem-se o valor máximo de $l$ dado por:

$$
l=\frac{\epsilon}{\left(1-\epsilon_{l}\right)}\left(4 \eta q^{\prime}\right)
$$

Análise semelhante leva ao estabelecimento de um limite inferior equivalente nos seguintes termos:

$$
l=\frac{\epsilon}{\left(1-\epsilon_{l}\right)}\left(-4 \eta q^{\prime}\right)
$$

Apesar da aparente sugestão de que se tem um controlador deficitário já que não se pode garantir sua ação para qualquer valor do nível do líquido, é necessário observar-se que esses limites são impostos pela expectativa de um controle global simultâneo para qualquer condição de erro de trajetória. É perfeitamente possível contornar essa suposta deficiência considerando estratégias de controle diferentes para diferentes condições, por exemplo, pode-se assumir uma estratégia que seja utilizada quando o erro resulte em uma superfície $s$ com valores negativos, e outra utilizada para valores que resultem $s$ positivo. Esse tipo de abordagem não é uma tarefa difícil caso observe-se que a maior parte da discussão realizada sobre as regiões de convergência do sistema são feitas para esses dois casos distintos $(s \geq 0$ e $s<0)$. O valor da superfície $s$ e seu significado foi apresentado na seção 6.1 .

Apesar, ainda, da viabilidade de implementação do controlador proposto, não serão necessárias a definição e assunção de estratégias distintas, pois, como discutido na seção 6.5 , características intrínsecas ao funcionamento do separador ciclônico permitem a elaboração do sinal de controle nos moldes do controlador proposto mas que trabalhe efetivamente apenas na região em que o erro de trajetória é positivo, ou seja, $s \geq 0$.

A importância de se estabelecer os limites de atuação do controlador de forma global, como discutido nesta seção, está na necessidade de se conhecer minuciosamente a ferramenta proposta deixando claro suas potencialidades e, principalmente, seus limites para que um possível implementação prática não venha a apresentar surpresas. Além disso, conhecendo os limites do controlador é possível propor-se modificações e aperfeiçoamentos mais facilmente. 


\subsection{Hipóteses Simplificadoras}

De modo geral, o controlador proposto pode ser visto como um composição de duas etapas: a elaboração do sinal de controle utilizando os conceitos de controle deslizante e a suavização do desse sinal para eliminar descontinuidades intrínsecas através da aplicação de um filtro linear. Entretanto, como visto nas seções 6.4.1 e 6.4.2, a filtragem do sinal acaba por impor uma série de limitações, inclusive prevendo limites para os valores da variável controlada (nível $l$ ) fora dos quais não se pode garantir a eficiência do controlador. Essas limitações são traduzidas em intervalos de valores para os quais o parâmetro $\delta$ e consequentemente $F$, impõem um comportamento convergente onde a trajetória do nível do líquido no interior do separador convergirá para uma trajetória desejada, previamente estabelecida. Essas intervalos de valores foram denominados intervalos produtivos.

Fora do intervalo produtivo espera-se um comportamento divergente, ou seja, a trajetória descrita se distanciará da desejada. Essa é uma situação que deve ser evitada sempre que possível pois sua persistência poderia colocar o sistema em risco. No entanto, o que deve ficar claro a cerca do comportamento do sistema controlado é que a previsão do intervalo produtivo se baseia na expectativa de controle global do sistema. Por controle global, entende-se, para fins deste trabalho, um controle que garanta convergência do sistema para qualquer situação associada ao erro trajetória, em outras palavras, a lei de controle garantirá convergência de trajetórias quando o erro medido pela superfície $s$ for positivo tanto quanto, quando for negativo. O fato de a variável arbitrável $F$ estar localizada em um ponto fora do intervalo produtivo, num determinado momento não significa, necessariamente, que o sistema divergirá já que essa conclusão deve ser tomada com base no valor de $F$ e no sinal da superfície $s$. Para ilustrar a ideia, suponha que a variável $F$ tenha num dado instante um valor tal que impute a $\delta$ o seguinte valor:

$$
\delta(t)=-\left(\eta^{2}-2 q^{\prime} \eta\right)+1
$$

lembrando que $\delta$ é uma função $\delta(F)$ dada pela equação 6.93. Suponha ainda, que não haja atenuação de nenhuma parcela do sinal de controle, de forma que as frações de atenuação sejam iguais a unidade, $\epsilon_{F}=\epsilon_{l}=\epsilon=1$. Sob essa hipótese, o parâmetro $\delta$ estará posicionado fora do limite produtivo, o que pode induzir à conclusão de que o sistema tem comportamento divergente. Uma observação mais acurada, porém, revela que esse valor de $\delta$ implicará em divergência apenas quando o sinal de $s$ for negativo, já que $\delta$ estará posicionado na região marcada em vermelho da Figura 6.20. Se $s$ tiver sinal positivo, delta estará na região marcada em verde da Figura, justamente a região para a qual o sistema controlado apresentará comportamento convergente, sob a lei de convergência enunciada pela inequação 6.31 .

Quanto ao funcionamento do sistema, algumas hipóteses simplificadoras podem ser estabelecidas de forma nortear o projeto do controlador a cerca de quais regiões de comportamento se espera trabalhar. Assim, pode-se propor uma estratégia de controle que seja suficientemente geral para que se consiga manter o sistema devidamente controlado. O sistema estudado, trata-se de um recipiente fechado com vários estágios se separação de fases, gás e líquido em que cada fase 
será transportada por tubulações diferentes para seus destinos. A cerca do separador ciclônico submerso, as seguintes hipóteses são assumidas:

- Não se espera vazões negativas na entrada do separador, uma vez que é plausível supor-se que não haverá sucção do líquido que escoa pelo recipiente de separação, que leve o líquido já separado a retornar à tubulação de entrada em direção ao poço de petróleo. Essa hipótese impõe à vazão de entrada do separador um valor positivo. $q_{i n} \geq 0$

- Uma vez que a trajetória desejada é previamente determinada e ajustada segunda a conveniência do projetista, é perfeitamente factível o estabelecimento de um vetor de trajetória deseja $\left(\mathbf{l}_{d}=\left[\begin{array}{ll}l_{d} & i_{d}\end{array}\right]\right)$ que resulte em um parâmetro $q^{\prime}$ tal que $q^{\prime}$ seja sempre um valor positivo quando o erro de trajetória medido pela superfície $s$ for um valor negativo. Lembrando que o parâmetro é definido pela equação 6.112 da seguinte forma:

$$
q^{\prime}=\frac{q_{i n}}{A}+1-i_{d}=q-i_{d}
$$

O que se pretende evitar com isso é que o produto $\dot{s} s$ definido na forma da equação 6.111 resulte em um valor positivo o que inviabilizaria a lei de convergência:

$$
\dot{s} s \leq-\eta|s|
$$

- O bombeamento do líquido para tubulação de escoamento é realizado unidirecionalmente. Não se espera que haja bombeamento de líquido a partir da sua tubulação de escoamento para o interior do recipiente de separação, ou seja, no sentido reverso. Desta forma, a melhor estratégia a ser adotada quando a posição do nível do líquido for menor que a prevista pela trajetória desejada num determinado instante, é esperar o restabelecimento natural do nível o que pode ser conseguido simplesmente desativando o atuador, nesse caso a bomba submersa. Com isso, elimina-se a necessidade de se preocupar com o comportamento do sistema em termos das regiões de convergência sob a lei de convergência, convergência fraca e divergência discutidas nas seções anteriores quando o erro de trajetória for negativo, ou $s<0$. Não é necessário preocupar-se com valores impostos a $F$ que culminaram no estabelecimento do limite máximo do nível para o qual o sistema é seguramente aplicável como foi determinado pela equação 6.123. Em resumo, o controlador proposto só precisará atuar efetivamente para condições do sistema que resultem em $s=0$.

- A capacidade de atuação do sistema de bombeamento será admitida como limitada. A velocidade de rotação da bomba está relacionada à vazão de saída do líquido pela variável $\gamma^{2}$ conforma a equação 6.51. Essa variável, que representa o próprio sinal de controle filtrado, é um valor que varia de zero, quando a bomba está desligada até $\gamma^{2}=1$, quando a bomba opera em rotação máxima. 


\subsection{Formato Final do Controlador Proposto}

O formato final do controlador proposto no presente trabalho é obtido admitindo-se as simplificações introduzidas ao problema que foram discutidas na seção anterior (seção 6.5). Admite-se, então, que o atuador deverá ser desativado sempre que o erro de trajetória medido por $s$ for negativo (ver equação 6.48). Admite-se ainda, que o valor do sinal de controle filtrado $\gamma^{2}$ não deve passar da unidade, ou seja o controlador não deverá tentar forçar a bomba a trabalhar acima de sua capacidade máxima. Assim o sinal de controle passa a ser representado não mais por $u$ admitido anteriormente, mas por uma função $u^{\prime}(u)$ descrita da seguinte forma:

$$
\left\{\begin{array}{l}
u^{\prime}=1, \quad \text { se } \quad u \geq 1 \\
u^{\prime}=u, \quad \text { se } s \geq 0 \\
u^{\prime}=0, \quad \text { se } s<0
\end{array}\right.
$$

$u$ em 6.128 é o sinal predito pela teoria de controle deslizante na equação 6.89 . Semelhantemente às discussões anteriores o sinal $u^{\prime}$ será filtrado de forma a se obter o valor final $(\gamma)$ a ser aplicado ao sistema. A Figura 6.26 mostra o diagrama referente.

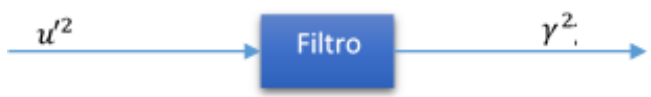

Figura 6.26: Sinal de controle assumindo as hipóteses simplificadoras

O filtro linear aplicado ao sinal $u^{\prime}$ elimina possíveis descontinuidades do sinal. Logo, tanto no caso em que $u^{\prime}$ assume valor unitário quanto no caso em que $u^{\prime}$ zera, o atuador não será forçado a mudar sua frequência de rotação abruptamente já que o sinal efetivamente utilizado para controlar o sistema é $\gamma^{2}$. Outras variações dos valores de $u^{\prime}$ são facilmente implementadas tomando a função $u^{\prime}(u)$ como guia geral. Por exemplo, pode-se impor que o atuador não ultrapasse $90 \%$ de sua capacidade máxima configurando $u^{\prime}=0,9$ se $u \geq 1$. Várias possibilidades são podem ser implementadas a depender da necessidade do projetista do controlador. Quando $s \geq 0$ a função $u^{\prime}(u)$ tem o mesmo valor de assumido nas seções anteriores de forma que toda a discussão realizada para o sinal de controle nessas condições continuam aplicáveis ao sinal $u^{\prime}$.

Quanto ao formato final atribuído algumas observações devem ser realizadas. A filtragem do sinal de controle foi proposta no intuito de se eliminar as descontinuidades intrínsecas ao controle deslizante, essas descontinuidades, senão tratadas, podem forçar uma mudança abrupta da frequência de rotação da bomba submersa ocasionando desgaste prematuro ou, até mesmo, danos ao atuador. Com a introdução do filtro porém, espera-se uma redução da velocidade de resposta do controlador fazendo com que a trajetória do nível do líquido leve mais tempo para convergir para trajetória desejada quando comparado ao mesmo controle aplicado diretamente ao sistema sem passar pelo filtro. Esse retardo na resposta do controlador não se configura um grande problema já que o principal papel a ser desempenhado pelo controlador não é manter um valor preciso da variável controlada ou manter uma trajetória próxima da desejada sob valores 
estritos de erro de forma que as duas trajetórias coincidam fortemente. O principal resultado esperado para o controlador é impedir que o nível do líquido ultrapasse limites superior e inferior de valores que possam ser prejudiciais ao sistema. Dessa forma, considera-se mais benéfico ao sistema manter-se o nível do líquido dentro de um intervalo operacional com o mínimo esforço do atuador, do que impor uma grande precisão da trajetória observada em relação à trajetória desejada.

Um vantagem esperada pela adoção do controlador proposto é a possibilidade de se determinar previamente a trajetória a ser seguida pelo nível do líquido. Essa possibilidade pode ser uma grande aliada na tentativa de se diminuir o esforço do atuador já que podem ser adotadas curvas que minimizem seu esforço otimizando o sistema como um todo. Como exemplo dessa versatilidade, pode-se impor ao sistema o desenvolvimento de uma trajetória que acomode características próprias de uma bomba específica aplicada a um caso prático, assim pode-se fazer que a bomba desenvolva valores de frequência diferentes para diferentes intervalos de valores do nível do líquido. O estudo de trajetórias desejadas que otimizem o sistema será tema de estudos posteriores. 


\section{Capítulo 7}

\section{Resultados}

Neste Capítulo é apresentado o algoritmo desenvolvido para solução numérica do sistema controlado (seção 7.1) e são apresentados alguns resultados obtidos para casos representativos com diferentes tipos de sinais para descrever a vazão de entrada do gás e do líquido no separador (seção 7.2 )

\subsection{Algorítimos de Solução do Sistema do Separador Ciclônico Submerso}

Para a computação dos escoamentos do líquido e do gás no interior de suas respectivas tubulações de saída, bem como do valor do nível do líquido no interior do separador ciclônico, foram elaborados algorítimos em MATLAB ${ }^{1}$ sob uma estrutura de programação orientada a objetos. Três classes foram elaboradas, a primeira para determinação da vazão e pressão (dada em termos de altura piezométrica) ao longo da tubulação de escoamento do líquido chamada classLiquidPipe. Uma segunda classe, denominada classGasPipe, foi elaborada para determinação da pressão e vazão mássica do gás ao longo de sua respectiva tubulação de saída, e a terceira classe, classVessel, foi escrita no intuito de se armazenar parâmetros geométricos referentes ao recipiente de separação. Os aspectos mais importantes das classes são discutidos a seguir.

A classe classLiquidPipe equaciona o comportamento do líquido na respectiva tubulação e é composta de propriedades que correspondem a parâmetros físicos do fluido e do tubo, e de funções responsáveis pela computação numérica da vazão e pressão em pontos ao longo da tubulação utilizando a técnica de equações características. As principais propriedades contidas na classe são elencadas na tabela 7.1. São duas as principais funções da classe: uma, steadyState, que calcula a pressão (ou altura piezométrica) correspondente ao estado estacionário de escoamento para vários pontos ao longo da tubulação, com base na vazão estacionária inicial e, uma função, pipeCalc, que calcula pressão e vazão ao longo da tubulação ao longo do tempo, com base nos valores obtidos em tempos imediatamente anteriores e valores atribuídos a condições de contorno

\footnotetext{
${ }^{1}$ software comercializado pela MathWorks
} 
do sistema. O acionamento da bomba ou o fechamento de uma válvula são inseridos no algorítimo através dessas condições de contorno e uma vez inseridos, propagam-se como perturbações no decorrer do histórico temporal do sistema.

Tabela 7.1: Propriedades da classe classLiquidPipe

\begin{tabular}{lr}
\hline $\mathrm{L}$ & vetor com os comprimentos de cada segmento da tubulação \\
\hline $\mathrm{D}$ & vetor com os diâmetros de cada segmento da tubulação \\
\hline $\mathrm{f}$ & vetor com os fatores de atrito de cada segmento da tubulação \\
\hline beta & vetor com ângulo de inclinação em relação à horizontal de cada segmento da \\
& tubulação \\
\hline $\mathrm{a}$ & velocidade do pulso de onda resultante de perturbação transiente \\
\hline Hs & máxima altura de elevação da bomba \\
\hline tc & tempo para forçamento de efeito transiente (fechamento de válvula) \\
\hline $\mathrm{g}$ & altura que a tubulação de saída de líquido é acoplada ap recipiente de \\
\hline lc & separação, em relação à base do recipiente \\
\hline dens & densidade do líquido \\
\hline tmax & tempo de simulação
\end{tabular}

A classe classGasPipe, com suas principais propriedades apresentadas na tabela 7.2 , tem duas funções usadas para se obter o escoamento do gás ao longo do comprimento da tubulação de saída do gás e ao longo do tempo. Essas funções dão os valores da pressão e da vazão mássica com base parâmetros como o comprimento da tubulação, diâmetro, fator de atrito e valores de contorno estabelecidos para as extremidades da tubulação. A função steadyState calcula os valores iniciais necessários para resolver o escoamento do gás já que as equações diferenciais que governam o escoamento formam um problema de valor inicial. A função calcInside é usada para calcular a pressão e vazão mássica com base nos valores iniciais, para tanto, a função utiliza o método das equações características discutidas na seção 4.5. Na utilização do método das equações características aparece um valor $(\alpha)$ chamado multiplicador inercial que deve ser obtido para que se possa calcular o escoamento do gás (ver seção 4.5.1), esse parâmetro é calculado por uma função denominada calcInertialMultiplier. 
Tabela 7.2: Propriedades da classe classGasPipe

\begin{tabular}{lr}
\hline $\mathrm{L}$ & vetor com os comprimentos de cada segmento da tubulação \\
\hline $\mathrm{D}$ & vetor com os diâmetros de cada segmento da tubulação \\
\hline $\mathrm{f}$ & vetor com os fatores de atrito de cada segmento da tubulação \\
\hline teta & vetor com ângulo de inclinação em relação à horizontal de cada segmento da \\
& tubulação \\
\hline $\mathrm{z}$ & compressibilidade do gás \\
\hline $\mathrm{Rg}$ & constante dos gases ideais \\
\hline Temp & Temperatura absoluta (Kelvin) \\
\hline $\mathrm{g}$ & aceleração da gravidade
\end{tabular}

O cálculo do nível no separador é realizado por um função externa às classes, LevelControl, responsável por criar instâncias das classes e chamar as funções necessárias à computação do escoamento das duas tubulações de saída, a de líquido e a de gás. Inicialmente a função LevelControl cria uma instância da classe classLiquidPipe que permite acessar suas propriedades e métodos. A nova instância de classe, ou objeto, tem suas propriedades configuradas de acordo com as características físicas do sistema estudado, essas propriedades incluem parâmetros como comprimento e diâmetro da tubulação, coeficiente de atrito da tubulação, e capacidade de elevação máxima da bomba. Da mesma maneira, é criada uma instância da classe classGasPipe, pela qual são atribuídos os valores das propriedades do gás, bem como de sua tubulação de saída. A classe classVessel também é instanciada pela função a fim de que se possa armazenar parâmetros físicos do recipiente de separação como sua altura, diâmetro e área de seção transversal. Configuradas as propriedades, a Função Nivel recebe um conjunto de dados numéricos que representam a curva correspondente à vazão de entrada de líquido no separador ciclônico. A rotina numérica responsável pelo cálculo do nível inicia chamando a função do objeto de classe que calcula o estado estacionário.

A partir de uma vazão inicial conhecida, são calculados valores de pressão para cada ponto da tubulação. Depois de estabelecidas as condições iniciais de operação é chamada as respectivas funções do objeto de classe responsáveis pelo cálculo da pressão e vazão ao longo da tubulação de gás e líquido para cada intervalo de tempo a ser computado. Valores de contorno dos problemas de escoamento do gás e do líquido são obtidos na função LevelControl e enviados para as respectivas classes para computação dos valores de pressão e vazão no interior das tubulações. Um valor de contorno associado ao problema do escoamento do líquido é a pressão na base de sua tubulação de saída, a qual é uma função do próprio nível do líquido no interior do separador. Um valor de contorno para o problema do escoamento na tubulação de saída do gás é a vazão no ponto de interseç̧ão entre a tubulação e o recipiente de separação, esse valor é admitido como o valor da vazão obtida no interior do separador.

Por fim, a lei de controle é implementada dentro da função LevelControl e utiliza os resultados apresentados no Capítulo 6, para manter o nível do líquido dentro de parâmetros de funcionamento previamente especificados. Um esquema do funcionamento do algorítimo é mostrado na Figura 
7.1.

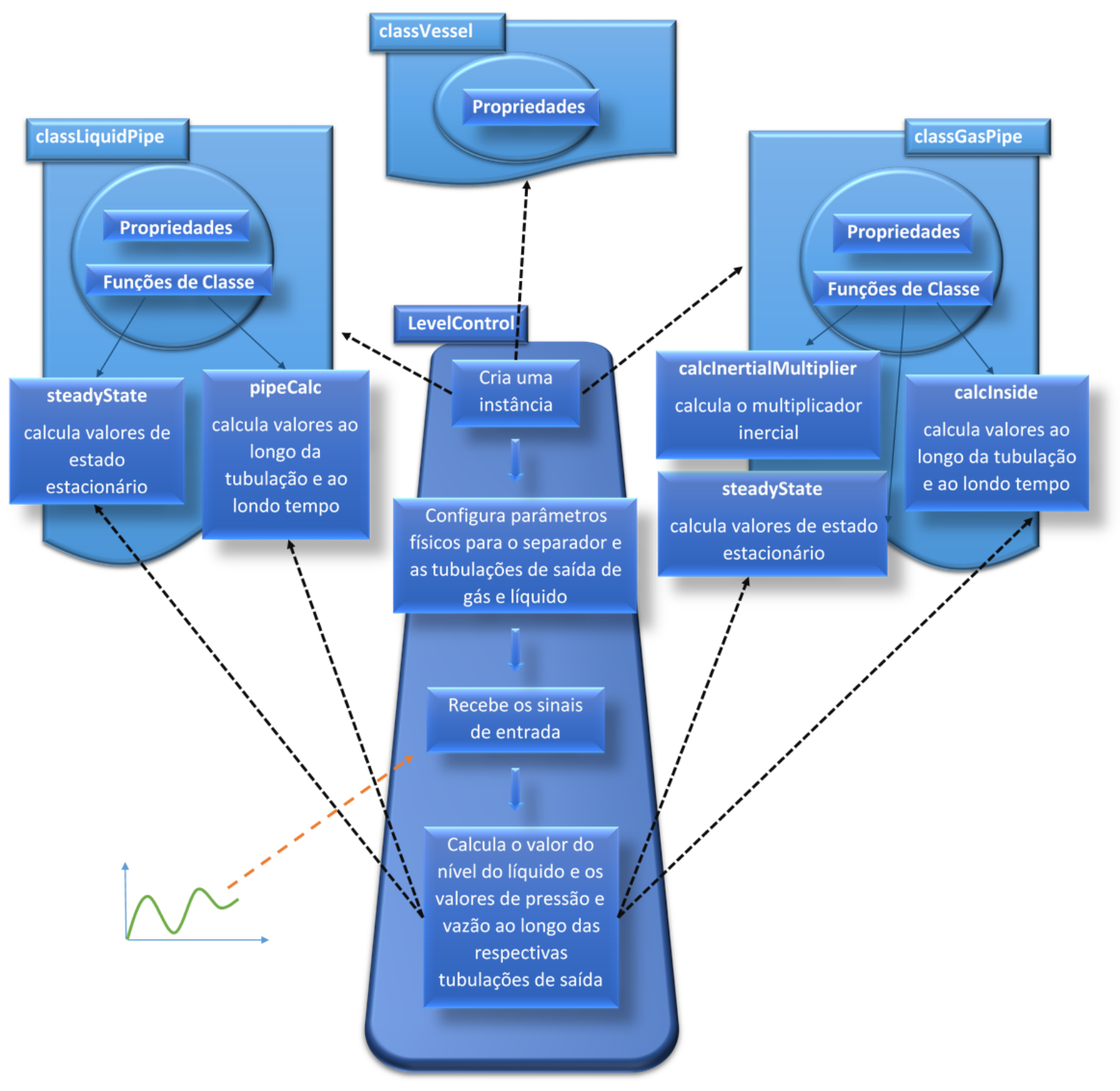

Figura 7.1: Organograma do algorítimo de cálculo do nível no interior do separador.

\subsection{Aplicação Teórica do Controlador a um Protótipo de Sepa- rador do tipo VASPS}

Storti 2013, realizou um estudo experimental do separador ciclônico submerso do tipo VASPS ${ }^{2}$ para estudo da eficiência de separação do primeiro estágio de separação: a câmara de expansão. Para tanto, o autor realiza testes de eficiência utilizando uma mistura ar/água e misturar ar/glicerina com diferentes viscosidades. Esse estudo serviu de base para a realização das simulações

\footnotetext{
${ }^{2} \mathrm{O}$ funcionamento desse tipo de separador foi apresentado na seção 2.4
} 
realizadas no presente trabalho uma vez que a descrição detalhada das características físicas do equipamento puderam ser adotadas como parâmetros de configuração do algorítimo de solução do comportamento do separador submerso discutido ao longo deste trabalho. Assim, todos os parâmetros necessários como diâmetro do recipiente de separação, altura do recipiente, diâmetros da tubulação de escoamento de saída do líquido, etc. foram obtidos a partir do trabalho de Storti 2013.

A Figura 7.2 ilustra o protótipo confeccionado para o estudo que consiste de dois tubos concêntricos um interno e outro externo, sobre as paredes do tubo interno é fixada uma hélice que forçará o movimento rotativo da mistura ar líquido. A separação das fases acontece no espaço anular entre os dois tubos sendo que o gás será escoado na parte interna do tubo interno do separador enquanto o líquido será bombeado por uma tubulação própria fixada na parte inferior do separador.

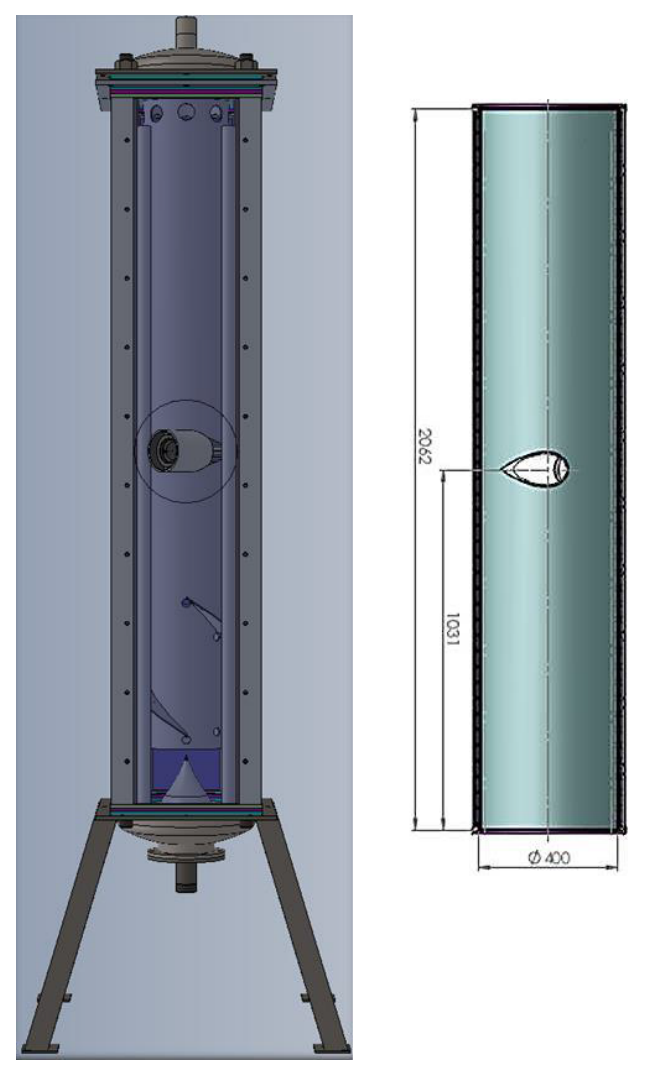

Figura 7.2: Ilustração do protótipo de separador ciclônico desenvolvido por Storti 2013, (esquerda) e vista do corte longitudinal vertical do protótipo (direita). Fonte: [Storti 2013]

O esquema geral do aparato experimental utilizado do estudo é mostrado na Figura 7.3. Quanto aos parâmetros geométricos, o protótipo apresenta comprimento total de $2062 \mathrm{~mm}$; sendo a altura em que o bocal de entrada da mistura bifásica coincide com a metade desse comprimento, ou seja, $1031 \mathrm{~mm}$; o tubo externo foi confeccionado com $392 \mathrm{~mm}$ de diâmetro enquanto o tubo interno foi confeccionado com $249 \mathrm{~mm}$ de diâmetro. Para o bombeamento da fase líquida separada coletada na parte inferior do separador ciclônico, foi utilizada uma bomba centrífuga com vazão máxima 
de $21,9 \mathrm{~m}^{3} / \mathrm{h}\left(0.0061 \mathrm{~m}^{3} / \mathrm{s}\right)$ e com pressões máxima de $95 \mathrm{mca}$.

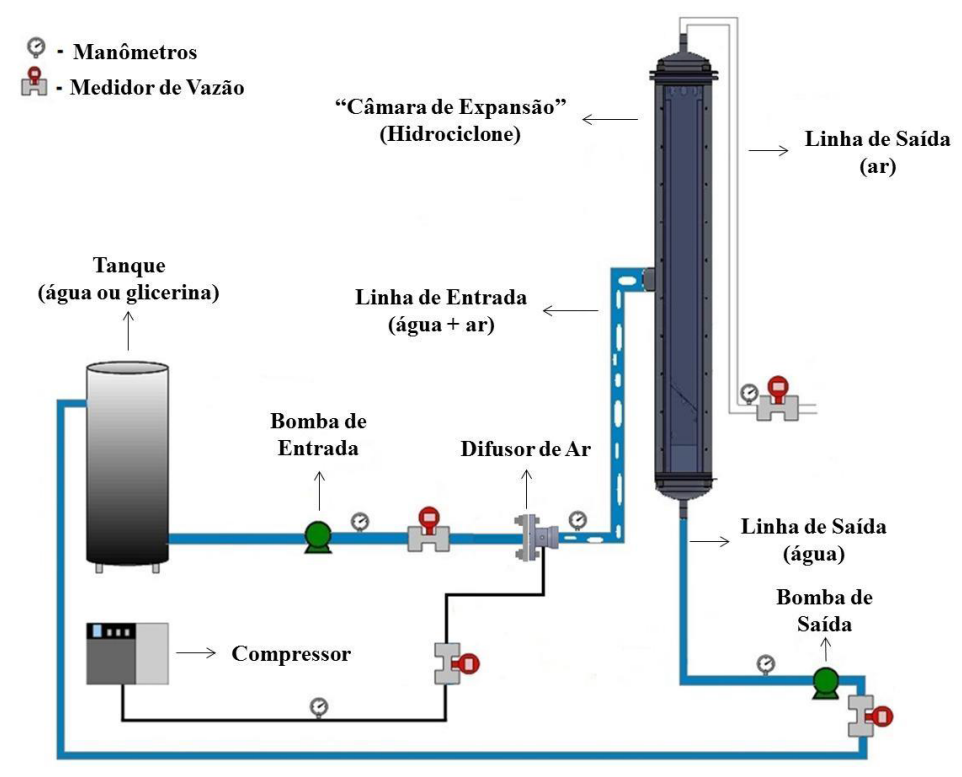

Figura 7.3: Esquema geral do aparato experimental utilizado. Fonte: [Storti 2013]

Considere então, um arranjo teórico em que duas tubulações para escoamento do gás e do líquido separados são acoplados ao separador. Os comprimentos de cada segmento da tubulação de escoamento de gás é descrita por um vetor $\mathbf{c}_{G}$ :

$$
\mathbf{c}_{G}=\left[\begin{array}{lllllll}
c_{G 1} & c_{G 2} & c_{G 3} & \ldots & c_{G i} & \ldots & c_{G n}
\end{array}\right]
$$

onde $i=1,2,3, \ldots, n$, e $n$ é o número de segmentos que a tubulação foi dividida.

Semelhantemente, a tubulação de escoamento de líquido é dividida em $n$ segmentos com comprimento $c_{l i}$ :

$$
\mathbf{c}_{l}=\left[\begin{array}{lllllll}
c_{l 1} & c_{l 2} & c_{l 3} & \ldots & c_{l i} & \ldots & c_{l n}
\end{array}\right]
$$

com $i=1,2,3, \ldots, n$.

Para cada tubulação dois vetores devem ainda ser definidos, um que descreve o diâmetro de cada segmento e o ângulo formado por cada segmento da tubulação em relação à horizontal. Logo, defini-se:

$$
\mathbf{D}_{G}=\left[\begin{array}{lllllll}
D_{G 1} & D_{G 2} & D_{G 3} & \ldots & D_{G i} & \ldots & D_{G n}
\end{array}\right]
$$

vetor com diâmetro de cada segmento da tubulação gás.

$$
\mathbf{D}_{l}=\left[\begin{array}{lllllll}
D_{l 1} & D_{l 2} & D_{l 3} & \ldots & D_{l i} & \ldots & D_{l n}
\end{array}\right]
$$

vetor com diâmetro de cada segmento da tubulação de escoamento de líquido. 
E para os ângulos dos segmentos dos tubos são definidos os seguintes vetores:

$$
\theta_{\mathbf{G}}=\left[\begin{array}{lllllll}
\theta_{G 1} & \theta_{G 2} & \theta_{G 3} & \ldots & \theta_{G i} & \ldots & \theta_{G n}
\end{array}\right]
$$

vetor com ângulo em relação à horizontal de cada segmento da tubulação gás.

$$
\theta_{\mathbf{l}}=\left[\begin{array}{lllllll}
\theta_{l 1} & \theta_{l 2} & \theta_{l 3} & \ldots & \theta_{l i} & \ldots & \theta_{l n}
\end{array}\right]
$$

vetor com ângulo em relação à horizontal de cada segmento da tubulação de escoamento de líquido.

O aparato hipotético utilizado nas simulações a serem desenvolvidas está ilustrado na Figura 7.4. Para este primeiro exemplo, as tubulações de escoamento de gás e líquido foram divididas em 5 segmentos com comprimento igual a $10 \mathrm{~m}$. A esse aparato é aplicado um controlador conforme o discutido no Capítulo 6. Para fins da simulação da aplicação do controlador ao separador é considerado um esquema simplificado do separador conforma o mostrado na Figura 7.4, onde as duas fases são consideradas já separadas e o nível do líquido no interior do separador é tomado como sendo o nível da piscina de líquido medido a partir da parte inferior do recipiente de separação, o nível da mistura bifásica alcançada pelo movimento centrífugo da mistura foi negligenciado. O nível zero é tomado na extremidade inferior do recipiente de separação.

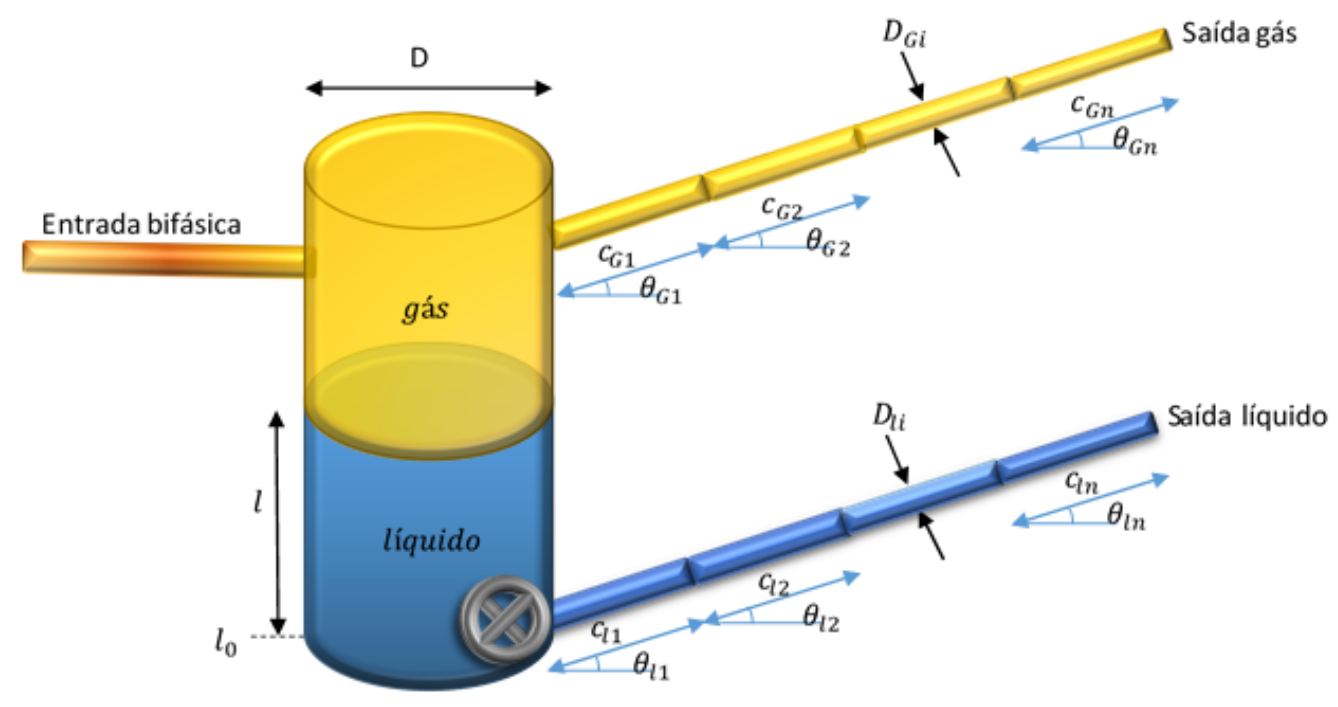

Figura 7.4: Esquema simplificado do separador com tubulações de escoamento das fases gasosa e líquida

O nível do liquido no interior do separador, conforme estudado em Capítulos anteriores, é descrito por:

$$
i=\frac{q_{\text {in }}}{A}-\frac{B}{2 a_{2} A}\left[1-\sqrt{1-\frac{4 a_{2}}{B^{2}}\left(\gamma^{2} H_{s}+\frac{p_{G}}{\rho g}+l-l_{0}-C_{M}\right)}\right]
$$

A área de seção transversal $(A)$ do separador é calculada a partir do diâmetro do tubo externo 
que compõe o protótipo $(D=0,392 \mathrm{~m})$. O parâmetro $B$ apresentado na seção 4.1.2 é uma quantidade proporcional à velocidade de propagação da frente de onda transiente gerada pela perturbação do escoamento do líquido no interior de sua tubulação de saída. Esse parâmetro foi definido como:

$$
B=\frac{a}{g A_{l i q}^{2}}
$$

onde $g$ é a aceleração da gravidade, $A_{l i q}$ a área de seção transversal da tubulação de líquido e $a$, a velocidade do pulso de onda discutida na seção 3.1.

Será considerado nos exemplos apresentados, primeiramente, a situação hipotética em que o protótipo do separador é submetido a uma mistura ar/água onde o líquido escoa pela tubulação pela respectiva tubulação de saída a uma vazão estacionária inicial de $Q_{0}=12 \mathrm{~m}^{3} / \mathrm{h}$ $\left(0.0033 \mathrm{~m}^{3} / \mathrm{s}\right)$. A bomba centrífuga utilizada pata elevação da fase líquida tem altura piezométrica máxima de $H_{s}=95 \mathrm{~m}$, trabalha inicialmente a $H_{r}=23 \mathrm{~m}$ de modo que:

$$
a_{2}=\frac{H_{r}-H_{s}}{Q_{0}^{2}}
$$

Dados $a=1200 \mathrm{~m} / \mathrm{s}, l_{0}=0$, e considerando fator de atrito igual para cada segmento de tubulação $f=0.018$. E dados os vetores $\mathbf{c}_{G}, \mathbf{c}_{l}, \mathbf{D}_{G}, \mathbf{D}_{l}, \theta_{\mathbf{G}}$ e $\theta_{\mathbf{l}}$ por:

$$
\begin{aligned}
& \mathbf{c}_{G}=\left[\begin{array}{lllll}
10 m & 10 m & 10 m & 10 m & 10 m
\end{array}\right] \\
& \mathbf{c}_{l}=\left[\begin{array}{lllll}
10 m & 10 m & 10 m & 10 m & 10 m
\end{array}\right] \\
& \mathbf{D}_{G}=\left[\begin{array}{lllll}
100 m m & 100 m m & 100 m m & 100 m m & 100 m m
\end{array}\right] \\
& \mathbf{D}_{l}=\left[\begin{array}{lllll}
100 \mathrm{~mm} & 100 \mathrm{~mm} & 100 \mathrm{~mm} & 100 \mathrm{~mm} & 100 \mathrm{~mm}
\end{array}\right] \\
& \theta_{\mathbf{G}}=\left[\begin{array}{lllll}
0 & 0 & \pi / 5 & \pi / 4 & \pi / 2
\end{array}\right] \\
& \theta_{\mathbf{l}}=\left[\begin{array}{lllll}
0 & 0 & \pi / 5 & \pi / 4 & \pi / 2
\end{array}\right]
\end{aligned}
$$

os ângulos são dados em radianos.

Qualquer modificação nos parâmetros que o sistema está submetido será explicitado durante as discussões subsequentes. 


\subsubsection{Arranjo do Separador com Pressão do Gás Constante}

Para fins de ilustração do funcionamento do sistema controlado e posterior comparação com outros casos considere, nessa primeira simulação a pressão do gás $p_{G}$ acima da coluna de líquido no interior do recipiente de separação, tem valor constante ao longo do tempo. Na prática, essa hipótese poderia ser conseguida eliminando-se a parte do separador referente à saída do gás a abrindo a parte superior do recipiente para a atmosfera. Lembrando que apesar de o separador ciclônico ter sido desenvolvido para utilização subaquática, o protótipo de Storti 2013, foi operado em superfície, o que tornaria fácil manter a pressão do gás no interior do recipiente a uma pressão constante.

Suponha que se espere que o nível no interior do recipiente de separação permaneça à altura de 0,5 metros com uma tolerância de $\pm 0.01 \mathrm{~m}$. Adicionalmente, o nível do líquido, inicialmente a $0,75 \mathrm{~m}$, deverá atingir a altura desejada em aproximadamente 120 segundos seguindo a uma trajetória dada pela seguinte equação equação deferencial de segunda ordem:

$$
\frac{1}{\omega_{n}^{2}} \ddot{l_{d}}+\frac{2}{\omega_{n}} \dot{l_{d}}+l_{d}=f
$$

onde $l_{d}$ é o nível do líquido, $\omega_{n}=0.05$ e $f=0.5$.

Conforme discutido no Capítulo 6, o valor do sinal de controle $\gamma$ é obtido pela filtragem em de sinal $u$ através de um filtro de primeira ordem como é mostrado na Figura 7.5.

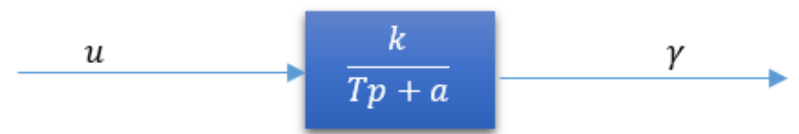

Figura 7.5: Sinal de controle passa por um filtro de primeira ordem. $k, T$ e $a$ são constantes e $p$ é o operador laplaciano

Neste exemplo, as constantes $T$, $a$ e $k$ do filtro são terão valor unitário $(T=a=k=1)$. O valor de $u$ é obtido a partir de um sinal $u^{\prime}$ de forma que as discutidas na seção 6.5 sejam aplicadas ao problema, assim, tem-se:

$$
\left\{\begin{array}{l}
u=1, \quad \text { se } u^{\prime} \geq 1 \\
u=u^{\prime}, \quad \text { se } s \geq 0 \\
u=0, \quad \text { se } s<0
\end{array}\right.
$$

onde $s$ é o erro de trajetória $\left(s=l-l_{d}\right)$

Finalmente, o valor do sinal $u^{\prime}$ é calculado, conforme discutido na seção 6.2 .2 da seguinte forma:

$$
\left(u^{\prime}\right)^{2}=\frac{1}{H_{s}}\left(\hat{C}_{M}-\frac{\hat{p}_{G}}{\rho g}-l+\frac{B^{2}}{4 a_{2}}\left(1-\varphi^{2}\right)\right)
$$


onde

$$
\varphi=\frac{2 a_{2}}{B}\left(A i_{d}-q_{i n}\right)+1+\eta \operatorname{sign}(s)
$$

O controle do sistema foi feito assumindo-se as hipóteses levantadas na seção 6.5. Além disso faz-se necessário observar que existem incertezas associadas ao modelo que descreve o nível no interior do recipiente de separação que devem ser consideradas na determinação do sinal de controle. As variáveis $C_{M}$ e $p_{G}$, da equação 7.7, são quantidades que não só variam com tempo mas também são funções do próprio nível do líquido. Dessa forma, apesar de a equação sugerir que o sistema a ser controlado trata-se de um sistema de primeira ordem, pode-se estar lidando com um sistema de ordem superior já que as variáveis são incertas e o comportamento do sistema pode ser imprevisível. Felizmente, o controlador proposto no presente trabalho é baseado na teoria de controle deslizante, que prevê sob certas condições, a possibilidade de se suprimir o efeito das incertezas associadas e controlar o sistema apesar dessas incertezas. Para compensar as incertezas do sistema devem ser admitidos valores de $\hat{C}_{M}$ e $\hat{p}_{G}$ para o sinal de controle 7.18 , que representem os máximos valores a serem assumidos por $C_{M}$ e $p_{G}$ ao longo do tempo. A despeito do procedimento apresentado na seção 6.2, para se estimar as variáveis incertas, e em razão do fato de não se conhecer previamente os máximos valores de $\hat{C}_{M}$ e $\hat{p}_{G}$ para o presente caso, foi arbitrado o seguinte valor constante para as variáveis incertas, esperando que seja suficiente para supressão das incertezas associadas:

$$
\hat{C}_{M}-\frac{\hat{p}_{G}}{\rho g}=10^{3}
$$

A Figura 7.6(a), mostra a trajetória seguida pelo nível do líquido para um tempo de simulação de $\sim 16$ minutos. A linha pontilhada central representa a trajetória a ser seguida pelo nível do líquido, enquanto as linhas tracejadas acima e abaixo representam os limites inferior e superior de tolerância para a trajetória efetivamente seguida pelo nível. A trajetória do nível é mostrada na Figura pela linha sólida em azul. Observe que a lei de controle proposta é bastante eficiente não só mantendo a trajetória do nível dentro dos limites especificados ao longo do tempo como apresentando boa coincidência entre a trajetória desejada, previamente estabelecida e a trajetória efetivamente seguida pelo nível no interior do recipiente. Como esperado, o nível do líquido é mantido no valor especificado, 0,5 metros por todo o tempo de simulação, sendo este o ponto de equilíbrio imposto pela trajetória da equação 7.16. 
(a)

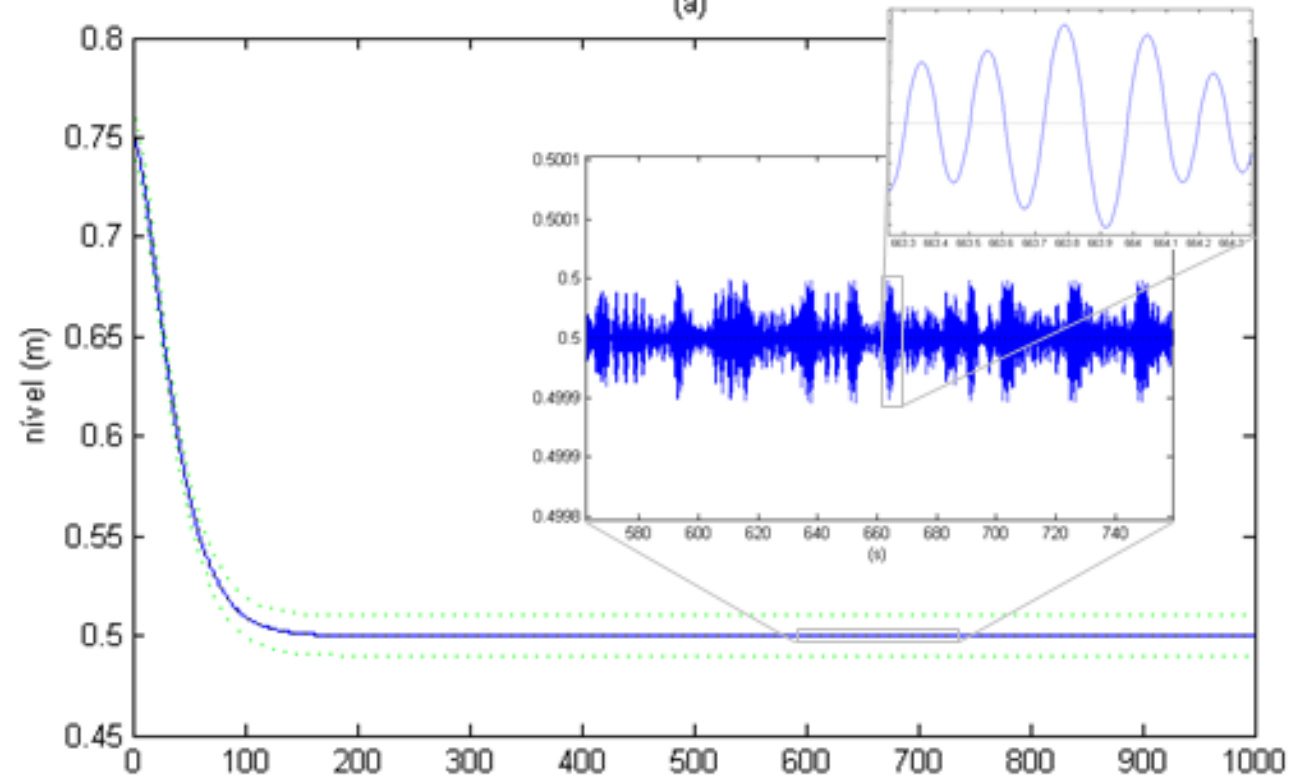

(s)

(b)

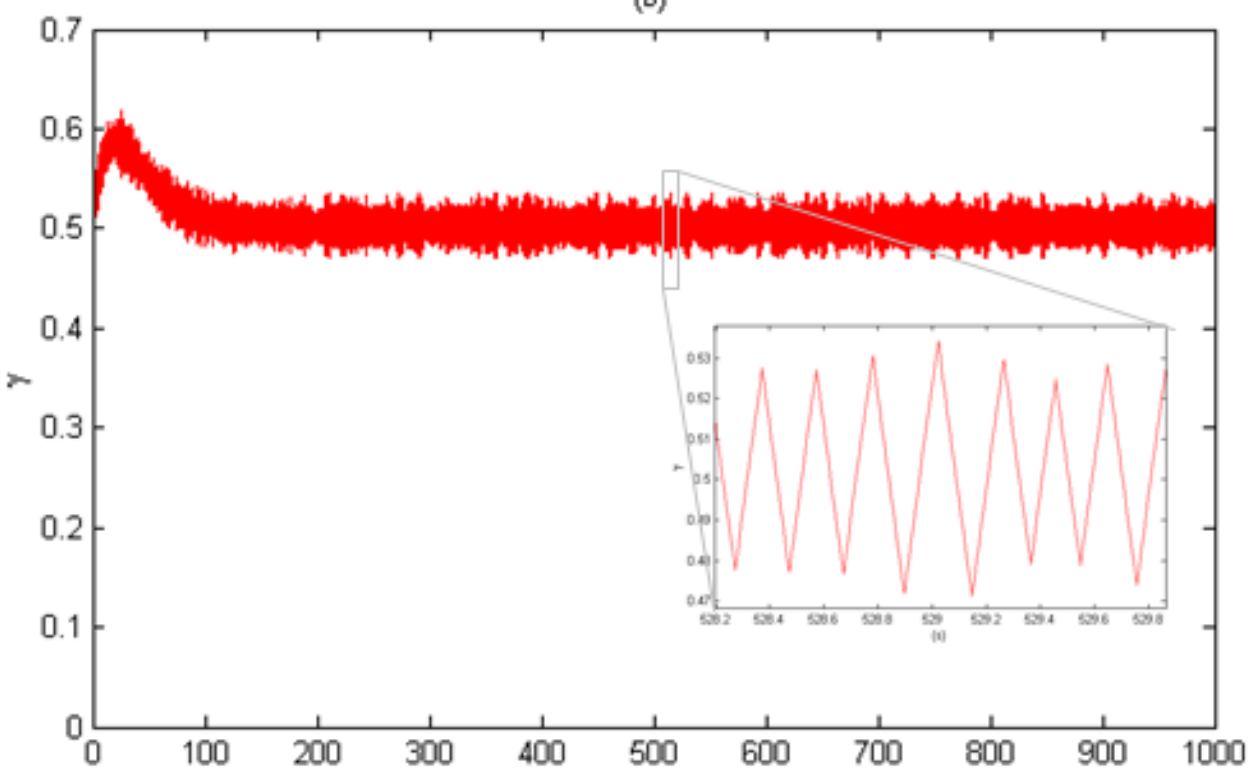

(s)

Figura 7.6: (a) Trajetória do nível do líquido no interior do separador. A linha pontilha escura indica a trajetória desejada. As linhas pontilhadas indicam indicam a tolerância permitida ao nível e a linha sólida indica a trajetória efetivamente seguida pelo nível. (b) $\gamma$, fração da frequência de rotação da bomba. 
Pequenas oscilações em torno do ponto de equilíbrio podem ser observados no detalhe ampliado da Figura, essas oscilações advêm do esforço empregado pelo sistema de bombeamento controlado no sentido de se restabelecer altura do nível para o ponto de equilíbrio do sistema que impõe a trajetória. Essas oscilações são esperadas dada a natureza do controlador. Como se trata de um controle baseado na teoria de Sliding Control, o próprio controlador induzirá oscilações no sistema quando o erro de trajetória passar mudar de sinal, ou seja, passar de um valor positivo para negativo, e vice-versa. Essa mudança de sinal do erro de trajetória é, justamente, a passagem do sistema pela superfície deslizante apresentada na seção 6.1. E como apresentado ao longo do Capítulo 6, o controlador tende a restaurar o sistema para superfície quando esta é atravessada. O detalhe amplificado mostrado na Figura 7.6(a) mostra que a oscilação do nível em torno do ponto de equilíbrio estabelecido não ultrapassa $0.2 \%$ do limite de tolerância estabelecido. O detalhe da Figura mostra uma segunda amplificação onde é possível observar que a oscilação do nível em torno do ponto de equilíbrio é uma curva suave.

O trabalho do atuador é representado pela quantidade adimensional $\gamma=f_{\text {rot }} / f_{\text {max }}$, onde $f_{\text {rot }}$ é a frequência de rotação da bomba centrífuga num determinado instante e $f_{\text {max }}$ é uma constante que se refere à frequência nominal da bomba. A Figura 7.6(b) mostra que as máximas rotações apresentadas pela bomba foram atingidas por volta dos 25 segundos, momento em que a trajetória desejada impõe um declive acentuado ao valor da altura do nível. Apesar da alta frequência de variação do valor de $\gamma$, que pode ser observado no detalhe amplificado mostrado na Figura 7.6(b), a amplitude de $\gamma$ não varia muito, permanecendo entre 45 e $65 \%$ da frequência de rotação nominal da bomba. Intervalos de amplitude de $\gamma$ ainda menores podem ser obtidos caso seja imposta uma trajetória desejada mais suave, ou seja, impondo uma trajetória com tempo de convergência maior. O exemplos apresentados neste Capítulo visam fornecer elementos para uma análise qualitativa do funcionamento do sistema controlado de modo que não serão propostos parâmetros de controle ótimos para casos específico, esse tipo de estudo deverá ser realizado em trabalhos posteriores.

Para o caso apresentado, tanto a pressão (medida em altura piezométrica $H$ ) quanto a vazão $(Q)$ no interior da tubulação de escoamento do líquido apresentam curvas temporais que tendem a acompanhar o comportamento de $\gamma$. Assim, para o intervalo de tempo até 120 segundos há uma variação da amplitude dos sinais $H$ e $Q$ em curvas com o mesmo formato onde, de forma geral, a vazão de altura piezométrica aumenta consideravelmente até o tempo de 25 segundos e depois diminuem até o tempo de 100 segundos. A partir de 100 segundos, o valor de $H$ permanecerá entre 20 e 27 metros enquanto a vazão $Q$ permanecerá entre 0,0031 e $0,0035 \mathrm{~m}^{3} / \mathrm{s}$. 


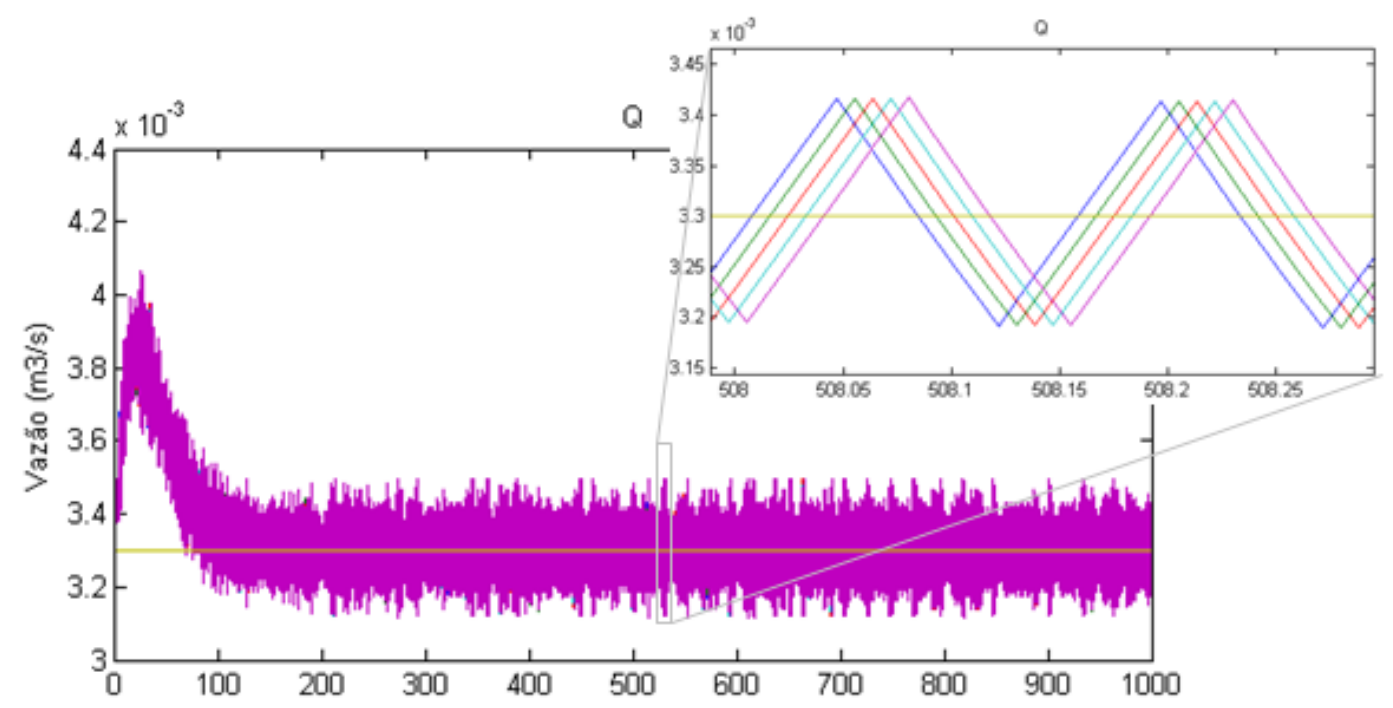

(s)

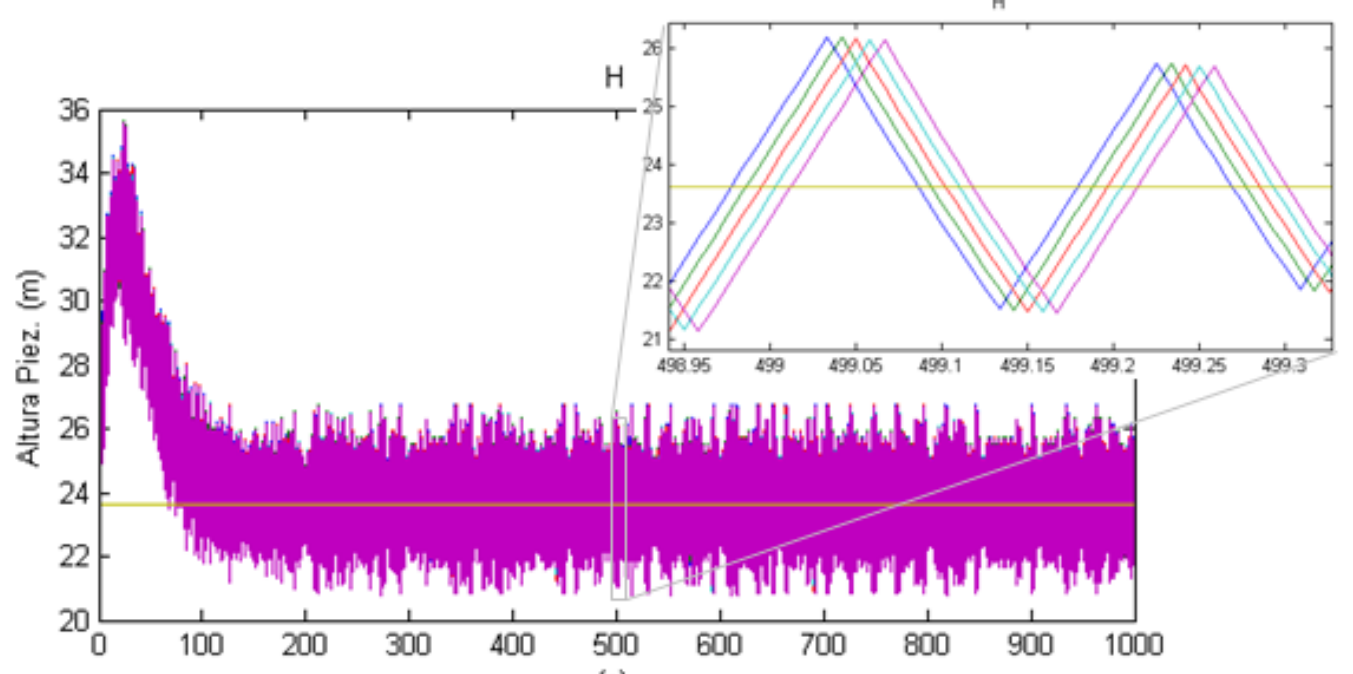

(s)

Figura 7.7: (a) Vazão na tubulação de escoamento do líquido em $\mathrm{m}^{3} / \mathrm{s}$ para cada ponto em que a tubulação foi divida. (b) Altura Piezométrica ( $m$ ) ao longo da tubulação de escoamento do líquido em para cada ponto em que a tubulação foi divida. Os valores de contorno do problema são mostrados pela retas amarelas em (a) e em (b).

As Figuras 7.7(a) e 7.7(b) mostram as curvas de $Q$ e $H$ para cada ponto ao longo da tubulação de escoamento do líquido, para a qual a tubulação foi segmentada. Assim, como para o presente caso a tubulação de escoamento do líquido foi dividida em seis segmentos (ver Figura 7.8). 


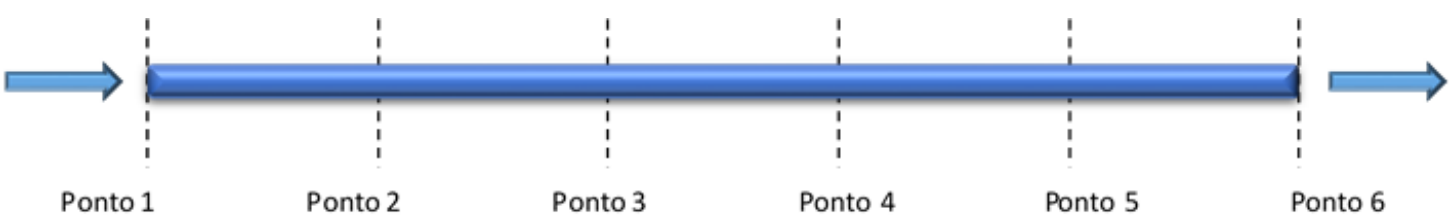

Figura 7.8: Pontos referentes aos segmentos da tubulação de escoamento do líquido. O sentido do escoamento a partir da base conectada ao recipiente de separação é identificado pelas setas

A pressão e a vazão para cada ponto são representadas por seis curvas distintas identificadas da seguinte forma:

- curva de cor azul: referente ao ponto 1 localizado na base da tubulação a qual é conectada ao recipiente de separação;

- curva de verde: referente ao ponto 2 , medida na extremidade do primeiro segmento;

- curva de vermelha: referente ao ponto 3, medida na extremidade do segundo segmento;

- curva de cor ciano: referente ao ponto 4, medida na extremidade do terceiro segmento;

- curva de cor roxa: referente ao ponto 5, medida na extremidade do quarto segmento;

- curva de cor amarela: essa curva é medida no extremidade de saída da tubulação onde são impostos os valores de contorno do sistema.

A identificação dos pontos e cores encontra-se sumarizada na tabela 7.3.

Tabela 7.3: Cores para identificação dos pontos ao longo das tubulações de saída

\begin{tabular}{llr}
\hline cor & ponto & descrição \\
\hline azul & 1 & localizado na base da tubulação a qual é conectada ao recipiente de \\
& & separação \\
\hline verde & 2 & medida na extremidade do primeiro segmento \\
\hline vermelha & 3 & medida na extremidade do terceiro segmento \\
\hline ciano & 4 & medida na extremidade do quarto segmento \\
\hline roxa & 5 & essa curva é medida no extremidade de saída da tubulação onde são \\
amarela & 6 & impostos os valores \\
\hline
\end{tabular}

A altas frequências de oscilação de $\gamma$ também são observadas nas curvas da $H$ e $Q$, o que evidencia a relação direta entre os comportamentos desses sinais e o comportamento do atuador. O detalhe da Figura 7.7(b), evidencia que quando a bomba impõe um dado valor de pressão da base da tubulação, essa pressão demandará um certo intervalo de tempo para ser propagada e alcançar os demais pontos ao longo da tubulação. Outro aspecto do comportamento do líquido evidenciado no detalhe da Figura, é que nos intervalos de tempo em que a pressão aumenta a 
pressão na base da tubulação é maior que nos demais pontos. Já nos intervalos de tempo em que a pressão ao longo da tubulação diminui, essa relação de inverte. Comportamento semelhante é observado para vazão de escoamento do líquido na Figura 7.7(a).

Apesar da eficiência do controlador em forçar o sistema controlado a seguir a trajetória desejada, fica evidente pela observação do comportamento do atuador mostrado na Figura 7.6(b), que o custo para o atuador é muito alto quando se implementa o controlador na forma como foi proposto no Capítulo 6. Por custo alto, refere-se às variações da frequência de rotação da bomba centrífuga que podem levar ao seu desgaste prematuro. Como já discutido, um controlador satisfatório deverá não só manter o nível do líquido no interior do separador dentro de limites pré-determinados como fazê-lo de forma a minimizar o trabalho do atuador. Isso que pode ser conseguido com variações suaves da frequência de rotação da bomba.

No entanto, a lei controle apresentada é bastante versátil e uma pequena adaptação aplicada à equação 7.17 pode melhorar significativamente a resposta do controlador no sentido de se preservar o atuador. Considere o nível do líquido dentro do intervalo:

$$
l_{d}-\delta \leq l \leq l_{d}+\delta
$$

$\delta$ é a tolerância de erro de trajetória que foi admitida até agora com valor de $\delta=0.01$.

Para esse intervalo, o valor de $u$ deverá variar de zero quando $l=l_{d}-\delta$, até o valor calculado para $u^{\prime}$ (eq. 7.18) seguindo uma função quadrática conforme a equação:

$$
u=u^{\prime} f(l)
$$

onde

$$
f(l)=\left(\frac{l-l_{d}+\delta}{2 \delta}\right)^{2}
$$

A ideia é que o atuador seja pouco solicitado em regiões em que o nível do líquido esteja próximo ao valor mínimo a partir do qual a bomba deverá ser solicitada. Semelhantemente, o controlador deverá solicitar máxima resposta do atuador, segundo a lei de controle $u^{\prime}$, apenas quando o nível do líquido ultrapassar um limite superior estabelecido por $l_{d}+\delta$. A variação de $u$ no intervalo dado em 7.21, é ilustrada na Figura 7.9. 


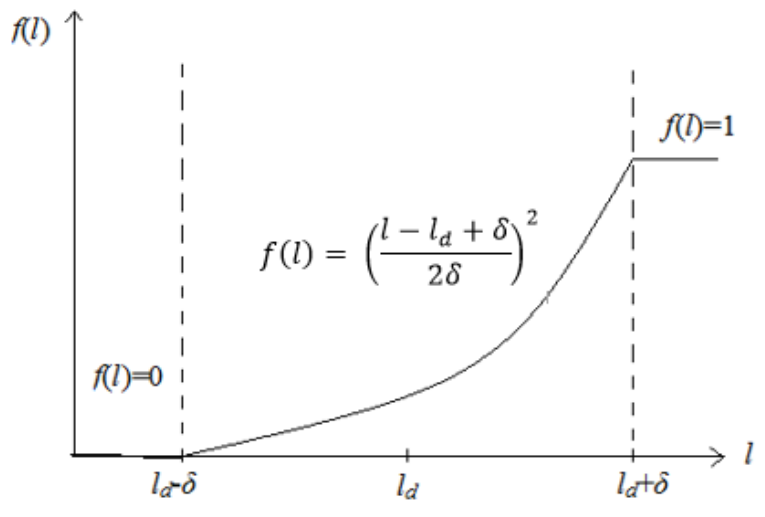

Figura 7.9: Variação quadrática de u no intervalo dado na inequação 7.21

O conjunto de restrições dados em 7.17 será reescrito da seguinte maneira:

$$
\begin{cases}u=1, & \text { se } u^{\prime} \geq 1 \\ u=u^{\prime}, & \text { se } l \geq l_{d}+\delta \\ u=f(l) u^{\prime}, & \text { se } l_{d}-\delta \leq l \leq l_{d}+\delta \\ u=0, & \text { se } l<l_{d}-\delta\end{cases}
$$

No que diz respeito à solicitação do atuador, uma melhoria significativa na resposta do sistema controlado pode ser verificada com a utilização da curva $f(l)$. A trajetória do nível do líquido bem como o histórico de solicitação do atuador são mostrados nas Figuras 7.10(a) e 7.10(b). Um pequeno erro em relação à trajetória desejada é observado na Figura 7.10(a), no entanto a trajetória do nível do líquido permanece dentro do intervalo de tolerância mostrado pelas linhas tracejadas em verde durante todo o intervalo de tempo da simulação. A solicitação do atuador mostrada na Figura 7.10(b), diminuiu em relação à simulação anterior mostrada na Figura 7.6(a) em que não havia sido implementado o aumento gradual da ação do controlador conforme 7.24. O comportamento geral de $\gamma$ com o tempo continua o mesmo uma vez que no intervalo de tempo até 120 segundos há uma maior solicitação do atuador e a frequência de rotação da bomba chega a quase $60 \%$ de valor nominal, esse intervalo de tempo coincide com o intervalo de tempo em que a trajetória desejada impõe uma da velocidade do nível de forma que ele saia de seu valor inicial e alcance o ponto de equilíbrio. 
(a)

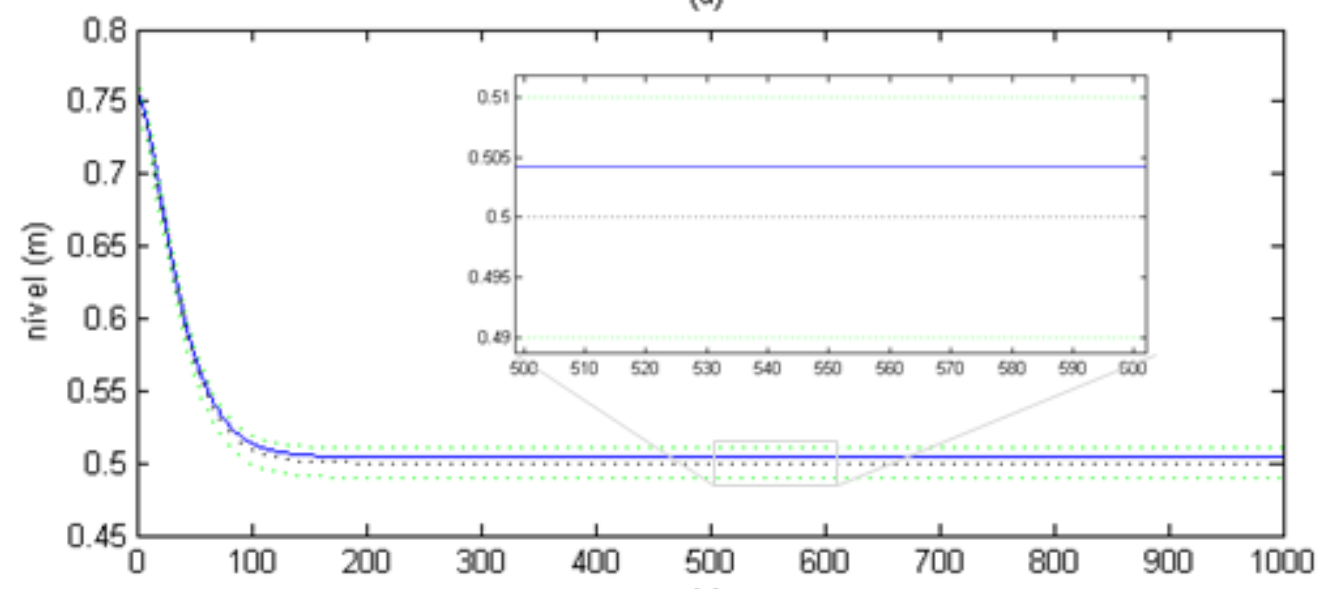

(s)

(b)

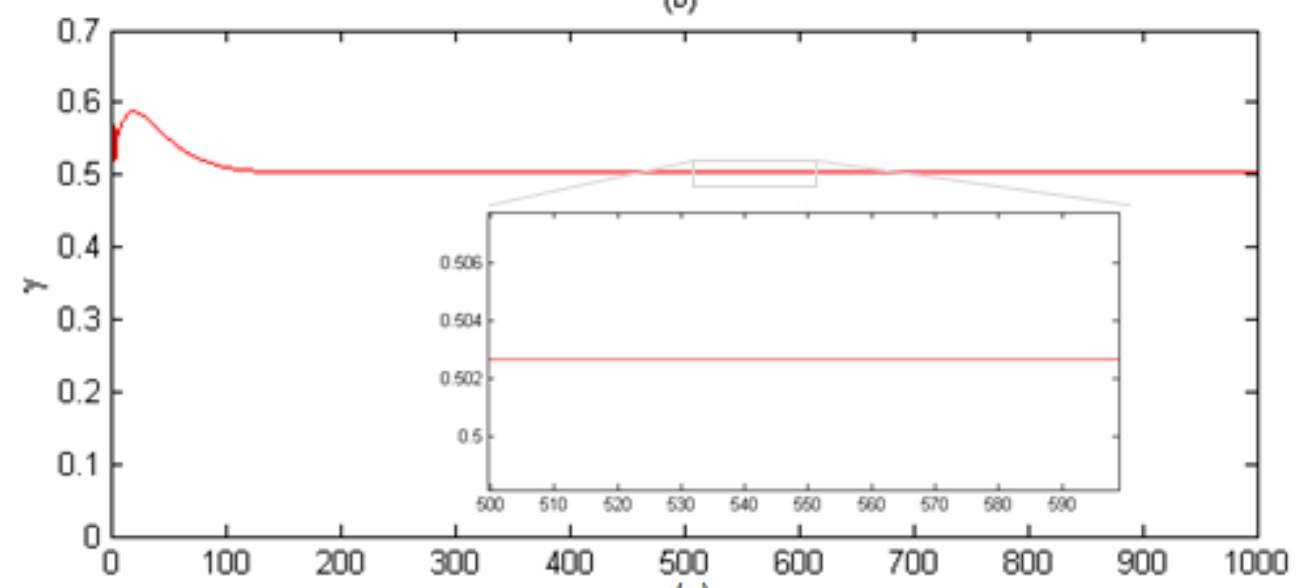

(s)

Figura 7.10: (a) Trajetória do nível do líquido no interior do separador. A linha pontilha escura indica a trajetória desejada. As linhas pontilhadas indicam indicam a tolerância permitida ao nível e a linha sólida indica a trajetória efetivamente seguida pelo nível. (b) $\gamma$, fração da frequência de rotação da bomba.

A partir de 120 , segundos $\gamma$ se estabiliza em aproximadamente 0.5 gerando vazão suficiente para manter o nível do líquido estável. As oscilações no valor de $\gamma$ foram suprimidas como pode ser observado no detalhe da Figura 7.10(b), e a partir de $\sim 120$ segundos $\gamma$ permanece constante o que indica que não haverá variação da frequência de rotação da bomba. Assim, espera-se que a menor solicitação do atuador seja refletido numa maior vida útil e consequentemente, menor necessidade de intervenções sobre o separador ciclônico advindas de desgaste do sistema de bombeamento. As Figuras 7.11(a) e 7.11(b) mostram que assim como no caso para o sinal de $\gamma$, as oscilações tanto na vazão quanto da altura piezométrica ao longo da tubulação de escoamento do líquido também foram suprimidas. 


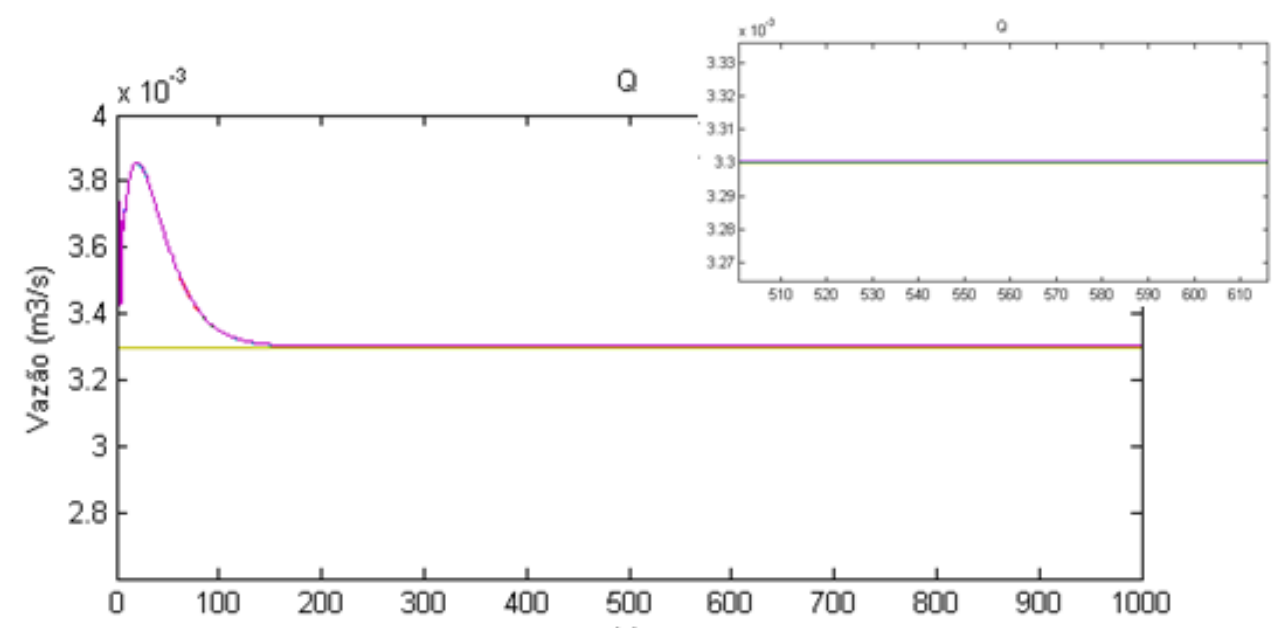

(s)

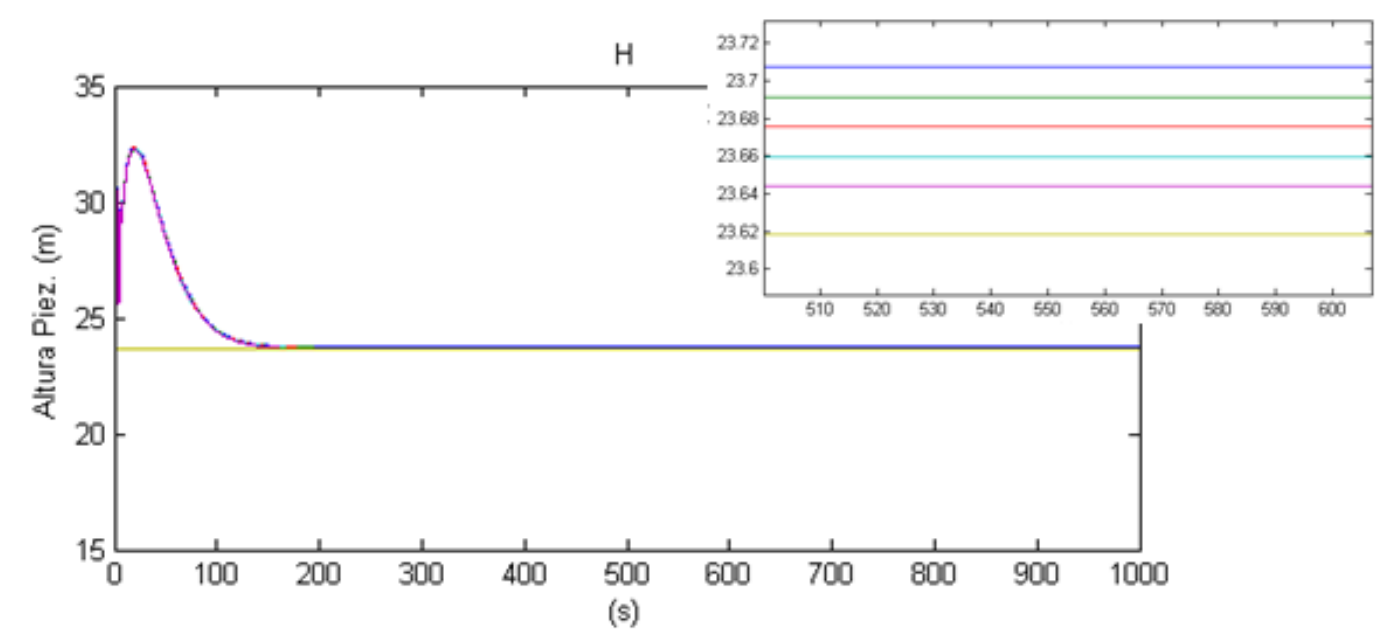

Figura 7.11: (a) Vazão na tubulação de escoamento do líquido em $\mathrm{m}^{3} / \mathrm{s}$ para cada ponto em que a tubulação foi divida.(b) Altura Piezométrica (m) ao longo da tubulação de escoamento do líquido em para cada ponto em que a tubulação foi divida. Os valores de contorno do problema são mostrados pela retas amarelas em (a) e em (b)

\subsubsection{Arranjo com Pressão Variável no Interior do Separador}

Como visto, o controlador se mostrou eficiente para controlar o sistema do separador quando foi admitida uma pressão do gás acima da coluna de líquido no interior do recipiente de separação, constante ao longo do tempo. O próximo arranjo a ser simulado é um arranjo em que a pressão é variável sendo obtida pela solução do problema de contorno para o escoamento do gás na sua tubulação de saída conforme procedimento discutido na seção 4.5. O problema do escoamento do fluido no interior da sua tubulação de saída é um problema de contorno e de valor inicial conforme as equações diferencias que descrevem o escoamento e que foram discutidas no Capítulo 3. Os valores iniciais de pressão e vazão do gás para cada segmento de sua tubulação de saída são obtidos considerando-se escoamento estacionário para o início da simulação (tempo $t=0$ ), assim como na caso do escoamento na tubulação saída do líquido. 
Os valores iniciais em regime estacionário do escoamento nas tubulações de líquido e gás dependem da consideração de valores de contorno do problema. Assim, tem-se como valor de contorno do problema do escoamento na tubulação de líquido, o valor da pressão na base da tubulação, ou seja, no ponto de intersecção entre a tubulação e o recipiente de separação. Como contorno do problema do escoamento do gás no interior de sua tubulação de saída pode-se admitir a vazão mássica na base da tubulação, ou a vazão mássica do gás no interior do recipiente de separação. Os pontos onde são estabelecidos os valores de contorno são mostrados na Figura 7.12.

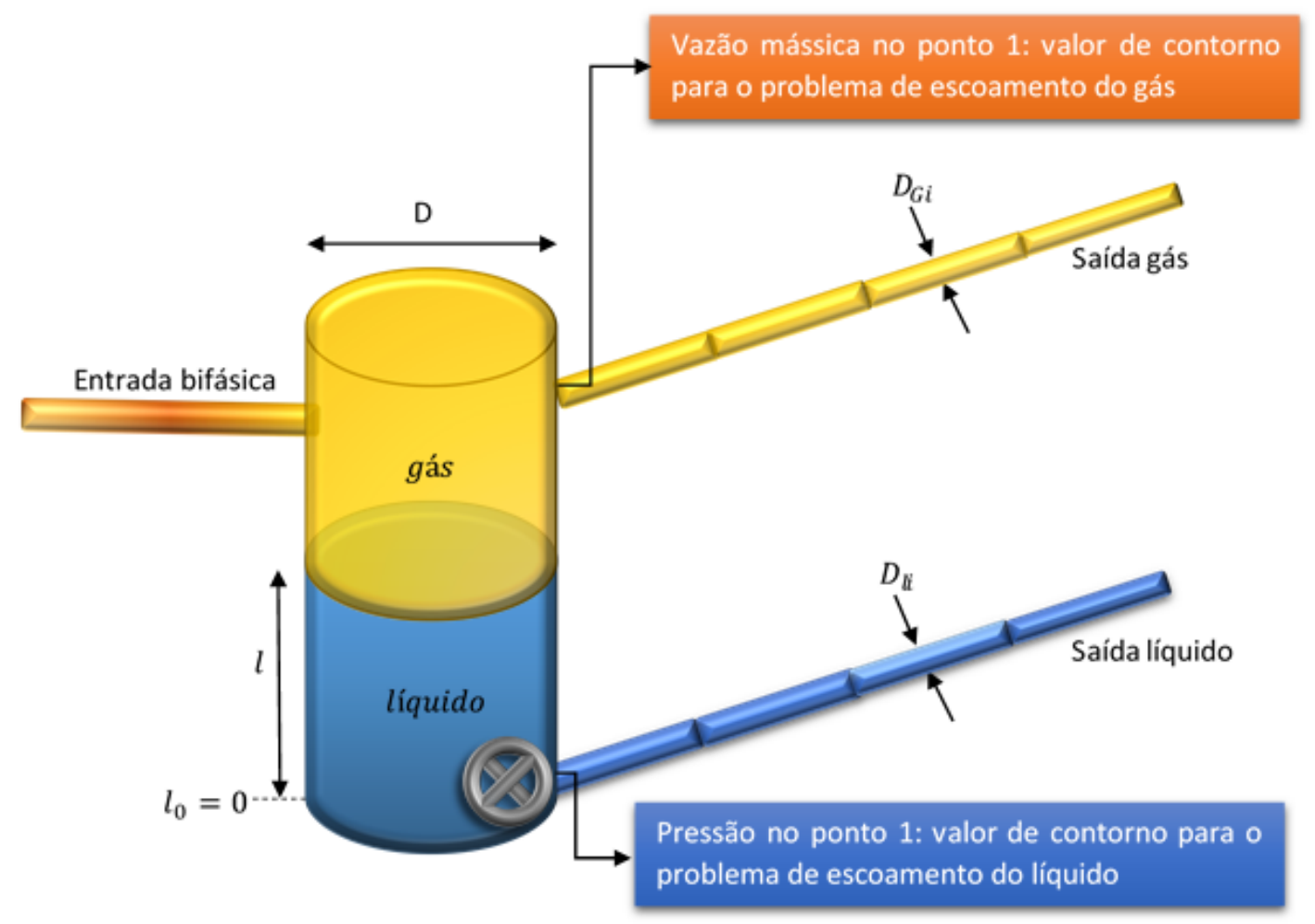

Figura 7.12: Valores de contorno para os problemas de escoamento nas tubulações de saída de gás e de líquido

A pressão de contorno da tubulação de saída do líquido é a pressão da coluna obtida pela coluna de líquido somada aà pressão que o gás acima da coluna no interior do separador exerce sobre o líquido. O valor do contorno da tubulação de saída do gás é dado no início da solução do problema, neste estudo, no início da simulação. Para a solução dos problemas escoamento do líquido e do gás faz-se necessário, ainda, a consideração do regime de escoamento na entrada da separador. Esse regime influenciará diretamente os valores de contorno dos problemas e, consequentemente, os valores de pressão e vazão em cada ao longo de cada tubulação e ao longo do tempo.

Dependendo da velocidade superficial de cada fase num escoamento bifásico, verificar-se-á padrões diferentes de escoamento no interior da tubulação. No caso do separador ciclônico estudado, esses padrões serão desenvolvidos no interior da tubulação de entrada da mistura ilustrada na Figura 7.12. Quanto aos padrões de escoamento bifásico em tubos horizontais, Bratland [Bratland, Gregory e Aziz 2010] classifica de acordo com suas características: 
- Padrão de bolhas dispersas: padrão observado quando a velocidade da fase líquida é alta. A fase gasosa é distribuída na forma de bolhas discretas no interior da fase líquida, com tendência a se aglomerar na parte superior devido a efeitos gravitacionais

- Padrão anular: padrão observado quando a velocidade superficial do gás é alta fazendo com que a fase gasosa concentre-se na parte central da tubulação enquanto a fase líquido escoa em forma de filme nas paredes da tubulação.

- Padrão Intermitente: neste padrão há alternância do escoamento do líquido e do gás. Pistões de líquido ocupam o diâmetro da tubulação enquanto bolhas de gás as separam. O padrão de bolhas alongadas observa as mesmas características, porém, com uma vazão de gás um pouco menor.

- Padrão estratificado: geralmente ocorrem quando as vazões do gás e do líquido são relativamente baixas, permitindo que as duas fases sejam separadas por ação gravitacional onde a fase líquida escoa na parte inferior enquanto a fase gasosa escoa na fase superior da tubulação. Esse padrão será classificado como liso, quando quando a interface gás/líquido for lisa e em ondulado, quando a interface for assumir a forma de ondas estáveis

Os diferentes padrões de escoamento horizontal são ilustrados na Figura 7.13. Mandhane, Gregory e Aziz 1973 descrevem um mapa do padrão de escoamento bifásico com base nos dados para escoamento ar/água, ao qual é pode ser aplicado correções das propriedades físicas dos fluídos a depender do tipo de fluido que se esteja trabalhando. Esse mapa relaciona o padrão de escoamento do fluido de acordo com a velocidade de cada fase e será utilizado como guia na determinação da forma do sinal de entrada ao qual o sistema controlado será submetido nas simulações subsequentes.

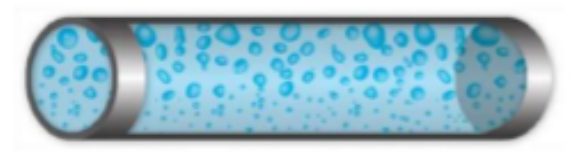

Bolhas Dispersas

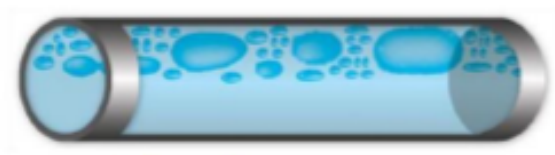

Bolhas Alongadas

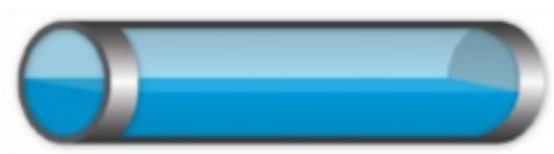

Estratificado Liso

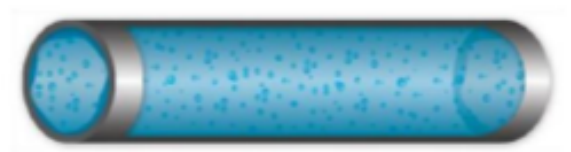

Anular

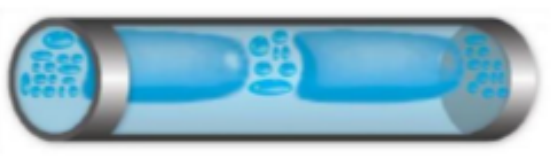

Intermitente

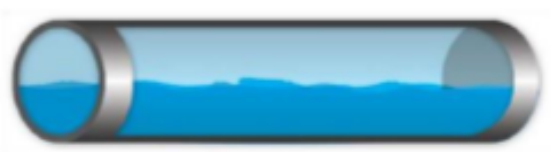

Estratificado Ondulado

Figura 7.13: Padrões de Escoamento bifásico gás/líquido em tubos horizontais. Fonte: [Bratland, Gregory e Aziz 2010]

Considere então, que o separador seja submetido a uma entrada bifásica em que a fase gasosa 
escoa a uma vazão de $8,64 \mathrm{~m}^{3} / \mathrm{h}(0,0028 \mathrm{~kg} / \mathrm{s})$ sob uma pressão de $\sim 10^{5} \mathrm{~Pa}$ na entrada, enquanto a fase líquida escoa a uma vazão de $0,86 \mathrm{~m}^{3} / h\left(0,00024 \mathrm{~m}^{3} / \mathrm{s}\right)$. O mapa do padrão de escoamento mostrado na Figura 7.14, prevê um padrão de escoamento estratificado na tubulação de entrada do separador (com área de seção transversal de $0,0079 \mathrm{~m}^{2}$ ) já que para essas vazões tem-se velocidades de $0.1 \mathrm{ft} / \mathrm{s}$ e $1 \mathrm{ft} / \mathrm{s}$ para as fases líquida e gasosa, respectivamente.

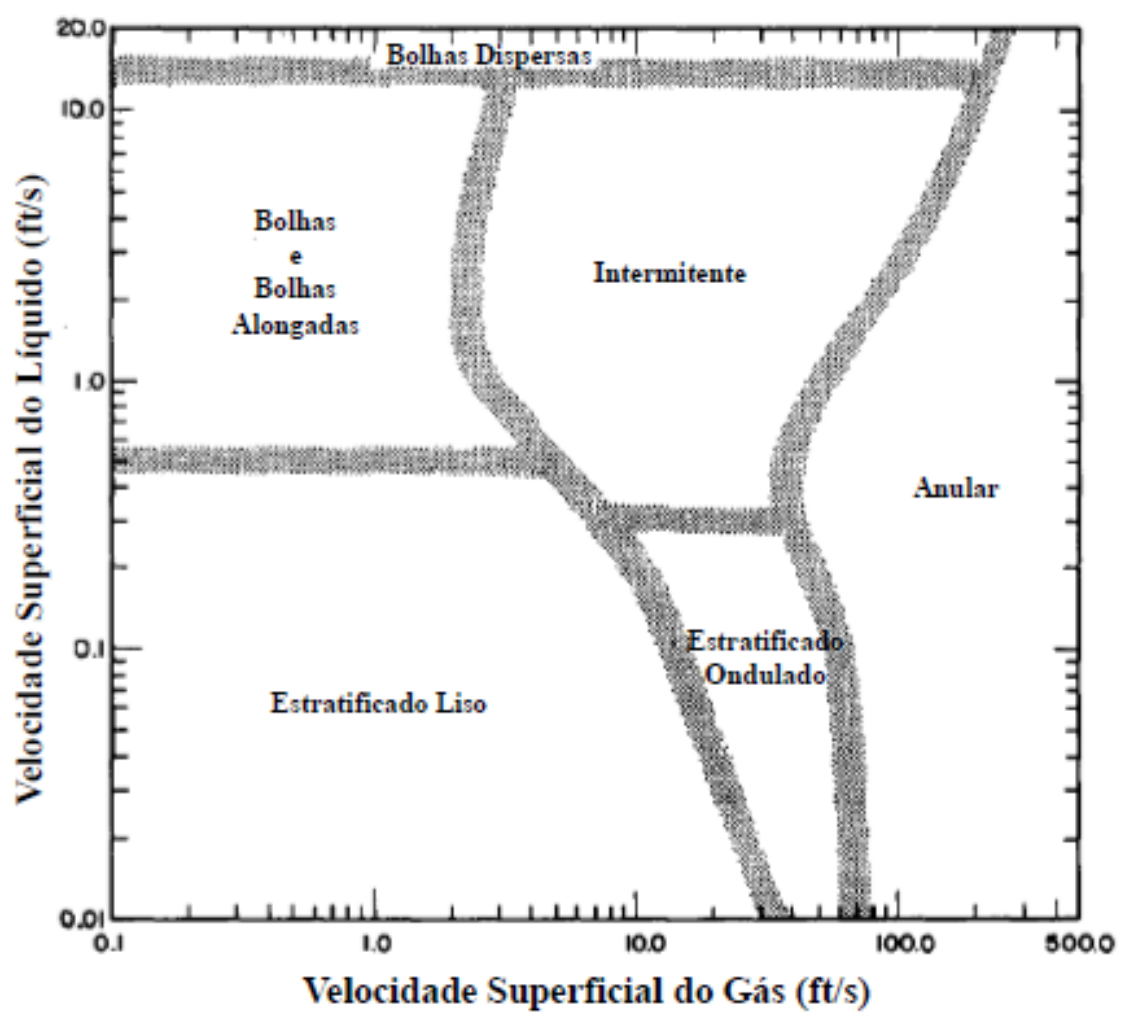

Figura 7.14: Mapa do padrão de escoamento em tubo horizontal. Fonte: [Mandhane, Gregory e Aziz 1973]

O padrão estratificado liso da entrada do separador será representado por um sinal de entrada para o qual impõe-se vazões constantes tanto para a vazão do gás quanto para vazão do líquido. Com vazões constantes na entrada do separador, o valor de contorno do problema de escoamento do gás por sua tubulação de saída não sofrerá alterações devido mudanças nos valores de pressão ou vazão causados por variações do escoamento na entrada do separador. No entanto, esse valor de contorno depende da pressão do gás no interior do recipiente de separação que é função de parâmetros como a altura da coluna de líquido (variável $l$ na Figura 7.12) e do volume total do recipiente de separação, quanto menor o espaço permitido para o gás maior será sua pressão.

Com o escoamento na entrada do separador em regime estratificado liso, consequentemente com sinal que descreve a vazão de entrada do líquido e do gás sendo representado por um valor constante, pode-se comparar o comportamento do sistema controlado com os resultados obtidos no exemplo anterior, onde a pressão do gás no interior do recipiente de separação foi considerada constante e a vazão de entrada do líquido também foi considerada constante.

Neste exemplo, os parâmetros geométricos do recipiente de separação, bem como os parâmetros 
geométricos das tubulações de saída de gás e líquido, as inclinações de cada segmento conforme ilustrado na Figura 7.4, são os mesmos do admitidos para o caso anterior, assim como os demais parâmetros necessários à solução do problema. Vale ressaltar a esse ponto, que as variáveis $p_{G} \mathrm{e}$ $C_{M}$ da equação que descreve o nível do líquido 7.7, foram admitidas como incertezas do modelo no momento da elaboração da lei de controle. Essas incertezas são compensadas pelo controlado com auxílio dos parâmetros $\hat{C}_{M}$ e $\hat{p}_{G}$ na equação 7.18 , que neste exemplo, foram consideradas com o mesmo valor atribuído no exemplo anterior:

$$
\hat{C}_{M}-\frac{\hat{p}_{G}}{\rho g}=10^{3}
$$

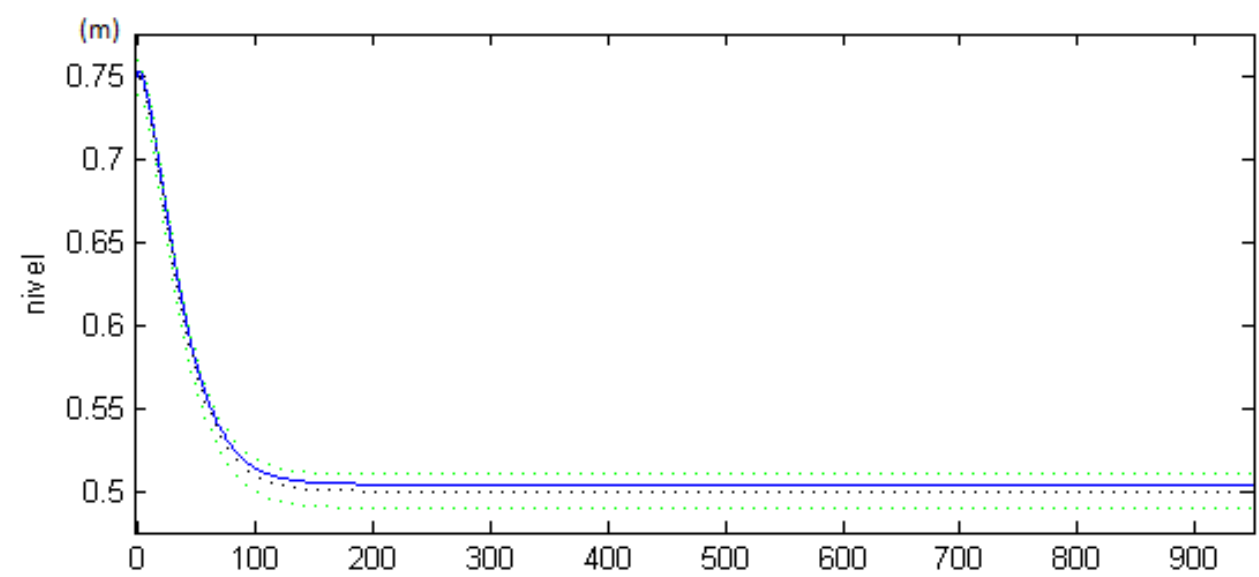

(s)

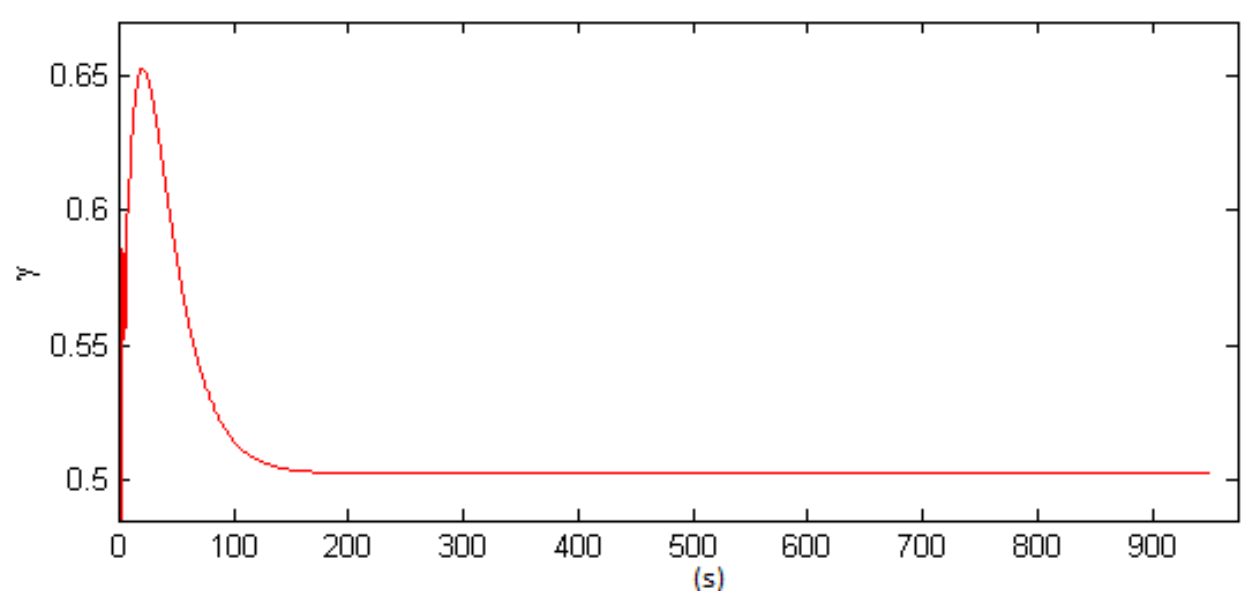

Figura 7.15: (a) Trajetória do nível do líquido no interior do separador. A linha pontilha escura indica a trajetória desejada. As linhas pontilhadas indicam a tolerância permitida ao nível e a linha sólida indica a trajetória efetivamente seguida pelo nível. (b) $\gamma$, fração da frequência de rotação da bomba. 
Como observado na Figura 7.15(a), o controlador continua respondendo satisfatoriamente, tendo mantido o nível do líquido dentro dos limites de tolerância durante todo o tempo de simulação. Após o tempo de simulação, relativamente pequeno, não se espera mudanças do com portamento do sistema a não ser que ocorram perturbações externas, caso a ser discutido posteriormente. O trabalho do atuador, mostrado na Figura 7.15(b) mostrou curva semelhante à obtida no exemplo anterior, porém, enquanto no primeiro caso o atuador chega a $60 \%$ da frequência máxima de rotação, neste caso chega a $65 \%$ nos primeiros 120 segundos se simulação, intervalo de tempo para o qual a trajetória desejada impõe forte declive à curva da altura do nível do líquido.

(a)

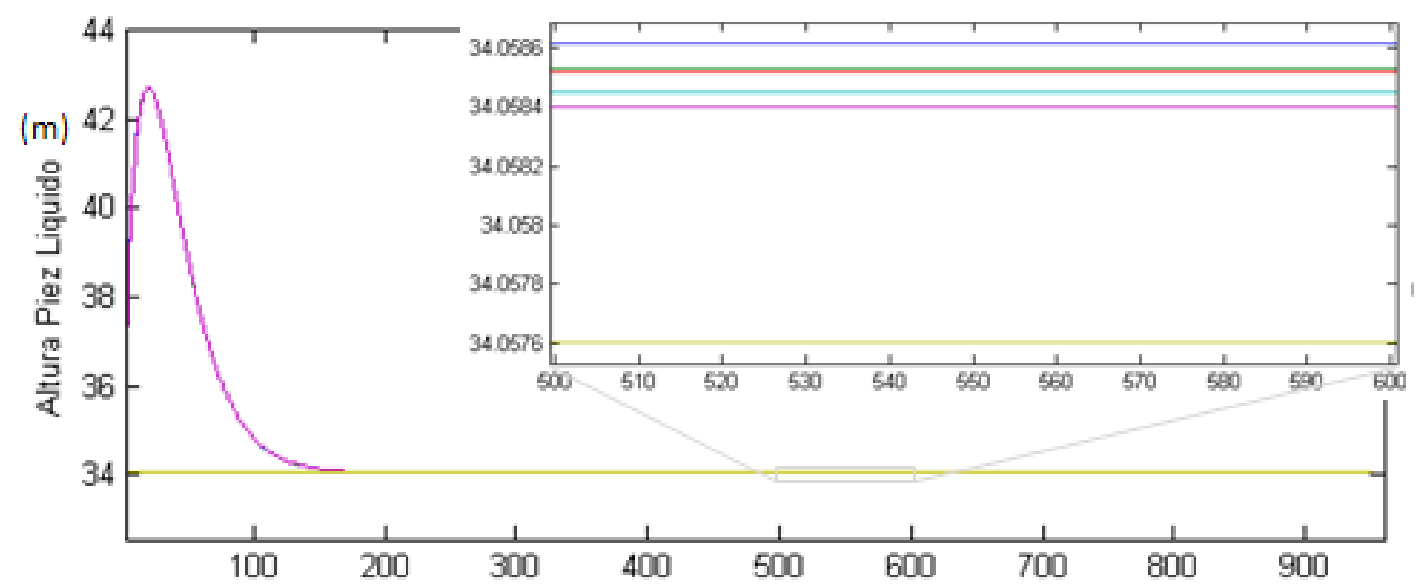

(s)

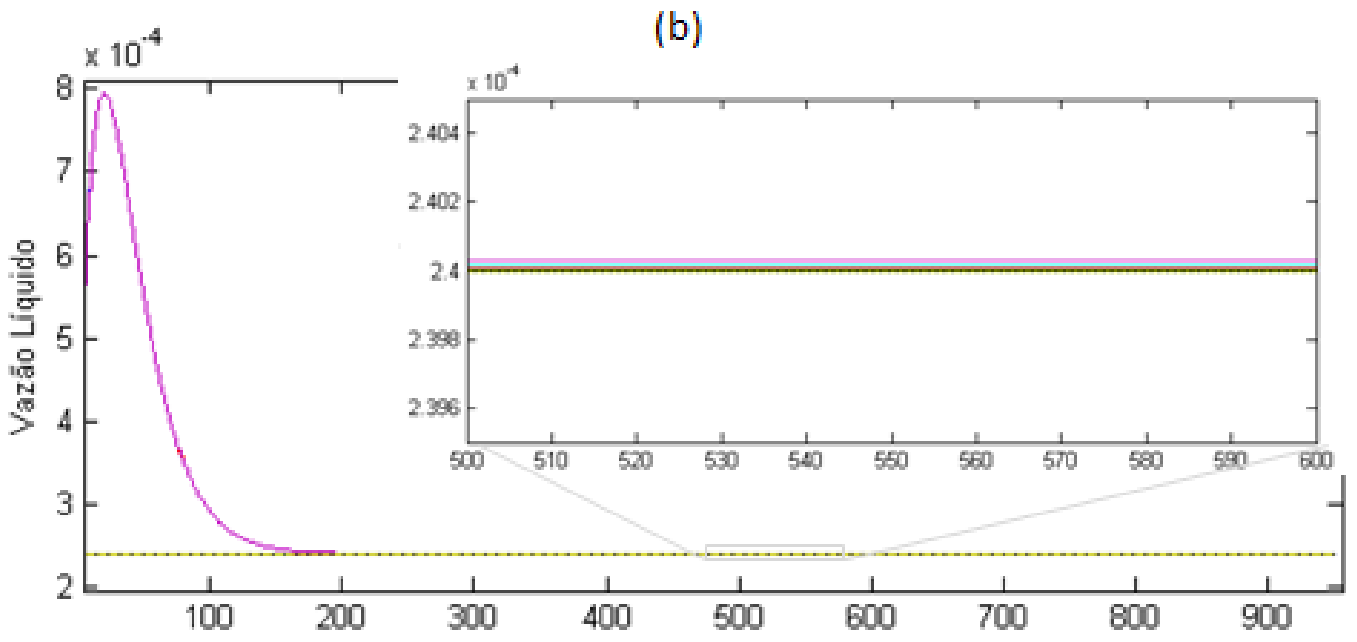

(s)

Figura 7.16: (a) Altura Piezométrica $(m)$ ao longo da tubulação de escoamento do líquido em para cada ponto em que a tubulação foi divida. (b) Vazão na tubulação de escoamento do líquido em $\mathrm{m}^{3} / \mathrm{s}$ para cada ponto em que a tubulação foi divida. Os valores de contorno do problema são mostrados pela retas amarelas em (a) e em (b)

A pressão do gás acima da coluna de líquido no interior do separador resulta num aumento 
da pressão do líquido ao longo de sua tubulação de saída. A pressão dada em termos de altura piezométrica na Figura 7.16(a) chega acima de 42 metros quando a curva da trajetória desejada (equação 7.16) impõe maior taxa de variação temporal para o nível do líquido. Após, aproximadamente 120 segundos, a pressão se estabiliza em $\sim 34 \mathrm{~m}$. A pequena diferença entre as alturas das linhas de pressão, mostrada no detalhe da Figura 7.16(a), resulta numa vazão praticamente constante na tubulação do líquido após a estabilização do escoamento, como mostrado no detalhe da Figura 7.16(b). O formato da curva de vazão segue a curva de pressão por todo o tempo de simulação. O mesmo padrão de cores representando cada segmento das tubulações de saída são adotados neste exemplo. 
(a)
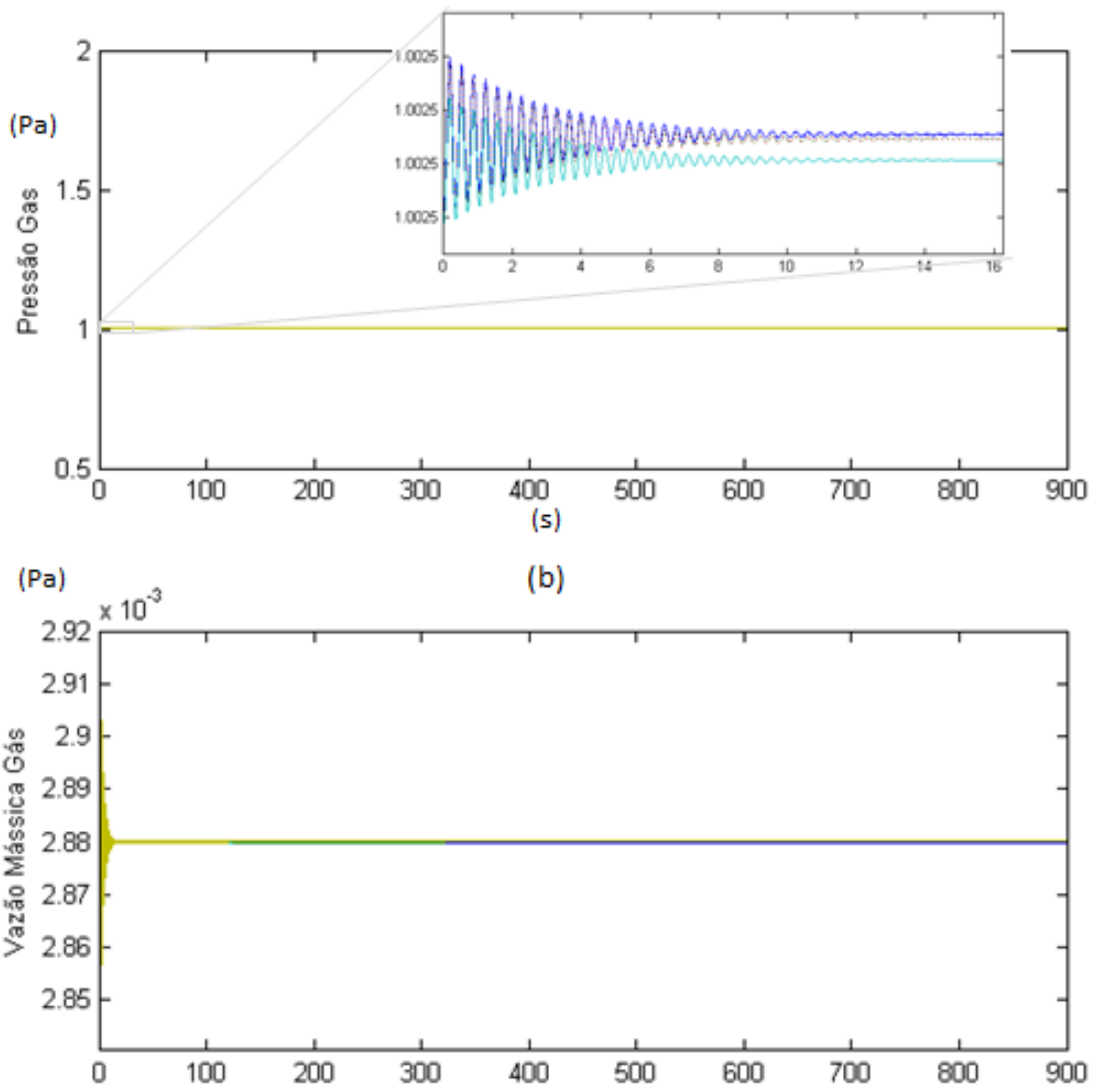

(s)

Figura 7.17: (a) Pressão do gás $\left(x 1,0132510^{5} \mathrm{~Pa}\right.$ ) ao longo da tubulação de escoamento do líquido em para cada ponto em que a tubulação foi divida, a abcissa é dada em segundos. (b) Vazão na tubulação de escoamento do líquido em $\mathrm{kg} / \mathrm{s}$ para cada ponto em que a tubulação foi divida, a abcissa é dada em segundos. Os valores de contorno do problema são mostrados pela retas amarelas em (a) e em (b)

A Figura 7.17(a), mostra que a pressão ao longo da tubulação de de saída do gás permanece aproximadamente constante, com o valor da pressão de entrada do gás, durante todo tempo da simulação. A vazão do gás ao longo da tubulação, Figura 7.17(b), também é constante para maior parte do tempo de simulação, no entanto, uma pequena oscilação nos primeiros segundos de simulação é pronunciada. Essa oscilação na vazão do gás acompanha uma pequena oscilação na pressão que só é percebida com aumento da imagem mostrada no detalhe da Figura 7.17(a), nesse detalhe são mostradas curvas de pressão dos primeiros segmentos da tubulação de escoamento do gás. 


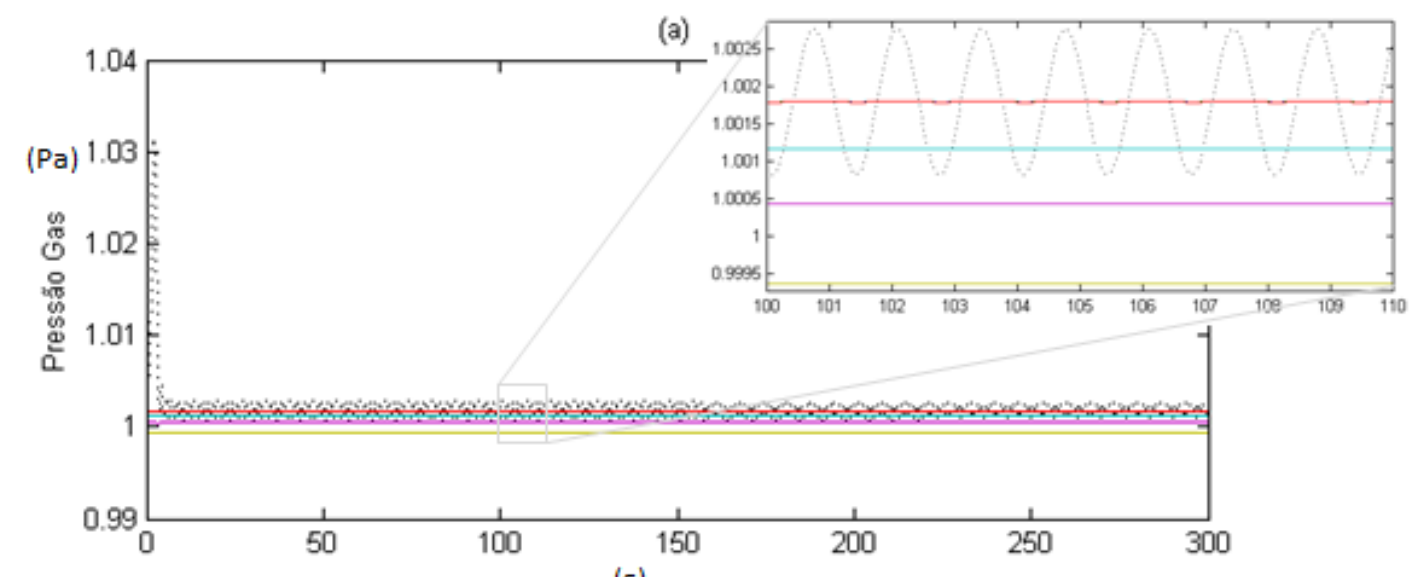

(s)

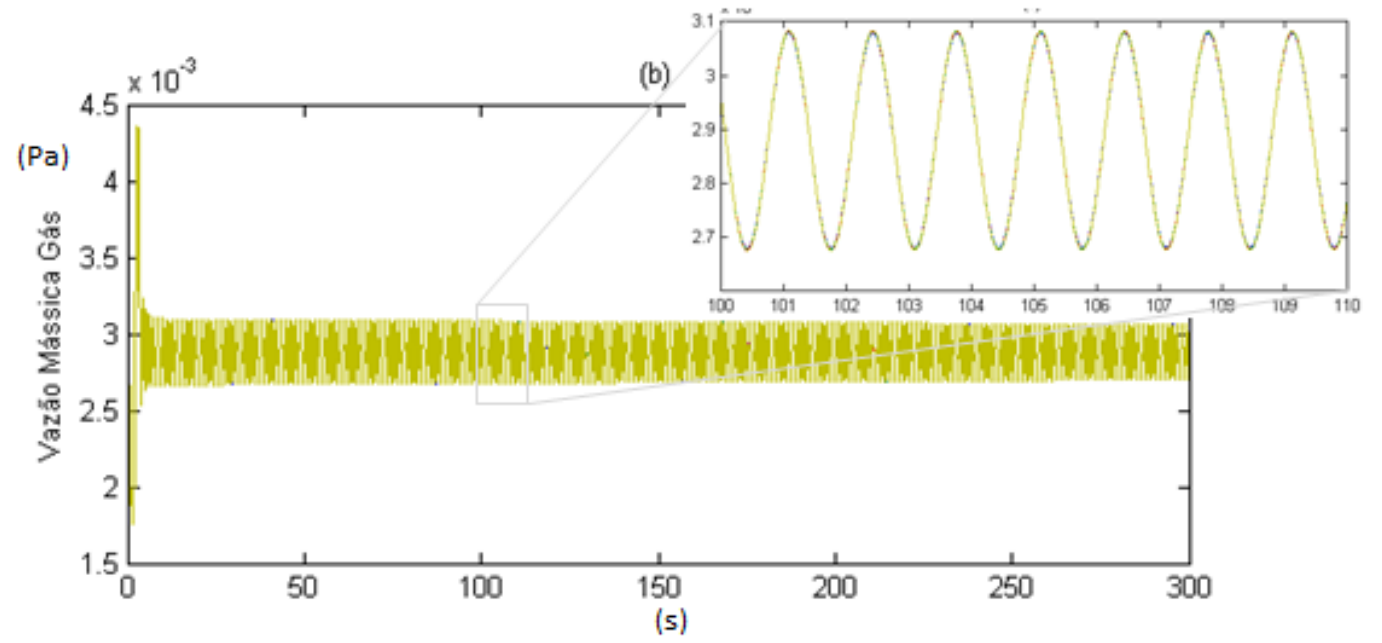

Figura 7.18: (a) Pressão do gás $\left(x 1,0132510^{5} \mathrm{~Pa}\right.$ ) ao longo da tubulação de escoamento do líquido em para cada ponto em que a tubulação foi divida, a abcissa é dada em segundos. (b) Vazão na tubulação de escoamento do líquido $\mathrm{em} \mathrm{kg} / \mathrm{s}$ para cada ponto em que a tubulação foi divida, a abcissa é dada em segundos. Os valores de contorno do problema são mostrados pela retas amarelas em (a) e em (b)

Para ilustrar o comportamento da pressão do gás no interior do recipiente de separação, considere o caso em que o mesmo aparato com mesmas dimensões, parâmetros, valores iniciais e condições de contorno é utilizado. Porém, no intuito de se observar o aumento da pressão do gás no interior do separador, a altura do aparato é modificada passando para 0,78 metros. Esse novo separador com altura modificada será utilizado apenas para simulação apresentada na Figura 7.18.

Percebe-se na Figura 7.18(a) uma elevação da pressão no interior do separador (linha preta pontilhada) em função do pequeno volume ocupado pelo gás, já que o nível inicial do líquido $(0,75 m)$ está próximo do teto do recipiente de separação $(0,78 m)$. Com abaixamento do nível do líquido a pressão diminui gradativamente até valores próximos ao da pressão inicial do gás. A pressão do gás passa a oscilar como mostrado no detalhe da figure sendo essa oscilação mais pronunciada do ponto equivalente ao interior do recipiente (linha pontilhada) e cada vez menos 
pronunciado ao longo do comprimento da tubulação de saída do gás. Percebe-se no detalhe da Figura 7.18(a) que as curvas correspondentes ao ponto 1 na base da tubulação, sobreposto pela curva correspondente à pressão no ponto 2 (em vermelho), oscilam a uma amplitude bem menor. A amplitude da oscilação diminui ao longo do comprimento da tubulação sendo que no ponto 3 (em ciano) já não se observa oscilações da pressão na Figura. O ponto 2 encontra-se à $10 \mathrm{~m}$ do ponto 1 conforme definido em pelo vetor $\mathbf{c}_{G}$ 7.10. As oscilações da pressão são acompanhadas de oscilações da vazão do gás em sua tubulação de saída como mostrado na Figura 7.18(b).

\subsubsection{Entrada em Sinal Senoidal}

De acordo com o mapa do padrão do escoamento em tubo horizontal proposto por Mandhane, Gregory e Aziz 1973, aumentando-se a velocidade superficial do gás em relação à velocidade do líquido considerada no exemplo anterior de $0,1 \mathrm{ft} / \mathrm{s}$ passa-se do regime estratificado liso para o regime estratificado ondulado. Este último será observado para velocidades de escoamento do gás de $50 \mathrm{ft} / \mathrm{s}$, conservando-se a velocidade superficial do líquido a $0,1 \mathrm{ft} / \mathrm{s}$.

Para observar o comportamento do sistema controlado frente a uma entrada representativa do regime estratificado ondulado, o sistema foi submetido a uma entrada senoidal as vazões de entrada do gás e do líquido. Os sinais de entrada propostos são apenas sinais oscilatórios representativos, adotados no intuito de forçar o controlador a responder em condições severas de funcionamento. Não foi adotado nesse exemplo um ponto equivalente no mapa de Mandhane, Gregory e Aziz 1973, (Figura 7.14) já que as altas velocidades superficiais de escoamento do gás, frente ao diâmetro da tubulação de entrada utilizada poderia induzir valores de pressão e vazão acima da capacidade de resposta do atuador, para o presente caso. Uma vez que o controlador responda satisfatoriamente à entradas de vazão do tipo sinusoidal, o problema de adaptar o aparato a valores altos da vazão de entrada é facilmente resolvido com a utilização de um atuador com maior capacidade, como no caso das bombas ESP utilizadas em separadores centrífugos submersos do tipo VASPS ${ }^{3}$.

Seja então, as vazões de entrada para o líquido e para o gás representadas pelas seguintes funções periódicas:

$$
\begin{gathered}
q_{i n}=q_{0 l i q}+q_{l i q} \sin \left(\omega_{l i q} t+\phi_{l i q}\right) \\
M_{i n}=M_{0 \text { gas }}+M_{\text {gas }} \sin \left(\omega_{\text {gas }} t+\phi_{\text {gas }}\right)
\end{gathered}
$$

A Figura 7.19(a) mostra que o controlador continua a responder satisfatoriamente mesmo quando as vazões de entrada se comportam como funções periódicas. O nível do líquido no interior do separador é mantido dentro dos limites de tolerância por todo tempo da simulação. Para simulação mostrada na Figura foram utilizados os seguintes valores:

\footnotetext{
${ }^{3}$ a instalação de um separador do tipo VASPS e utilização de uma bomda tipo ESP é discutida por Vale [Vale et al. 2002] em 2002
} 


$$
\begin{array}{ll}
q_{0 l i q}=0,0017 \mathrm{~m}^{3} / \mathrm{s}, & M_{0 \text { gas }}=0,0043 \mathrm{~kg} / \mathrm{s} \\
q_{\text {liq }}=0,0017 \mathrm{~m}^{3} / \mathrm{s}, & M_{\text {gas }}=0,0043 \mathrm{~kg} / \mathrm{s} \\
\omega_{\text {liq }}=1 / 2, & \omega_{\text {gas }}=1 / 2 \\
\phi_{\text {liq }}=0, & \phi_{\text {gas }}=\pi
\end{array}
$$

O comportamento do nível do líquido passa a ser oscilatório conforme mostra o detalhe da Figura 7.19, assim a curvas desenvolvida pelo atuador mostrada na Figura 7.19(b). A frequência de rotação da bomba, descrito por $\gamma$ chega a quase $80 \%$ da frequência máxima, numa curva oscilatória que tende a acompanhar a vazão de entrada de líquido, nos intervalos em que a vazão é baixa a curva de $\gamma$ chega a valores próximos de zero, ou seja, praticamente não há ação do atuador.
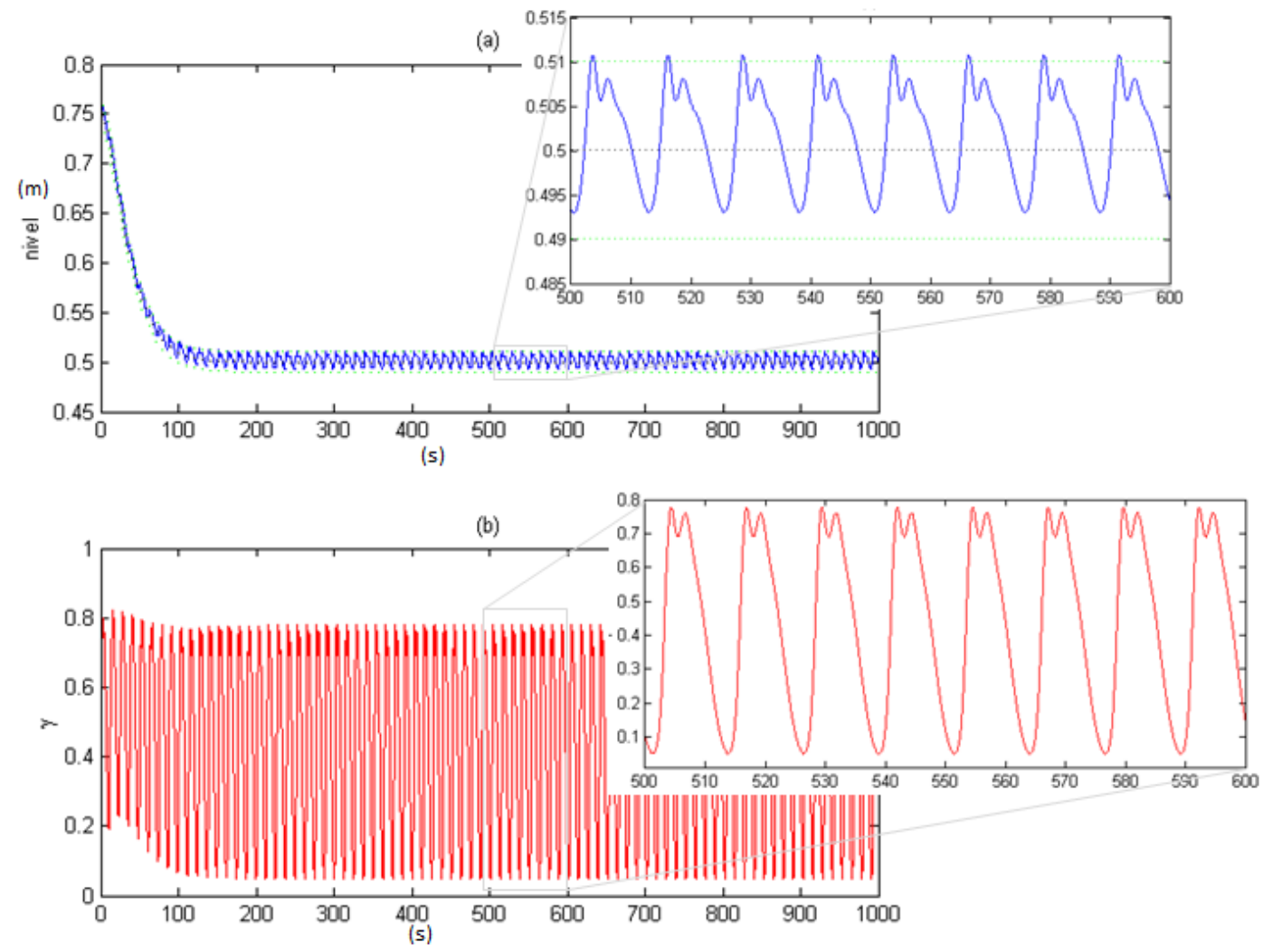

Figura 7.19: (a) Trajetória do nível do líquido no interior do separador em metros $(m)$. A linha pontilhada escura indica a trajetória desejada. As linhas pontilhadas indicam indicam a tolerância permitida ao nível e a linha sólida indica a trajetória efetivamente seguida pelo nível. (b) $\gamma$, fração da frequência de rotação da bomba.

As Figuras 7.20(a) e (b) mostram a vazão e altura piezométrica para o escoamento do líquido ao longo de sua tubulação de saída. Tanto a altura piezométrica quanto a vazão apresentam comportamento oscilatório o qual, imposto pelo atuador, tende a acompanhar a vazão de entrada. Na Figura 7.20(b) é mostrada (linha preta pontilhada) a vazão do líquido na entrada do separador conforme a equação 7.26, sendo possível comparar-se, com auxílio do detalhe da Figura, a evolução 
da vazão ao longo da tubulação em relação à vazão de entrada, ao longo do tempo. O padrão de cores relativo a cada ponto ao longo da tubulação é o mesmo utilizado nos exemplos anteriores.

As Figuras 7.21(a) e (b) mostram a evolução temporal das curvas de pressão e vazão mássica ao longo da tubulação de saída do gás. A curvas de vazão também tendem a acompanhar a vazão de entrada como pode ser observado no detalhe da Figura 7.21(b), no entanto, a interação com o sistema provoca oscilações adicionais de maior frequência que podem ser vistas no detalhe da Figura que mostra uma segunda ampliação das curvas de vazão. 


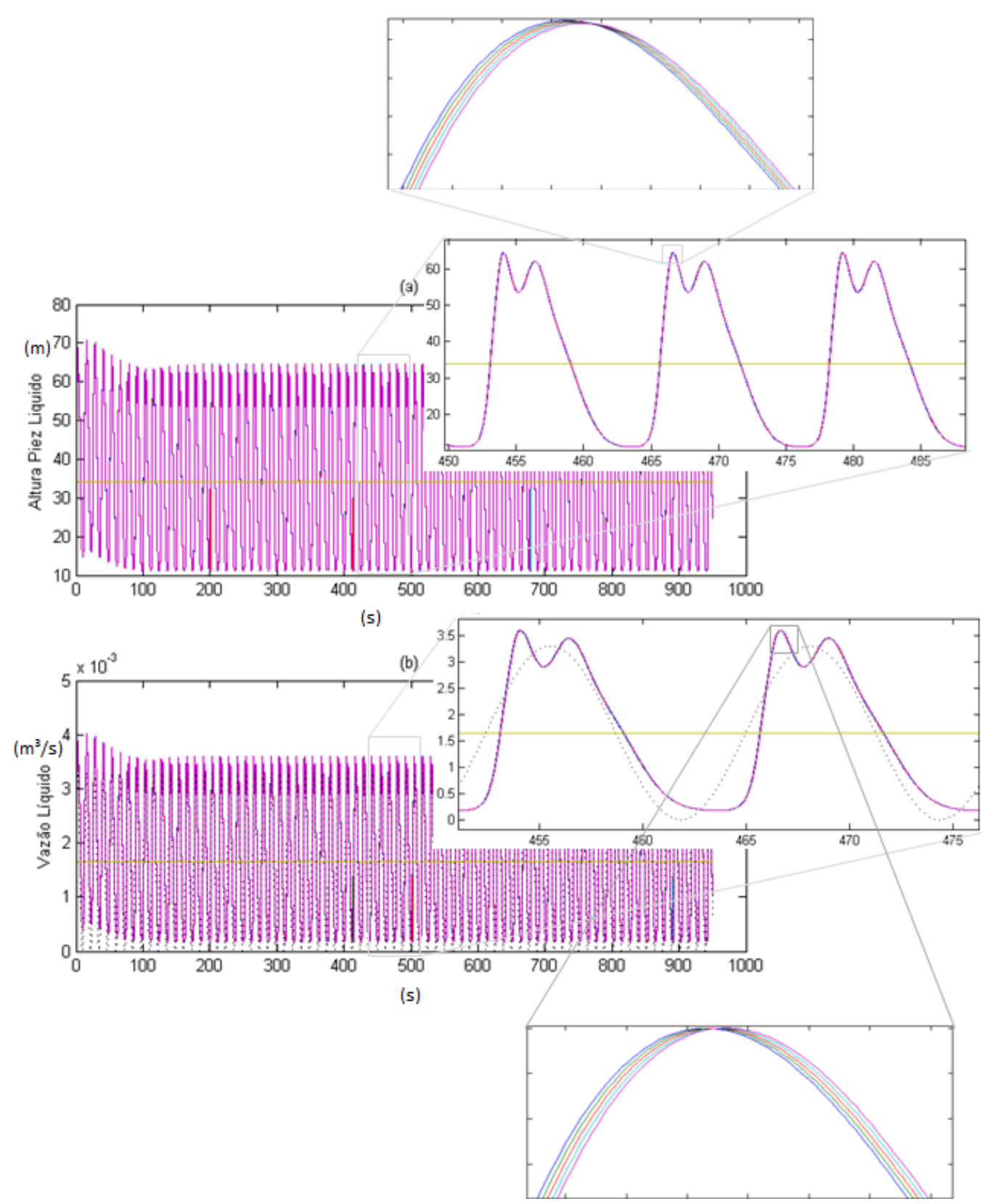

Figura 7.20: (a) Altura Piezométrica $(m)$ ao longo da tubulação de escoamento do líquido em para cada ponto em que a tubulação foi divida. (b) Vazão na tubulação de escoamento do líquido em $\mathrm{m}^{3} / \mathrm{s}$ para cada ponto em que a tubulação foi divida. A linha pontilhada preta que aparece no detalhe superior de (b) é a curva da vazão mássica do líquido na entrada do separador. Os valores de contorno do problema são mostrados pela retas amarelas em (a) e em (b) 


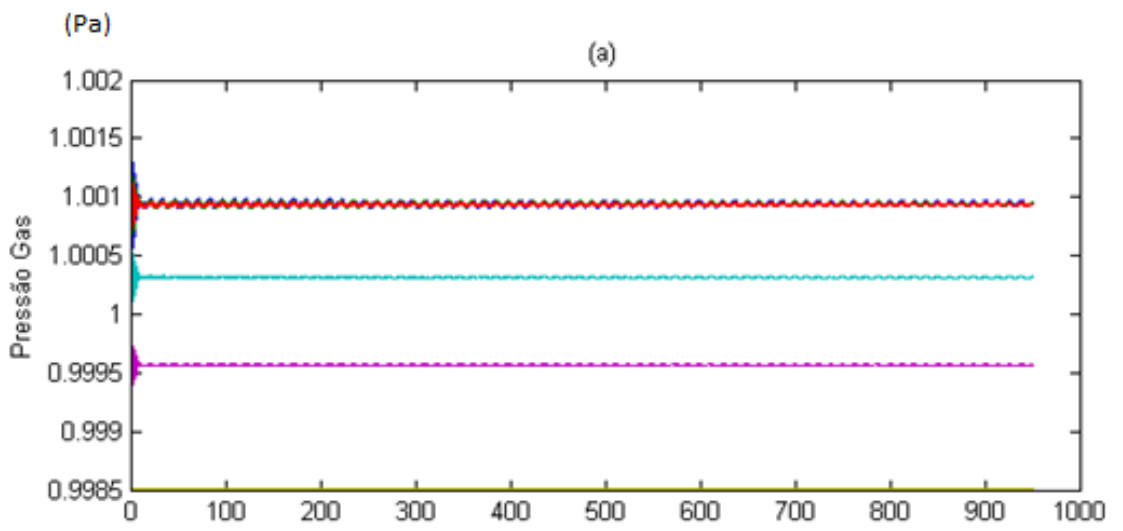

(s)

(Pa)
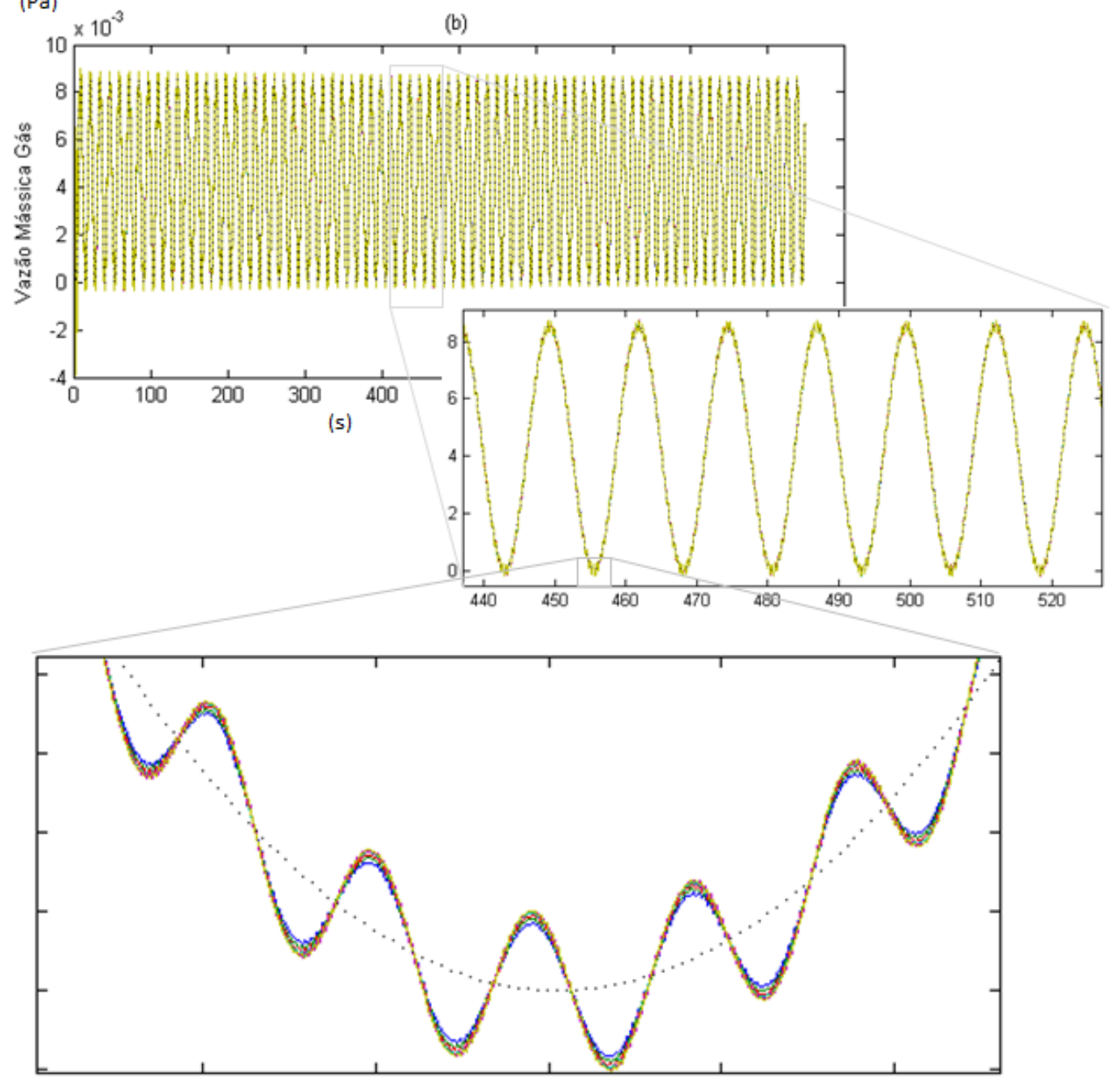

Figura 7.21: (a) Pressão do gás $\left(x 1,0132510^{5} \mathrm{~Pa}\right.$ ) ao longo da tubulação de escoamento do líquido em para cada ponto em que a tubulação foi divida, a abcissa é dada em segundos. (b) Vazão na tubulação de escoamento do líquido em $\mathrm{kg} / \mathrm{s}$ para cada ponto em que a tubulação foi divida, a abcissa é dada em segundos. A linha pontilhada preta é a curva da vazão mássica de gás na entrada do separador. Os valores de contorno do problema são mostrados pela retas amarelas em (a) e em (b) 


\subsubsection{Entrada em Sinal de Onda Quadrada}

Um terceiro tipo de regime de escoamento do fluido bifásico na entrada do separador a ser discutido é o regime intermitente. Nesse regime, a alternância do escoamento do gás e do líquido forma pistões de líquido que ocupam o diâmetro da tubulação, esses pistões são separados por bolhas de gás de maneira que se for medida a vazão do gás ou do líquido num ponto especifico da tubulação, um sinal alternado será lido. Uma boa maneira de se representar esse tipo de escoamento é com um sinal de onda quadrada. Variando-se a frequência do sinal e a largura de cada pulso, pode-se representar tanto o regime intermitente quanto os regime de bolhas alongadas. Neste exemplo, será considerado um sinal de entrada em onda quadrada com parâmetros representativos. Assim como no caso apresentado na seção anterior 7.2.3, não se intenta realizar análise de um caso prático experimental, mas observar o comportamento do controlador, bem como a forma típica dos sinais de saída do sistema para esse tipo de entrada. No arranjo deste exemplo, o recipiente de separação tem altura de $0,78 \mathrm{~m}$, de modo que será possível observar-se não só as respostas típicas do sistema controlado a um sinal de entrada em onda quadrada como a capacidade do atuador em trabalhar em condições teóricas um pouco mais severas.

Seja então o sinais de entrada do separador para o líquido e para o gás dados pelas seguintes equações:

$$
\begin{gathered}
q_{i n}=q_{0 l i q}+q_{l i q} \text { square }\left(\omega_{l i q} t+\phi_{l i q}\right) \\
M_{\text {in }}=M_{0 \text { gas }}+M_{\text {gas }} \text { square }\left(\omega_{\text {gas }} t+\phi_{\text {gas }}\right)
\end{gathered}
$$

onde a função square $(t)$ traça um sinal de onda quadrada com período $2 \pi$. Para o presente exemplo foram utilizados os seguintes parâmetros das nas equações 7.29 e 7.30:

$$
\begin{array}{ll}
q_{0 l i q}=0,000825 \mathrm{~m}^{3} / \mathrm{s}, & M_{0 \text { gas }}=0,001 \mathrm{~kg} / \mathrm{s} \\
q_{\text {liq }}=0,0004125 \mathrm{~m}^{3} / \mathrm{s}, & M_{\text {gas }}=0,00026 \mathrm{~kg} / \mathrm{s} \\
\omega_{\text {liq }}=1 / 2, & \omega_{\text {gas }}=1 / 2 \\
\phi_{\text {liq }}=0, & \phi_{\text {gas }}=\pi
\end{array}
$$

As simulações foram corridas até um tempo de 500 segundos. Não se fez necessário tempos maiores de simulação, pois, como nos casos anteriores, assim que o sistema controlado se estabiliza para tempos maiores que $\sim 120$ segundos, não haverá mudanças comportamento do sistema e os sinais de saída correspondentes a $H, Q, P$ e $M$ permanecerão descrevendo a mesma curva periódica. Aproximadamente 120 segundos é o tempo que a curva da trajetória desejada força o sistema controlado a alcançar o seu ponto de equilíbrio em $0.5 \mathrm{~m}$.

A Figura 7.22(a) mostra o nível do líquido dentro do recipiente de separação ao longo do tempo de simulação. Assim como nos casos anteriores, para entrada em sinal de onda quadrada o controlador mostra-se satisfatoriamente eficaz no que tange sua capacidade de manter o nível do líquido dentro dos limites especificados. O nível do líquido apresenta oscilações, melhor visualiza- 
das no detalhe da Figura 7.22(a) que tendem a acompanhar as oscilações da vazão na entrada do separador, essas oscilações são acompanhadas por variações na frequência de rotação da bomba, representado por $\gamma$ na Figura 7.22(b).

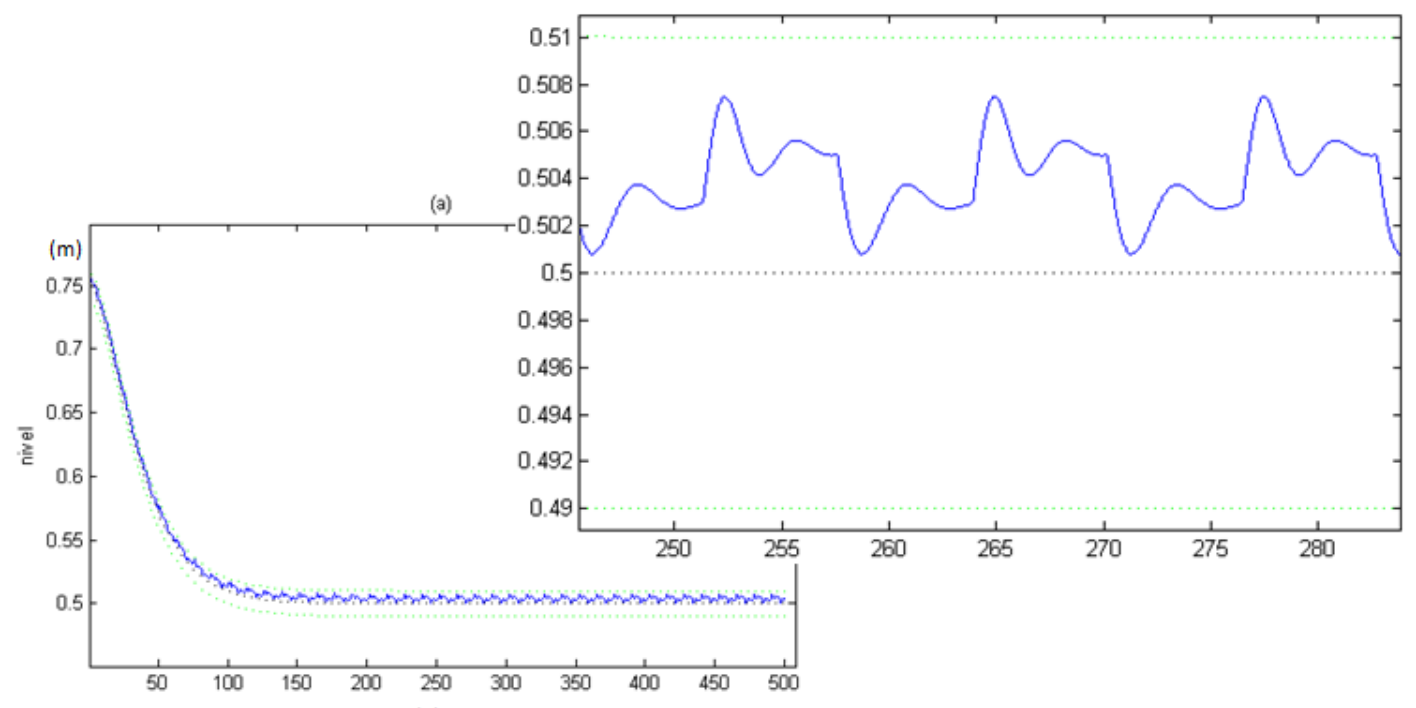

(s)

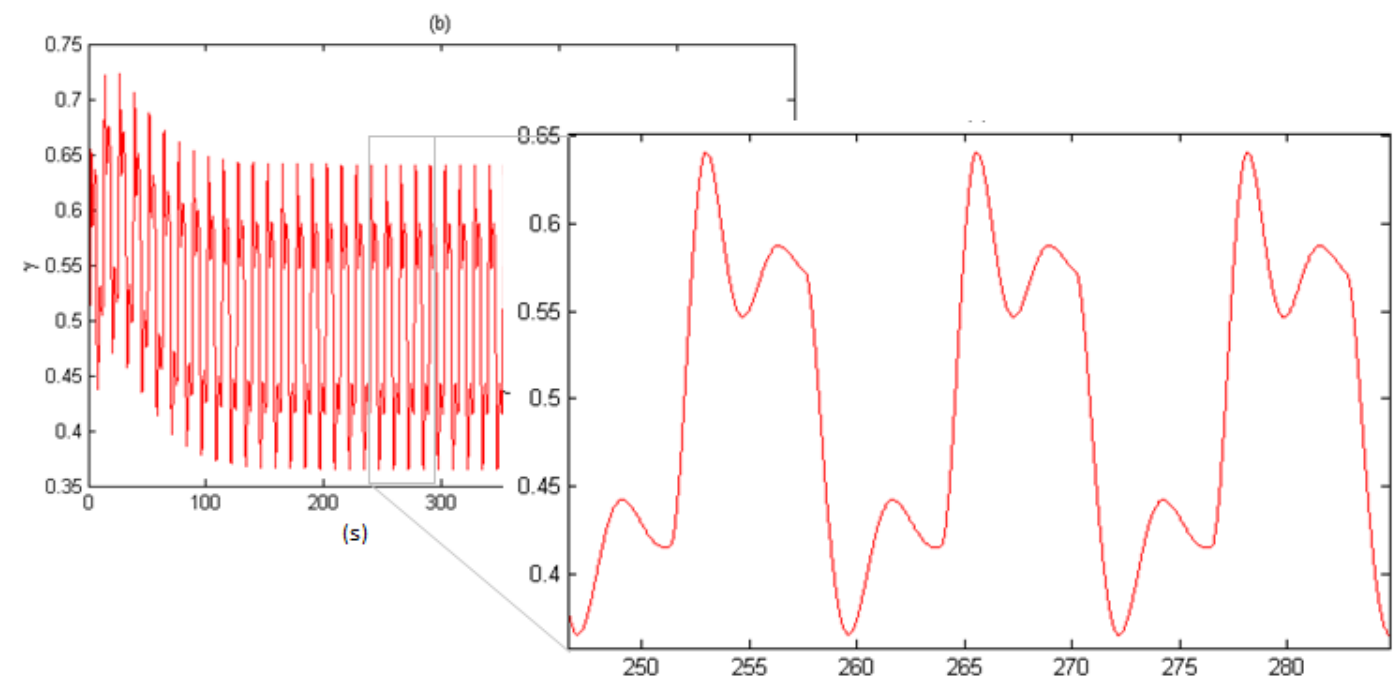

Figura 7.22: (a) Trajetória do nível do líquido no interior do separador em metros (m). A linha pontilhada escura indica a trajetória desejada. As linhas pontilhadas indicam indicam a tolerância permitida ao nível e a linha sólida indica a trajetória efetivamente seguida pelo nível. (b) $\gamma$, fração da frequência de rotação da bomba.

Tanto altura piezométrica ao longo da tubulação de saída do líquido, Figura 7.23(a), quanto a vazão do líquido ao longo da tubulação, Figura 7.23(b), tendem a acompanhar as oscilações provocadas pelo sinal periódico na entrada do separador. No detalhe da Figura 7.23(b), é mostrada 
o sinal de onda quadrada que descreve a vazão de entrada (linha pontilhada preta) onde visualizase claramente, que a pressão da vazão ao longo do comprimento da tubulação tende a seguir o sinal de entrada.

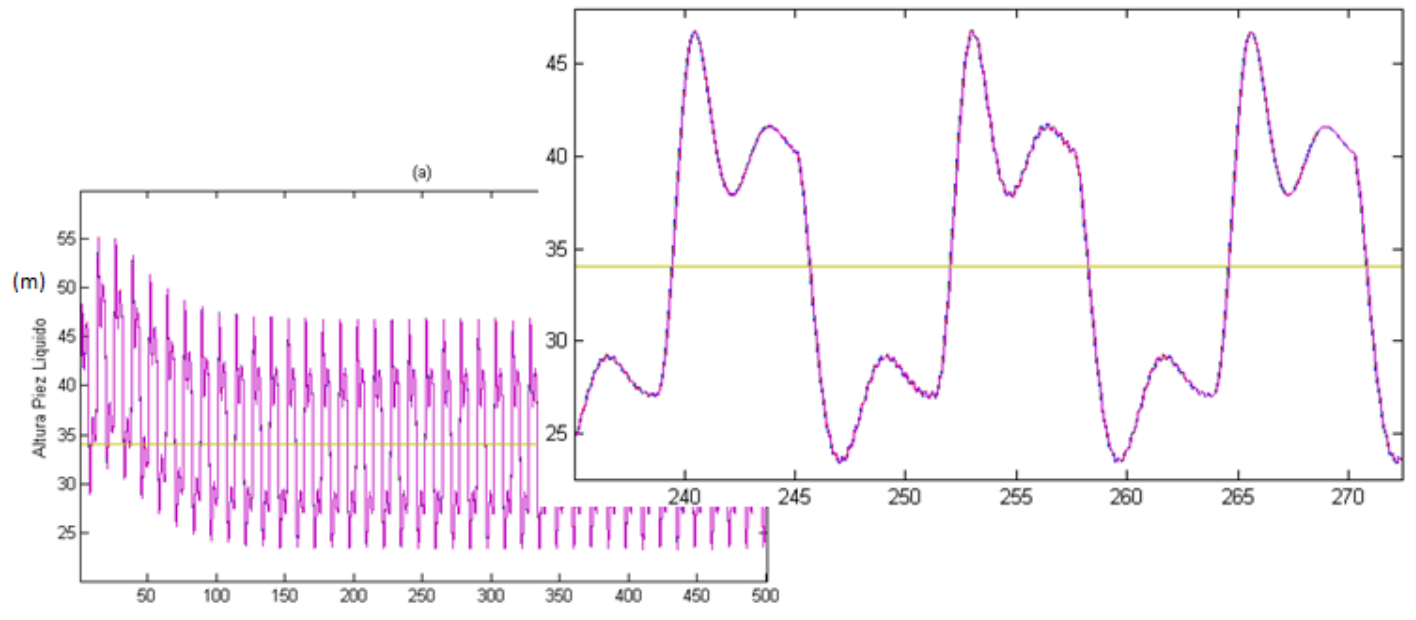

(s)

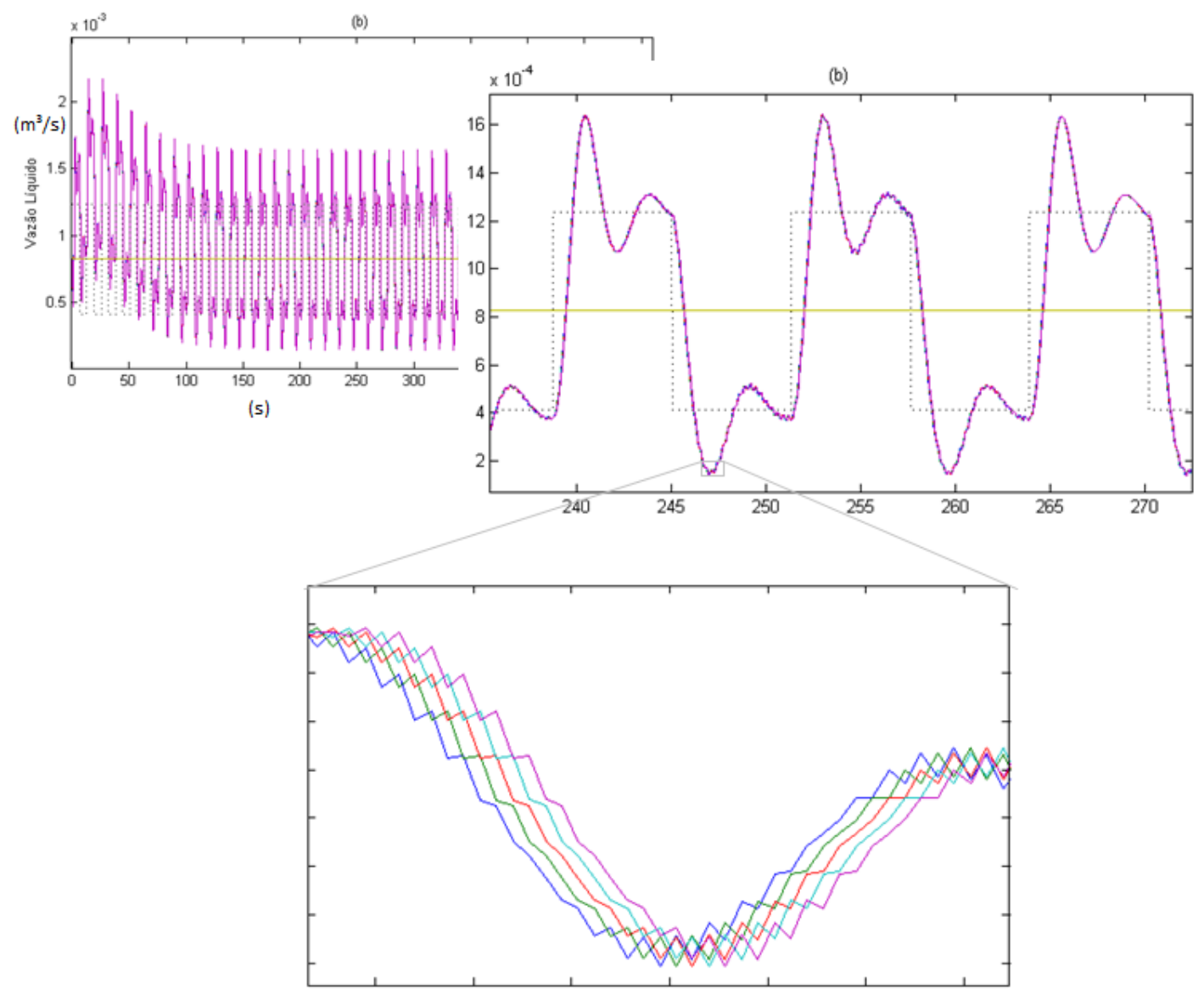

Figura 7.23: (a) Altura Piezométrica $(m)$ ao longo da tubulação de escoamento do líquido em para cada ponto em que a tubulação foi divida. (b) Vazão na tubulação de escoamento do líquido em $\mathrm{m}^{3} / \mathrm{s}$ para cada ponto em que a tubulação foi divida. A linha pontilhada preta que aparece no detalhe superior de (b) é a curva da vazão mássica do líquido na entrada do separador.. Os valores de contorno do problema são mostrados pela retas amarelas em (a) e em (b) 
Altas variações da vazão de saída do gás são observadas para o presente caso em tudo como pode ser visualizado na Figura 7.24(b). Nessa Figura, o sinal de onda que descreve a vazão de entrada é descrita pela curva preta pontilha. Percebe-se no detalhe da Figura 7.24(b), que a variação brusca da vazão de entrada causa variação da amplitude de oscilação das vazões ao longo da tubulação de saída. Apesar das variações da amplitude do sinal que descreve a vazão do gás, um fluxo positivo será observado já que a pressão decresce ao longo da tubulação como ilustrado na Figura 7.24(a). A curva da pressão na base da tubulação (ponto 1) mostrado em azul, apresenta valores de pressão maiores que nos pontos mais próximos da extremidade oposta. O detalhe da Figura mostra uma superposição das curvas de pressão para os três primeiros pontos da tubulação, sendo que o ponto $1 \mathrm{em}$ azul apresenta um amplitude de oscilação maior que o a curva de pressão no ponto 3, em vermelho. A curva em verde refere-se ao ponto 2. Os pontos ao longo da tubulação de saída do gás são marcado de acordo com a Figura 7.8 e o esquema de cores que identifica cada ponto foi apresentado na tabela 7.3. 

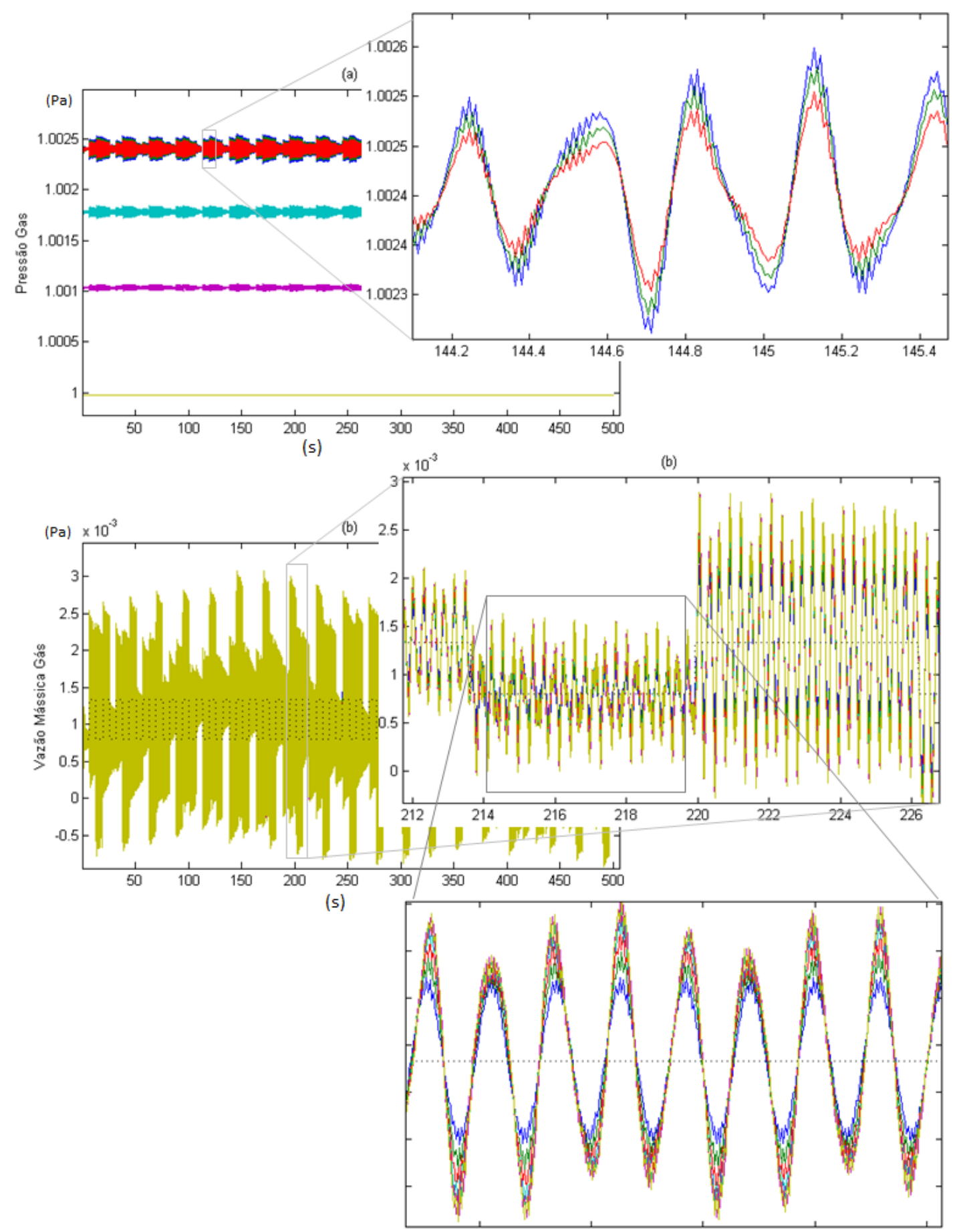

Figura 7.24: (a) Pressão do gás $\left(x 1,0132510^{5} \mathrm{~Pa}\right.$ ) ao longo da tubulação de escoamento do líquido em para cada ponto em que a tubulação foi divida, a abcissa é dada em segundos. (b) Vazão na tubulação de escoamento do líquido em $\mathrm{kg} / \mathrm{s}$ para cada ponto em que a tubulação foi divida, a abcissa é dada em segundos. A linha pontilhada preta é a curva da vazão mássica de gás na entrada do separador. Os valores de contorno do problema são mostrados pela retas amarelas em (a) e em (b) 


\subsubsection{Sistema Controlado sob Ação de Perturbação Transiente}

As equações que regem o escoamento do gás e do líquido ao longo de suas respectivas tubulações de saída e ao longo do tempo, são formuladas, como apresentado no Capítulo 3, a partir da teoria de transiente em fluidos [Wylie e Streeter 1978]. Dessa forma, é possível prever o comportamento do sistema sob ação de uma perturbação externa que gere um efeito transiente no escoamento. Nas seções 4.3.1 e 4.2.3, foram apresentadas as equações necessárias à descrição do problema do escoamento do líquido, de forma que a condição de contorno é determinada sob a influência de uma válvula na extremidade da tubulação. Na ocasião, foi definido uma variável $(\tau)$ que mede a fração de abertura da válvula e a partir da qual é possível obter-se o valor da vazão de pressão do líquido no lugar onde a válvula está posicionada.

Considere, então, uma válvula colocada na extremidade final da tubulação de saída do líquido. Num dado instante de tempo $(t=200$ segundos $)$ essa válvula é fechada a 0,9 da abertura inicial $(\tau=0,9)$. O sistema considerado é o mesmo do caso anterior com altura normal do recipiente de separação (2,062 metros - ver Figuras 7.2 e 7.4). O sistema foi submetido a uma entrada oscilatória em onda quadrada conforme as equações 7.29 e 7.30, com os seguintes parâmetros:

$$
\begin{array}{ll}
q_{0 l i q}=0,000825 \mathrm{~m}^{3} / \mathrm{s}, & M_{0 \text { gas }}=0,001 \mathrm{~kg} / \mathrm{s} \\
q_{\text {liq }}=0,0004125 \mathrm{~m}^{3} / \mathrm{s}, & M_{\text {gas }}=0,00026 \mathrm{~kg} / \mathrm{s} \\
\omega_{\text {liq }}=1 / 10, & \omega_{\text {gas }}=1 / 10 \\
\phi_{\text {liq }}=0, & \phi_{\text {gas }}=\pi
\end{array}
$$

As frequências de oscilação do sinais de entrada foram diminuídas em relação ao exemplo da simulação anterior para melhorar a visualização do comportamento do sistema.

O controlador contínua hábil em mantar o nível do líquido dentro dos limites de tolerância especificados por todo o tempo de simulação mesmo quando uma carga adicional é imposta ao sistema com o fechamento da válvula em $t=200 \mathrm{~s}$ (ver Figura 7.25(a)). Após o fechamento parcial da válvula, o atuador passa a trabalhar com uma maior amplitude do sinal $(\gamma)$ que mede a frequência rotação da bomba centrífuga (ver Figura 7.25(b)). 
(a)

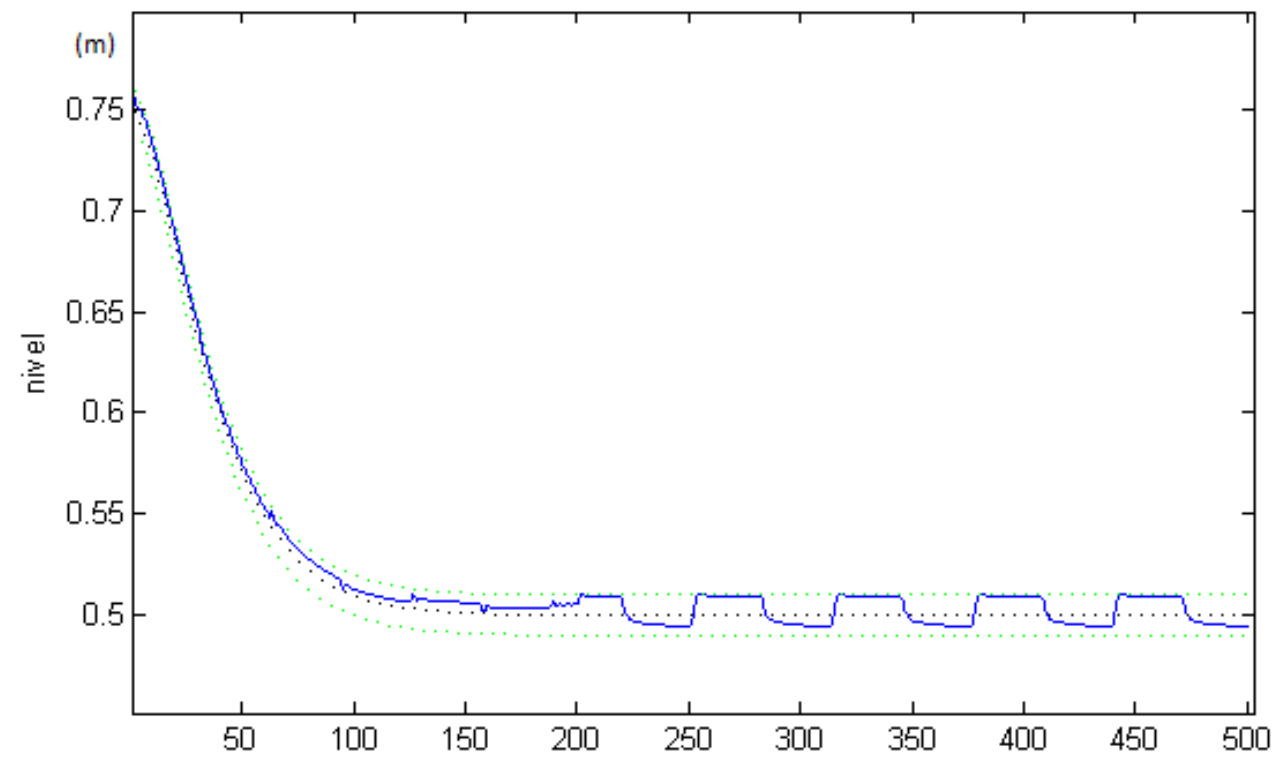

(s) .

(b)

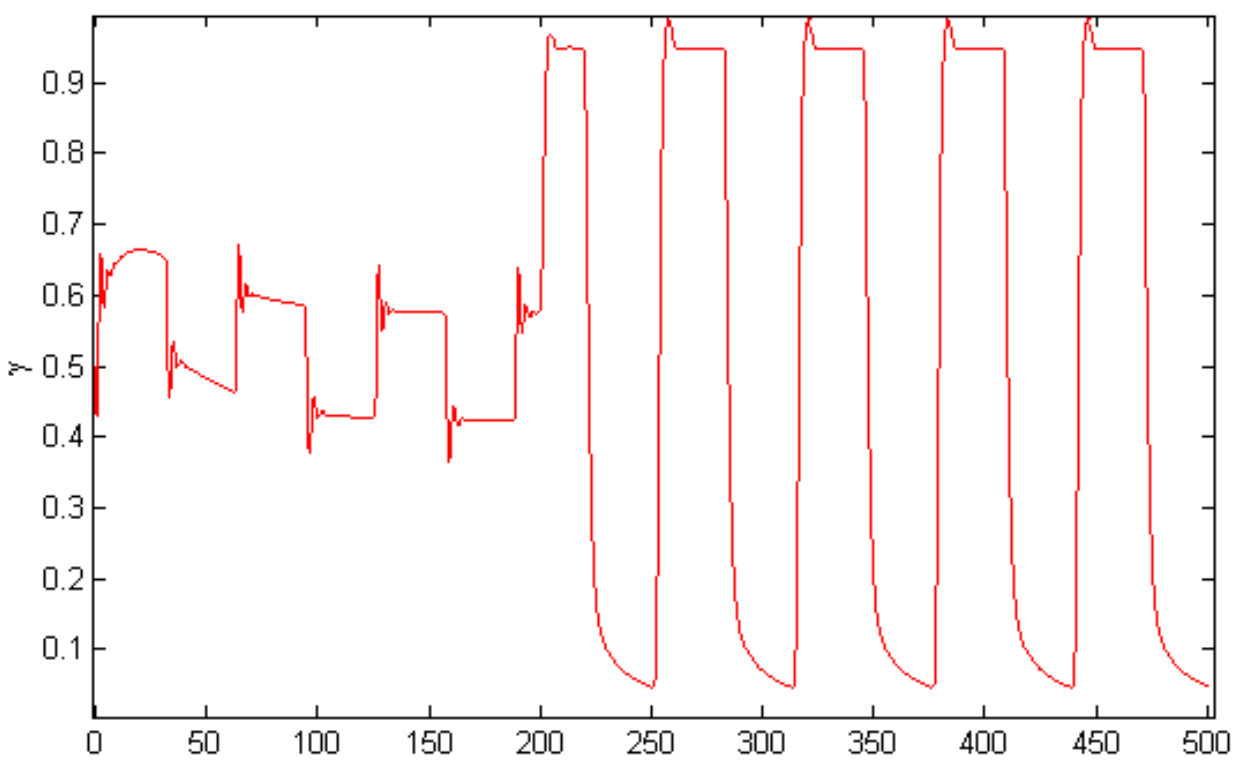

Figura 7.25: (a) Trajetória do nível do líquido no interior do separador em metros ( $m)$. A linha pontilha escura indica a trajetória desejada. As linhas pontilhadas indicam indicam a tolerância permitida ao nível e a linha sólida indica a trajetória efetivamente seguida pelo nível. (b) $\gamma$, fração da frequência de rotação da bomba. 
O efeito da perturbação transiente sobre o escoamento do líquido é mostrada nos detalhes da Figura 7.27(a) para a pressão e da Figura 7.27(b) para a vazão. Nota-se que um pulso de pressão causado pelo fechamento da válvula é propagado ao longo do comprimento da tubulação através de pulsos com duração cada vez menor em direção à base da tubulação. Assim, o tempo de duração do pulso de pressão na válvula (linha amarela no detalhe da Figura 7.27(a)) é maior que o tempo de duração do pulso no ponto 5 (linha roxa) o qual é maior que no caso do ponto 4 (linha ciano), seguindo a mesma lógica até o ponto 1 na base, onde a tubulação de saída do líquido é acoplada ao recipiente de separação. A duração do pulso de pressão segue a seguinte ordem:

$\begin{array}{lllll}\text { ponto } 6>\quad \text { ponto } 5> & \text { ponto } 4> & \text { ponto } 3> & \text { ponto } 2> & \text { ponto } 1 \\ \text { linha amarela linha roxa } & \text { linha ciano } & \text { linha vermelha } & \text { linha verde } & \begin{array}{l}\text { linha azul (base } \\ \text { da tubulação) }\end{array} \\ \text { (extremidade da } & & & \\ \text { tubulação onde } \\ \text { está conectada a } \\ \text { válvula) } \\ \text { forme ilustrado na Figura } 7.26 .\end{array}$

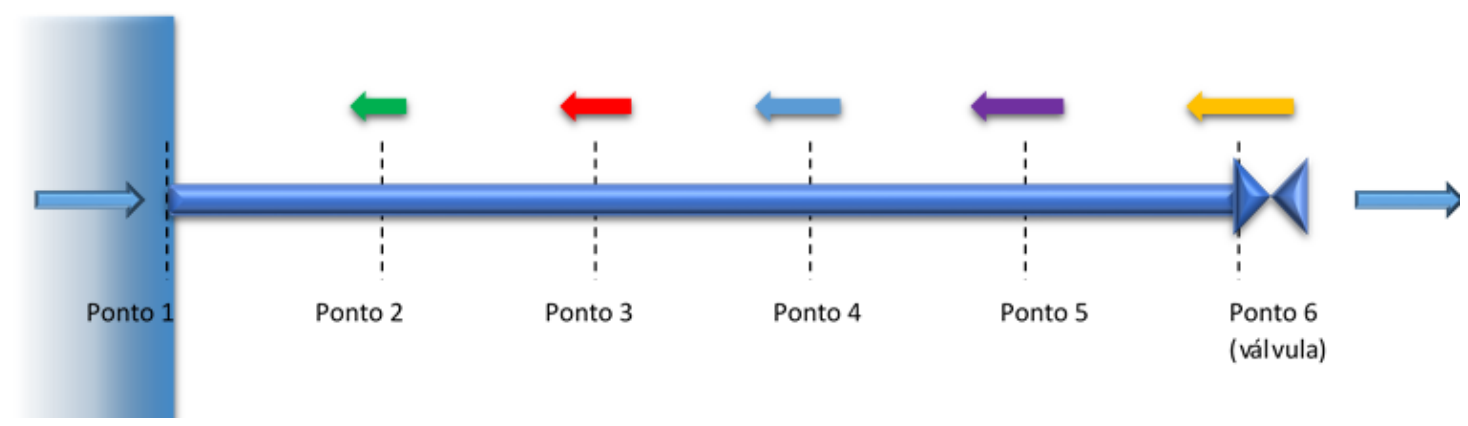

Figura 7.26: O pulso de pressão ao longo da tubulação de escoamento de líquido causado pelo fechamento parcial da válvula, tem duração menor à medida que se aproxima da base da tubulação. As cores das setas indicam o padrão de cores adotado para cada ponto ao longo da tubulação, utilizado nas simulações.

A partir do fechamento parcial da válvula há uma aumento significativo da altura piezométrica no interior da tubulação de saída do líquido que passa a oscilar de acordo com o sinal de entrada desenvolvendo uma curva que se assemelha ao sinal de onda quadrada que foi imposto na entrada do separador. Nota-se que a pressão na extremidade da tubulação (linha amarela na Figura 7.27), constante até o tempo de 200 segundos, também passa a desenvolver comportamento oscilatório. Essa linha representa um valor de contorno imposto ao problema do escoamento do líquido no interior da tubulação, logo, uma vez fechada a válvula, a pressão na extremidade da tubulação passa a depender da pressão desenvolvida no início.

A Figura 7.27(b), mostra a variação da vazão no interior do tubulação ao longo do tempo. Assim como no caso da da altura piezométrica, a vazão do líquido na altura da válvula (linha amarela) passa a desenvolver comportamento oscilatório que tende a acompanha a vazão de entrada do separador. A vazão de entrada é mostrada na Figura pela linha preta pontilha. O detalhe da Figura 7.27(b) mostra o efeito transiente causado pela perturbação produzida pelo fechamento 
parcial da válvula onde é possível observar que a duração do pulso de vazão tem comportamento inverso ao observado para a pressão, ou seja, maior duração na base da tubulação e menor duração na extremidade junto à válvula. A pressão e a vazão mássica ao longo da tubulação de escoamento do líquido é mostrada nas Figuras 7.28(a) e 7.28(a), respectivamente. 

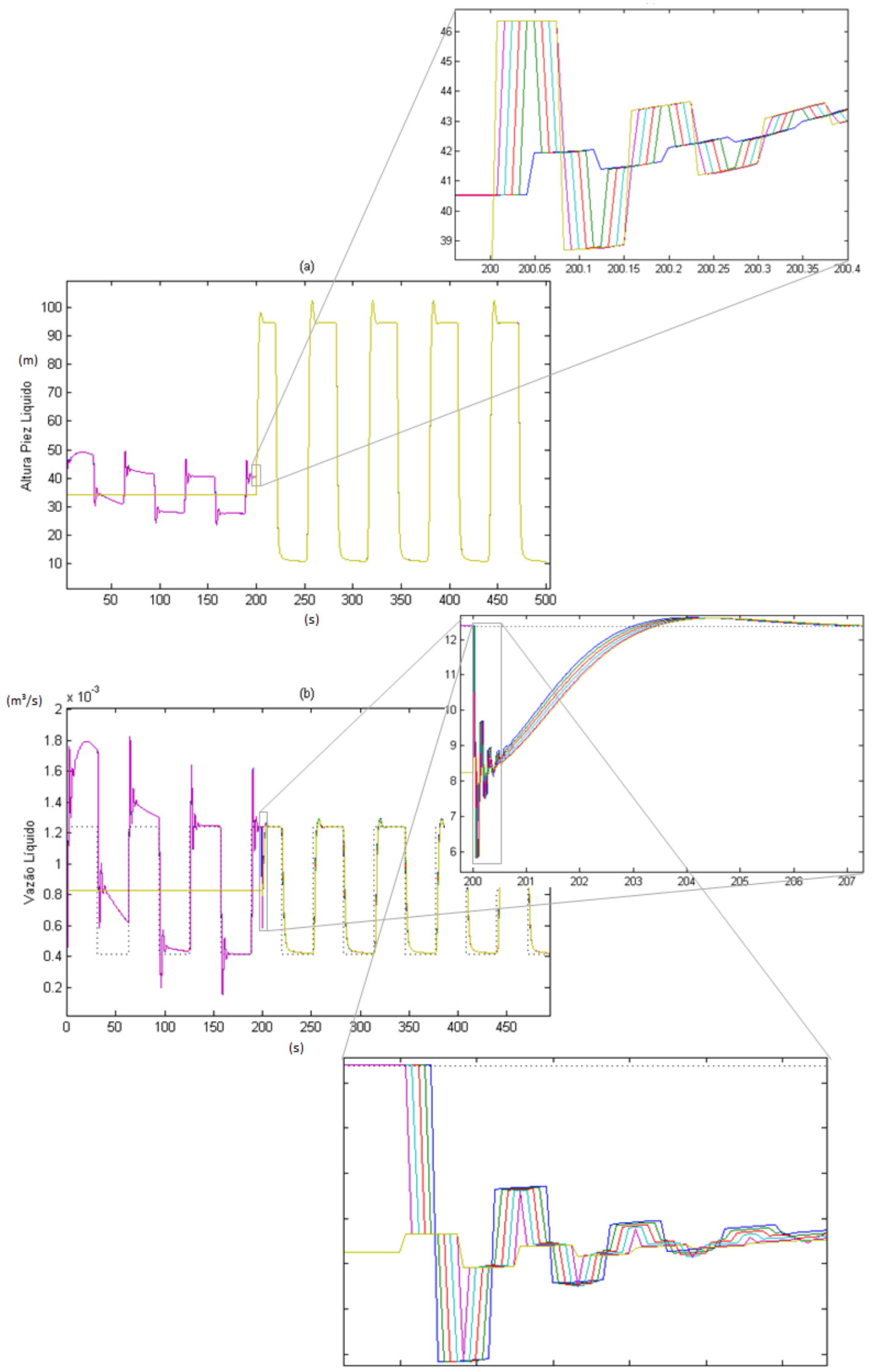

Figura 7.27: (a) Altura Piezométrica $(m)$ ao longo da tubulação de escoamento do líquido em para cada ponto em que a tubulação foi divida. (b) Vazão na tubulação de escoamento do líquido em $\mathrm{m}^{3} / \mathrm{s}$ para cada ponto em que a tubulação foi divida. A linha pontilhada preta que aparece no detalhe superior de (b) é a curva da vazão mássica do líquido na entrada do separador. 
(a)

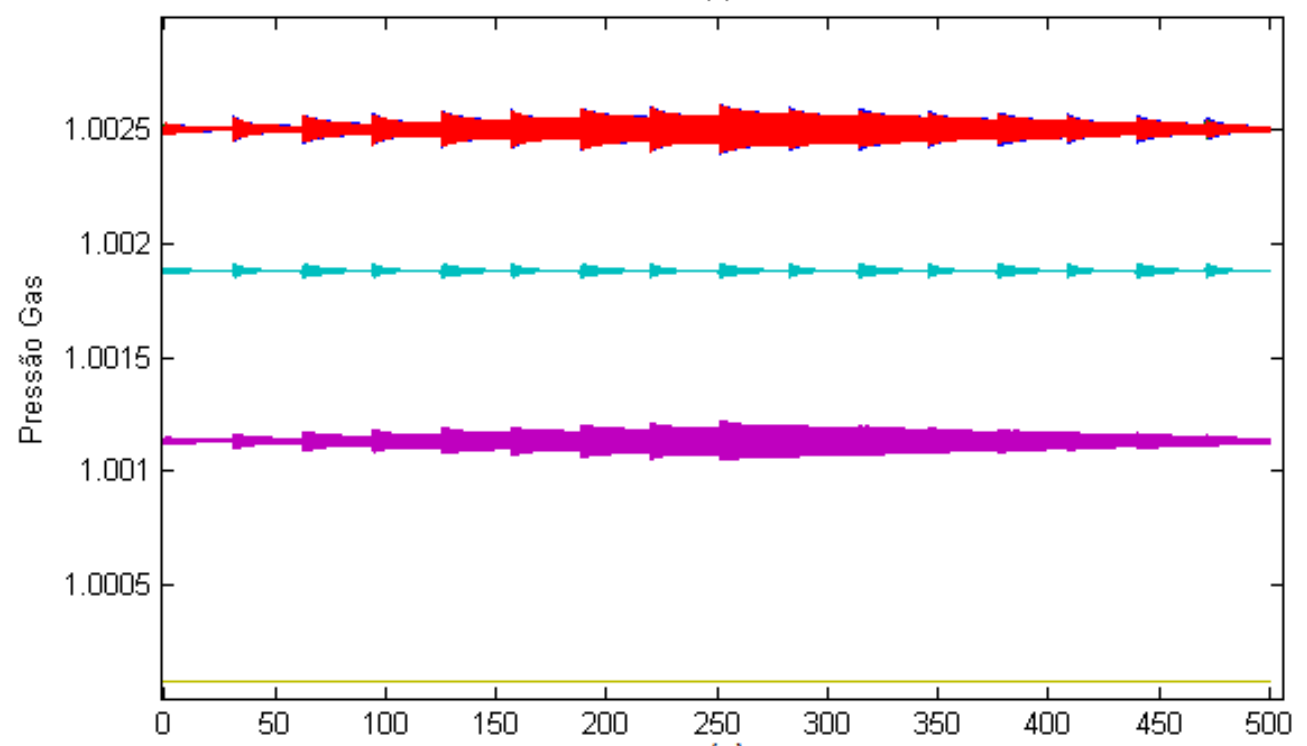

(s)

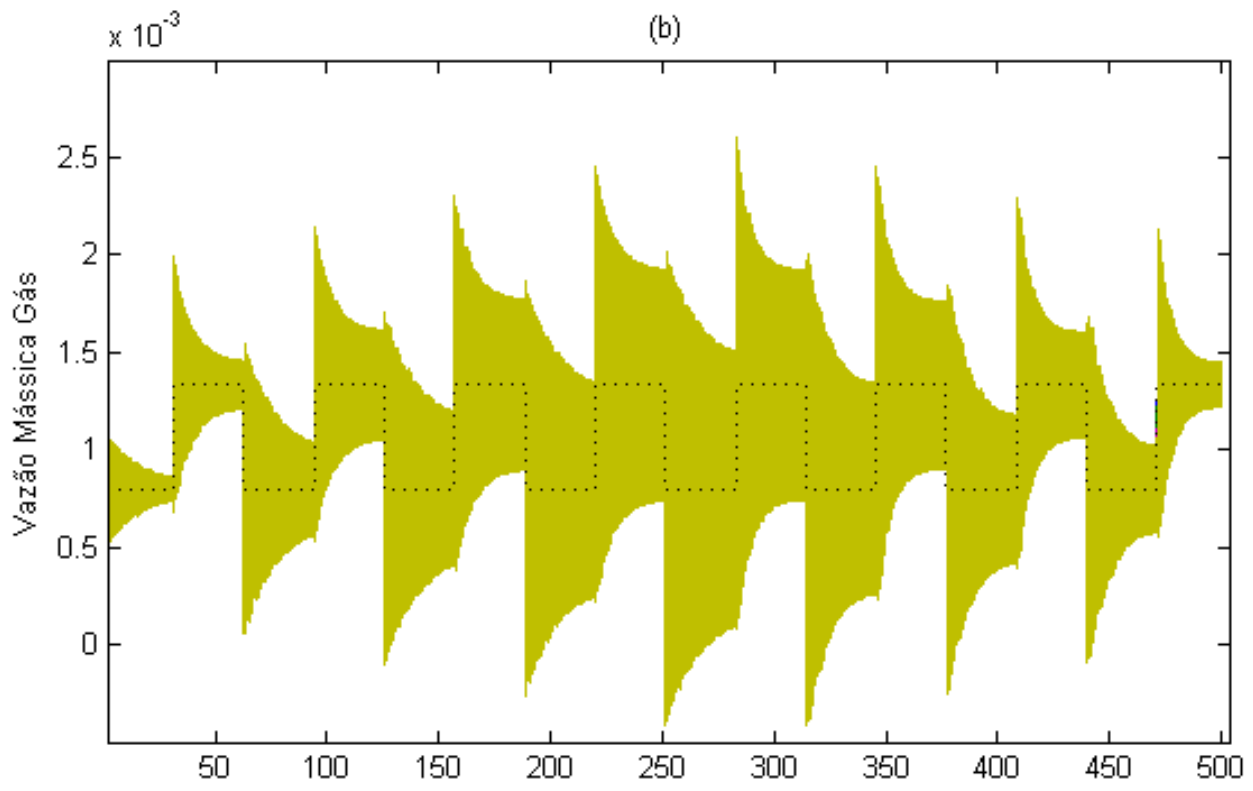

Figura 7.28: (a) Pressão do gás (x1,01325 105 Pa) ao longo da tubulação de escoamento do líquido em para cada ponto em que a tubulação foi divida, a abcissa é dada em segundos. (b) Vazão na tubulação de escoamento do líquido em $\mathrm{kg} / \mathrm{s}$ para cada ponto em que a tubulação foi divida, a abcissa é dada em segundos. A linha pontilhada preta é a curva da vazão mássica de gás na entrada do separador. 


\subsection{Conclusões}

O controlador apresentado no presente trabalho apresentou-se satisfatoriamente eficiente em manter o nível do líquido no interior do separador ciclônico. Quando o sistema foi submetido aos típicos de sinais de entrada representativos das vazões de entrada que podem ser encontrados na prática, o controlador manteve o nível próximo aos limites de tolerância impostos. O desenvolvimento do controlador baseado na teoria de Sliding Control, traz algumas vantagens ao controlador como a capacidade de forçar a variável controlada a seguir uma trajetória previamente especificada e a possibilidade de se controlar o sistema mesmo não se conhecendo totalmente seu comportamento.

Apesar de ter-se trabalhado com uma equação diferencial aparentemente de primeira ordem para o descrição do comportamento do sistema, há duas variáveis incertas no modelo utilizado. Uma dessas variáveis é a pressão do gás $\left(p_{G}\right)$ acima da coluna de líquido no interior do recipiente de separação. Sendo a pressão dependente do volume ocupado pelo gás e sendo esse volume uma função do nível do líquido, verifica-se que a própria pressão do gás é uma função da variável a ser controlada. A relação entre a pressão do gás e a variável controlada, no entanto não é uma relação simples já que depende da vazão de entrada e da vazão do gás ao longo de sua tubulação saída, essa vazão é descrita por um modelo próprio em termos de um conjunto de equações diferenciais que formam um problema de valor inicial e de contorno conforme proposto pela teoria de transientes em fluidos. Além da dificuldade associada a determinação de $p_{G}$, o sistema a ser controlado ainda apresenta uma segunda variável incerta em seu modelo, a variável $C_{M}$ a qual, medida em metros, é uma função da pressão e da vazão ao longo da tubulação de saída do líquido e ao longo do tempo. Essa variável surge da técnica de solução numérica adotada (método das equações características) e pode ser entendida com uma medida do histórico de comportamento da pressão e da vazão na tubulação, já que relaciona valores de pressão e vazão no espaço e no tempo a cada iteração computacional necessária à resolução do problema. Assim como no caso do escoamento na tubulação de saída do gás, no caso do líquido também são resolvidos um conjunto de equações diferenciais não lineares que dão o comportamento do escoamento em termos de pressão e vazão ao longo do tempo e ao longo do comprimento da tubulação. A equação utilizada para determinação do nível do líquido é reescrita em 7.33, com as variáveis incertas evidenciadas em negrito.

$$
i=\frac{q_{\text {in }}}{A}-\frac{B}{2 a_{2} A}\left[1-\sqrt{1-\frac{4 a_{2}}{B^{2}}\left(\gamma^{2} H_{s}+\frac{\mathbf{p}_{\mathbf{G}}}{\rho g}+l-l_{0}-\mathbf{C}_{\mathbf{M}}\right)}\right]
$$

O comportamento do nível do líquido no interior do separador estudado terá natureza não linear que é obtido a partir solução de quatro equações diferenciais não lineares. Além, disso o comportamento será imprevisível, dada as variáveis incertas associadas ao modelo adotado para determinação do nível do líquido. Apesar disso, dada a previsão da teoria de Sliding Control de que é possível controlar um sistema com essas características, o controlador proposto foi capaz não só de seguir a trajetória estabelecida como manter o nível do líquido dentro de limites especificados. A despeito do procedimento utilizado para obtenção dos valores limites das incertezas associadas ao sistema (ver seção 6.2), para os exemplos mostrados bastou-se arbitrar um valor constante 
para as variáveis incertas para que o controlador fosse capaz de suprimir essas incertezas e impor o comportamento desejado.

Em suma, das maiores vantagens da utilização do controlador baseado em controle deslizante é a possibilidade de se controlar o sistema mesmo quando parte do modelo que o descreve não for devidamente conhecido, bastando que seus limites de valores inferiores e superiores sejam quantidades conhecidas.

A bruscas variações do sinal de controle impostas pela natureza descontínua de um controlador baseado na teoria de Sliding Control foram amenizadas pela introdução da filtragem do sinal pelos filtros de primeira e segunda ordem, conforme mostrado nos exemplos discutidos nesse Capítulo. O parâmetros associados a esses filtros não foram amplamente variados pois não se intenta no presenta trabalho estabelecer um controlador ótimo para um caso particular, mas estudar o comportamento do controlador. Vários arranjos podem ser implementados dependendo da necessidade prática, pode-se variar os parâmetros dos filtros a fim de se obter o melhor ajuste do controlador a partir de parâmetros de operação de um dado controlador como vazões típicas de entrada de gás e líquido. Por exemplo, pode-se estabelecer parâmetros do filtro de primeira ou segunda ordem que atenuem valores de frequências altas de acordo com a necessidade, fazendo com que o controlador ignore oscilações de alta frequência no sinal de entrada. Isso pode ser conseguido uma vez que o sinal de entrada antes de ser filtrado responde prontamente às oscilações impostas pelo sinal de entrada. O estabelecimento de um controlador ótimo para um caso prático deverá ser alvo de estudos futuros.

Os filtros foram implementados com a função principal de se preservar o atuador impedindo que a bomba de elevação do líquido seja submetida à variações bruscas de sua frequência de rotação como seria solicitado por um controlador descontínuo, no entanto uma das desvantagens da filtragem do sinal de controle é a diminuição da velocidade de resposta do controlador, que apresentará uma defasagem de tempo entre a solicitação e sua resposta. Por outro lado, a possibilidade de se planejar a trajetória a ser seguida pela variável controlada pode atuar a favor, já que pode-se predeterminar uma trajetória branda que leve o nível do líquido ao valor desejado de forma suave principalmente se não houverem exigências de tempo para que o nível do líquido alcance um dado valor. Outra forma de se preservar o atuador é às custas da adequação à trajetória desejada, quanto menor a exigência de se segui-la e quanto maior for o intervalo de valores que o nível pode assumir, menor será a necessidade de variações da frequência de rotação da bomba.

Apesar de evitar as variações bruscas impostas pelo sinal de controle descontínuo, a utilização apenas do filtro ainda se mostrou muito ávida por seguir a trajetória desejada. O que por uma lado, dá precisão na resposta, por outro pode aumentar o esforço do atuador. No intuito de aliviar ainda mais o esforço do atuador foi proposta a modificação nos termos das restrições 7.24. A ideia é que apenas uma fração do sinal de controle seja utilizado quando o nível do líquido estiver dentro dos limites de tolerância da trajetória, de forma que essa fração seja máxima quando o nível ultrapassar o limite de tolerância superior e mínima quando o nível do líquido estiver abaixo do limite de tolerância inferior. Essa fração é calculada por um coeficiente de proporcionalidade $f(l)$ que segue uma função quadrática entre os limites máximo e mínimo de tolerância. A variação 
da proporção do sinal calculado pela teoria de controle deslizante que será aplicada ao sistema dentro dum intervalo de valores especificados conforme calculado pela equação 7.23 , foi obtida por uma função quadrática. Nada impede a utilização de outras funções como um função exponencial. O que deverá ser observado na utilização de outras funções é que o atuador deverá sofrer pequenas solicitações quando nível do líquido estiver próximo ao limite inferior do intervalo considerado e deverá seguir a o sinal de controle sem atenuações, quando o nível ultrapassar o limite superior considerado. Esses limites inferior e superior não precisam coincidir com os limites impostos na prática, uma boa opção seria observar-se valores superiores e inferiores do intervalo para o qual a função $f(l)$ será considerada de modo a se trabalhar com um fator de segurança. A solução do problema do escoamento do líquido no interior de sua respectiva tubulação de saída depende de seu valor de contorno, ou seja, dos valores da pressão e vazão do líquido no ponto de intersecção entre o recipiente de separação e a tubulação. Assim, espera-se que um aumento da pressão nesse ponto causado pelo gás acima da coluna de líquido, resulte num aumento da pressão ao longo da tubulação.

Além de melhorias para o controlador proposto, algumas adaptações podem ser realizadas no intuito de se melhorar o controlador. Uma modificação a ser considerada é a filtragem não de todo o sinal de controle, mas apenas dos termo que geram a descontinuidade do sinal. Modificações como essa além da aplicação do controlador a casos reais serão alvo de estudos posteriores. 


\section{REFERÊNCIAS BIBLIOGRÁFICAS}

[Albuquerque et al. 2013]ALBUQUERQUE, F. A. et al. Subsea processing systems: future vision. Offshore Technology Conference, Houston, p. 1-14, may 2013.

[Baker e Lucas-Clementes 1990]BAKER, A. C.; LUCAS-CLEMENTES, D. Application of Subsea Separation and Pumping to Marginal and Deepwater Field Developments. [S.l.]: Society of Petroleum Engineers, 1990.

[Bensoussan e Lions 1984]BENSOUSSAN, A.; LIONS, J. L. Impulse control and quasi-variational inequalities. Paris: Gauthier-Villars, 1984.

[Bratland, Gregory e Aziz 2010]BRATLAND, J. M.; GREGORY, G. A.; AZIZ, K. A. A flow pattern map for as liquid flow in horizontal pipes. Int. J. Multiphase Flow, Houston, v. 1, p. 537-553, 2010 .

[Chiesa e Eriksen 2000]CHIESA, G.; ERIKSEN, R. Subsea Processing - The Solution to cost efficient Deeopwater Field Developents. [S.l.]: Offshore Technology Conference. OTC 11892., 2000 .

[Conte 2014]CONTE, M. G. Estudo numérico e experimental da geração de golfadas em um escoamento bifásico de gás líquido. Dissertação (Mestrado) - Universidade Tecnológica Federal do Paraná, Curitiba, PR, 2014.

[Deuel et al. 2011]DEUEL, C. et al. Field validation and learning of the parque da conchas (bc-10) subsea processing system and flow assurance design. Offshore Technology Conference, Houston, p. 1-12, may 2011.

[Devegowda e Scott 2003]DEVEGOWDA, D.; SCOTT, S. Anassessment of Subsea Production Systems. [S.1.]: Society of Petroleum Engineers. Denver. Colorado, USA, SPE 84045., 2003.

[Estrela 2003]ESTRELA, G. The Importance of Brazilian Deepwater Activities to the Oil Industry Technological Development. [S.l.]: Offshore Technology Conference. Houston. Texas. OTC 15049., 2003.

[Fjosne 2002]FJOSNE, E. Subsea Processing - Maximizing Value in Areas with Existing Infrastructure. [S.1.]: paper presentes at Ofshore Technology Conference. Houston. Texas USA., 2002 . 
[Kremleva et al. 2010]KREMLEVA, E. et al. Inline technology: New solutions for gas/liquid separation. Society of Petroleum Engineers, Moscou, p. 1-12, october 2010.

[Mandhane, Gregory e Aziz 1973]MAnDhANE, J. M.; GREGORY, G. A.; AZIZ, K. A. A flow pattern map for as liquid flow in horizontal pipes. Int. J. Multiphase Flow, Houston, v. 1, p. 537-553, 1973.

[McClimans e Fantoft 2006]MCCLIMANS, O. T.; FANTOFT, R. Status and New Developments in Subsea Processing. [S.l.]: Offshore Technology Conference, Houston, Texas,USA, OTC 17984., 2006.

[Melo, Mendes e Serapiao 2007]MELO, A. V.; MENDES, J. R.; SERAPIAO, A. D. Controle Inteligente para o Separador VASPS. [S.l.]: 4ô PDPETRO, 2007.

[Melo, Mendes e Serapiao 2007]MELO, A. V.; MENDES, J. R. P.; SERAPIAO, A. B. S. Intelligent Supervision Control for the VASPS Separator. [S.l.]: Brazilian Journal of Petroleum and Gas, 2007. 67-77 p.

[Melo, Serapiao e Mendes 2009]MELO, A. V.; SERAPIAO, A. B.; MENDES, J. R. Método de histerese por auto-ajuste para minimização de esforço de controle no separador submarino VASPS. [S.l.: s.n.], 2009. 105-107 p.

[Morais 2013]MORAIS, J. M. Petróleo em Águas Profundas. Uma história tecnológica da Petrobrás nas exploração e produção offshore. [S.l.]: Instituto de Pesquisa Econômica Aplicada - IPEA., 2013.

[Ogata 2010]OGATA, K. Engenharia de Controle Moderno, 5th edn, Pearson. [S.l.]: SÃ£o Paulo, 2010 .

[Petrobras 2014]PETROBRAS. Quem somos:Perfil. [S.l.]: Fonte:www.petrobras.com.br/pt/quemsomos/perfil/, 2014.

[Pinheiro, Val e Mendes 2009]PINHEIRO, N.; VAL, J. do; MENDES, R. Sthocastic Intervation Strategy Applies to a Level Control with a Trade-off between Risky Operation and Actuator Variations. [S.l.]: Joint 48th IEEE Conference on Decision Control 28th Chinese Control Conference, 2009.

[Pinheiro, Val e Mendes 2009]PINHEIRO, N. C.; VAL, J. B.; MENDES, R. S. Stochastic Intervention Strategy Applied to a Level Control with a Trade-off between Risky Operation and Actuator Variations. [S.l.]: Joint 48th IEEE Conference on Decision and Control and 28t̂th Chinese Control Conference., 2009.

[Procad 2004]PROCAD, J. B. S. C. do. Águas Profundas. [S.l.]: site da Cooperativa de Profissionais da Indústria de Petróleo. www.coopetroleo.com.br/pagua01.htm, 2004.

[Rassenfoss 2011]RASSENFOSS, S. Growing offshore water production pushes search for subsea solution. [S.1.]: Subsea Processing, 36-40., 2011. 
[Rosa, Franca e Ribeiro 2001]ROSA, E.; FRANCA, F.; RIBEIRO, G. The cyclone gas-liquid separator: operating mechanistic modeling. [S.l.]: Journal of Petroleum Science and Engineering., 2001.

[Shiguemoto et al. 2011]SHIGUEMOTO, D. et al. NUmerical Simulation of an Oil and Gas Subsea Separation and Pumping System for Offshore Petroleum Production Using the Method of Characteristics. [S.l.]: 21 Brazilian Congress of Mechanical Engineering, 2011.

[Shiguemoto et al. 2011]SHIGUEMOTO, D. A. et al. Numerical simulation of an oil and gas subsea separation and pumping system for osffshore petroleun production ising the method of characteristics. [S.l.]: 21 Brazilian Congress of Mechanical Engeneering., 2011.

[Slotine e LI 1991]SLOTINE, J.; LI, W. Applied Nonlinear Control. : Prentice Hall, 1991.

[Storti 2013]STORTI, F. C. Estudo Esperimental da eficiência da separação da câmara de expansão do separador VASPS. Dissertação (Mestrado) - Universidade Estadual de Campinas, Campinas, SP, 2013.

[Teixeira et al. 2004]TEIXEIRA, A. et al. Um controlador fuzzy para o sistema de separa ̃̃ß̃̃£o e bombeamento submarino vasps. Rio Oil Gas Expo and Conference, Rio de Janeiro, 2004.

[Teixeira et al. 2006]TEIXEIRA, A. et al. Controle inteligente para o sistema de separaÃ§Ã£o e bombeamento submarino vasps. Rio Oil Gas Expo and Conference, Rio de Janeiro, 2006.

[Vale et al. 2002]VALE, O. et al. VASPS Installation and Operation at Campos Basin. [S.1.]: Offshore Technology Conference, 2002.

[Vale, Garcia e Villa 2002]VALE, O. R.; GARCIA, J. E.; VILLA, M. VASPS Instalation and Operation at Campos Basin. [S.1.]: Offshore Technology Conference. Houston. Texas - OTC 14003., 2002.

[Volk 2013]VOLK, M. Pump Characteristics and Applications, Third Edition. CRC Press, 2013. (Mechanical Engineering). ISBN 9781466563094. Disponível em: $<$ https://books.google.com.br/books?id=QFjSBQAAQBAJ $>$.

[Wylie e Streeter 1978]WYLIE, B.; STREETER, V. Fluid Transients, 2nd edn. [S.l.]: McGrawHill, 1978.

[Yow 1972]YOW, W. Numerical Error on Natural Gas Tansient Calculations. [S.l.]: American Society of Mechanical Engeneering, 1972. 422-428 p. 
ANEXOS 


\section{ANEXO 01}

\section{I.1 Instrução para Utilização da Interface Gráfica}

Uma interface gráfica nomeada ControlPanel3 foi elaborada par simular o funcionamento do separador centrífugo submerso. A simulação consiste em um separador ao qual é acoplado duas tubulações de saída para o fluído, uma para gás e outra para o líquido, na extremidade da tubulação de líquido é colocada uma válvula,e na junção dessa tubulação com o recipiente de separação está acoplada a bomba de elevação do líquido. As instruções para utilização da interface são listadas a seguir.

- Abra a interface gráfica ControlPanel3;

- Entre o tempo de simulação;

- Configure os parâmetros para tubulação de líquido (tubo de liquido)

- altura da bomba: e a altura da bomba em relacao ao fundo, do recipiente. Na posição zero a bomba está no fundo do recipiente;

-Cda: produto entre o coeficiente de abertura da válvula $\left(C_{d}\right)$ e a área e a área da válvula aberta quando fluido escoa em regime estacionário, que é condição inicial da solução do escoamento na tubulação de líquido (referência - seção 4.3.1);

-válvula: abertura da válvula, sendo 1 quando a válvula está totalmente aberta e 0 quando está totalmente fechada;

-tempo crítico: tempo em que a válvula é acionada;

- gravidade: aceleração da gravidade $(9,806 \mathrm{~m} / \mathrm{s})$;

-vazão inicial: condição inicial da vazão do líquido no estado estacionário;

-densidade: densidade do líquido;

-altura máxima: elevação máxima produzida pela bomba;

- altura bomba: elevação inicialmente produzida pela bomba;

- pulso transiente: velocidade do pulso transiente;

-ângulo horizontal: vetor com os ângulos de cada segmento da tubulação do líquido em relação à horizontal;

-fatores de atrito: vetor com os fatores de atrito de cada segmento da tubulação;

-diâmetros: vetor com os diâmetros de cada segmento da tubulação;

-comprimentos: vetor com os comprimentos de cada segmento da tubulação;

- Configure os parâmetros para tubulação de gás (tubo de gás) 
- ângulo horizontal: âgunlo de cada segmento da tubulação de gás em relação à horizontal;

-fatores de atrito: vetor com os fatores de atrito de cada segmento da tubulação;

-diâmetros: vetor com os diâmetros de cada segmento da tubulação;

-comprimentos: vetor com os comprimentos de cada segmento da tubulação;

- Configure as dimensões do recipiente de separação (Vessel)

- nivel inicial: altura inicial do nível do líquido no interior do separador. Zero equivale ao nível em que o líquido coincide com o fundo do recipiente;

-altura: altura do recipiente de separação;

- diâmetro: diâmetro do recipiente de separação;

obs.: o recipiente considerado tem geometria cilíndrica.

- Configure os parâmetros referentes ao Regime (Regime):

- pressão de contorno: pressão do gás na extremidade da saída da tubulação. Esse valor será utilizado como valor de contorno na simulação do escoamento do gás pela respectiva tubulação;

-Escolha o tipo de regime:

*zonas: o tempo de simulação é dividido em vários segmentos temporais para os quais são requeridos diferentes taxas de vazão mássica do gás. A entrada do campo tempos será um vetor em que cada elemento dá o tempo para início da contagem do segmento temporal. O campo zonas temporais será preenchido com os valores da taxa de massa previstos para cada segmento. Durante a simulação serão interpolados linearmente valores intermediários entre os admitidos no campo zonas temporais;

* contínuo: O campo $d M$ será preenchido com um valor contínuo de taxa de massa requerida ao longo da simulação;

* periódico: A taxa de massa ao longo da simulação é uma função periódica no tempo descrita por um função senoidal do tipo $M+M_{a} \operatorname{sen}(w t)$. $M, M_{a}$ e $w$ são valores a serem configurados nos respectivos campos.

Após configurados os parâmetros do separador, basta pressionar o botão $\gg$ que a simulação será realizada. Os resultados serão mostrados forma de gráficos de pressão e vazão ao londo das tubulações para cada segmento da tubulação. 


\section{ANEXO 02}

\section{II.1 Exemplo de Utilização do algorítimo de Resolução Numérica}

Na seção 7.1 foi apresentado o algorítimo desenvolvido no presente trabalho para solução numérica do das equações necessárias Ã determinação do nível do líquido no interior do separador centrífugo submerso pelo método das equações características. Este anexo apresenta um exemplo de utilização do algoritmo.

A função principal de solução numérica do sistema é chamada pelo seguinte comando em MATLAB:

LevelControl $\left(1_{0}, q_{1 i q}, q_{g a s}, t_{\max }\right)$;

$1_{0}$ é o nível inicial do líquido no interior do separador para $t=0$. q q $\mathrm{m}^{3} / \mathrm{s}$ do líquido escoando em estado estacionário. qgas, é a vazão inicial $\mathrm{em} \mathrm{m}^{3} / \mathrm{s}$ do gás escoando em estado estacionário. $t_{\max }$, é o tempo de simulação em segundos.

A função LevelControl cria tr $\tilde{A}^{\mathrm{a}} \mathrm{s}$ instâncias das classes classLiquidPipe, classGasPipe e classVessel, respectivamente, lp, gp e vs Os principais parâmetros a serem configurados dentro da função para cada instância de classe são:

\begin{tabular}{ll}
\hline vs.heigth & configura a altura do recipiente de separação \\
\hline vs.D & configura o diâmetro do recipiente de separação \\
\hline lp.tc & $\begin{array}{l}\text { tempo em que a válvula na extremidade da tubulação de escoamento } \\
\text { do líquido será acionada }\end{array}$ \\
\hline lp.Hs & altura máxima produzida pela bomba \\
\hline lp.lc & altura da interseção entre o recipiente de separação e a tubulação de \\
& escoamento do líquido] \\
\hline lp.dens & densidade do líquido \\
\hline lp.L & vetor com os comprimentos dos segmentos da tubulação do líquido \\
\hline lp.D & vetor com os diâmetros dos segmentos da tubulação do líquido \\
\hline lp.f & vetor com os fatores de atrito de cada segmento da tubulação do \\
\hline lp.beta & líquido \\
\hline vetor com os ângulos de inclinação de cada segmento da tubulação \\
de líquido em relação Ã horizontal
\end{tabular}


Na linha do código onde está escrito \%Choose gas flow regime, a opção:

$\%(1)$ - Constant countour values

deverá ser descomentada caso se queira simular um caso em que sinal de entrada da vazão do líquido e do gás no separados são descritas por uma função contante no tempo. Para o caso de entradas em que as vazões de entrada podem ser descritas por funções periódicas, a linha:

$\%(2)$ - Oscilatory countour values

deverá ser descomentada. Nesse caso os parâmetros:

qOLiq; qLiq; wLiq; defLiq; MOGas; MGas; wGas; defGas;

deverão ser configurados.

Esses parâmetros formam funções periódicas segundo a seguintes equações:

$$
\begin{aligned}
& q_{i n}=\text { qOLiq }+\operatorname{text} q L i q \sin (\text { wLiq } t+\operatorname{defLiq}) \\
& M_{\text {in }}=\text { MOGas }+ \text { MGas } \sin (\text { wGas } t+\text { defGas })
\end{aligned}
$$

onde $q_{i n}$ é a vazão volumétrica de entrada de líquido do separador e $t$ é o tempo. $M_{i n}$ é a vazão mássica de entrada de gás do separador. 


\section{ANEXO 03}

\section{III.1 Código da função LevelControl}

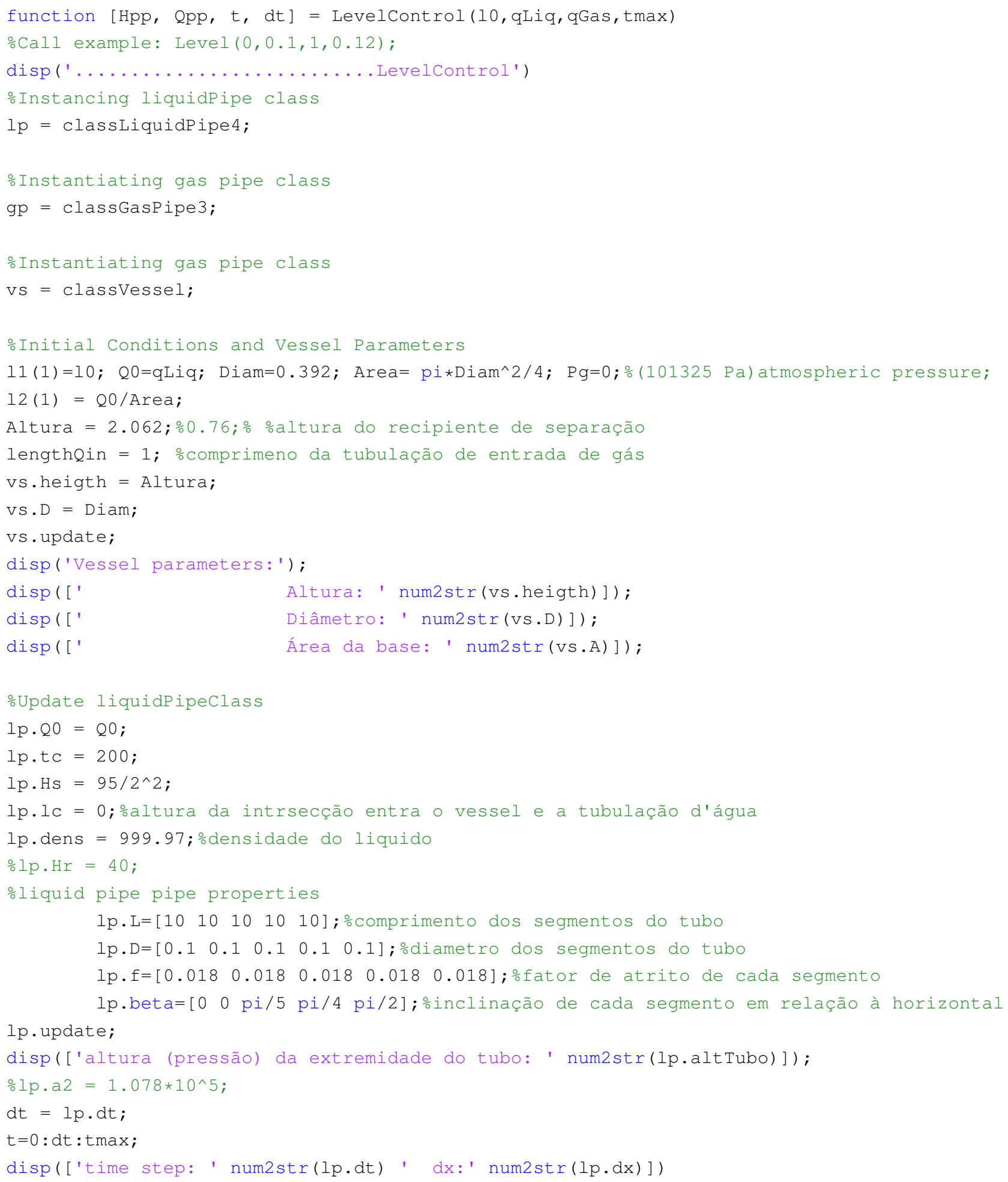




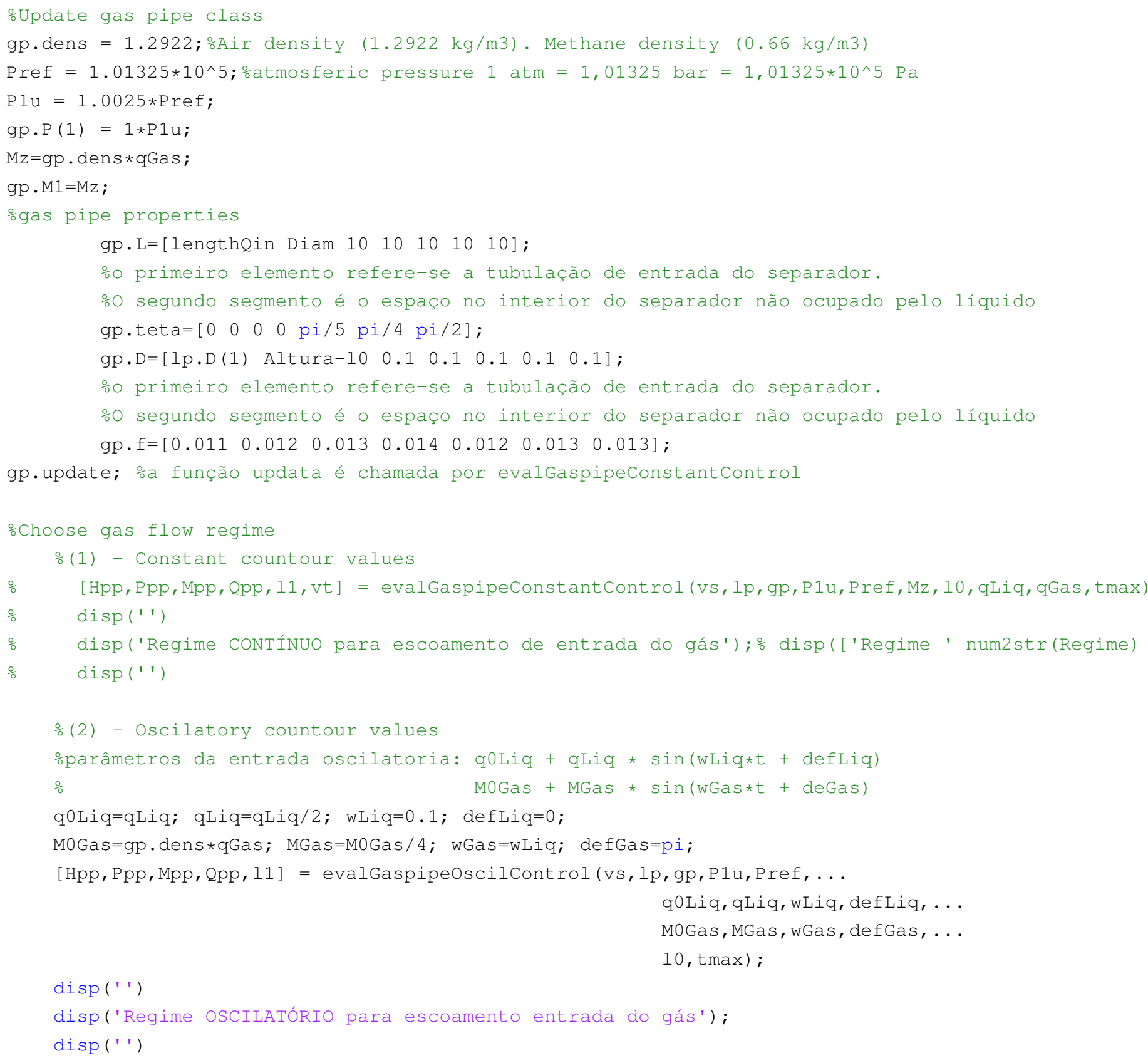

\title{
III.2 Código da função classGasPipe
}

\author{
classdef classGasPipe 3 handle \\ properties (SetAccess = public)
}




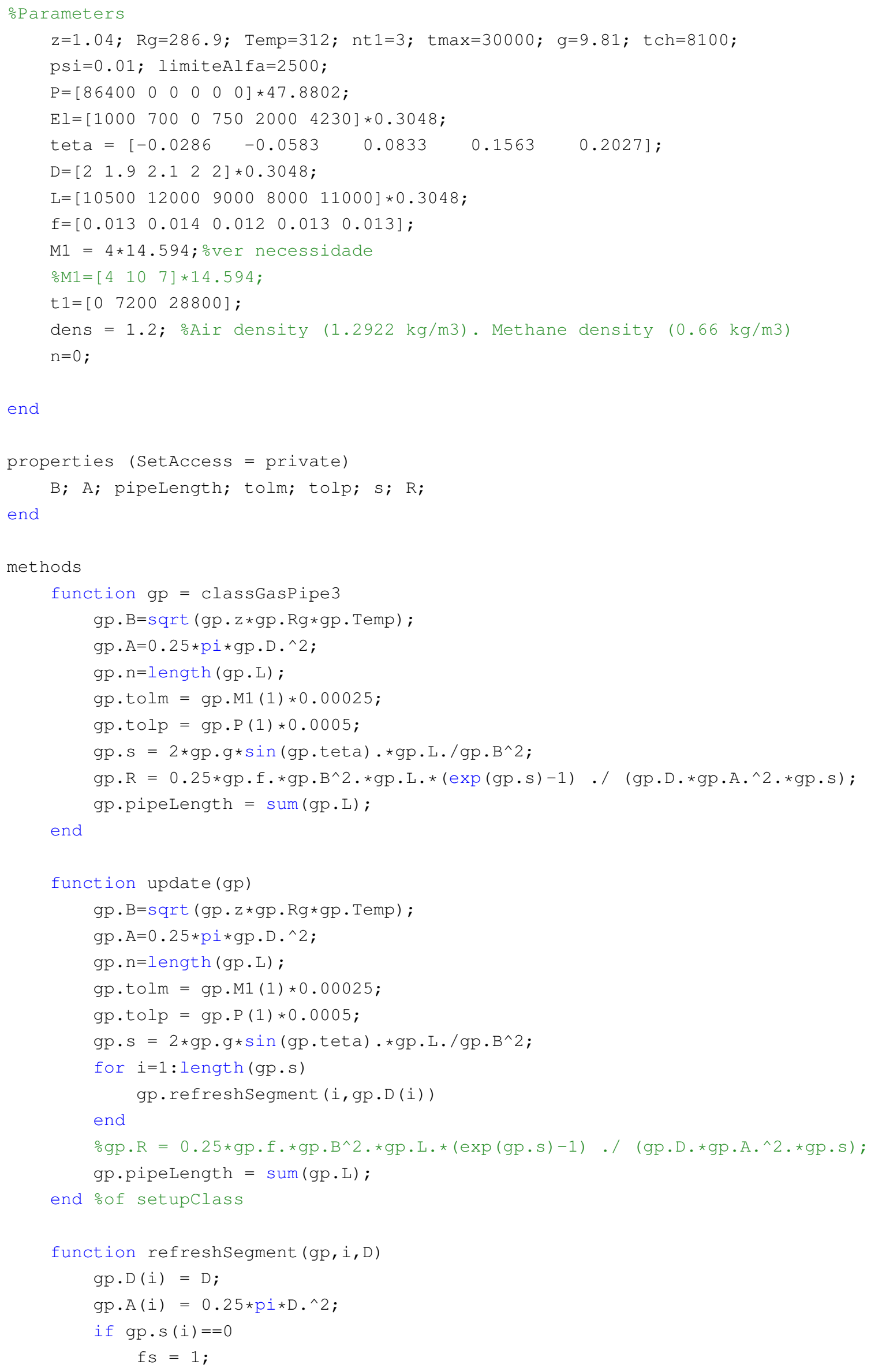




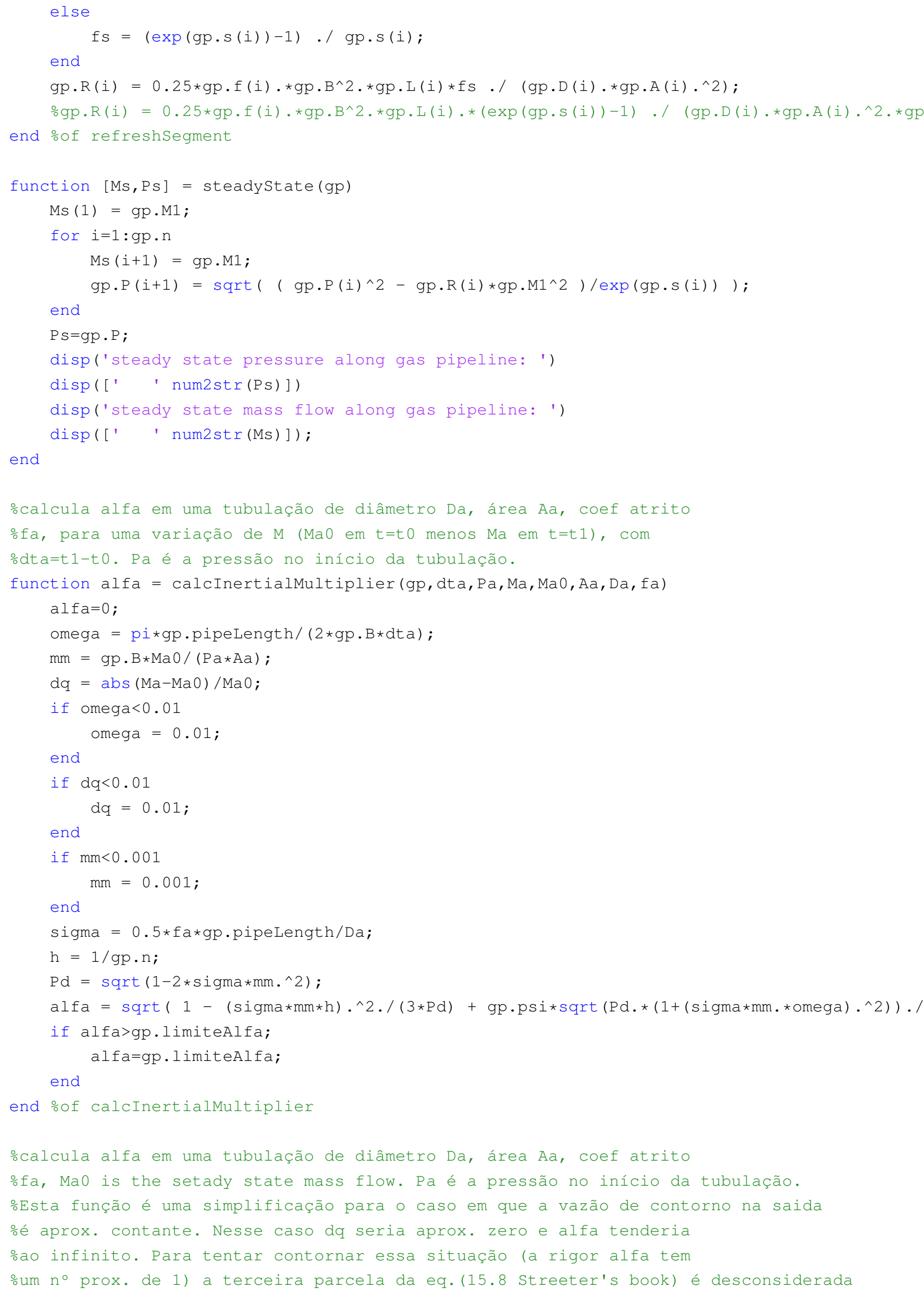




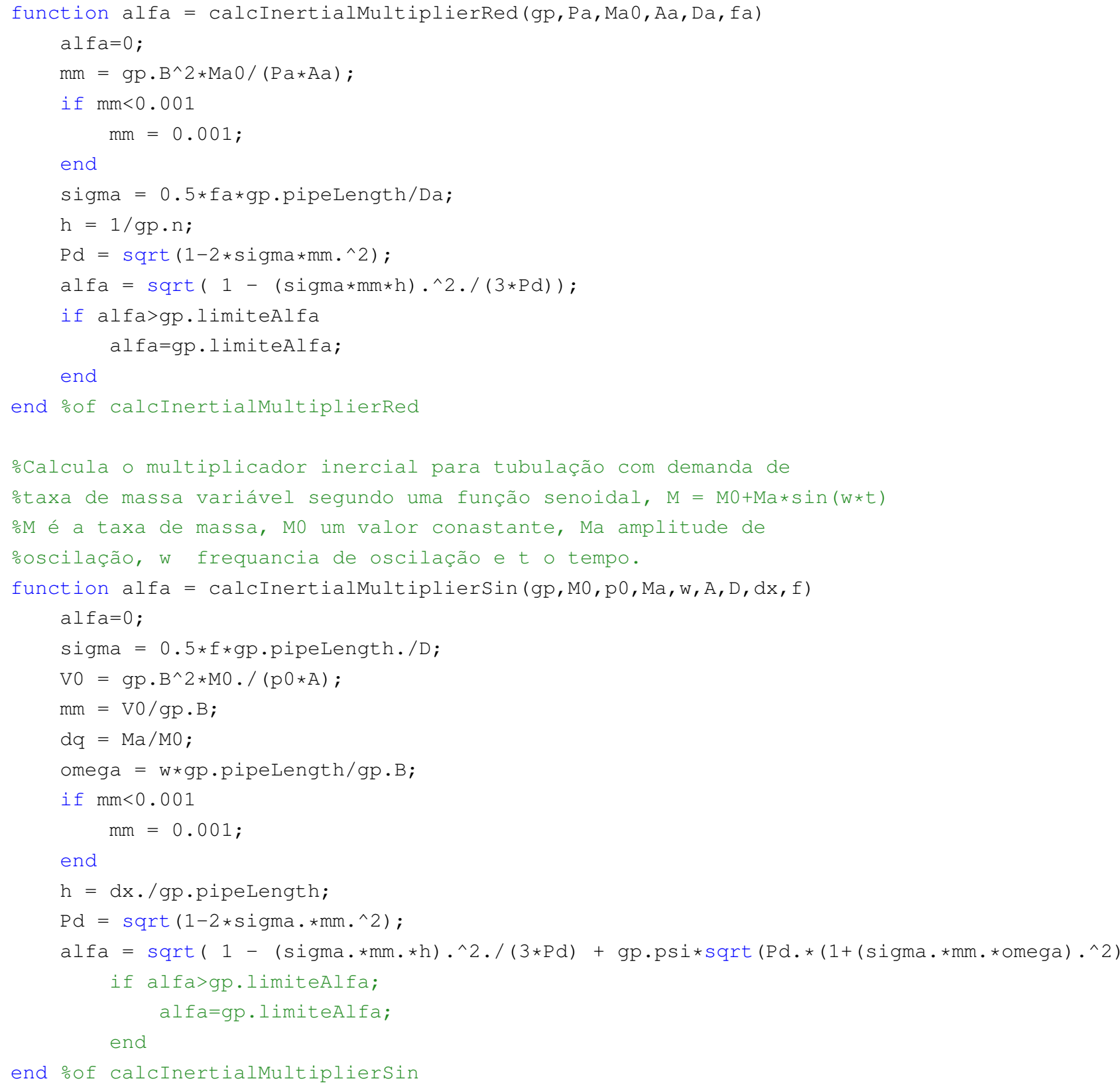




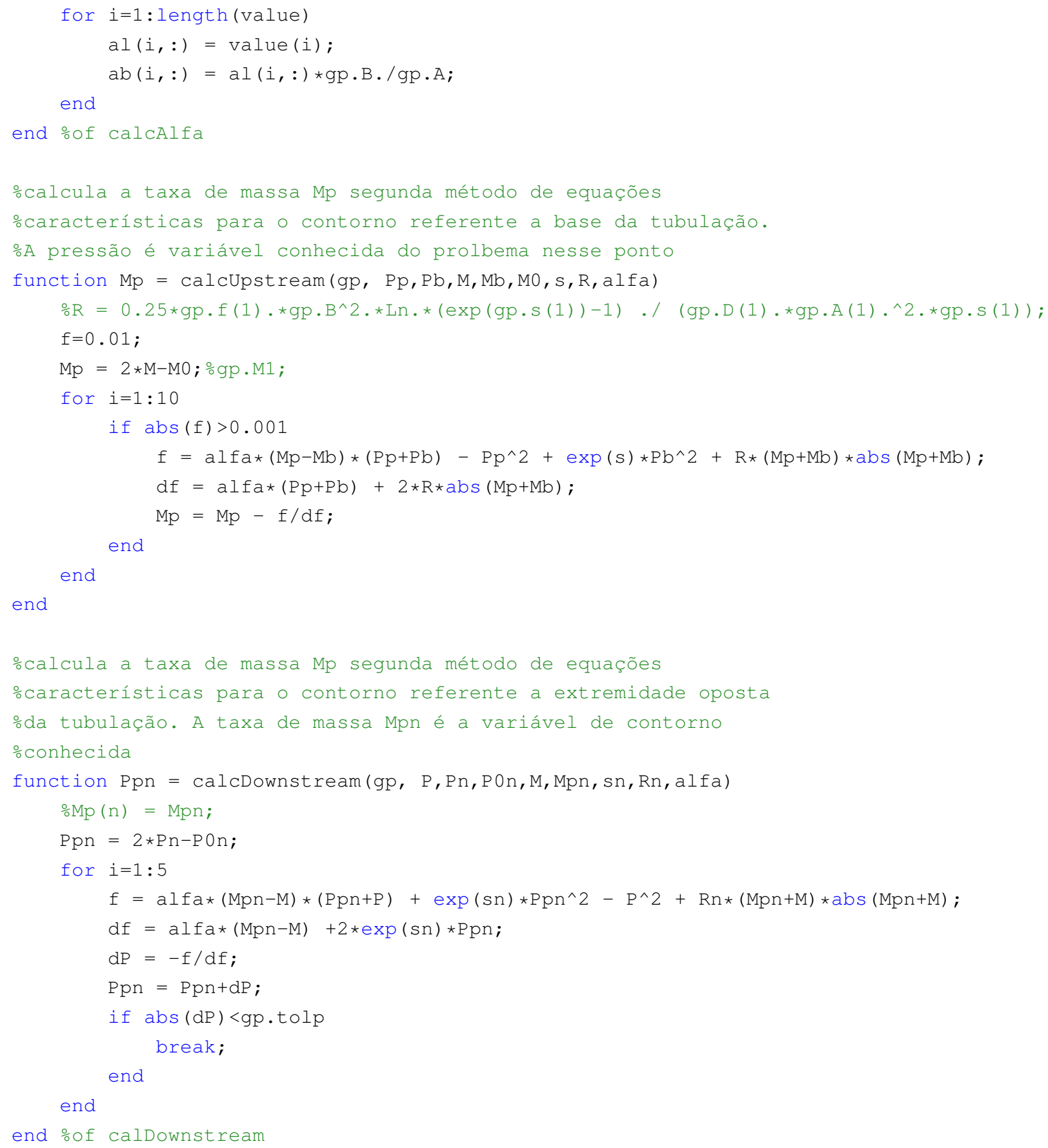




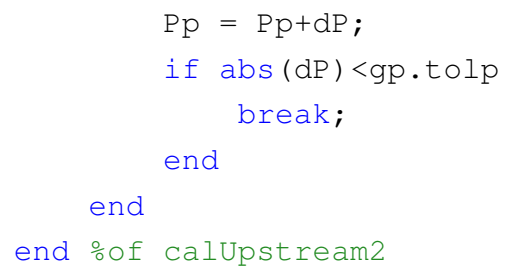




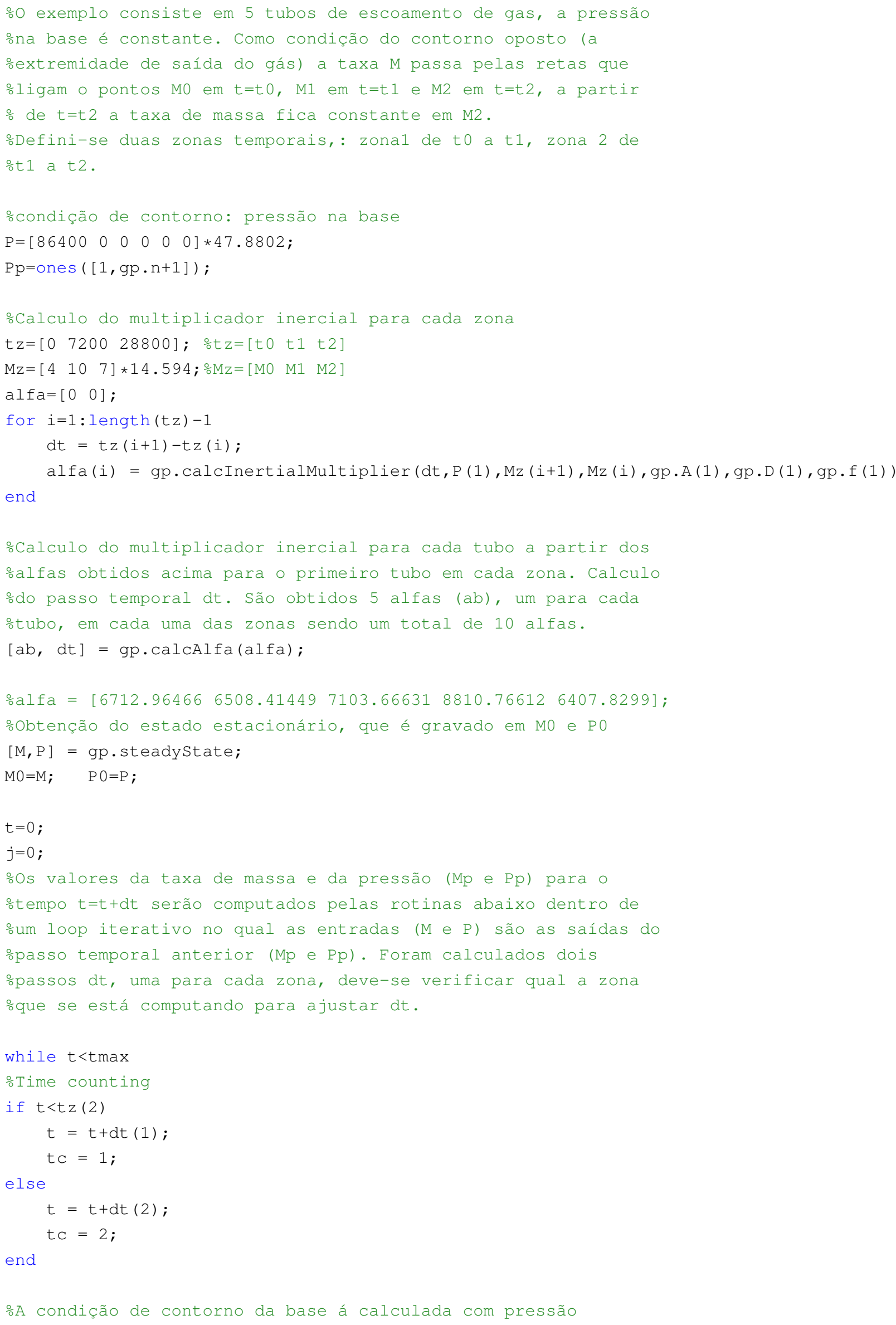




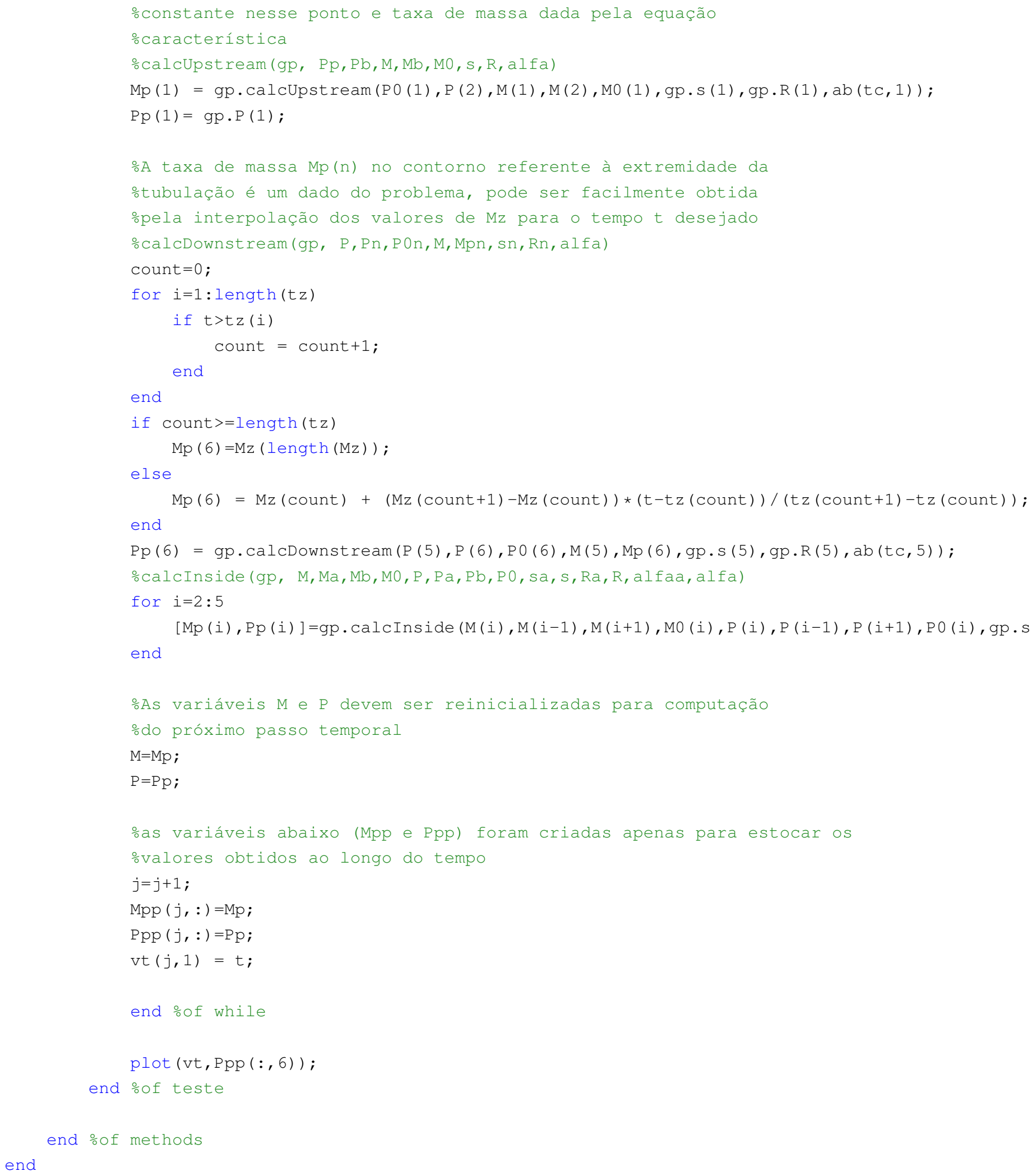

\section{III.3 Código da função classLiquidPipe}

classdef classLiquidPipe 4 handle 


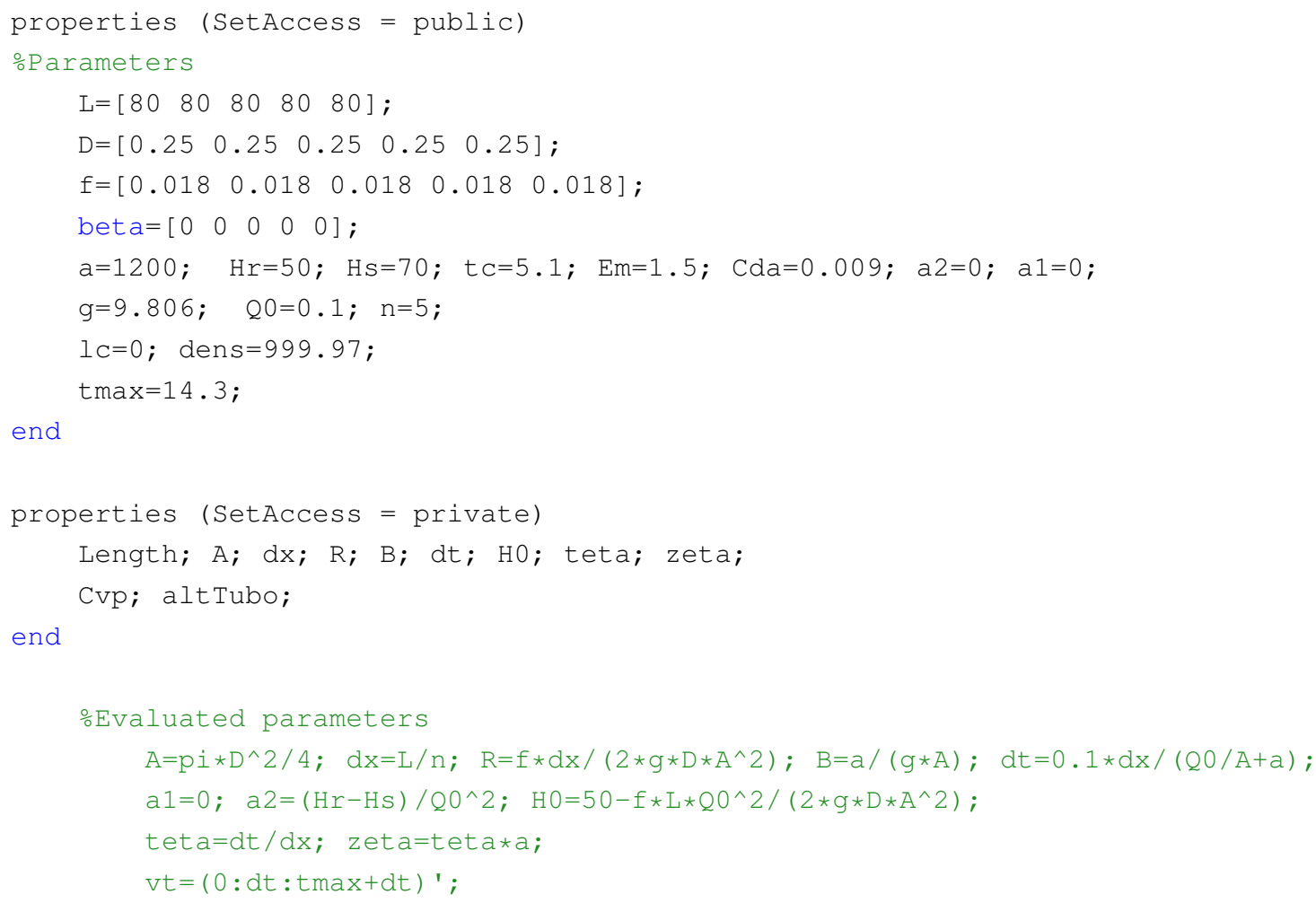

methods

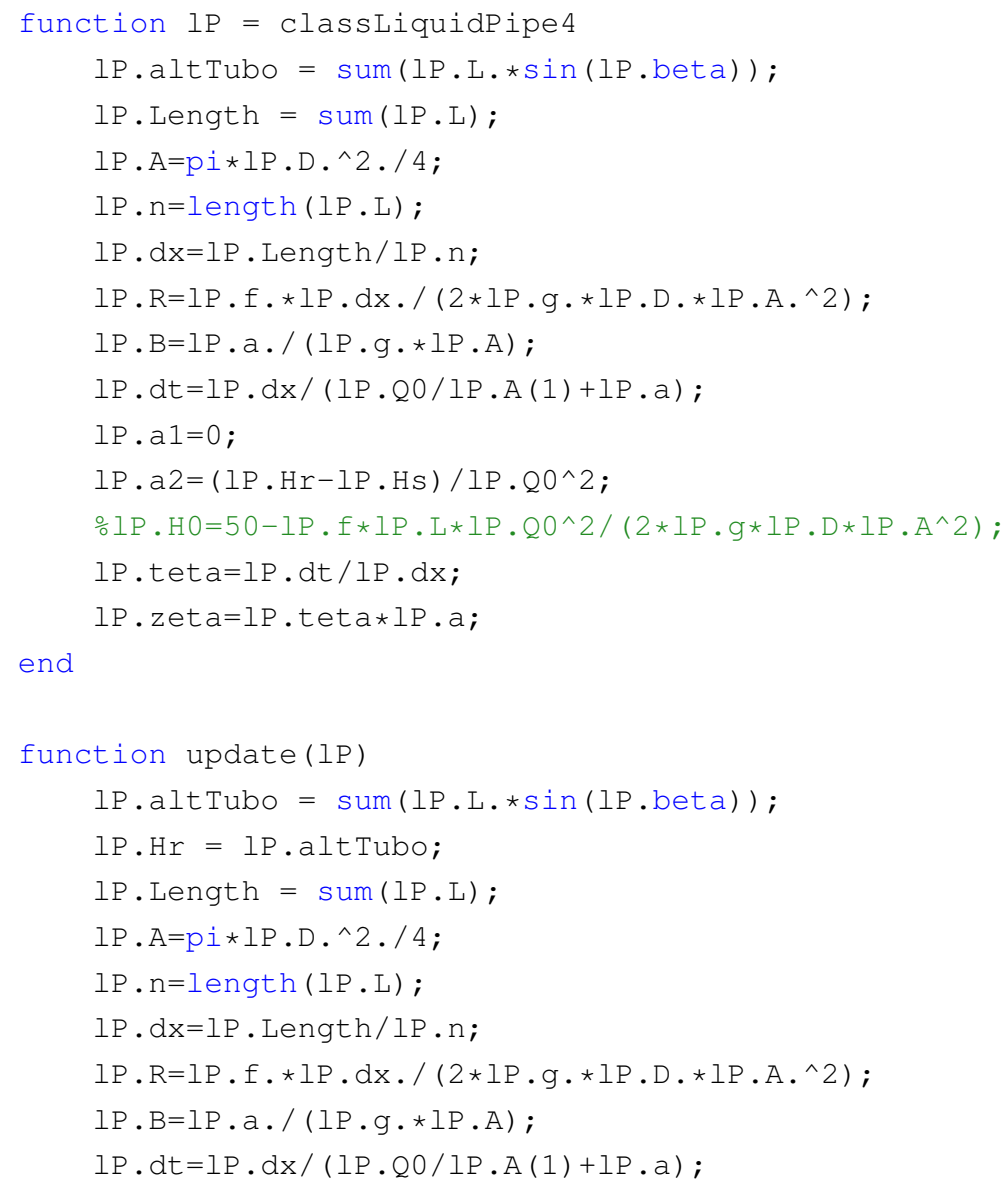




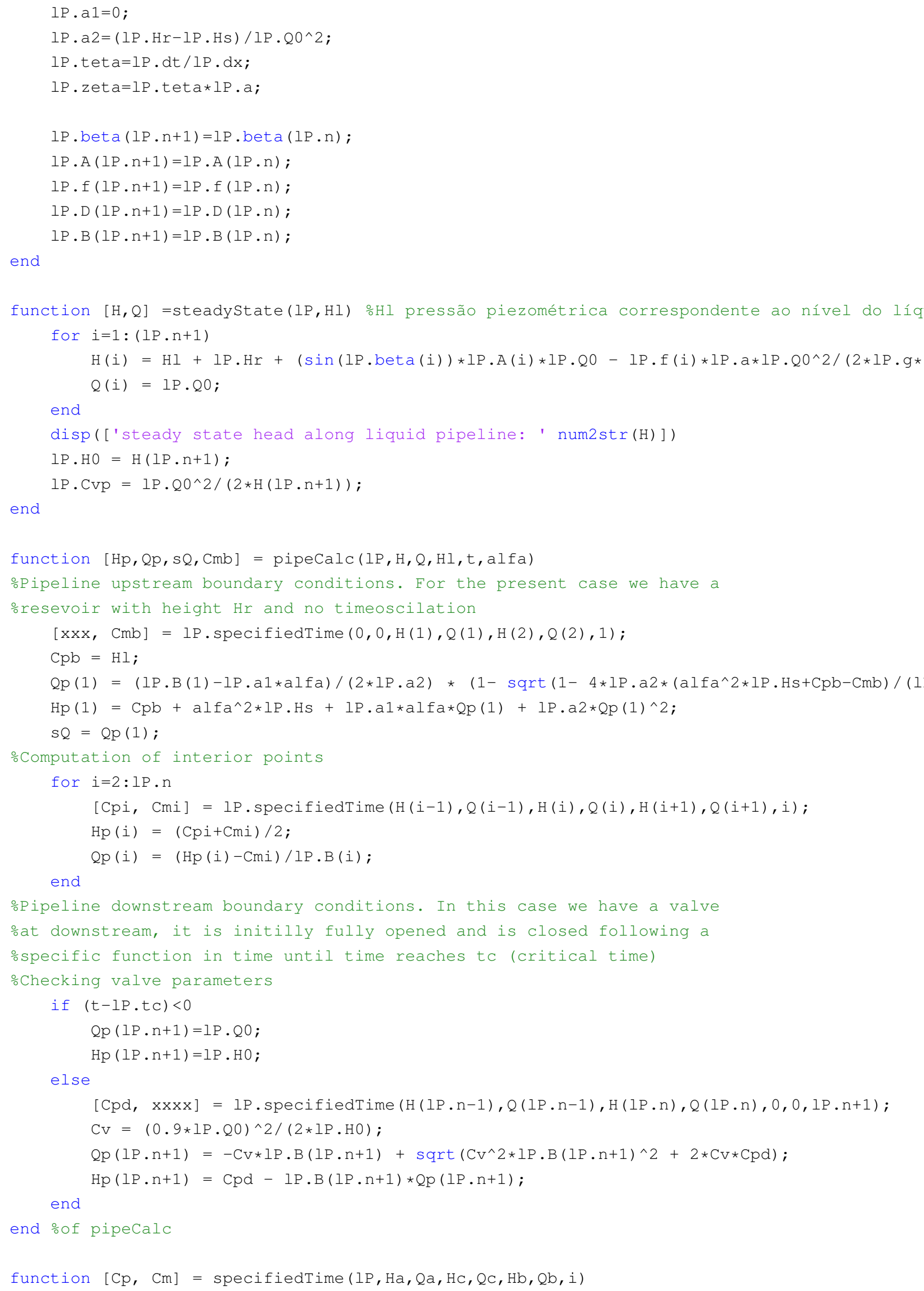




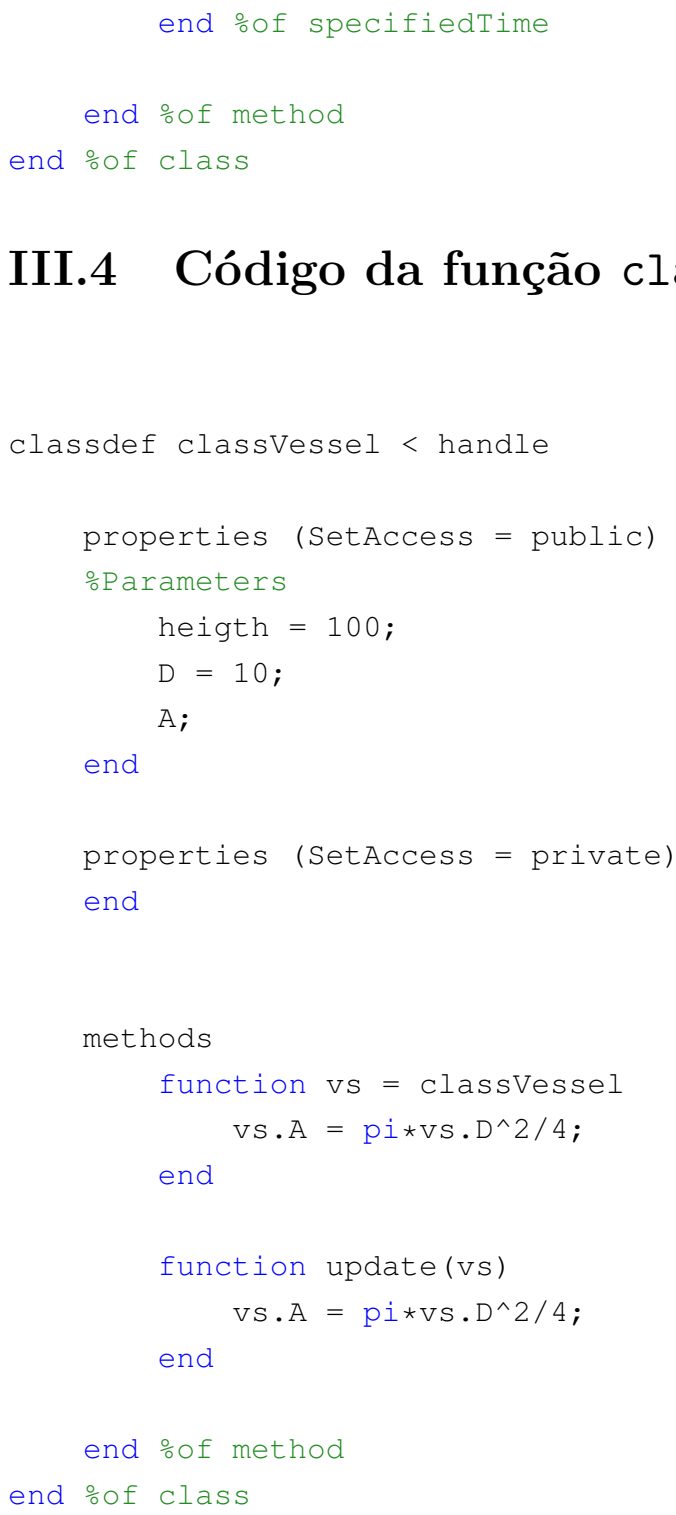

\section{III.4 Código da função classVessel}

